Universidade de São Paulo

Faculdade de Medicina de Ribeirão Preto

Departamento de Neurociências e Ciências do Comportamento

\title{
ESTUDO DAS RELAÇÕES ENTRE POPULAÇÕES CELULARES, EXPRESSÃO DE AQUAPORINA-4 E SULFATO DE CONDROITINA COM O TEMPO DE RELAXAMENTO E A TAXA DE TRANSFERÊNCIA DE MAGNETIZAÇÃO NO HIPOCAMPO DE PACIENTES COM EPILEPSIA DO LOBO TEMPORAL FARMACORRESISTENTE
}

José Eduardo Peixoto Santos

Versão Corrigida

Ribeirão Preto

2014 
José Eduardo Peixoto Santos

ESTUDO DAS RELAÇÕES ENTRE POPULAÇÕES CELULARES, EXPRESSÃO DE AQUAPORINA-4 E SULFATO DE CONDROITINA COM O TEMPO DE RELAXAMENTO E A TAXA DE TRANSFERÊNCIA DE MAGNETIZAÇÃO NO HIPOCAMPO DE PACIENTES COM EPILEPSIA DO LOBO TEMPORAL FARMACORRESISTENTE

Tese apresentada ao Departamento de Neurociências e Ciências do Comportamento da Faculdade de Medicina de Ribeirão Preto para obtenção do título de Doutor em Ciências Médicas

Área de Concentração: Neurologia Opção: Neurociências 
Ficha de Aprovação

\section{ESTUDO DAS RELAÇÕES ENTRE POPULAÇÕES CELULARES, EXPRESSÃO DE AQUAPORINA-4 E SULFATO DE CONDROITINA COM O TEMPO DE RELAXAMENTO E A TAXA DE TRANSFERÊNCIA DE MAGNETIZAÇÃO NO HIPOCAMPO DE PACIENTES COM EPILEPSIA DO LOBO TEMPORAL FARMACORRESISTENTE}

Tese apresentada ao Departamento de Neurociências e Ciências do Comportamento da Faculdade de Medicina de Ribeirão Preto para obtenção do título de Doutor em Ciências Médicas

Área de Concentração: Neurologia

Opção: Neurociências

COMISSÃO JULGADORA

Presidente e Orientador: Prof. Dr. João Pereira Leite

Examinador: Prof. Dr. Fernando Cendes

Examinador: Profa. Dra. Orfa Yineth Galvis Alonso

Examinador: Prof. Dr. Luciano Neder Serafini

Examinador: Prof. Dr. Tonicarlo Rodrigues Velasco

Aprovado em 
Ce que j'ai fait jusqu'ici n'est rien encore. Je ne suis qu'au début de la carrière que je dois parcourir.

Napoleão Bonaparte. Memoires du comte Miot de Melito, 1873, capítulo 6, página 154. 


\section{Dedicatória}

A todos aqueles que dedicam sua vida ao desenvolvimento do conhecimento humano, em todos os seus campos 


\section{Agradecimentos}

Ao Professor Doutor João Pereira Leite, por toda a paciência, por compartilhar sua ampla experiência, pelo suporte e auxílio na análise e discussão deste trabalho.

Aos Professores Doutores Antônio Carlos dos Santos, Carlos Ernesto Garrido Salmon, Márcio Flávio Dutra Moraes e Tonicarlo Rodrigues Velasco, pela colaboração na realização deste projeto.

Às agências de fomento FAPESP, CNPq, CAPES e FAEPA pelo apoio financeiro, direto e indireto, cruciais para o desenvolvimento deste trabalho

Às técnicas do Laboratório de Investigação em Epilepsia, Renata e Daniela, por todo o carinho e ajuda em meus experimentos.

Aos técnicos das seções de ressonância magnética Cecílio, Jaqueline, Luciana, Luciano e Rodrigo, e da seção de patologia, Ana, José, Edson e Diógenes, por toda a ajuda e paciência.

Aos funcionários do departamento de Neurociências e Ciências do Comportamento Silvana, Sílvia, Vilma, Renato e Cássio.

Aos amigos de laboratório Ana Clara, Cleiton, Daniele, Danilo, Ingrid, Jana, Lézio, Ludmyla, Mariana, Matheus, Patrícia, Priscila, Rafael e Raquel, pelo companheirismo, colaboração e auxílio em todos estes anos.

Aos meus pais, Carla e João, à minha avó Odete, à minha irmã Natália e sobrinha Maria Eduarda, pelo amor, suporte e paciência.

Aos meus amigos fora do laboratório, em especial Carlos Eduardo, Paula, Karla e Lia. Sua amizade é inestimável. 


\section{Resumo}

Racional: A epilepsia do lobo temporal está comumente associada à farmacorresistência e tem a esclerose hipocampal como achado neuropatológico em mais da metade dos casos. Histologicamente, a esclerose hipocampal está associada à perda neuronal diferencial e gliose, além de alterações nos níveis de moléculas associadas à homeostase da água tecidual, como a aquaporina 4 e a molécula de matriz sulfato de condroitina. Em imagens de ressonância nuclear magnética, a esclerose é caracterizada por redução de volume em sequências ponderadas em T1, aumento de sinal e tempo de relaxamento em sequências ponderadas em T2 e redução na transferência de magnetização. Justificativa e Objetivos: Uma vez que tanto o sinal T2 quando a transferência de magnetização são dependentes da água tecidual, nosso objetivo é avaliar, na formação hipocampal de pacientes com epilepsia do lobo temporal, as correlações entre populações celulares e moléculas ligadas à homeostase da água e as imagens ponderadas em T2 e transferência de magnetização. Visamos ainda definir, na formação hipocampal de indivíduos sem alterações neuropatológicas, o volume de cada um dos subcampos hipocampais. Metodologia: Pacientes com epilepsia do lobo temporal farmacorresistente (ELT, $\mathrm{n}=43$ ), bem como voluntários sadios (controle radiológico, $\mathrm{CH}, \mathrm{n}=20$ ), foram submetidos a exames de ressonância magnética em máquina de 3T para mensuração da volumetria hipocampal, tempo de relaxamento T2 e transferência de magnetização hipocampal (exames in vivo). Após o tratamento cirúrgico para o controle das crises, os hipocampos dos pacientes com ELT foram fixados por 8 dias e submetidos aos exames ex vivo em máquina de $3 \mathrm{~T}$ para cálculo do tempo de relaxamento T2 de cada subcampo hipocampal. Hipocampos controle (Controle historadiológico, CHR, $\mathrm{n}=14$ ), foram obtidos de autópsias de pacientes sem histórico ante-mortem de doença neurológica ou presença 
de patologia no exame do encéfalo pos mortem. Ambos os grupos controle foram pareados para idade em relação ao grupo ELT. Alguns dos casos CHR $(n=6)$ foram também submetidos à imagem 3D T2 em máquina de 4,7T para cálculo de volumetria dos subcampos hipocampais. Após emblocamento em parafina, secções coronais hipocampais dos casos CHR e ELT foram submetidas às técnicas de histoquímica básica Hematoxilina e Eosina e Luxol Fast Blue, e às imuno-histoquímicas para avaliação das populações neuronais (NeuN), astrócitos reativos (GFAP), micróglias ativadas (HLA-DR) e para a expressão de aquaporina 4 (AQP4) e níveis de sulfato de condroitina (CS-56). Para a comparação entre os grupos, foram realizados testes t para dados paramétricos e Mann-Whitney para dados não-paramétricos. Testes de correlação foram empregados para análise da associação entre as avaliações histológicas e os exames de ressonância magnética. Resultados: Pacientes com ELT apresentaram menor volume hipocampal, maior tempo de relaxamento T2 e menor transferência de magnetização no exame in vivo, quando comparados com o CR. O exame ex vivo para a volumetria dos subcampos hipocampais em casos do grupo CHR indicou que a fascia dentata, a região CA1 e o subículo correspondem à $85 \%$ do volume hipocampal total. Quanto ao tempo de relaxamento T2 ex vivo, foi observado aumento em todos os subcampos hipocampais do grupo ELT, à exceção da fascia dentata, quando comparados ao CHR. A avaliação da densidade neuronal indicou redução significativa em todos os subcampos dos casos ELT, à exceção do subículo, quando comparados ao CHR. Em relação aos valores do grupo $\mathrm{CHR}$, foi observada astrogliose em quase todos subcampos da formação hipocampal (a exceção da zona subgranular e do hilo) e microgliose em todos os subcampos (exceto pelo subículo) dos casos com ELT. Pacientes com ELT apresentaram redução na expressão de aquaporina 4 perivascular em todos os subcampos do hipocampo, comparados ao 
CHR. Aumento nos níveis de sulfato de condroitina foi observado em todos os subcampos da formação hipocampal, à exceção da camada granular, nos pacientes com ELT. O volume hipocampal e a transferência de magnetização in vivo dos pacientes com ELT correlacionaram-se tanto com a população neuronal como com os níveis de sulfato de condroitina, enquanto que o tempo de relaxamento in vivo correlacionou-se com a população astroglial e os níveis de sulfato de condroitina. $\mathrm{O}$ exame ex vivo corroborou a correlação entre a população glial e o tempo de relaxamento observado nos pacientes com ELT. A diferença entre o tempo de relaxamento in vivo e ex vivo correlacionou-se tanto com a difusibilidade da água no tecido como com os níveis de sulfato de condroitina. Conclusões: Nossos dados indicam correlação entre a patologia hipocampal e as imagens de ressonância nuclear magnética, sendo que a maior qualidade das imagens ex vivo permitiu uma avaliação mais direta entre o sinal de ressonância e a patologia, indicando importância da população celular e matriz extracelular para o volume hipocampal e a transferência de magnetização, e da astrogliose para o tempo de relaxamento T2. Finalmente, nossos dados mostraram que CA1, subículo e fascia dentata tem grande participação no volume hipocampal, sendo que alterações nestas regiões tem um papel mais relevante nas alterações observadas na ressonância magnética, como indicado por nossas correlações.

\section{Abstract}

Rationale: Drug resistant temporal lobe epilepsy is often associated with hippocampal sclerosis. Histological evaluation reveals differential neuronal loss, gliosis and changes in molecules associated with water homeostasis, such as aquaporin 4 and chondroitin sulfate. Magnetic resonance imaging in these cases often 
reveals hippocampal atrophy, increased $\mathrm{T} 2$ signal and $\mathrm{T} 2$ relaxation and reduced magnetization transfer ratio in the hippocampus. Aims: Once both T2 signal and magnetization transfer are affected by tissue water, our goal was to evaluate, in the hippocampus of drug-resistant temporal lobe epilepsy patients who underwent surgery for seizure control, the associations between cellular populations, aquaporin 4 and chondroitin sulfate with T2 relaxation time and magnetization transfer. Additionally, we intended to measure the individual volume of each hippocampal subfield in hippocampus from patients without neurological disease. Methods: Patients with drug-resistant temporal lobe epilepsy (TLE, $\mathrm{n}=43$ ) and age-matched health volunteers (radiological control, $\mathrm{RC}, \mathrm{n}=20$ ) were submitted to magnetic resonance in a $3 \mathrm{~T}$ machine for hippocampal volumetry measure, $\mathrm{T} 2$ relaxation and magnetization transfer (in vivo examination). After surgical treatment for seizure control, hippocampi from the TLE patients were fixed in formalin for 8 days and then submitted to ex vivo imaging in $3 \mathrm{~T}$ for relaxation time of every hippocampal subfield. Control hippocampi were obtained from autopsies of age-matched patients without ante mortem history of neurological disease or post mortem neurological pathology, and underwent the same ex vivo imaging (histo-radiological control, HRC, $\mathrm{n}=14$ ). Six cases from the HRC underwent 3D T2 imaging in a 4.7T machine, in order to measure the volumes of the hippocampal subfields. Paraffin embedded hippocampal sections from TLE and HRC were submitted to Hematoxilin-Eosin and Luxol Fast Blue histochemistries, and to immunohistochemistries for the evaluation of neurons (NeuN), reactive astrocytes (GFAP), activated microglia (HLA-DR), for aquaporin 4 (AQP4) and for chondroitin sulfate (CS-56). Student's t-test or Mann-Whitney's test were performed for comparison between groups, and correlation tests were performed for the comparison between histological and magnetic resonance measures. Results: 
Patients with TLE presented reduced hippocampal volume, increased T2 relaxation time and reduced magnetization transfer, when compared to $\mathrm{RC}$. The ex vivo volumetry of the hippocampal subfields revealed that fascia dentata, CA1 and subiculum together correspond to $85 \%$ of the total hippocampal volume. Ex vivo relaxation time, as the in vivo, were increased in the subfields of TLE patients, when compared to HRC. Compared to HRC, TLE patients presented neuron loss and microgliosis in all hippocampal subfields but the subiculum, and astrogliosis in all hippocampal subfields but the subgranule zone and the hilus. Reduced perivascular aquaporin 4 was observed in all hippocampal subfields of TLE patients, and increased chondroitin sulfate was observed in all hippocampal subfields, with the exception of granule cell layer, of TLE patients, when compared to HRC. In TLE, both in vivo hippocampal volume and magnetization transfer correlated with the levels of chondroitin sulfate and the neuronal population, whereas the in vivo relaxation time correlated with the astroglial population and the levels of chondroitin sulfate. Ex vivo relaxation time also correlated with the astroglial population in TLE patients. The difference between in vivo and ex vivo relaxation values correlated with water difusibility and the levels of chondroitin sulfate. Conclusion: Our data indicate the importance of neuron population and extracellular matrix to both hippocampal volume and magnetization transfer, and of the reactive astrocytes for $\mathrm{T} 2$ relaxation. Ex vivo relaxation time allowed a more detailed evaluation, and indicated more robust correlations between reactive astrocytes and T2 relaxation. Finally, Our data indicated that CA1, the subiculum and fascia dentata are the major contributors to hippocampal volume, so changes in these subfields most likely will affect magnetic resonance imaging. 


\section{Sumário}

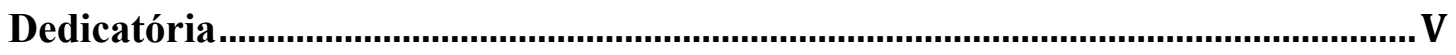

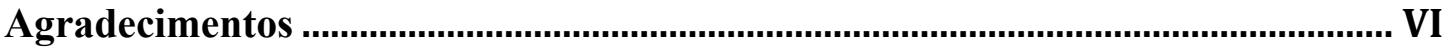

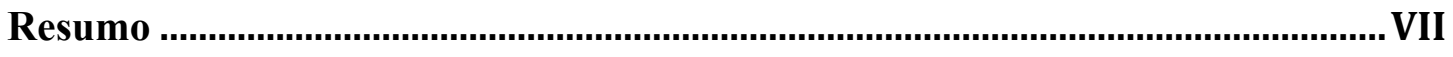

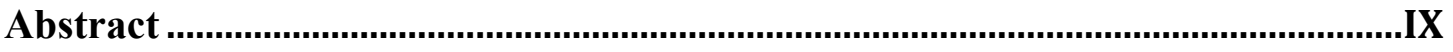

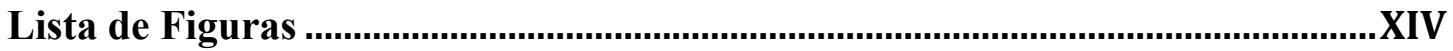

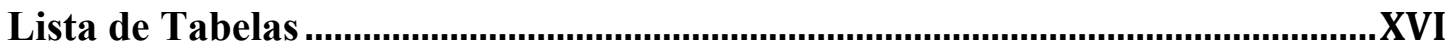

Lista de Abreviações e Símbolos ....................................................................... XVII

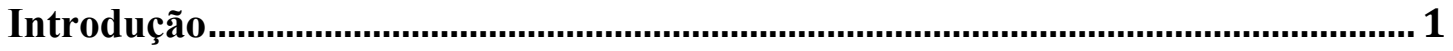

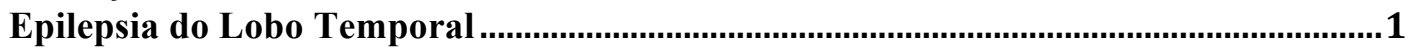

A formação hipocampal e a esclerose hipocampal ........................................................2

Imagens por ressonância magnética na investigação da ELT ……..................................5

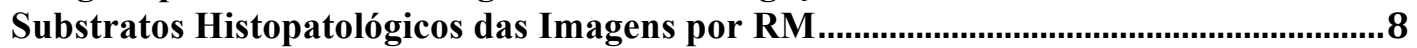

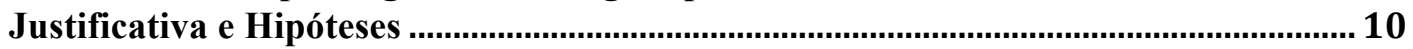

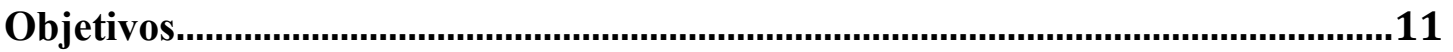

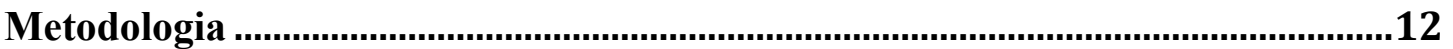

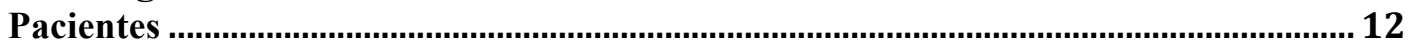

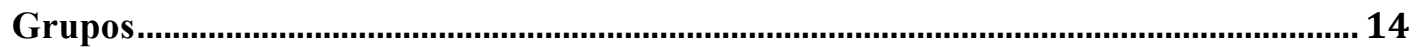

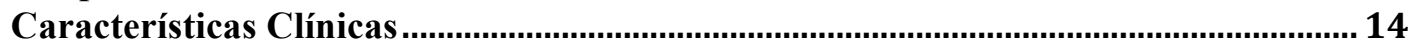

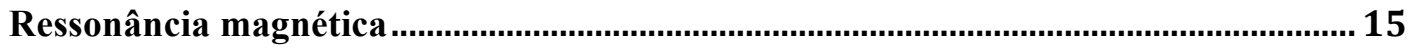

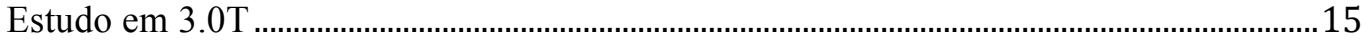

Estudos em 4.7T ....................................................................................................................17

Cálculos de volumetria, taxas de relaxamento e de transferência de magnetização. . 18

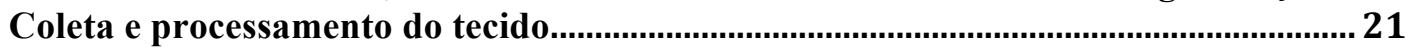

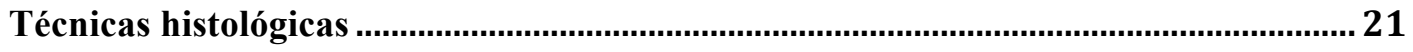

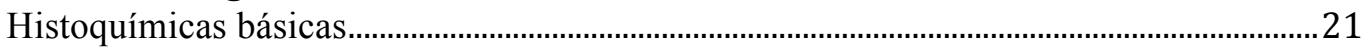

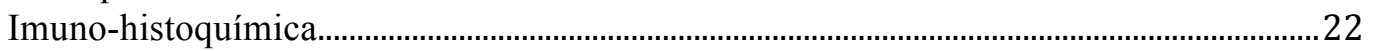

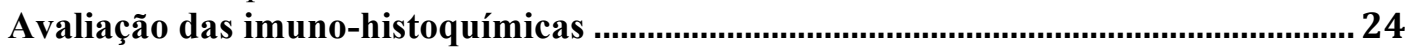

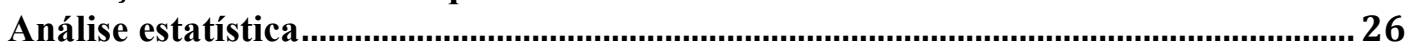

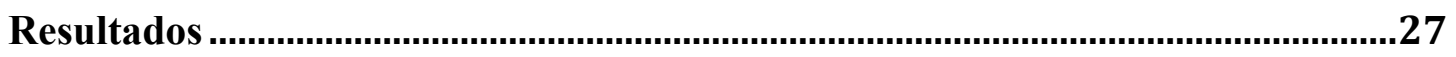

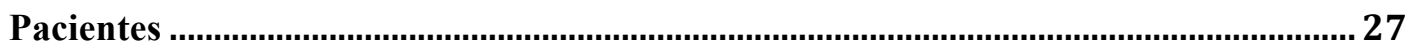

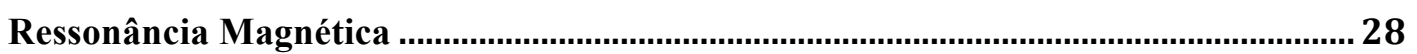

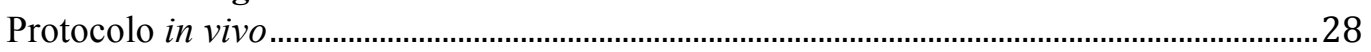

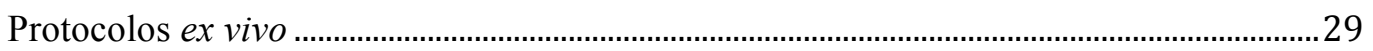

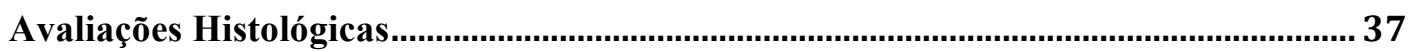

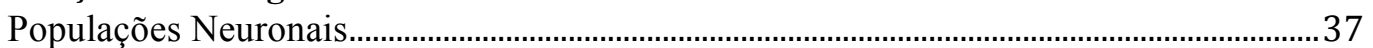

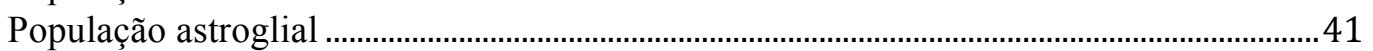

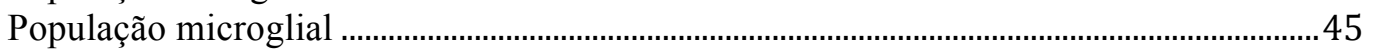

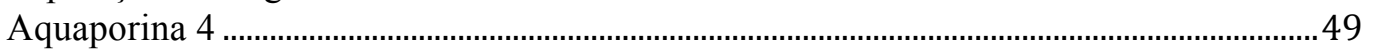

Sulfato de Condroitina......................................................................................................... 53

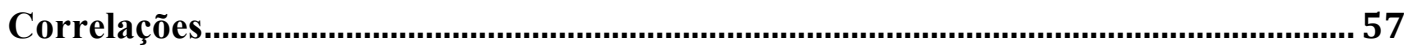

Protocolo de ressonância in vivo e alterações histológicas no grupo ELT..........................57

Protocolo de ressonância ex vivo e alterações histológicas no grupo ELT .........................62

Variação no tempo de relaxamento, difusibilidade da água e alterações histológicas em

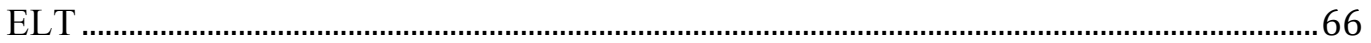




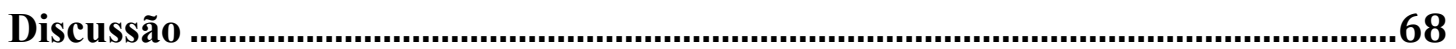

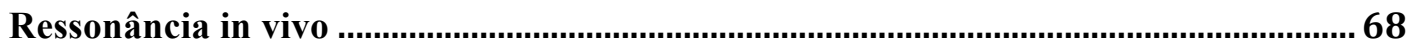

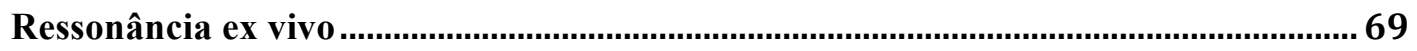

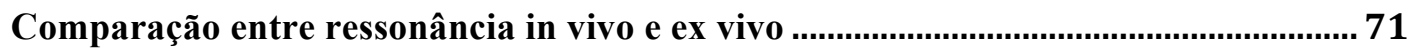

Ressonância magnética e as alterações teciduais hipocampais........................................ 73

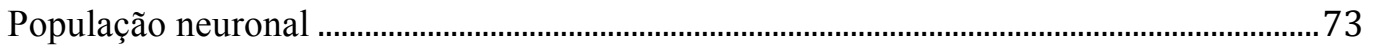

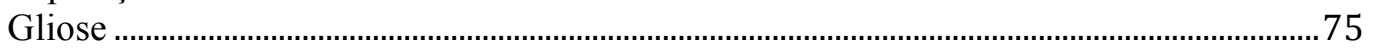

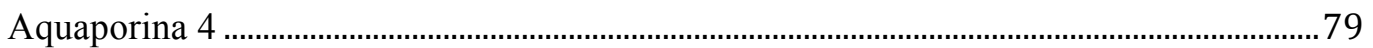

Sulfato de Condroitina.............................................................................................................

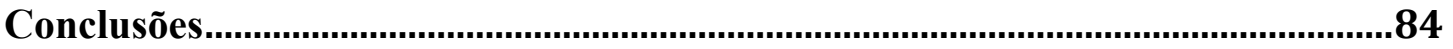

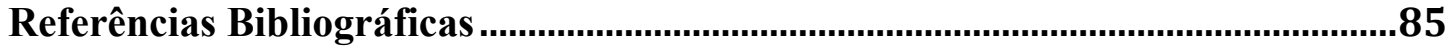

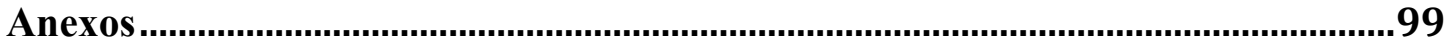

Cálculos dos mapas e medidas nas ressonâncias ex vivo.................................................99

Artigos publicados e submetidos para publicação ……......................................................101 


\section{Lista de Figuras}

Figura 1. Desenho esquemático de cortes coronais do hipocampo .............................4

Figura 2. Imagem representativa dos diferentes tempos de eco ................................17

Figura 3. Imagens representativas de imagens para transferência de magnetização..17

Figura 4. Imagens ex vivo mostrando as subdivisões do hipocampo.........................20

Figura 5. Imagens representativas da quantificação das áreas imunopositivas ...........24

Figura 6. Fotomicrografia dos subcampos hipocampais ........................................25

Figura 7. Volume hipocampal, tempo de relaxamento e taxa de transferência de

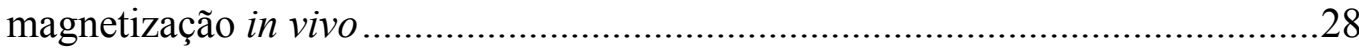

Figura 8. Imagens representativas das sequências ex vivo comparadas a cortes histológicos

Figura 9. Imagens representativas das sequências ex vivo comparadas com imagens

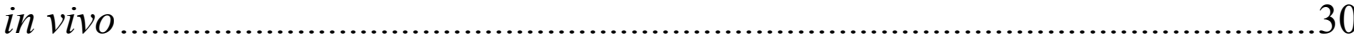

Figura 10. Imagens de ressonância 4,7T de hipocampos de casos CHR ....................33

Figura 11. Volumes dos subcampos hipocampais de pacientes do grupo CHR ..........34

Figura 12. Volumes dos subcampos hipocampais em casos do grupo CHR e ELT ...34

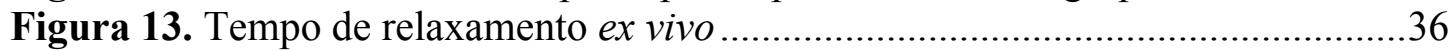

Figura 14. Taxa de transferência de magnetização ex vivo...........................................36

Figura 15. Fotomicrografias da imuno-histoquímica para NeuN .............................38

Figura 16. Fotomicrografias da imuno-histoquímica para NeuN .............................39

Figura 17. Densidade neuronal nos grupos CHR e ELT ….......................................40

Figura 18. Fotomicrografias da imuno-histoquímica para GFAP ...........................42

Figura 19. Fotomicrografias da imuno-histoquímica para GFAP ..........................43

Figura 20. Área imunopositiva para GFAP nos grupos CHR e ELT …….................44

Figura 21. Área imunopositiva para GFAP nos grupos CHR e ELT .........................44

Figura 22. Fotomicrografias da imuno-histoquímica para HLA-DR .........................46

Figura 23. Fotomicrografias da imuno-histoquímica para HLA-DR .......................47

Figura 24. Área imunopositiva para HLA-DR nos grupos CHR e ELT.....................48

Figura 25. Área imunopositiva para HLA-DR nos grupos CHR e ELT.....................48

Figura 26. Fotomicrografias da imuno-histoquímica AQP4 ...................................50

Figura 27. Fotomicrografias da imuno-histoquímica AQP4 …...............................51

Figura 28. Área imunopositiva para AQP4 nos grupos CHR e ELT .........................52

Figura 29. Área imunopositiva para AQP4 nos grupos CHR e ELT ...........................52

Figura 30. Fotomicrografias da imuno-histoquímica CS-56 .................................54

Figura 31. Fotomicrografias da imuno-histoquímica CS-56 ................................55

Figura 32. Área imunopositiva para CS-56 nos grupos CHR e ELT .......................56

Figura 33. Área imunopositiva para CS-56 nos grupos CHR e ELT .........................56

Figura 34. Regressão linear entre volume hipocampal in vivo e a densidade neuronal em CA3

Figura 35. Regressão linear entre volume hipocampal in vivo e a área imunopositiva para CS-56 em CA3

Figura 36. Regressão linear entre volume hipocampal in vivo e a área imunopositiva para CS-56 em CA1

Figura 37. Regressão linear entre o tempo de relaxamento hipocampal in vivo e a área imunopositiva para GFAP no subículo

Figura 38. Regressão linear entre o tempo de relaxamento hipocampal in vivo e a área imunopositiva para CS-56 no hilo 
Figura 39. Regressão linear entre a taxa de transferência de magnetização hipocampal in vivo e a densidade neuronal em CA3

Figura 40. Regressão linear entre a taxa de transferência de magnetização hipocampal in vivo e a área imunopositiva para CS-56 em CA3 .

Figura 41. Regressão linear entre a taxa de transferência de magnetização hipocampal in vivo e a área imunopositiva para CS-56 em CA1

Figura 42. Regressão linear entre a taxa de transferência de magnetização hipocampal in vivo e a área imunopositiva para sCS-56 no subículo

Figura 43. Regressão linear entre o tempo de relaxamento ex vivo na camada molecular da fascia dentata e a área imunopositiva para GFAP na camada molecular externa da fascia dentata....

Figura 44. Regressão linear entre o tempo de relaxamento ex vivo na camada molecular da fascia dentata e a área imunopositiva para GFAP na camada molecular interna da fascia dentata.

Figura 45. Regressão linear entre o tempo de relaxamento ex vivo na fascia dentata e a área imunopositiva para GFAP no hilo

Figura 46. Regressão linear entre o tempo de relaxamento ex vivo em e a área imunopositiva para GFAP em CA4

Figura 47. Regressão linear entre o tempo de relaxamento ex vivo e a área imunopositiva para GFAP no subículo

Figura 48. Regressão linear entre o tempo de relaxamento ex vivo e a área imunopositiva para HLA-DR em CA1

Figura 49. Regressão linear entre a variação no tempo de relaxamento hipocampal e difusibilidade média da água

Figura 50. Regressão linear entre a variação no tempo de relaxamento hipocampal e a área imunopositiva para CS-56 no hilo 


\section{Lista de Tabelas}

Tabela 1. Alterações observadas nos exames de ressonância magnética dos

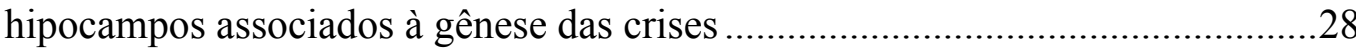

Tabela 2. Volumes dos subcampos hipocampais em pacientes do grupo CHR 32 


\section{Lista de Abreviações e Símbolos}

$\begin{array}{ll}\text { ADC } & \text { Coeficiente de difusão aparente (Apparent Diffusion Coefficient) } \\ \text { ADC }_{\text {TMA }} & \text { Coeficiente de difusão aparente medido por tetrametilamônio } \\ \text { ADC }_{\mathbf{W}} & \text { Coeficiente de difusão aparente da água } \\ \text { AQP4 } & \text { Aquaporina } 4 \\ \text { B } & \text { Fator B (B factor, Bihan) } \\ \text { CA } & \text { Corno de Amon } \\ \text { CHR } & \text { Controle Historadiológico } \\ \text { CIREP } & \text { Centro Regulador de Cirurgias de Epilepsia } \\ \text { CME } & \text { Camada molecular externa da fascia dentata } \\ \text { CMI } & \text { Camada molecular interna da fascia dentata } \\ \text { CR } & \text { Controle Radiológico } \\ \text { Ctrl } & \text { Controle } \\ \text { DAB } & \text { Tetrahidrocloreto de Diaminobenzidina (3,3'-Diaminobenzidine) } \\ \text { ECoG } & \text { Eletrocorticografia } \\ \text { EEG } & \text { Eletrencefalografia } \\ \text { ELT } & \text { Epilepsia do lobo temporal } \\ \text { ELTM } & \text { epilepsia do lobo temporal mesial } \\ \text { EPI } & \text { Imagem eco planar (Echo Planar Imaging) } \\ \text { FOV } & \text { Campo de visão (Field of View) } \\ \text { CG } & \text { Camada de células granulares da fascia dentata } \\ \text { GFAP } & \text { Proteína acídica fibrilar glial (Glial Fibrillary Acidic Protein) } \\ \text { H2O } & \text { Peróxido de hidrogênio } \\ \text { HIL } & \text { Hilo } \\ \text { HLA-DR } & \text { Antígeno leucocitário humano tipo DR (Human Leukocyte Antigen } \\ \text { IPI } & \text { type DR) } \\ \text { MEC } & \text { Injúria precipitante inicial } \\ \text { NeuN } & \text { Matriz extracelular } \\ \text { PBS } & \text { Antígeno nuclear neuronal (Neuronal Nuclei) } \\ \text { PRO } & \text { Tampão fosfato-salina (Phosphate Saline Buffer) } \\ \text { RM } & \text { Prosubículo } \\ \text { SNC } & \text { Ressonância Magnética } \\ \text { SPECT } & \text { Sistema nervoso central } \\ \text { TUB } & \text { Tomografia por emissão de fóton único (Single-Photon Emission } \\ \text { TE } & \text { Computed Tomography) } \\ \text { TFE } & \text { Subículo } \\ \text { TM } & \text { Tempo de eco } \\ \text { TR } & \text { Tradiente eco rápido (Turbo Field Echo) } \\ \text { Tempo de repetição } & \text { 2-Amino-2-hidroximetil-propano-1,3-diol } \\ & \end{array}$




\section{Introdução}

\section{Epilepsia do Lobo Temporal}

As epilepsias são um conjunto de desordens definidas pela ocorrência de crises recorrentes, normalmente autolimitadas, causadas por sincronização da atividade neuronal (Engel, 1995). Dentre as epilepsias focais em adultos, a epilepsia do lobo temporal (ELT) é a mais frequente, e estima-se que até $45 \%$ dos pacientes não conseguem bom controle das crises com tratamento farmacológico de primeira linha (Gastaut et al., 1975; Cascino, 2004).

É comum à história clínica dos pacientes com ELT a ocorrência de injúria precipitante inicial (IPI) nos primeiros anos de vida (Mathern et al., 1996). A natureza da IPI é variável, sendo que ocorrência de crises é a etiologia mais frequente $(70,8 \%$ dos casos), seguida do trauma crânio-encefálico, da hipóxia cerebral, da infecção sistêmica com coma e de experiências de quase-afogamento (Mathern et al., 2002). Após a ocorrência da IPI, os pacientes passam por um período silente que dura até o final da adolescência ou começo da vida adulta, após o qual aparecem as crises recorrentes espontâneas (Mathern et al., 1996; Pitkanen e Sutula, 2002).

Nos pacientes com controle insatisfatório das crises pelas drogas antiepilépticas, a ressecção da região associada à gênese das crises é o tratamento recomendado. O substrato patológico encontrado em até $66 \%$ destes casos é a esclerose hipocampal (French et al., 1993; Engel, 1997). 


\section{A formação hipocampal e a esclerose hipocampal}

Nos primatas, a formação hipocampal é uma região de arquicórtex situada na base dos ventrículos laterais, na região mesial dos lobos temporais. Macroscopicamente, o hipocampo é dividido em cabeça, corpo e cauda. Em termos de estrutura interna, a formação hipocampal é dividida em diversos subcampos com citoarquitetura própria, cuja nomenclatura e limites variam conforme autor e animal usado para o estudo. A nomenclaturas mais amplamente utilizada na atualidade, tanto para humanos como para outros primatas e roedores, foi criada por Lorente de Nó (Lorente De Nó, 1934; Amaral e Insausti, 1990). Segundo esta, a formação hipocampal pode ser dividida em giro denteado, corno de Amon, complexo subicular e córtex entorrinal.

O giro denteado é composto de camadas moleculares, camada granular e região polimórfica/hilo. Nas camadas moleculares encontram-se os dendritos apicais dos neurônios granulares, sendo assim a principal região de entrada de informação na formação hipocampal. Densamente organizados na camada granular encontram-se os corpos celulares dos neurônios principais do giro denteado, denominados células granulares. Finalmente, o hilo é uma região rica em interneurônios, além de conter os dendritos basais e axônios dos neurônios granulares (Amaral e Insausti, 1990).

O corno de Amon ou hipocampo próprio, por sua vez, pode ser subdividido em regiões $\mathrm{CA} 4, \mathrm{CA} 3, \mathrm{CA} 2$ e CA1, sendo basicamente composto por neurônios piramidais. CA4 encontra-se inserido dentro do hilo, sendo distinto deste pela morfologia de seus neurônios. Seguindo-se a CA4 encontra-se CA3, região alvo dos axônios das células granulares. Adjacente a CA3 encontra-se CA2, um subcampo pequeno e de células piramidais mais compactadas. Finalmente, CA1 ocupa a maior 
porção do corno de Amon e apresenta neurônios mais distantes entre si (Amaral e Insausti, 1990).

O complexo subicular é constituído de prosubículo, subículo, pré-subículo e parasubículo. Estes subcampos possuem como tipo celular principal neurônios piramidais, e encontram-se entre CA1 e o córtex entorrinal. O prosubículo, encontrado entre CA1 e o subículo, apresenta características intermediárias em relação às estrutura de ambos. No subículo, os neurônios estão ainda mais distantes entre si do que em CA1. No pré-subículo, os neurônios são pequenos e mais próximos, sendo organizados em ilhas, enquanto no parasubículo os neurônios estão mais espaçados. Finalmente, o córtex entorrinal possui a estrutura mais complexa, sendo dividido em 2 ou até 6 camadas, de acordo com o autor (Amaral e Insausti, 1990).

Em termos de população neuronal, estudos indicam que o número total de neurônios em cada subcampo varia, indo de 220 mil em CA2 até 9 milhões na camada granular (Amaral e Insausti, 1990). Há também grande variação no formato e volumes dos subcampos em cada nível da formação hipocampal, se vistos em cortes transversais ao eixo mais longo do hipocampo. O clássico formato de $C$ observado na maioria das descrições e ilustrações é encontrado ao nível do corpo do hipocampo. Em cortes da cabeça ou cauda, entretanto, sua estrutura é bem diferente (Figura 1).

Nos pacientes com ELT que apresentam esclerose hipocampal, as principais alterações histológicas observadas na formação hipocampal são perda neuronal, gliose e reorganização dos axônios dos neurônios granulares na camada molecular interna (Babb et al., 1984; Babb et al., 1991; Salanova et al., 1999). A perda neuronal vista na esclerose hipocampal tem a IPI como o causa principal, porém estudos indicam que crises recorrentes podem causar perda neuronal adicional (Mathern et al., 2002; 
Pitkanen e Sutula, 2002). Esta perda neuronal ocorre em grau variável em cada subcampo da formação hipocampal. Em sua forma mais clássica, observa-se perda importante no hilo, CA4, CA1 e prosubículo, enquanto na camada granular a perda é moderada. CA2 e subículo, por sua vez, são preservados de perda neuronal (Margerison e Corsellis, 1966; Babb et al., 1984; Babb et al., 1991; Mathern et al., 1996). Além da forma clássica, foram descritos desde casos com perda intensa em todos os subcampos (esclerose hipocampal grave) até casos onde a perda é restrita a apenas um subcampo, como na esclerose de CA1 e do endfolium (Blumcke et al., 2007; Blumcke et al., 2012).
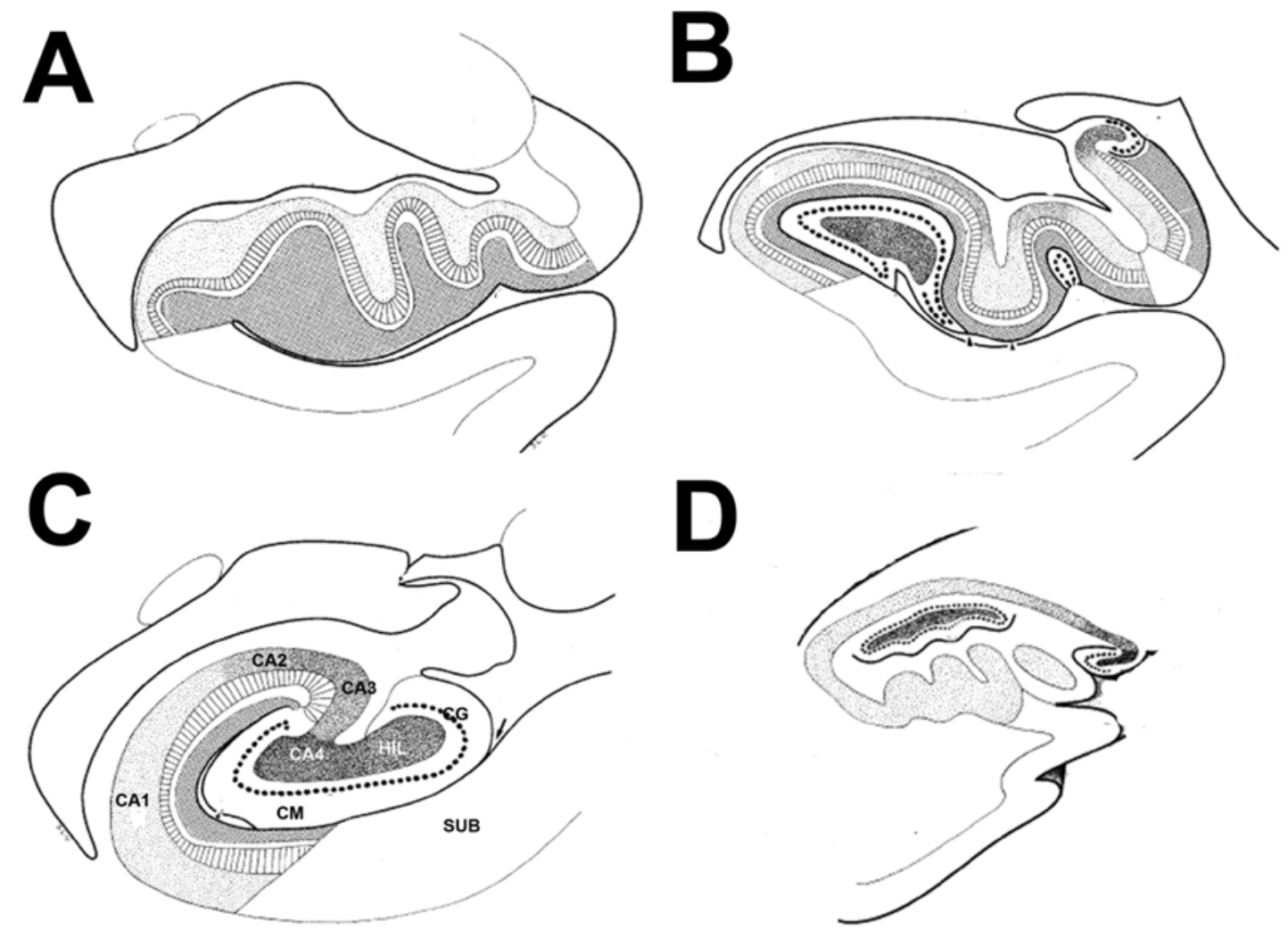

Figura 1. Desenho esquemático de cortes coronais do hipocampo nos níveis da cabeça (A e B), corpo (C) e cauda (D). Note a diferença da área ocupada pelos subcampos em cada nível do hipocampo: e.g., a região CA1 (indicada nas imagens pelo granulado fino) é muito maior em A do que em C. Nos desenhos, os pontos negros grandes indicam a camada granular, o granulado cinza intenso indica o hilo/CA4, o granulado médio indica CA3, o granulado médio-leve indica CA2 e o granulado fino, CA1. O prosubículo, não sendo reconhecido como distinto de CA1 pelos autores, não encontra-se representado nas imagens. Adaptado de Duvernois (2005) 
A gliose é outro achado patológico importante na formação hipocampal de casos com ELT (Salanova et al., 1999; Proper et al., 2001; Swartz et al., 2006; Prayson e Yoder, 2007). Esta reação pode ocorrer antes da morte neuronal (Uhlmann et al., 2002; Kang et al., 2006), provavelmente para impedir danos teciduais, envolvendo tanto células microgliais como astrócitos. Apesar de estudos com modelos experimentais mostrarem que a reação microglial volta rapidamente aos níveis basais (Benkovic et al., 2006), a gliose microglial é encontrada em hipocampos submetidos à lobectomia (Borges et al., 2003; Boer et al., 2006; Chakir et al., 2006; Kang et al., 2006; Block et al., 2007; Choi et al., 2009), indicando sua persistência em processos crônicos. Em condições fisiológicas os astrócitos controlam a concentração de potássio no líquido extracelular e o volume do espaço extracelular (Borges et al., 2003). Estudos com modelos experimentais indicam que a astrogliose é importante para a gênese das crises e da alteração tecidual encontrada na ELT (Khurgel e Ivy, 1996; Kralic et al., 2005; Vessal et al., 2005; Kang et al., 2006). Vários trabalhos ligam a astrogliose à excitabilidade alterada que é vista na epilepsia, principalmente através de liberação de glutamato (Binder e Steinhauser, 2006; Chakir et al., 2006), redução de transportadores de glutamato e de sua corrente em astrócitos (Drage et al., 2002; Wong et al., 2003), e desregulação da homeostase de potássio (Mcnamara, 1994).

\section{Imagens por ressonância magnética na investigação da ELT}

No campo diagnóstico, as imagens por Ressonância Magnética (RM) possuem alto impacto na confirmação e no plano de tratamento de várias condições (Hollingworth et al., 2000). Ao contrário dos exames que utilizam tomógrafos (i.e., tomografia computadorizada, tomografia por emissão de pósitrons e tomografia por 
emissão de fóton único), a ressonância não utiliza radiação ionizante, sendo portanto considerada mais segura.

Nas imagens por RM, o contraste é obtido através do ganho e perda de energia, passada por meio de radiofrequência, por átomos com spin nuclear em um campo magnético (Brown e Semelka, 2003). Todos os isótopos atômicos que possuam spin nuclear podem ser visualizados por RM. Por sua abundância em moléculas estruturais dos seres vivos (especialmente água e lipídios), a ressonância baseada no hidrogênio é a mais difundida e utilizada na prática clínica, conferindo imagens com ótima resolução anatômica. Menos frequentes são os estudos baseados em outros núcleos. Por exemplo, espectroscopia por RM baseada em núcleos de fósforo-17 é utilizada em pesquisas para quantificar metabólitos indicadores de consumo energético (Hiremath e Najm, 2007).

Na investigação pré-cirúrgica dos casos de ELT fármaco-resistentes, exames de RM revelam que o hipocampo destes pacientes apresenta redução de volume, medido em sequências ponderadas em $\mathrm{T} 1$, e aumento de sinal nas sequências ponderadas em T2 (Berkovic et al., 1991; Cendes et al., 1993; Briellmann et al., 2002). As imagens ponderadas em T2 dependem da relação entre a água livre e a água presa no tecido (Eriksson et al., 2007). Qualitativamente, o hipocampo associado à gênese das crises e, em menor grau, o hipocampo contralateral, apresentam aumento do brilho nas imagens ponderadas em T2 (Briellmann, Syngeniotis, et al., 2004).

A quantificação do sinal T2 aumenta ainda mais o poder de detecção de anormalidades teciduais pela RM. Coan e colaboradores (2006) mostram que, enquanto a avaliação visual de alterações em T2 indica aumento de sinal em $24 \%$ dos casos com ELTM, a avaliação quantitativa do sinal T2 indica aumento em $42 \%$ dos casos pela medida do brilho e em $78 \%$ dos casos por medida do tempo de 
relaxamento de T2. Nesta casuística, todos os pacientes submetidos à cirurgia apresentaram esclerose hipocampal e a alteração em T2 foi observada no hipocampo ressecado (Coan et al., 2006). Outros estudos com ELT e esclerose hipocampal mostram que o tempo de relaxamento T2 é aumentado no hipocampo esclerótico em 74 a 100\% dos casos (Van Paesschen et al., 1997; Scott et al., 2003; Briellmann, Jackson, et al., 2004; Pell et al., 2004) e, mesmo com aumento bilateral, o hipocampo esclerótico apresenta tempo de relaxamento maior, o que possibilita definir corretamente o hipocampo foco em todos os casos (Scott et al., 2003). Em casos de ELTM onde o hipocampo apresenta volume normal na RM, o tempo de relaxamento é capaz de indicar o foco em até $82 \%$ dos casos (Bernasconi et al., 2000). Mesmo em casos onde o hipocampo não está diretamente ligado à gênese das crises, como ELT lesional ou epilepsia extra-temporal, e apresenta-se volumetricamente normal, observam-se alterações no seu tempo de relaxamento (Scott et al., 2003; Briellmann, Jackson, et al., 2004).

Além das imagens clássicas, atualmente estuda-se a utilidade da transferência de magnetização na investigação de epilepsia. As imagens de transferência de magnetização medem a troca de magnetização entre macromoléculas do tecido e a água livre (Widdess-Walsh et al., 2006; Eriksson et al., 2007), permitindo a visualização de prótons presos à macromoléculas que não são visíveis por outras modalidades de imagem por RM (Ge et al., 2001; Flugel et al., 2006) por apresentarem tempos de relaxamento muito curtos (Foong et al., 2001; Mclean et al., 2005).

Alterações na taxa de transferência de magnetização foram observadas em várias condições patológicas do SNC (Tofts et al., 1995; Foong et al., 2001; Ge et al., 2001; Bagary et al., 2003). Quanto à sensibilidade, vários estudos demonstraram que 
as alterações na transferência de magnetização ocorrem em uma área mais abrangente do que a da lesão delimitada por outras imagens de RM ou mesmo por demonstrarem alterações em áreas normais na RM que apresentavam alterações fisiopatológicas. Por exemplo, na esquizofrenia, as alterações captadas pela transferência de magnetização tiveram área maior do que as captadas pela densidade de prótons (Foong et al., 2001). O mesmo ocorre na epilepsia (Rugg-Gunn et al., 2003), onde foi observada redução em todos os casos com lesão na RM e mesmo casos com RM normal apresentam redução da transferência de magnetização em regiões com anormalidades epileptiformes no EEG interictal ou ictal. Kumar e colaboradores (2003) observaram redução de transferência de magnetização além da área de alteração em T2 em pacientes com epilepsia pós-traumática. Tofts e colaboradores (1995) observaram redução de transferência de magnetização coincidente com o atrofia no hipocampo na ELTM. Outros estudos, entretanto, não evidenciaram alterações significativas na transferência de magnetização na ELT, indicando falta de alteração na transferência de magnetização em casos cujas biópsias evidenciaram alterações neuropatológicas (Salmenpera et al., 2007) e incorreta lateralização baseada na transferência de magnetização (Li et al., 2000).

\section{Substratos Histopatológicos das Imagens por RM}

Patologicamente, as alterações no sinal T2 estão associadas tanto à astrogliose (Briellmann et al., 2002) como ao edema tecidual (Scott et al., 2002). Entretanto, estudos conduzidos na formação hipocampal (Van Paesschen et al., 1997) e no córtex (Eriksson et al., 2007) de pacientes com ELT observaram correlação entre a relaxometria com a densidade neuronal, mas não com a população astroglial, colocando dúvidas sobre qual característica tecidual da ELT melhor reflete o sinal T2. 
Na substância branca, redução na transferência de magnetização está associada à desmielinização e à perda axonal. Na substância cinzenta, acredita-se que as alterações gliais e a perda neuronal sejam os substratos para a redução de sinal (Flugel et al., 2006), porém esta associação na substância cinzenta ainda necessita confirmação (Bagary et al., 2003; Flugel et al., 2006).

Além das alterações relacionadas à excitabilidade tecidual, a astrogliose também está relacionada a alterações na homeostase da água no tecido, por alterar a proporção e constituição da matriz extracelular (MEC) e por alterar a expressão e disposição dos canais de água aquaporina 4 (AQP4) no tecido.

A MEC cerebral, rica em proteoglicanos e glicosaminoglicanos hidrofílicos (Costa et al., 2007; Galtrey e Fawcett, 2007), tem importante papel na homeostase da água (Hawkins e Davis, 2005; Vitellaro-Zuccarello et al., 2005), afetando a permeabilidade da barreira hematoencefálica (Hawkins e Davis, 2005; Kawakita et al., 2006; Swann et al., 2007), o volume do espaço extracelular e o coeficiente de difusão aparente da água (Heck et al., 2004; Sykova et al., 2005). No cérebro, esta MEC é basicamente composta por proteoglicanos tais como o sulfato de condroitina e o ácido hialurônico (Laurent e Fraser, 1992; Knudson e Knudson, 1993; VitellaroZuccarello et al., 2005). Na epilepsia do lobo temporal, Perosa e colaboradores (2002) mostraram aumento nos níveis de ambas estas moléculas no hipocampo. O acúmulo destas duas moléculas está associado ao edema tecidual (Laurent e Fraser, 1992) e às alterações na tortuosidade (Vorisek et al., 2002; Sykova, 2004) e no volume do EEC (Knudson e Knudson, 1993). Em estudos de lesão cerebral, o aumento de sulfato de condroitina está relacionado à redução do coeficiente de difusão aparente da água (aparent diffusion coeficient of water, $\mathrm{ADC}_{\mathrm{W}}$ ) medida por $\mathrm{RNM}$ e o coeficiente de difusão medido por tetrametilamônio $\left(\mathrm{ADC}_{\mathrm{TMA}}\right)$ (Vorisek et al., 2002). 
No SNC, a AQP4 é a principal molécula associada à homeostase da água (Rash et al., 1998; Furman et al., 2003; Nagelhus et al., 2004; Guerin et al., 2005; Verkman et al., 2006), afetando a gênese e dissipação de edema (Papadopoulos et al., 2004; Papadopoulos e Verkman, 2005; Wang et al., 2006). Em pacientes com ELT, as alterações da AQP4 envolvem aumento de expressão (Lee et al., 2004; Eid et al., 2005) e perda de polarização, causando redução na quantidade de AQP4 perivascular (Eid et al., 2005). Estudos de difusão indicam que a perda da polarização perivascular da AQP4 afeta as alterações de ADC observadas no edema citotóxico (AmiryMoghaddam et al., 2003).

\section{Justificativa e Hipóteses}

Uma vez que o sinal T2 é dependente da relação entre a água livre e a água presa no tecido, e que a transferência de magnetização depende da troca de magnetização entre prótons presos em macromoléculas e prótons livres da molécula de água, o presente trabalho visou avaliar: 1) quais alterações teciduais estariam ligadas à alteração destes parâmetros de ressonância magnética; 2) qual a contribuição de cada subcampo hipocampal para o volume total da estrutura, através de avaliação em imagens de ressonância de alto campo $(4,7 T)$. Propomos que: 1) alterações nas características teciduais ligadas à homeostase da água, assim como nas populações celulares hipocampais, correlacionar-se-iam com as alterações observadas nas imagens ponderadas em T2 e na transferência de magnetização no hipocampo de pacientes com ELT; e 2) que a região CA1 seja uma das principais contribuintes para o volume hipocampal total, de acordo com estimativas obtidas em um estudo prévio (Vide Anexo). 


\section{Objetivos}

Nosso objetivo foi avaliar as correlações entre imagens de ressonância magnética e alterações teciduais observadas no hipocampo de pacientes com ELT. Com esta finalidade, avaliamos, no hipocampo de pacientes com ELT: 1) tempos de relaxamento in vivo e ex vivo; 2) taxa de transferência de magnetização in vivo e ex vivo; 3) volumetria in vivo e ex vivo de hipocampos; 4) densidade neuronal, por imuno-histoquímica de NeuN; 5) astrogliose fibrilar, por imuno-histoquímica para GFAP; 6) microgliose, por imuno-histoquímica para HLA-DR; 7) expressão de aquaporina 4, por imuno-histoquímica para AQP4; 8) níveis de sulfato de condroitina, por imuno-histoquímica para CS-56; 9) características clínicas dos pacientes, por avaliação de prontuários; 10) correlações entre as imagens de ressonância magnética e as alterações patológicas observadas em pacientes com ELT. 


\section{Metodologia}

\section{Pacientes}

Pacientes com crises parciais complexas fármaco-resistentes originadas pelo lobo temporal foram avaliados pelo Centro de Cirurgia de Epilepsia (CIREP) da Faculdade de Medicina de Ribeirão Preto - USP, utilizando protocolos padronizados e previamente publicados (Engel J., 1991; Engel J., 1993). A abordagem diagnóstica presume que as crises do lobo temporal iniciam na região de dano cerebral ou em regiões adjacentes e que estas regiões podem ser localizadas por meio da identificação da estrutura com hiperexcitabilidade e déficits funcionais. A consideração sobre a terapia cirúrgica foi baseada na localização de uma área única para ressecção, não requerendo necessariamente uma injuria cerebral inicial ou crises na infância como critério de inclusão. A avaliação incluiu: uma detalhada história pregressa e exames neurológicos; EEG de escalpo/esfenoidal interictal e ictal; uma extensa bateria de testes neuropsicológicos; injeção de amital sódico em ambas as carótidas (teste de Wada) para avaliação da memória (quando necessário) e representação da fala; além de uma detalhada avaliação neurorradiológica utilizando tomografia computadorizada e RM de alta resolução, com protocolos especiais para visualização da formação hipocampal (Leite et al., 2000). Os pacientes foram adicionalmente submetidos à avaliação funcional da atividade cerebral utilizando tomografia computadorizada por emissão de fóton único (SPECT). Nos casos de discordância entre as avaliações nãoinvasivas, EEG de forâmen oval ou ECoG foram utilizados para a correta localização da zona epileptogênica.

Quando os dados desta avaliação localizaram inequivocamente a região temporal anterior como a região de origem das crises, os pacientes foram submetidos 
à remoção en bloc da região temporal anterior, incluindo 3 a $4 \mathrm{~cm}$ do hipocampo (Crandall, 1987), com passos técnicos utilizados há mais de 30 anos (Hill et al., 1953; Falconer et al., 1955). O risco de complicação cirúrgica é considerado baixo, principalmente por se tratar, na maioria dos casos, de uma cirurgia eletiva e não haver efeito de massa na estrutura a ser removida. No entanto, todos os pacientes candidatos à cirurgia foram informados pela equipe cirúrgica a respeito destes riscos e foi discutido o prognóstico do controle de crises com ou sem intervenção cirúrgica. Todos os dados de exames neurológicos, psicológicos e clínicos foram arquivados e a confidencialidade destas informações assegurada. Em caso de publicações, toda e qualquer informação pessoal será omitida. Uma vez esclarecido sobre estes procedimentos, o paciente então assinou um termo de consentimento que autoriza a utilização do material biológico cirúrgico para este estudo. Todos os protocolos diagnósticos e de conduta cirúrgica estão baseados em estudos visando otimizar o controle de crises sem que isto acarrete em prejuízos cognitivos permanentes. A aplicação destes protocolos possibilitou a realização deste projeto, assegurando que nenhum procedimento feito levasse a um comprometimento do bem estar do paciente.

Todo material a ser utilizado neste projeto foi coletado prospectivamente, sendo que a utilização destes casos foi aprovada pelo Comitê de Ética (processo HCRP 6286/2010) e o uso do material ocorreu após a aprovação, por Termo de Consentimento, pelos pacientes operados para tratamento de ELT. O material restante foi incorporado ao Banco de Tecido Cerebral do Laboratório de Investigação em Epilepsia, aprovado pelo Comitê de Ética em Pesquisa da FMRP-USP (processo HCRP 9370/2003). Tecidos dos casos pertencentes ao grupo controle foram coletados durante procedimento de necropsia, com o consentimento do responsável legal pelo sujeito. 


\section{Grupos}

Os pacientes foram classificados em dois grupos: ELT $(n=43)$, pacientes com diagnóstico de epilepsia do lobo temporal mesial ou com tumor ou displasia cortical, todos com exame de RM; Ctrl $(n=34)$, pacientes com idade semelhante a do grupo ELT, que faleceram de causas não associadas à patologia cerebral e sem evidência de dano cerebral no exame post mortem $(\mathrm{n}=14$, controle historadiológico, CHR) e voluntários sem alterações neurológicas, submetidos ao protocolo de RNM para investigação de epilepsia $(n=20$, controle radiológico, CR).

Os critérios de inclusão foram: idade entre 20 e 60 anos para ELT e Ctrl; diagnóstico de epilepsia do lobo temporal para os pacientes do grupo ELT; com realização de exame de $\mathrm{RM}$ com volumetria hipocampal, relaxometria T2 e transferência de magnetização para ELT e CR (exame in vivo) e com relaxometria T2 e transferência de magnetização para os grupos ELT e CHR (exame ex vivo).

Os critérios de exclusão foram: EEG com paroxismos epileptiformes extratemporais ou generalizados para o grupo ELT; acentuado prejuízo cognitivo nos testes neuropsicológicos para o grupo ELT; histórico de quaisquer problemas neurológicos para o grupo Ctrl; existência de patologia no exame post-mortem para o grupo CHR; tempo post-mortem superior a 12 horas para o grupo CHR; e existência de alterações na RM para o grupo CR.

\section{Características Clínicas}

As características clínicas dos pacientes com ELT, bem como dos casos controle, foram levantadas por avaliação de prontuários médicos. Nos pacientes com ELT foram levantadas: idade na operação; idade de início das crises recorrentes; 
presença, tipo e idade de ocorrência de IPI; frequência mínima de crises; avaliação patológica pelo Serviço de Patologia do Hospital das Clínicas de Ribeirão Preto (SERPAT). Nos pacientes do grupo controle foram avaliadas: idade no óbito; causa mortis; e tempo post mortem até a coleta do material.

\section{Ressonância magnética}

Imagens de RM foram realizadas em máquina de RM Achieva 3.0T X-series (Philips) e foram utilizadas bobinas para cabeça humana de 8 elementos para o protocolo in vivo (pré-operatório) e bobina para mão (dedos) em quadratura para o protocolo ex vivo. Imagens adicionais da formação hipocampal foram realizadas em máquina de RM de 4.7T, com bobina para pequenos animais.

\section{Estudo em 3.0T}

Protocolo in vivo

Os pacientes a serem submetidos à cirurgia para controle das crises, bem como voluntários saudáveis, foram examinados na máquina de RM, onde foram realizadas imagens para volumetria, relaxometria e transferência de magnetização.

Para a volumetria foram utilizadas imagens 3D ponderadas em T1 (3DT1) single shot com shot interval de $2500 \mathrm{~ms}$, tempo de recuperação (TR) de $7 \mathrm{~ms}$, tempo de eco (TE) de 3,2 ms, flip angle de $8^{\circ}$ e prepulso de inversão com tempo de $900 \mathrm{~ms}$, com FOV de 240x240mm e resolução de $1 \mathrm{~mm}$ isotrópica. O tempo total para obtenção desta imagem foi de 4 minutos e 30 segundos. A volumetria foi posteriormente avaliada como índice de assimetria (hipocampo menor/hipocampo maior para CR e hipocampo foco/hipocampo contralateral para ELT). 
Para relaxometria foram utilizadas imagens obtidas com sequências turbo spin eco com fator EPI de 5, com TE de 20, 40, 60, 80 e 100 ms, TR de 3000 ms, 48 cortes axiais com resolução de $1 \mathrm{~mm}$, espessura de corte de $3 \mathrm{~mm}$ e FOV de 240x180 mm. O tempo total para aquisição da imagem foi de 4 minutos.

Para o cálculo da transferência de magnetização foram utilizadas imagens ponderadas em transferência de magnetização com sequência 3DT1 com fator TFE 3, TE de 3,6 ms, TR de 7,3 ms, flip angle de $8^{\circ}$, pulso de transferência de magnetização on resonance, resolução 1x1x3 mm e FOV de 240x180mm. A duração da aquisição da imagem foi de 5 minutos.

Para as imagens de tensor de difusão foram utilizadas imagens single shot ponderadas em difusão $\left(b=1000 \mathrm{~s} / \mathrm{mm}^{2}\right.$ e $\left.b=0 \mathrm{~s} / \mathrm{mm}^{2}\right)$, com TE de $65 \mathrm{~ms}$ e TR de 8400 ms, flip angle de $90^{\circ}$, resolução de $2 \times 2 \times 2 \mathrm{~mm}$ e FOV de 256x144. O tempo total de aquisição foi de 6 minutos.

\section{Protocolo ex vivo}

Os hipocampos vindos da cirurgia foram lavados em salina $0,9 \%$ para remoção de excesso de sangue, seccionados em fragmentos de 10 a $15 \mathrm{~mm}$ de espessura e colocados em recipientes plásticos cheios de formol 10\% tamponado por sete dias. $\mathrm{Na}$ noite do oitavo dia, os fragmentos foram acondicionados em recipientes próprios para realização da ressonância magnética, preenchidos por formol, e algodão embebido em formol foi usado para impedir que os hipocampos mudassem de posição durante o procedimento de ressonância. Este recipiente fechado foi levado até o centro de ressonância magnética, onde os tecidos foram escaneados. Para os casos de necropsia que foram avaliados apenas em ressonância de 3T, o mesmo procedimento foi utilizado. Para os 6 casos avaliados pelo protocolo de 4.7T, os hipocampos foram 
fixados inteiros, sendo seccionados apenas após a realização das imagens para volumetria.

Para a relaxometria (Figura 2) foram utilizadas sequências turbo spin eco com fator EPI 3, TE de 25, 50, 75, 100 e $125 \mathrm{~ms}$, TR de $3400 \mathrm{~ms}, 54$ cortes coronais com 30 médias, FOV de $25 \times 25 \mathrm{~mm}$, resolução de $0,4 \mathrm{~mm}$, espessura de corte de $0,5 \mathrm{~mm}$. O tempo total para aquisição da imagem foi de $2 \mathrm{~h} 18 \mathrm{~m}$.

Para o cálculo da transferência de magnetização (Figura 3) foram utilizadas imagens 3DT1 com fator TFE de 4, TE de $11 \mathrm{~ms}$, TR de $23 \mathrm{~ms}$, flip angle de $8^{\circ}$, FOV de $25 \times 25 \mathrm{~mm}, 12$ médias, resolução isotrópica de $0,3 \mathrm{~mm}$ e pulso de transferência de magnetização on resonance. O tempo total para obtenção da imagem foi de $1 \mathrm{~h} 45 \mathrm{~m}$.

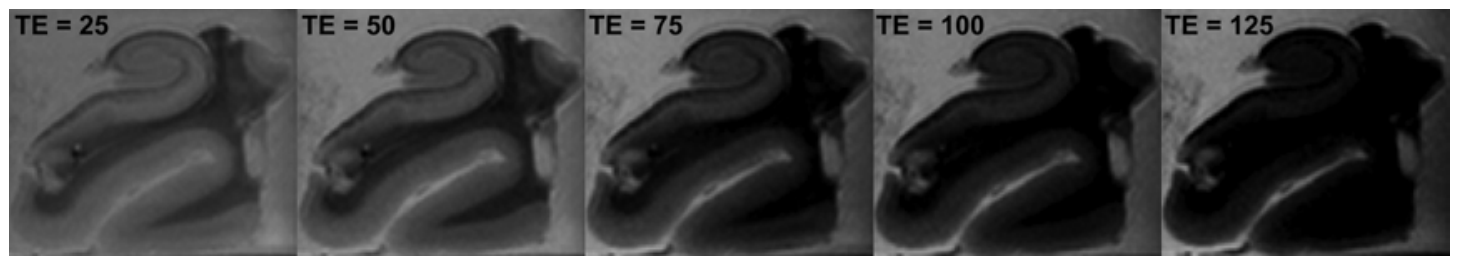

Figura 2. Imagem representativa dos diferentes tempos de eco (25 a 125) coletados para o cálculo do tempo de relaxamento ex vivo. Note que, quanto menor o tempo de eco, maior o brilho da imagem. O tempo de relaxamento nada mais é do que o tempo da perda do brilho T2/DP para cada região de interesse. Para maiores detalhes vide seção Cálculos de volumetria, taxas de relaxamento e de transferência de magnetização.

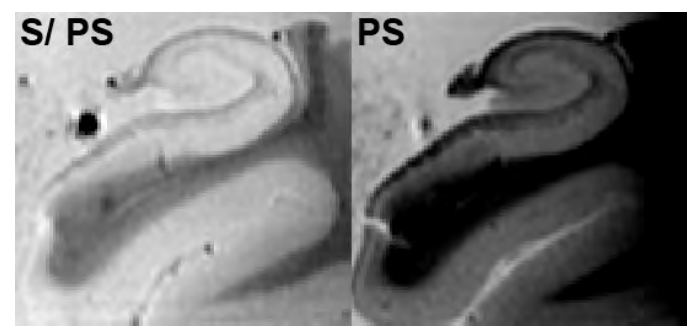

Figura 3. Imagens representativas de RM coletadas para o cálculo da transferência de magnetização. Para o cálculo da transferência, efetua-se a diferença de sinal entre imagem com pulso de saturação (PS) e imagem sem o pulso de saturação (S/ PS). Para maiores detalhes vide seção Cálculos de volumetria, taxas de relaxamento e de transferência de magnetização.

\section{Estudos em 4.7T}

Para estudar a volumetria específica de cada subcampo da formação hipocampal, hipocampos inteiros fixados em formol $10 \%$ tamponado foram examinados em máquina de RM de 4.7T.

Foram adquiridas imagens ponderadas em T2, com TE de $50 \mathrm{~ms}$, TR de 3000 ms, 45 cortes coronais com resolução de $0,01 \times 0,02 \mathrm{~mm}$, espessura de corte de 0,1 
mm e FOV de 240x180 mm. O tempo total para aquisição das imagens foi de 1 hora e 30 minutos.

Ao contrário das máquinas de RM clínicas, a coleta de imagens nesta máquina de 4.7T exige vários ajustes prévios para cada imagem. Assim que o espécime é posicionado dentro da bobina e esta é inserida no magneto, deve-se realizar ajuste do ângulo dos receptores de radiofrequência. Nas máquinas convencionais, estes receptores estão sempre em ângulo de 90 graus. Entretanto, qualquer corpo presente no campo magnético distorce o mesmo, causando pequenas alterações que podem impactar a qualidade das imagens. O reajuste manual dos receptores serve para que a perturbação no campo influencie minimamente na qualidade da imagem. Deve-se ainda informar para o equipamento a amplitude das variações do sinal captado (i.e., o maior e o menor pico de sinal), garantindo assim o melhor contraste possível à imagem. Após estes ajustes iniciais, indica-se as coordenadas do espécime no campo, bem como as características da imagem a ser coletada (i.e., espessura de corte, número de cortes, espaço entre cortes, etc.).

\section{Cálculos de volumetria, taxas de relaxamento e de transferência de magnetização.}

A volumetria, a relaxometria e o cálculo da taxa de transferência de magnetização in vivo foram realizados automaticamente com o uso do programa FreeSurfer (Athinoula A. Martinos Center for Biomedical Imaging). Brevemente, as imagens foram alimentadas em um computador MacBook Pro (Apple), onde o programa FreeSurfer realizou a segmentação de várias estruturas cerebrais e realizou 
os cálculos dos valores de volumetria, tempo de relaxamento e taxa de transferência de magnetização dos hipocampos direito e esquerdo.

A relaxometria e a taxa de transferência de magnetização ex vivo foram calculadas manualmente com o uso dos programas XQuartz e Display (parte da plataforma Minc Tool Kit, McConnell Brain Imaging Centre) em um computador MacBook Pro. As imagens ex vivo foram convertidas para o formato $m n c$, a partir das quais foram calculados os mapas de relaxometria e de transferência de magnetização.

Para o cálculo do tempo de relaxamento e taxa de transferência de magnetização, as regiões de interesse foram delimitadas com diferentes labels no programa Display, usando-se o segundo eco da relaxometria $(\mathrm{TE}=50 \mathrm{~ms})$ e a imagem sem o pulso de saturação da transferência de magnetização. Delimitações diferentes tiveram que ser realizadas para a relaxometria e a taxa de transferência de magnetização uma vez que a espessura dos voxels era diferente em cada uma destas imagens. As regiões delimitadas foram: camadas moleculares da fascia dentata, que incluíram camada molecular externa e camada molecular interna; fascia dentata, incluindo hilo, camada granular e camadas moleculares; CA4-CA1 do Corno de Amon; prosubículo e subículo. As regiões quantificadas podem ser observadas na Figura 4. As bordas dos tecidos foram excluídas da delimitação, para evitar a quantificação de voxels com nível de cinza influenciado parcialmente pela solução de formol. Como o hipocampo foi seccionado coronalmente e as imagens foram realizadas no mesmo plano, muitas vezes os primeiros e últimos cortes da imagem eram irregulares. Por este motivo, estes cortes foram descartados, fazendo com que apenas cortes com boa definição fossem quantificados. Ainda, sempre que houve dúvida sobre o formato das subregiões, foram consultadas imagens panorâmicas dos hipocampos por secções coradas pela técnica de Hematoxilina \& Eosina. Após feitos 
os labels, foram calculados o tempo de relaxamento e a taxa de transferência de magnetização das diferentes regiões de interesse, através de linhas de comando no programa XQuartz (vide Anexo).
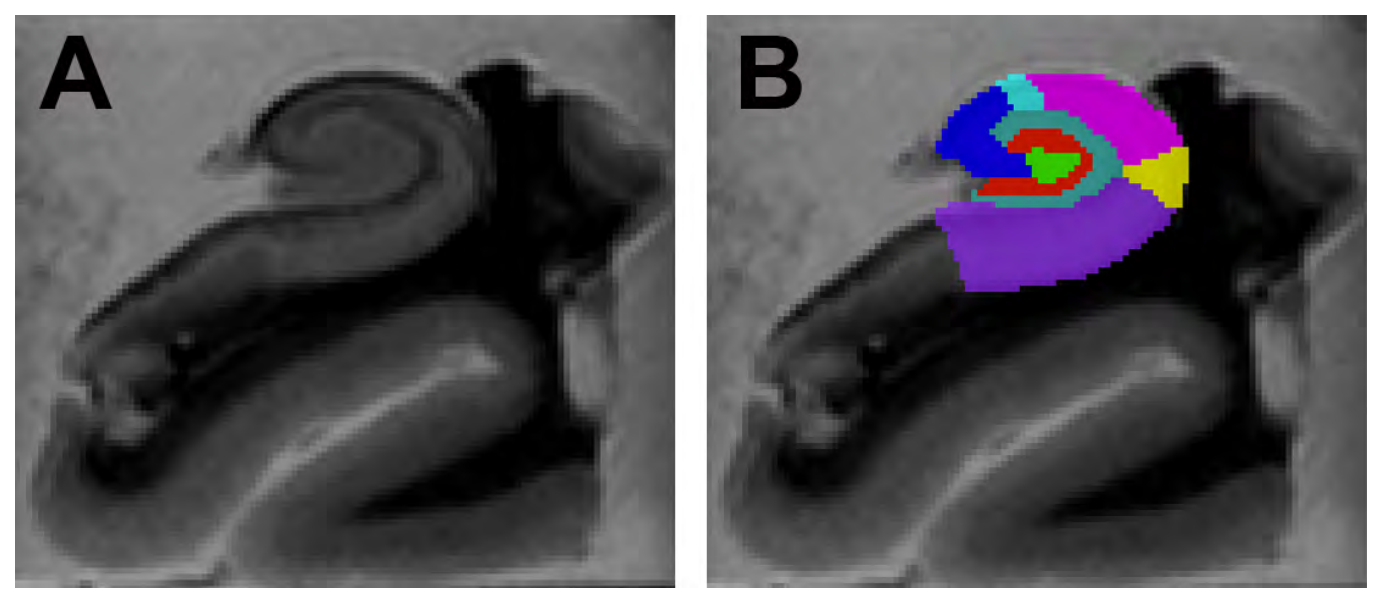

Figura 4. Imagens ex vivo para relaxometria de caso controle, mostrando em $\mathrm{B}$ as subdivisões do hipocampo em camada molecular (verde escuro), hilo + camada granular (vermelho), CA4 (verde claro), CA3 (azul escuro), CA2 (azul claro), CA1 (rosa), prosubículo (amarelo) e subículo (roxo).

A volumetria dos subcampos hipocampais foi calculada manualmente no programa MeVisLab (MeVis Medical Solution AG). Cada secção coronal da imagem de RM 4,7T gerou uma imagem no formato FDF, sendo depois convertidas em imagem única no formato IMG. Estas imagens foram então avaliadas através de rotinas para delimitação freehand, sendo os subcampos hipocampais definidos de acordo com a classificação de Lorente de Nó (1934). Cada subcampo hipocampal foi delimitado separadamente, gerando máscaras cujo volume foram posteriormente quantificados no programa MATLAB (MathWorks). A segmentação de cada subcampo foi realizada separadamente para a cabeça, corpo e cauda do hipocampo. Adicionalmente, visando comparar os casos de ELT com dados de volumetria de cada subcampo do grupo CHR, os subcampos hipocampais foram também avaliados em imagens ponderadas em $\mathrm{T} 2(\mathrm{TE}=50 \mathrm{~ms})$ obtidas com o protocolo para cálculo do tempo de relaxamento. Para estas avaliações, as delimitações foram realizadas manualmente no software Display. 


\section{Coleta e processamento do tecido}

Após a obtenção de todas as imagens de ressonância ex vivo do estudo, as secções hipocampais, já fixadas em formol $10 \%$ tamponado por pelo menos 8 dias, foram desidratadas, diafanizadas e incluídas em parafina. Parte do tecido retirado na cirurgia foi enviado ao SERPAT, que emitiu um laudo sobre a biópsia e parte foi processado e integrado ao banco de tecido cerebral do Laboratório de Investigação em Epilepsia, sendo este último tecido o utilizado neste estudo. Todo o tecido coletado durante necropsia foi integrado ao banco de tecido supracitado.

\section{Técnicas histológicas}

\section{Histoquímicas básicas}

\section{Hematoxilina e Eosina}

As secções foram desparafinizadas, lavadas em água corrente por 5 minutos e imersas em Hematoxilina de Harris (Laborclin) por tempo variável (em média 8 minutos). Após novas lavagens em água corrente, as secções passaram por solução de álcool ácido (99 $\mathrm{ml}$ de álcool $70 \%$ e 0,5 $\mathrm{ml}$ de ácido clorídrico) por 3 segundos, para remoção do excesso de Hematoxilina. As secções foram novamente lavadas em água e passaram por solução de água e amônia ( 1 gota de $\mathrm{NH}_{3}$ para cada $50 \mathrm{ml}$ de água) até que atingissem o tom roxo-azulado desejado. As secções foram lavadas, imersas em etanol $70 \%$, seguido de etanol $95 \%$, e finalmente solução de Eosina-Floxina (50 ml de Eosina Amarelada Inlab 1 \% em água, $5 \mathrm{ml}$ de Floxina B Sigma $1 \%$ em água, 380 $\mathrm{ml}$ de álcool comercial e $2 \mathrm{ml}$ de ácido acético glacial). As secções então seguiram para desidratação, clarificação e montagem em Krystalon (Harleco). 


\section{Luxol Fast Blue}

As secções foram desparafinizadas até solução de álcool $95 \%$, sendo então incubadas em solução de Luxol Fast Blue (0,1 g de Solvente Blue 38 Sigma e 0,5 ml de ácido acético glacial em $100 \mathrm{ml}$ de álcool $95 \%$ ) por 16 horas a $60^{\circ} \mathrm{C}$. Na manhã seguinte, as secções foram lavadas em água corrente, imersas em carbonato de lítio 0,05\% (em água destilada) por 30 segundos, imersas em álcool $70 \%$ por 30 segundos e lavadas novamente em água por 5 minutos. Em seguida, as secções foram coradas em solução de Cresil Violeta (6 g de Violeta cristal e 0,5 $\mathrm{ml}$ de ácido acético glacial em $600 \mathrm{ml}$ de água destilada), aquecida a $56^{\circ} \mathrm{C}$, por 30 segundos. Segue-se a coloração desidratação a partir de álcool $70 \%$, clarificação e montagem em Krystalon.

\section{Imuno-histoquímica}

Secções hipocampais dos tecidos emblocados foram colocadas em lâminas previamente gelatinizadas e foram utilizadas para avaliar: a gliose, através da expressão de marcadores de astrócitos reativos (GFAP) e de micróglias ativadas (HLA-DR); a população neuronal, pela expressão da proteína NeuN; e a expressão de AQP4; e moléculas de matriz extracelular, pela medida dos níveis de sulfato de condroitina. As imuno-histoquímicas foram realizadas por protocolos previamente publicados (Peixoto-Santos et al., 2012).

As secções foram desparafinizadas e submetidas ao bloqueio da peroxidase endógena com 4,5\% de $\mathrm{H}_{2} \mathrm{O}_{2}$ em PBS $50 \mathrm{mM} \mathrm{pH} \mathrm{7,4.} \mathrm{Em} \mathrm{seguida,} \mathrm{a} \mathrm{recuperação} \mathrm{antigênica} \mathrm{foi}$ realizada em micro ondas Brastemp DES com tampões citrato de sódio 10 mM pH 6 (para GFAP e AQP4), Tris-HCl 50 mM pH 9,5 (para NeuN e HLA-DR) e TrizmaHCl 50 mM pH 9 (para CS-56). Após a recuperação, as lâminas ficaram em repouso 
no tampão de recuperação até atingirem temperatura ambiente, quando então realizouse então o bloqueio de grupos aldeídos livres com Trizma-Glicina $0,1 \mathrm{M} \mathrm{pH} \mathrm{7,4} \mathrm{por}$ 45 minutos. As secções foram incubadas em tampão de bloqueio (5 \% p/v leite desnatado, 10 \% v/v soro normal de cabra Vector em tampão Triton-PBS) por 4 horas, após as quais esta solução foi substituída por solução contendo os anticorpos primários diluídos em tampão de bloqueio. Foram utilizados anticorpos monoclonais produzidos em camundongos anti-NeuN (clone A60, \#MAB377, Chemicon), antiGFAP (clone 6F2, \#M0761, Dako), anti-HLA-DR (clone TAL.1B5, \#M0746, Dako) e anti-CS-56 (clone CS-56, \#C8035, Sigma), e anticorpo policlonal produzido em coelho anti-AQP4 (H-80, \#sc-20812, Santa Cruz Biotechnology), diluídos em tampão de bloqueio a, respectivamente, 1:500, 1:500, 1:100, 1:50 e 1:1000. A detecção das moléculas foram realizada em secções de $3 \mu \mathrm{m}$ (para GFAP e HLA-DR) ou $8 \mu \mathrm{m}$ de espessura (para NeuN, AQP4 e CS-56). Após incubação em anticorpo primário (por 20 horas para CS-56 e 16 horas para os demais antígenos), seguiu-se incubação em anticorpos secundários biotinilados produzidos em coelho anti-IgG de camundongo (\#E0354, Dako) ou produzidos em porco anti-IgG de coelho (\#E0353, Dako), diluídos à 1:100 (para CS-56) ou 1:200 (demais antígenos). O sinal foi amplificado por meio do kit ABC Elite (Vector) diluído em PBS, de acordo com as instruções do fabricante. A revelação foi processada por reação em solução de $4 \mathrm{ml}$ de cromógeno 3,3"diaminobenzidine tetrahydrochloride $2 \%$ (DAB Sigma), $30 \mu \mathrm{lde} \mathrm{H}_{2} \mathrm{O}_{2}$ em $96 \mathrm{ml}$ de tampão Trizma-HCl pH 7,6. Os tempos de revelação foram de 5 minutos para AQP4 e CS-56, 8 minutos para GFAP, 11 minutos para NeuN e 12 minutos para HLA-DR. Finalmente, as secções foram desidratadas, clarificadas e montadas em Krystalon. Todos os tempos e diluições específicos para cada antígeno foram estabelecidos de acordo com experimentos-piloto. 


\section{Avaliação das imuno-histoquímicas}

Para as medidas semi-quantitativas de todas as imuno-histoquímicas, as imagens das regiões de interesse foram coletadas por uma câmara de alta resolução AxioCamMR5 instalada a um microscópio Zeiss Axio Imager M1 e foram convertidas em sinais digitais e alimentadas a um computador Windows usando o programa de análise de imagem AxioVision 4.8.1. A iluminação foi mantida uniforme (3V, 100\%, com exposição de 30 ms para AQP4, 33 ms para NeuN e GFAP, 40 ms para CS-56 e 60 ms para HLA-DR) e estável durante todas as medidas. As imagens foram capturadas com aumento de 100x para todas as imuno-histoquímicas exceto a imunohistoquímica para HLA-DR, que foi capturada com aumento de 200x. As imagens foram transferidas para computador MacBook Pro e, com o programa ImageJ 1.45s (National Institutes of Health), foram convertidas para imagens de 8 bits e processadas pela ferramenta de limiar, onde o software marca pixels que possuam cor cinza igual ou superior ao limiar de marcação em vermelho, calculando então a área marcada em vermelho em cada área amostral (Figura 5).

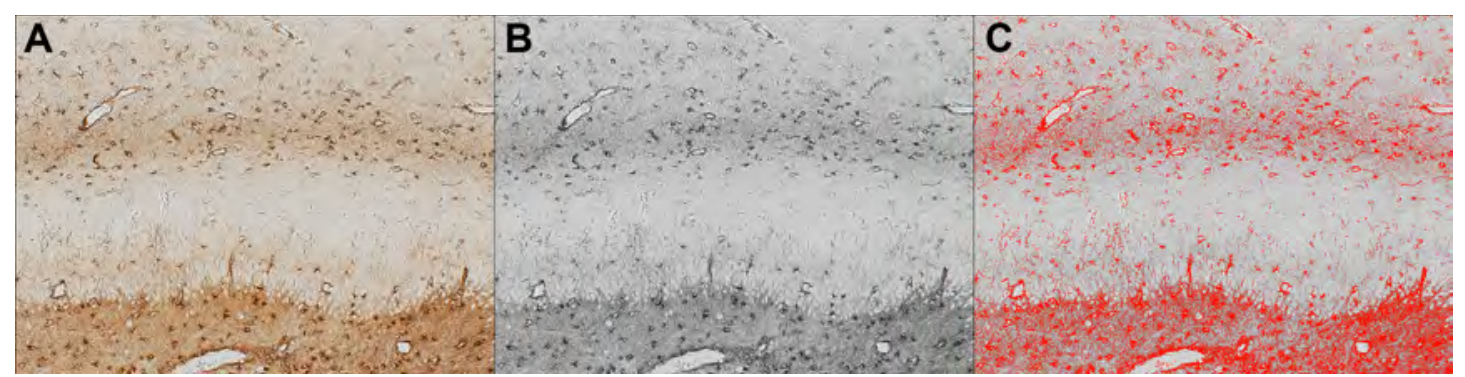

Figura 5. Imagens representativas da quantificação das áreas imunopositivas. Após capturadas em RGB pela AxioCamMR5 (A), as imagens das regiões a serem avaliadas são convertidas em imagens de 8 bits em escala de cinza (B). Após a conversão, pixels com valor de cinza considerados positivos para presença do antígeno de interesse são marcados em vermelho pela ferramenta Limiar (C), e calcula-se a área positiva em relação à área amostral total.

O valor limiar foi estabelecido através dos padrões encontrados nas secções de pacientes do grupo controle, para estabelecer qual era a marcação padrão de cada proteína. As medidas foram realizadas na forma de porcentagem de área de pixels 
marcados na área amostral total. Mais detalhes sobre este procedimento podem ser vistos em rsbweb.nih.gov/ij/docs/examples/stained-sections/index.html

As contagens celulares para cada subcampo do hipocampo foram realizadas em seções do corpo do hipocampo de $8 \mu \mathrm{m}$ de espessura para densidade neuronal, com aumento de 100x, com contagens em uma área definida e aplicação do fator de correção de Abercrombie (1946) para espessura do corte.

As regiões analisadas foram delimitadas de acordo com a classificação de Lorente de Nó (1934): camadas moleculares da fascia dentata, camada granular, hilo, CA4, strata oriens, pyramidale e radiatum de CA3-1, prosubículo e subículo (Figura 6). Todas as avaliações histológicas foram realizadas sem que o observador soubesse a que grupo pertencia cada caso.

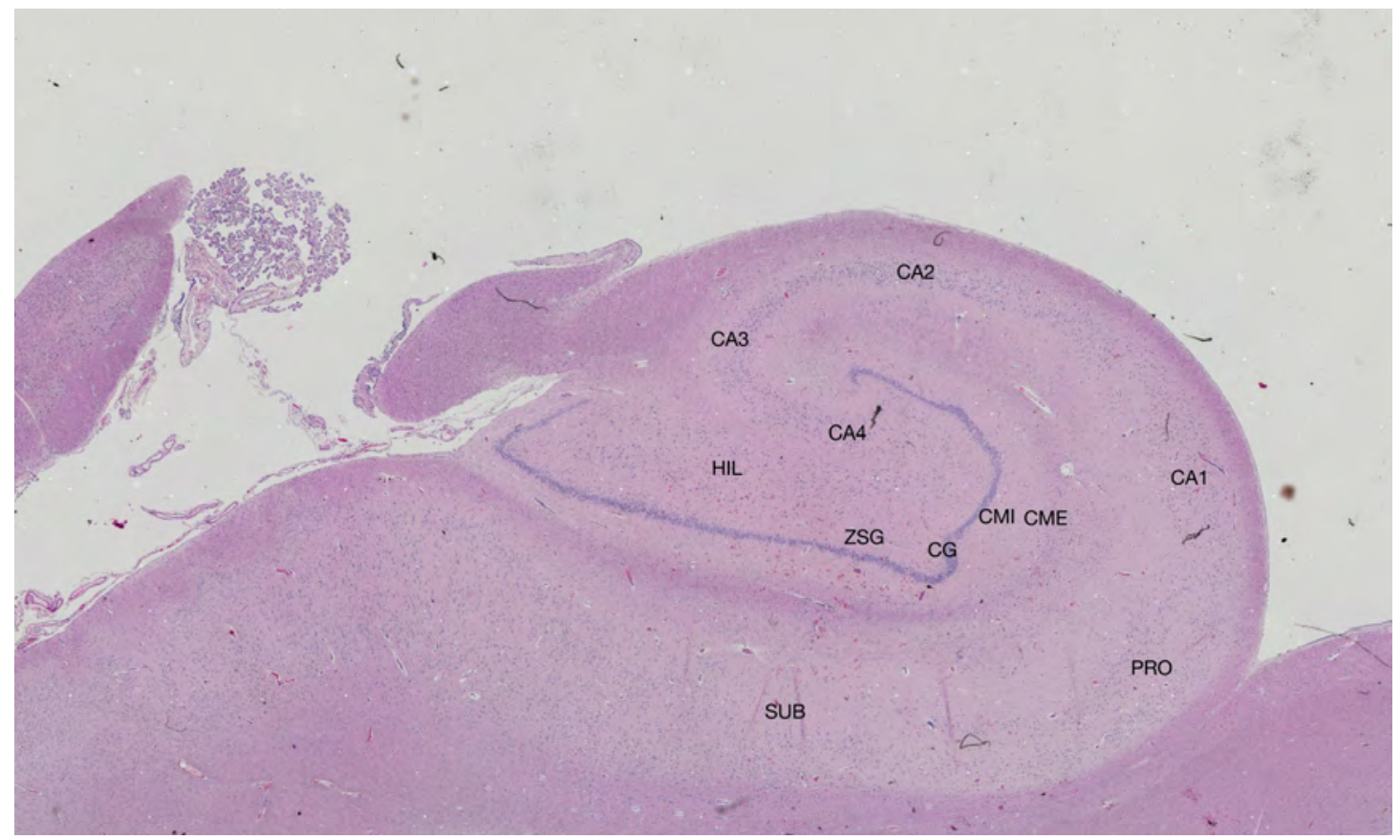

Figura 6. Fotomicrografia de um hipocampo do grupo CHR com a indicação das subdivisões do hipocampo. CME = camada molecular externa; $\mathrm{CMI}=$ camada molecular interna; $\mathrm{CG}=$ camada granular; $\mathrm{ZSG}=$ zona subgranular; $\mathrm{HIL}=$ hilo; $\mathrm{PRO}=$ prosubículo; $\mathrm{SUB}=$ subículo. 


\section{Análise estatística}

Todos os dados foram submetidos a teste para avaliar a normalidade e a igualdade de variâncias dos dados. Para as variáveis que cumpriram ambos os critérios foram utilizados testes paramétricos Teste-t de Student ou ANOVA. Quando pelo menos um dos critérios não foi cumprido, foram aplicados testes não-paramétricos de MannWhitney ou Kruskal-Wallis. Testes de correlação de Spearman foram utilizados para avaliar as correlações entre as variáveis estudadas. Todas as análises foram realizadas no programa SigmaPlot 9 (Systat Software), e os resultados foram considerados como significativos com um nível de confiança de $\mathrm{p}<0,05$. Todos os gráficos foram construídos no programa Minitab 14 (Minitab). 


\section{Resultados}

\section{Pacientes}

Foram avaliados 34 indivíduos do grupo controle, sendo 14 do grupo CHR e 20 do grupo CR, e 43 indivíduos com ELT. Todos os grupos foram pareados por idade $(\mathrm{CHR}=48,6 \pm 12,8 ; \mathrm{CR}=43,6 \pm 7,6 ; \mathrm{ELT}=42,2 \pm 10,8 ;$ ANOVA, $\mathrm{P}=0,147)$

Todos os pacientes com ELT apresentaram esclerose hipocampal, sendo que seis apresentaram displasia cortical associada à esclerose e um apresentou astroglioma grau II associado à esclerose hipocampal. Foram observadas perda neuronal e gliose no hipocampo em todos os casos avaliados. A primeira crise ocorreu em média aos $9,2 \pm 8,8$ anos e a recorrência aos 16,9 $\pm 10,6$ anos. Em 19 pacientes houve injúria precipitante inicial nos primeiros anos de vida. A etiologia da injúria foi uma crise em 19 dos casos. A frequência de crises foi de $9,7 \pm 9,4$ por mês, sendo relatado agrupamento de crises em 10 pacientes. Foi ainda relatado status epilepticus em oito dos pacientes. Em 24 casos foi detectado histórico familiar de epilepsia.

Dos pacientes do grupo CHR, 57,2\% foram a óbito por problemas cardíacos, $21,4 \%$ por pneumonia e $21,4 \%$ por neoplasia. O tempo post mortem (i.e., entre a morte e o início da fixação do hipocampo) foi de 7,814 $\pm 4,17$ horas. 


\section{Ressonância Magnética}

\section{Protocolo in vivo}

Foi realizado protocolo quantitativo para medida do tempo de relaxamento e da taxa de transferência de magnetização dos pacientes com ELT envolvidos no estudo, bem como de voluntário sem alterações neurológicas (Controle Radiológico, CR).

Foi observado menor volume hipocampal (Teste-t, $p=0,039$ ), aumento do tempo de relaxamento (Mann-Whitney, $\mathrm{p}<0,001)$ e redução da taxa de transferência de magnetização (Mann-Whitney, $\mathrm{p}<0,001$ ) em pacientes com ELT, quando comparados com indivíduos do grupo CR (Figura 7 e Tabela 1).
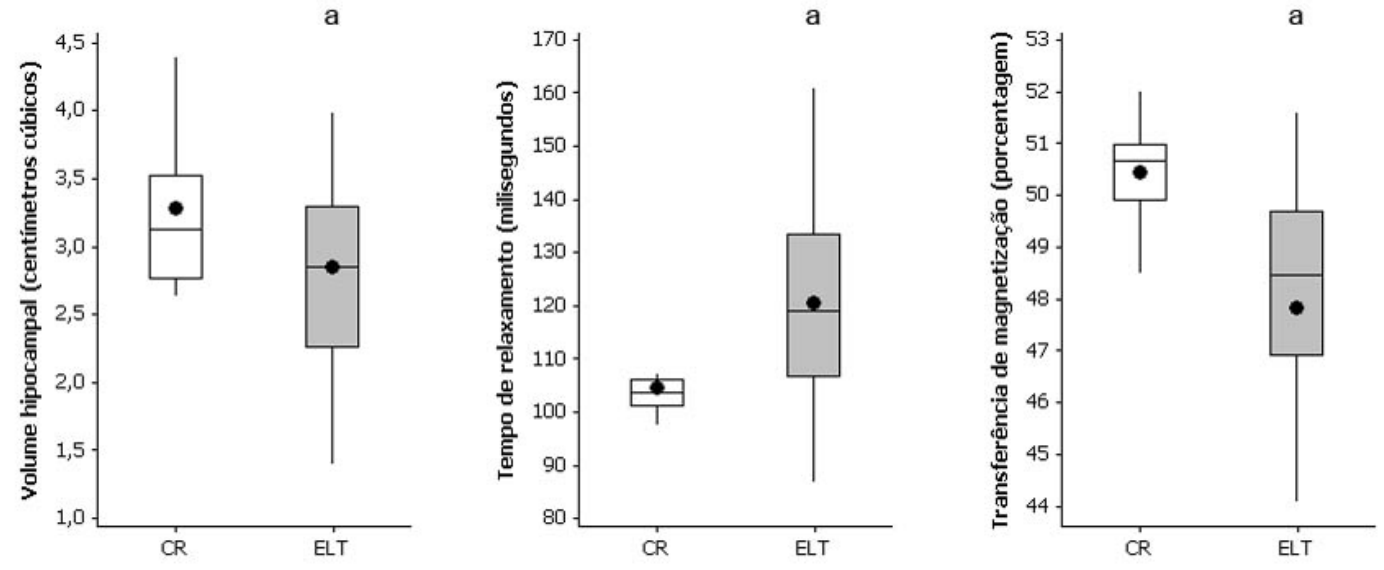

Figura 7. Volume hipocampal (esquerda; Teste-t, $\mathrm{p}=0,039$ ), tempo de relaxamento (centro; Mann-Whitney, $\mathrm{p}<$ 0,001 ) e taxa de transferência de magnetização (direita; Mann-Whitney, $p<0,001$ ) em pacientes com ELT (boxplots cinzas) e controles (CR, boxplots brancos). A letra a sobre os boxplots indica diferença em relação ao $\mathrm{CR}$. Os círculos negros indicam as médias.

Tabela 1. Alterações observadas nos exames de ressonância magnética dos hipocampos associados à gênese das crises.

\begin{tabular}{ccccc}
\hline & $\begin{array}{c}\text { Volumetria } \\
\text { hipocampal }\end{array}$ & $\begin{array}{c}\text { Índice de } \\
\text { assimetria }\end{array}$ & $\begin{array}{c}\text { Tempo de } \\
\text { relaxamento }\end{array}$ & $\begin{array}{c}\text { Transferência de } \\
\text { Magnetização }\end{array}$ \\
\hline Normais & $62 \%$ & $85 \%$ & $40 \%$ & $52 \%$ \\
Aumento & $0 \%$ & $0 \%$ & $59 \%$ & $0 \%$ \\
Redução & $38 \%$ & $15 \%$ & $1 \%$ & $48 \%$ \\
\hline
\end{tabular}




\section{Protocolos ex vivo}

Com o protocolo de ressonância magnética ex vivo realizado em máquina de 3T, foram obtidas imagens de grande qualidade e definição, possibilitando a observação de detalhes da estrutura hipocampal (Figura 8) e coletar dados de subregiões separadamente. Para exemplificar a qualidade da imagem, foi possível observar uma fina faixa hipointensa em T2 e transferência de magnetização na região correspondente à camada granular da fascia dentata. Uma comparação da diferença entre a qualidade das imagens in vivo e ex vivo (ambas obtidas em 3T) pode ser observada na Figura 9.

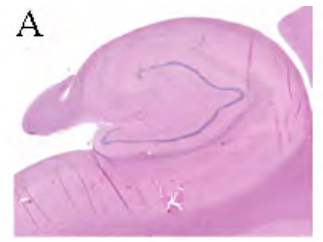

B

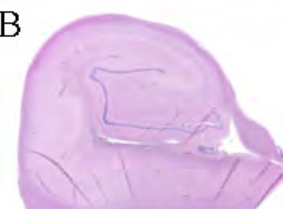

C

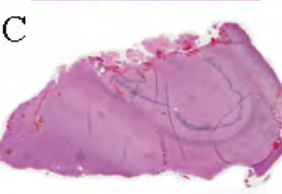

$\mathrm{D}$

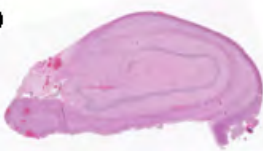

E

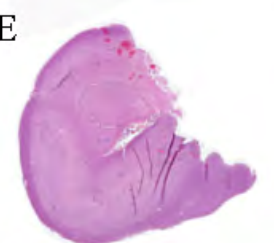

$\mathrm{F}$

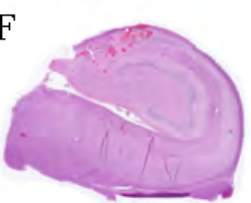

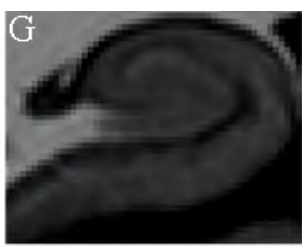
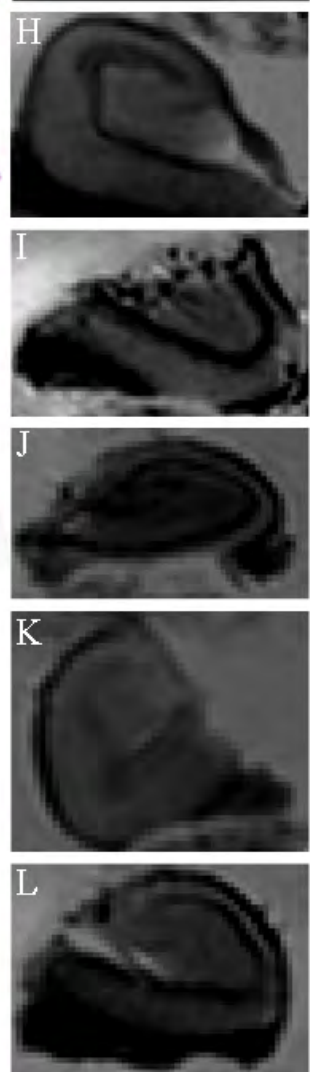
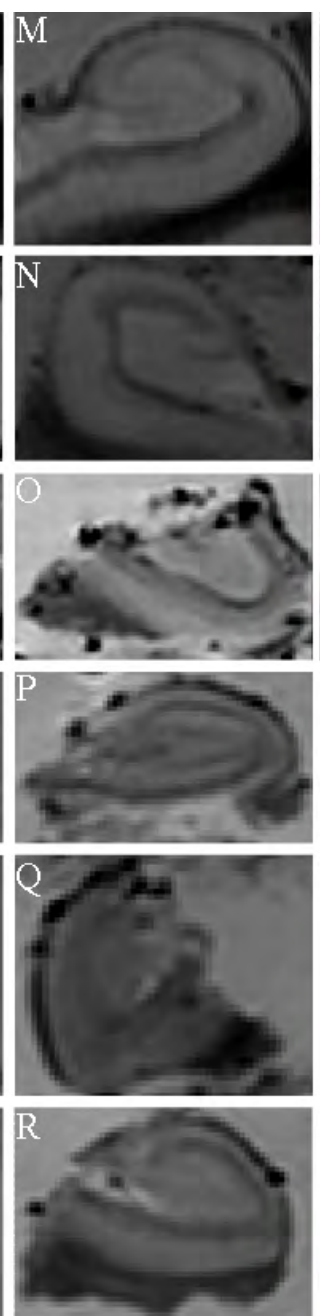
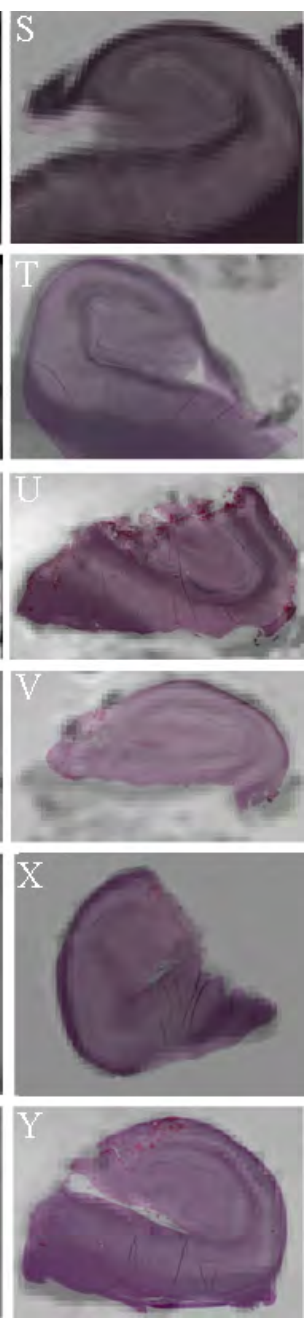

Figura 8. Imagens representativas das sequências de ressonância magnética ex vivo para relaxometria (G-L) e de transferência de magnetização (M-R), quando comparadas a imagens panorâmicas dos respectivos cortes histológicos (A-F) de casos controle (A, B, G, H, M, N, S e T) e de pacientes com ELT (C-F, I-L, O-R, U-Y). Em cada linha observam-se imagens do mesmo caso. A sobreposição das imagens de ressonância e histologia (S-Y) evidencia o grande detalhamento de estruturas observadas pelo protocolo ex vivo de RM. 

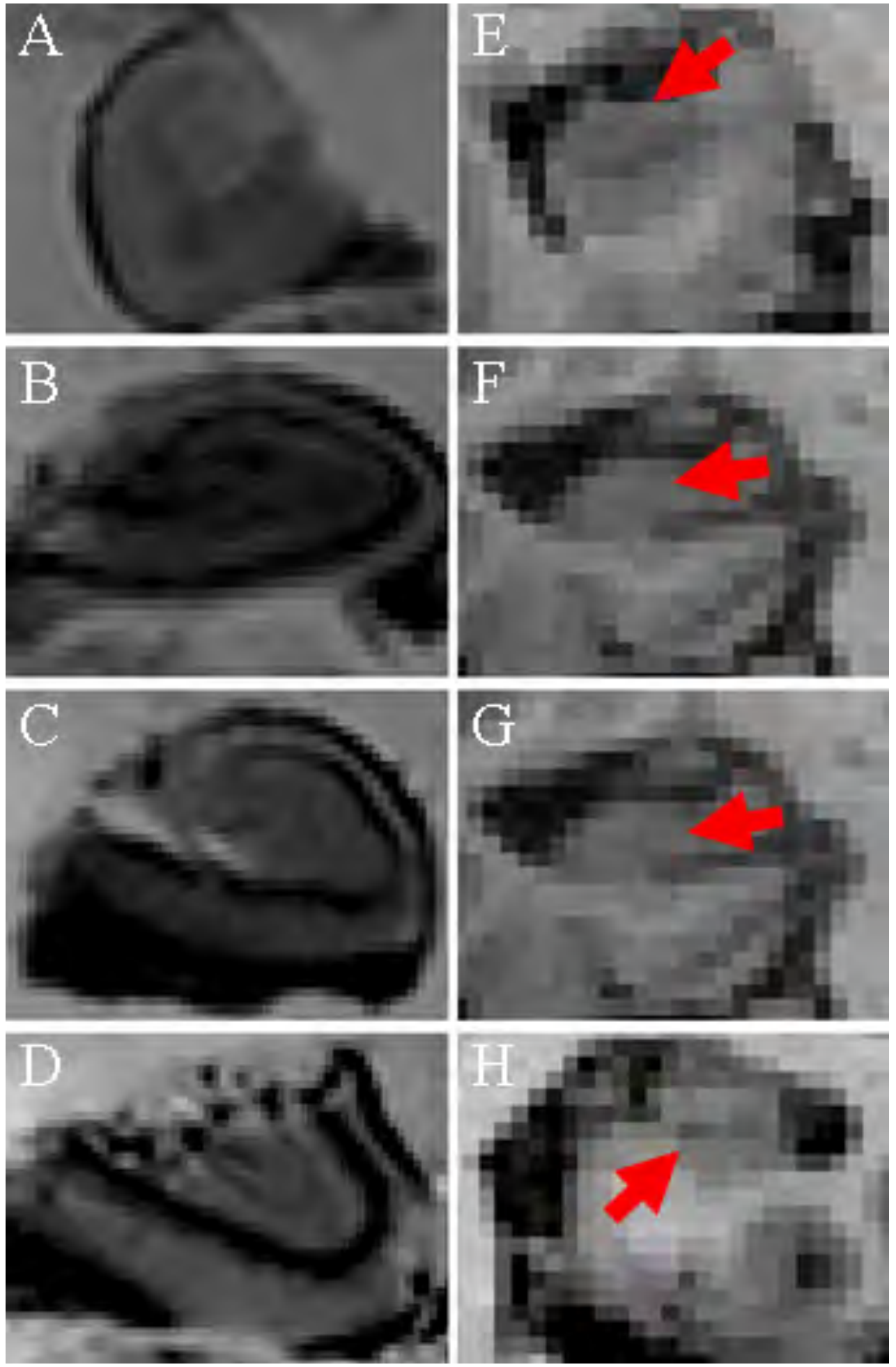

Figura 9. Imagens representativas das sequências de ressonância magnética ex vivo para relaxometria (A-D) comparadas com imagens 3DT1 in vivo (E-H) de pacientes com ELT. Em cada linha observam-se imagens do mesmo caso. Mesmo com imagens ponderadas em T1, que tem alta definição na separação entre substância cinza e substância branca, o hipocampo apresenta pouca distinção in vivo, ao contrário de imagens realizadas com a mesma estrutura ex vivo. As setas em E-H apontam a exata posição do hipocampo nas respectivas imagens. 
Volumetria dos subcampos hipocampais em $3 T$ e 4,7T

Em 6 casos do grupo CHR, a formação hipocampal foi avaliada, em máquina de 4,7T, para a determinação dos volumes de cada subcampo. As regiões, delimitadas manualmente em todo o hipocampo, estão representadas na Figura 10, onde pode-se também comparar a qualidade anatômica das imagens com secções histológicas coradas com a técnica Luxol Fast Blue. As quantificações indicaram grande contribuição dos subcampos subículo, CA1 e fascia dentata (i.e., camadas moleculares interna e externa, camada granular e hilo) para o volume hipocampal, correspondendo a $85,46 \%$ do volume hipocampal total (Tabela 2 e Figuras 11).

Para comparação com pacientes do grupo ELT, os subcampos da região hipocampal foram novamente medidos no corpo da formação hipocampal em 3T. Foi observada redução significativa da porcentagem do volume hipocampal de CA3 (Teste-t, $\mathrm{p}=0,017)$, CA1 (Mann-Whitney, $\mathrm{p}<0,001$ ) e do prosubículo (Teste-t, $\mathrm{p}=$ 0,006) nos pacientes com ELT, comparados com o CHR (Figura 12) 
Tabela 2. Volumes dos subcampos hipocampais na cabeça, corpo, cauda e hipocampo total, medido em pacientes do grupo CHR $(n=6)$ com RM de 4,7T.

\begin{tabular}{|c|c|c|c|c|}
\hline \multicolumn{2}{|c|}{ Região } & \multirow[t]{2}{*}{ Volume $\left(\mathrm{cm}^{3}\right)$} & \multicolumn{2}{|c|}{ Volume (\%) } \\
\hline & & & Relativo ao volume total* & Relativo ao volume da região** \\
\hline \multirow[t]{4}{*}{ FD } & Cabeça & $0,22 \pm 0,05$ & $7,88 \pm 1,80$ & $18,43 \pm 1,85$ \\
\hline & Corpo & $0,28 \pm 0,09$ & $9,90 \pm 3,09$ & $22,85 \pm 3,12$ \\
\hline & Cauda & $0,12 \pm 0,06$ & $4,14 \pm 2,09$ & $27,97 \pm 5,01$ \\
\hline & Total & $0,62 \pm 0,08$ & $21,93 \pm 2,33$ & \\
\hline \multirow[t]{4}{*}{ CA4 } & Cabeça & $0,01 \pm 0,003$ & $0,24 \pm 0,11$ & $0,54 \pm 0,24$ \\
\hline & Corpo & $0,04 \pm 0,02$ & $1,46 \pm 0,54$ & $3,31 \pm 0,54$ \\
\hline & Cauda & $0,01 \pm 0,004$ & $0,38 \pm 0,14$ & $2,68 \pm 0,83$ \\
\hline & Total & $0,06 \pm 0,015$ & $2,07 \pm 0,26$ & \\
\hline \multirow[t]{4}{*}{ CA3 } & Cabeça & $0,06 \pm 0,03$ & $1,99 \pm 1,09$ & $4,48 \pm 2,02$ \\
\hline & Corpo & $0,11 \pm 0,02$ & $3,78 \pm 0,58$ & $9,05 \pm 1,75$ \\
\hline & Cauda & $0,03 \pm 0,01$ & $0,96 \pm 0,25$ & $6,84 \pm 0,70$ \\
\hline & Total & $0,19 \pm 0,03$ & $6,72 \pm 0,64$ & \\
\hline \multirow[t]{4}{*}{ CA2 } & Cabeça & $0,02 \pm 0,01$ & $0,81 \pm 0,30$ & $1,91 \pm 0,64$ \\
\hline & Corpo & $0,03 \pm 0,01$ & $1,08 \pm 0,28$ & $2,54 \pm 0,48$ \\
\hline & Cauda & $0,01 \pm 0,002$ & $0,35 \pm 0,09$ & $2,59 \pm 0,82$ \\
\hline & Total & $0,06 \pm 0,01$ & $2,24 \pm 0,22$ & \\
\hline \multirow[t]{4}{*}{ CA1 } & Cabeça & $0,60 \pm 0,12$ & $21,30 \pm 4,10$ & $50,33 \pm 5,96$ \\
\hline & Corpo & $0,19 \pm 0,03$ & $6,81 \pm 1,19$ & $16,17 \pm 2,56$ \\
\hline & Cauda & $0,09 \pm 0,01$ & $3,06 \pm 0,46$ & $22,89 \pm 7,98$ \\
\hline & Total & $0,89 \pm 0,30$ & $31,17 \pm 1,91$ & \\
\hline \multirow[t]{4}{*}{ PRO } & Cabeça & $0,02 \pm 0,01$ & $0,67 \pm 0,46$ & $1,53 \pm 0,92$ \\
\hline & Corpo & $0,07 \pm 0,03$ & $2,40 \pm 1,13$ & $5,44 \pm 1,41$ \\
\hline & Cauda & $0,01 \pm 0,01$ & $0,50 \pm 0,21$ & $3,43 \pm 0,32$ \\
\hline & Total & $0,10 \pm 0,02$ & $3,57 \pm 0,60$ & \\
\hline \multirow[t]{4}{*}{ SUB } & Cabeça & $0,28 \pm 0,09$ & $9,81 \pm 3,08$ & $22,77 \pm 4,01$ \\
\hline & Corpo & $0,50 \pm 0,12$ & $17,61 \pm 4,34$ & $40,65 \pm 3,61$ \\
\hline & Cauda & $0,14 \pm 0,06$ & $4,88 \pm 2,04$ & $33,60 \pm 3,30$ \\
\hline & Total & $0,92 \pm 0,15$ & $32,30 \pm 3,15$ & \\
\hline
\end{tabular}

\footnotetext{
* porcentagem relativa ao volume hipocampal total

** porcentagem do subcampo nas diferentes subdivisões anatômicas do hipocampo (i.e., cabeça, corpo e cauda)
} 
A

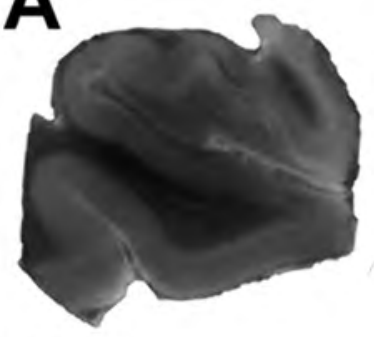

D

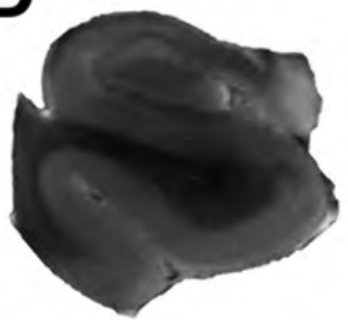

G

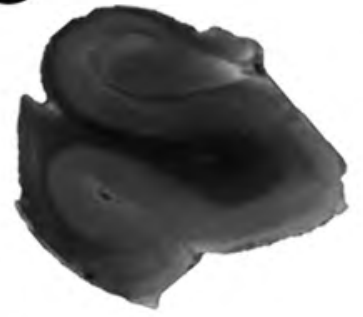

J

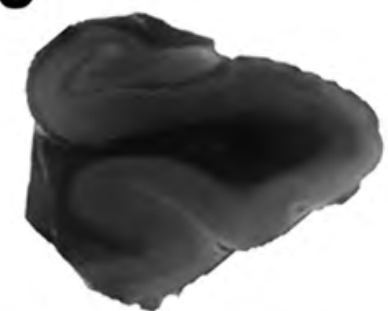

M

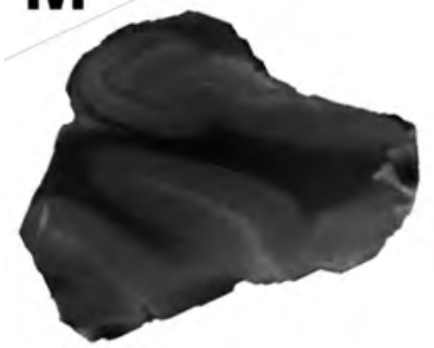

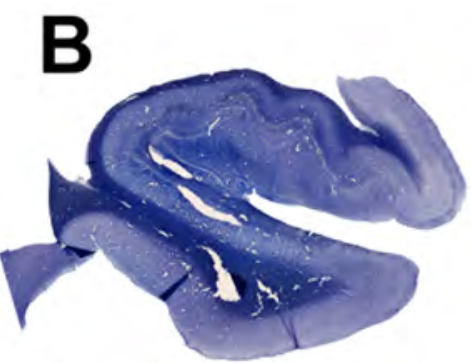

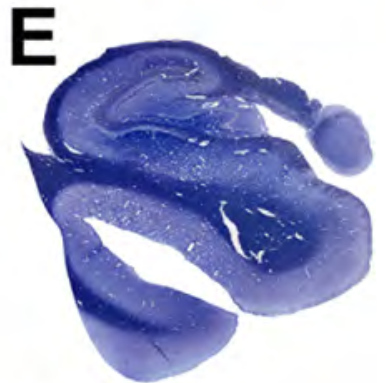

H

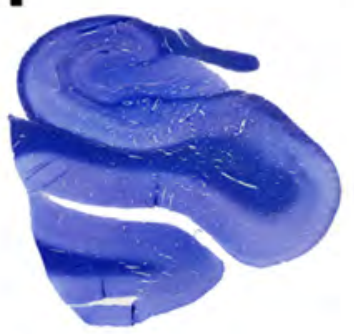

K
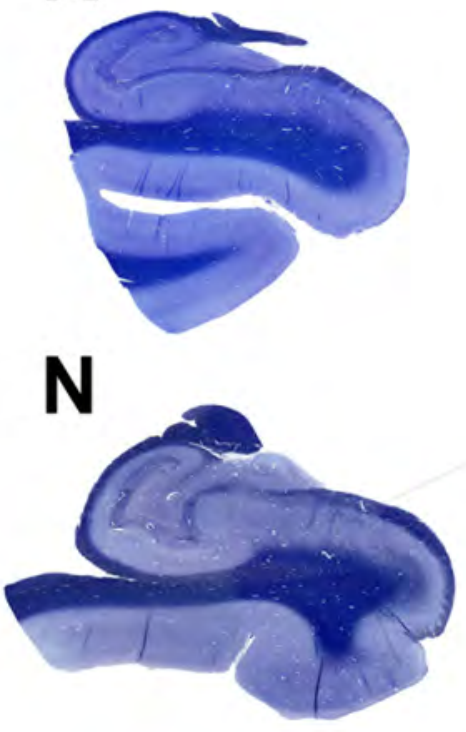

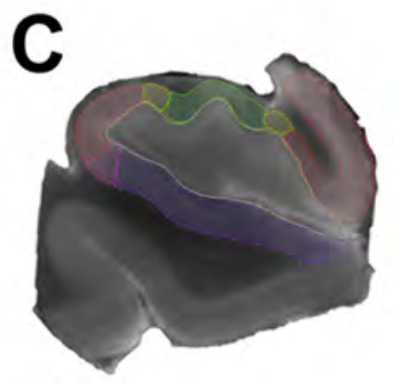

F

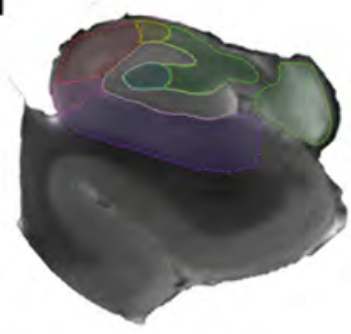

I

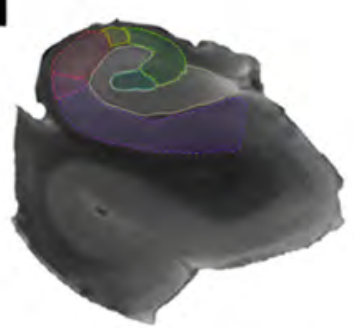

L

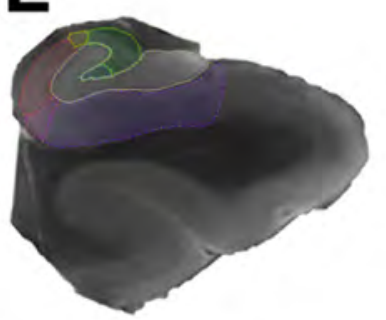

0

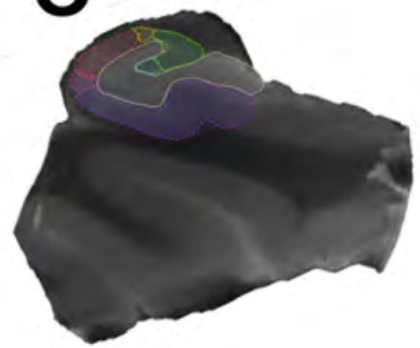

Figura 10. Imagens de ressonância 4,7T representativas de secções coronais da cabeça (A e C), transição entre cabeça e corpo (D e F), corpo (G, I, J e L) e cauda (M e O) de hipocampos de casos CHR, comparadas a imagens panorâmicas dos respectivos cortes histológicos (B, E, H, K e N). Em cada linha observam-se imagens do mesmo corte coronal, e na coluna da direita (C, F, I, L e O) estão representadas as delimitações de cada subcampo hipocampal, realizadas manualmente. Na delimitação (coluna da direita), branco representa fascia dentata, azul claro representa CA4, verde representa CA3, amarelo representa CA2, vermelho representa CA1, rosa representa o prosubículo e roxo representa o subículo. 


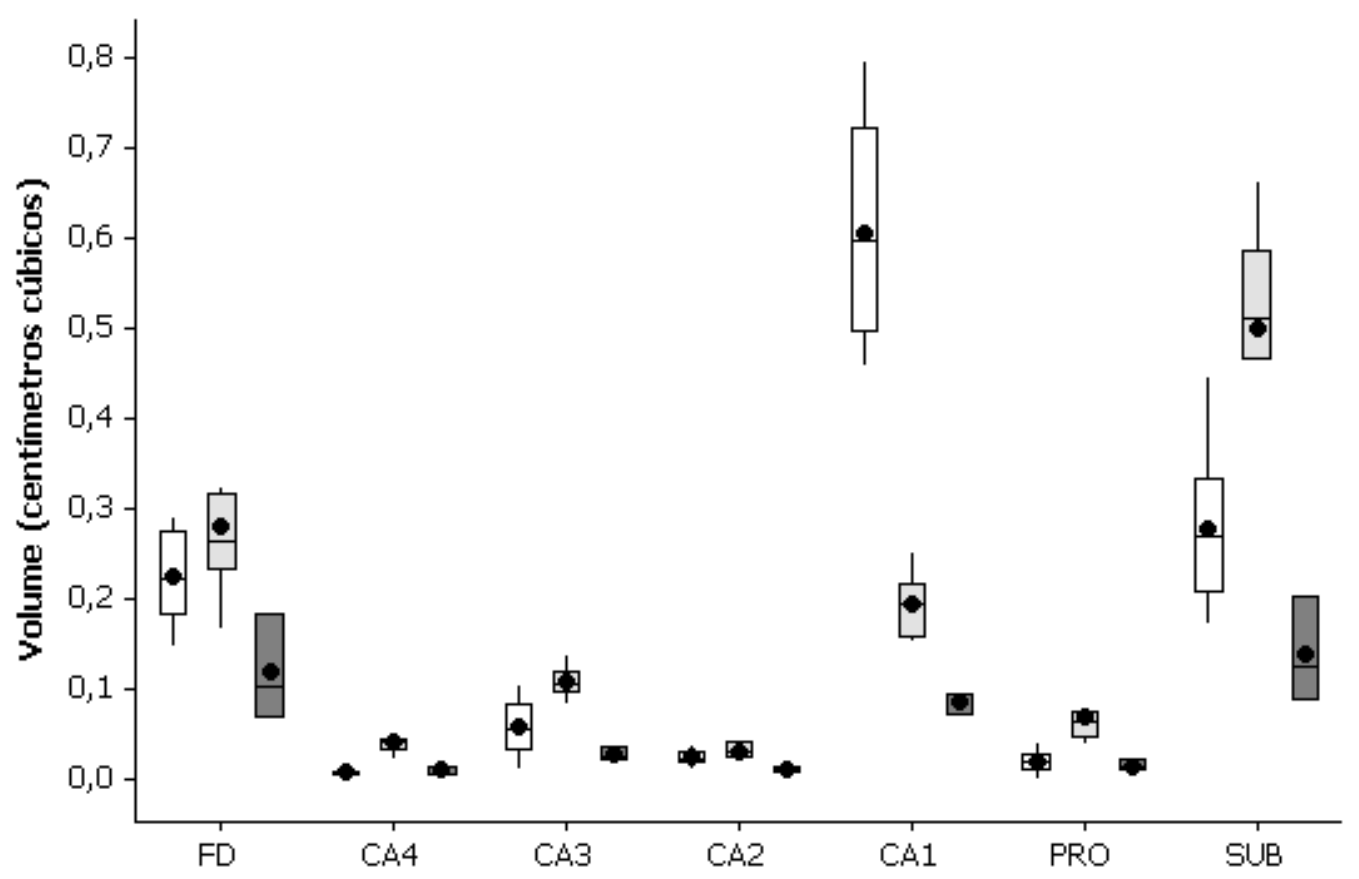

Figura 11. Volumes dos subcampos hipocampais, em centímetros cúbicos, na cabeça (boxplots brancos), corpo (boxplots cinza-claros) e cauda (boxplots cinza-escuros) da formação hipocampal de pacientes do grupo CHR, medidos em imagens de ressonância de 4,7T. Os círculos negros nos boxplots indicam média. $\mathrm{FD}=$ fascia dentata; $\mathrm{PRO}=$ prosubículo; $\mathrm{SUB}=$ subículo.

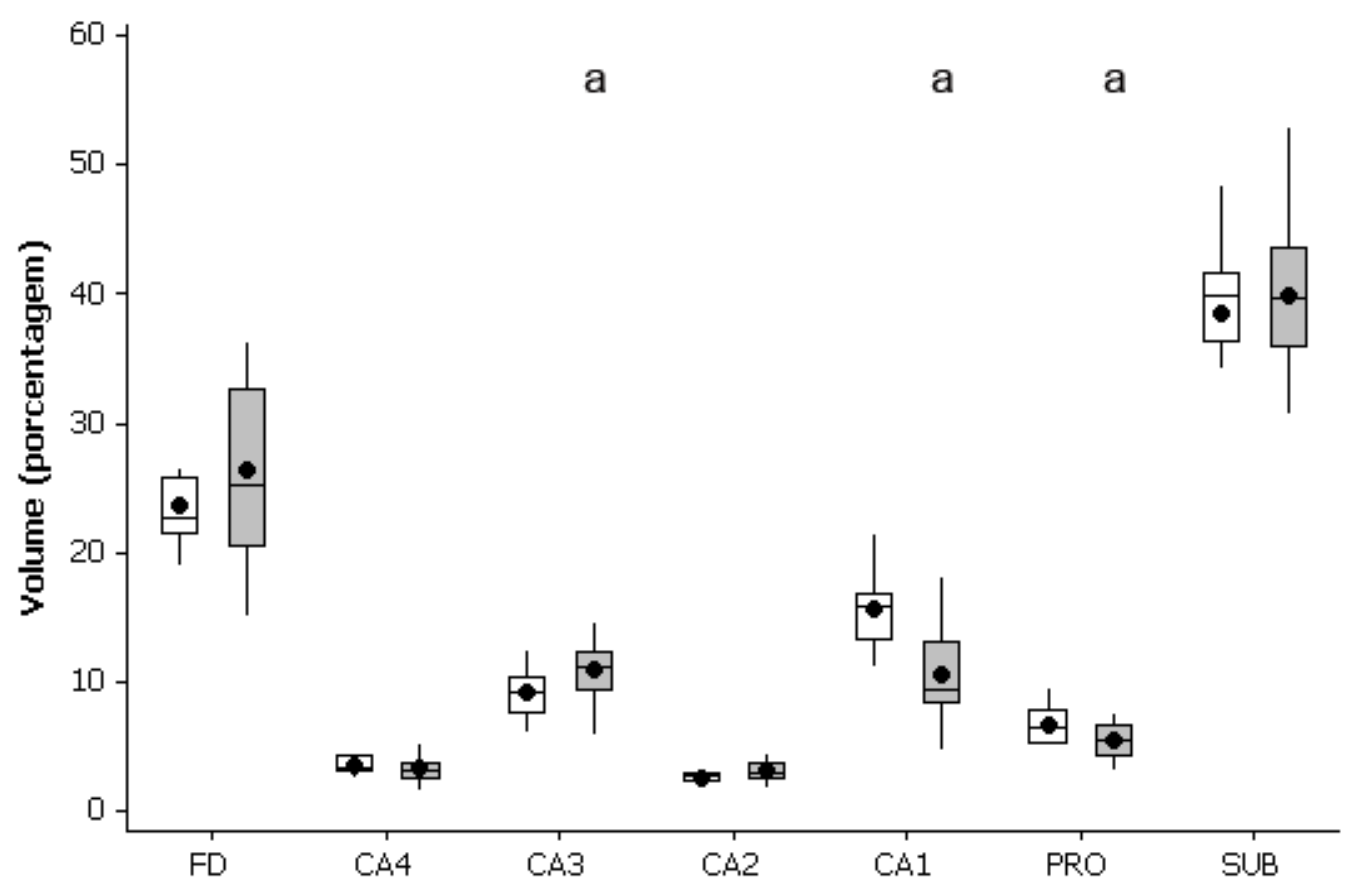

Figura 12. Volumes dos subcampos hipocampais(relativos ao volume do corpo do hipocampo apenas) em casos do grupo CHR (boxplots brancos) e ELT (boxplots cinzas), medidos em imagens de ressonância de 3T. A letra $a$ representa diferença em relação ao CHR. Os círculos negros nos boxplots indicam média. Teste-t, $\mathrm{p}=0,017$ para CA3 e $\mathrm{p}=0,006$ para PRO; Mann-Whitney, $\mathrm{p}<0,001$ para $\mathrm{CA} 1$. $\mathrm{FD}=$ fascia dentata $; \mathrm{PRO}=$ prosubículo; $\mathrm{SUB}=$ subículo. 
Tempo de relaxamento e transferência de magnetização

A avaliação ex vivo dos casos coletados indica que os pacientes com ELT apresentam maior tempo de relaxamento quando comparados com os CHR nas camadas moleculares da fascia dentata (Mann-Whitney, $\mathrm{p}=0,020$ ), CA4 (Teste-t, $\mathrm{p}$ $<0,001$ ), CA3 (Mann-Whitney, $\mathrm{p}<0,001$ ), CA2 (Teste-t, $\mathrm{p}<0,001$ ), CA1 (Teste-t, $\mathrm{p}$ $<0,001$ ), prosubículo (Mann-Whitney, $\mathrm{p}=0,003$ ), subículo (Mann-Whitney, $\mathrm{p}<$ 0,001) e na média do hipocampo (Mann-Whitney, $\mathrm{p}<0,001$ ) (Figura 13). Houve apenas tendência a um maior aumento no tempo de relaxamento dos casos com ELT, quando comparados com o CHR, na fascia dentata (Teste-t, $\mathrm{p}=0,078)$. Em relação à taxa de transferência de magnetização, medida com pulso de saturação on resonance, não houve diferença entre os grupos ELT e CHR (Mann-Whitney, p > 0,182) (Figura 14). 


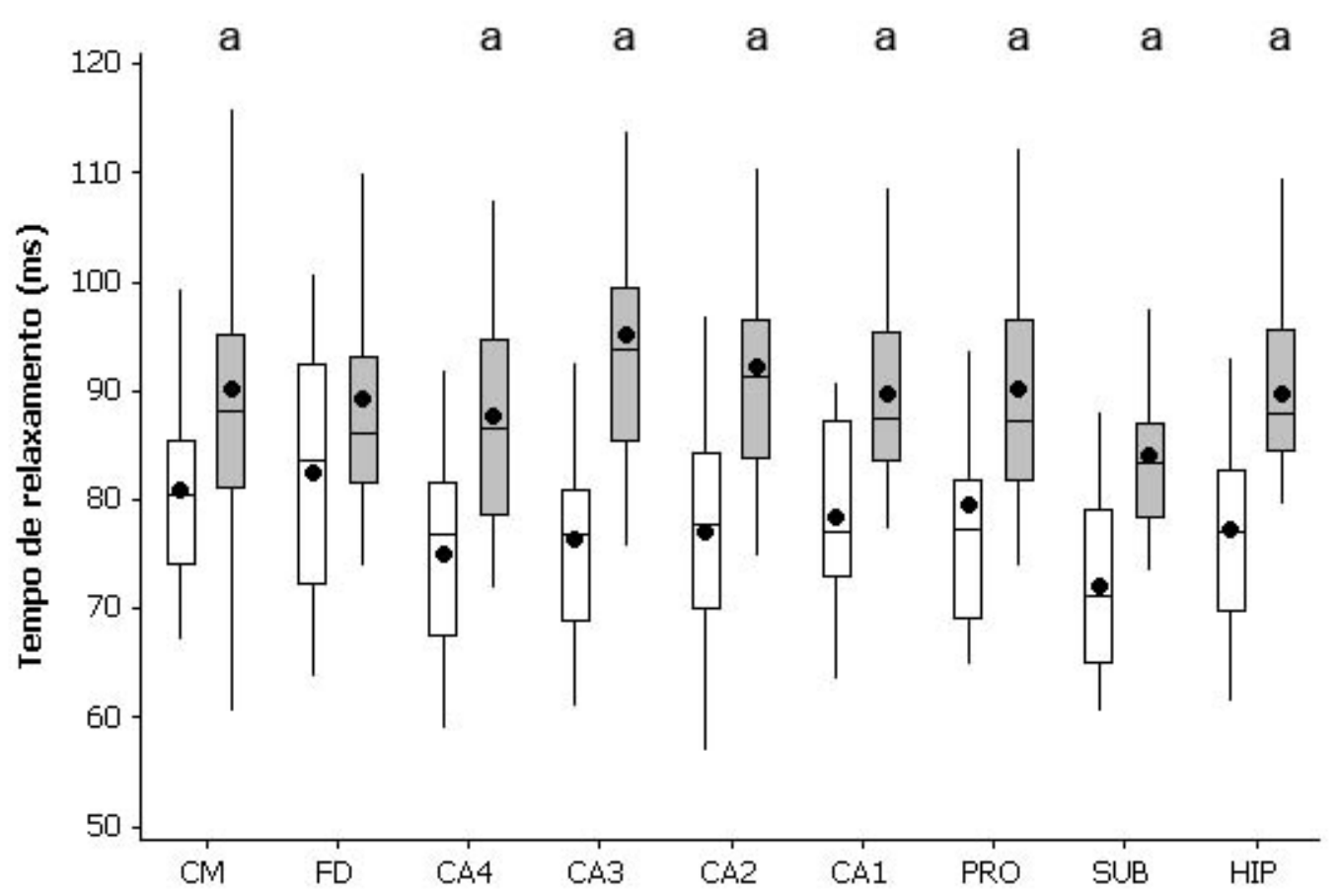

Figura 13. Tempo de relaxamento ex vivo dos pacientes com ELT (boxplots cinzas) e dos casos CHR (boxplots brancos). A letra a sobre os boxplots indica diferença em relação ao CHR. O círculo negro no boxplot indica a média. Teste-t, $\mathrm{p}<0,001$ para CA4, CA2 e CA1; Mann-Whitney, $\mathrm{p}=0,02$ para CM, $\mathrm{p}=0,003$ para PRO e $\mathrm{p}<$ 0,001 para CA3, SUB e HIP.

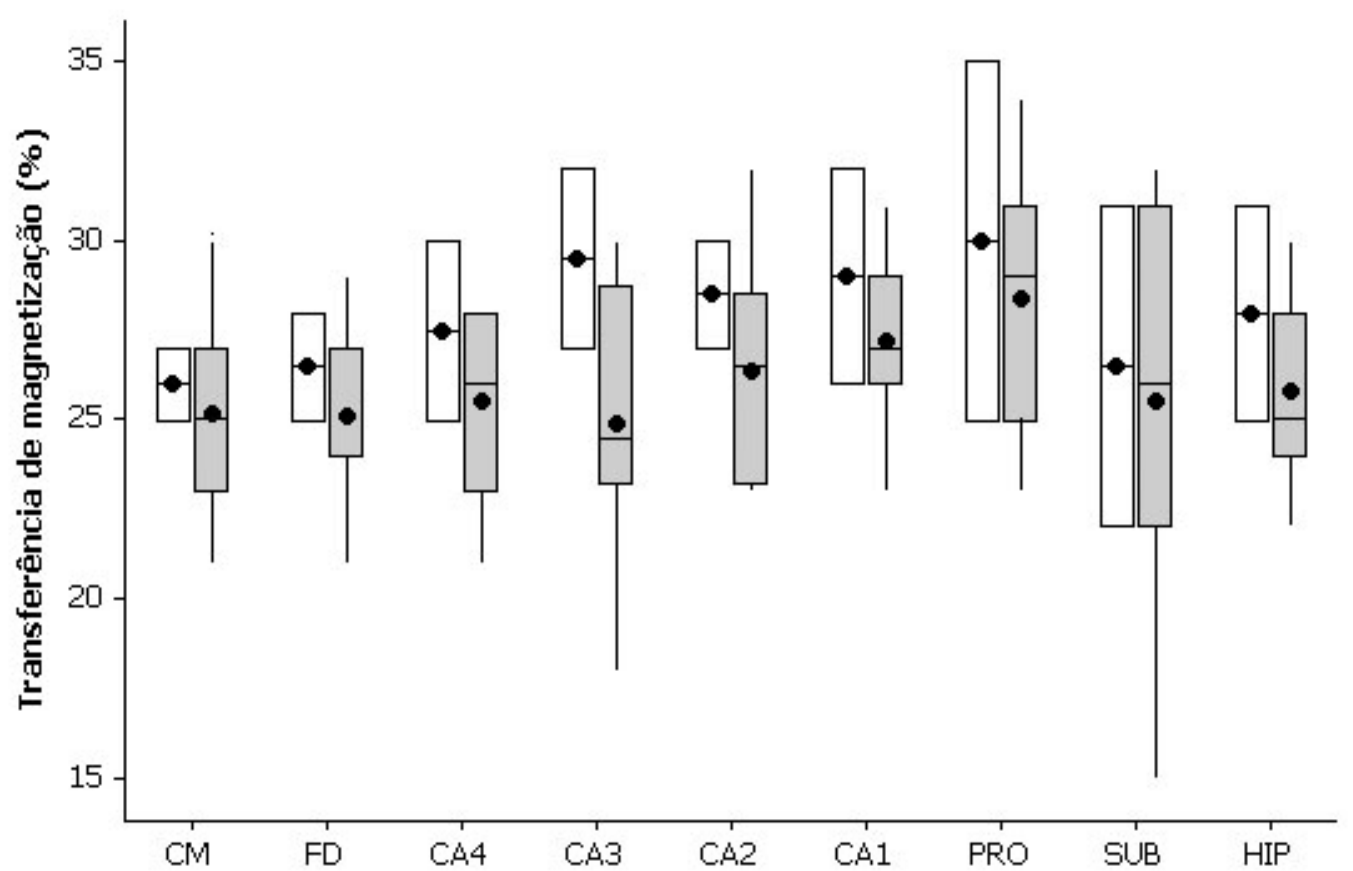

Figura 14. Taxa de transferência de magnetização ex vivo dos pacientes com ELT (boxplots cinzas) e dos casos CHR (boxplots brancos). O círculo negro no boxplot indica a média. 


\section{Avaliações Histológicas}

\section{Populações Neuronais}

A avaliação das populações neuronais, através da densidade neuronal em secções submetidas à imuno-histoquímica para detecção da proteína NeuN (Figuras 15 e 16), revelou redução significativa da densidade neuronal na camada granular (Mann-Whitney, $\mathrm{p}<0,001$ ), hilo (Mann-Whitney, $\mathrm{p}<0,001$ ), CA4 (Mann-Whitney, $\mathrm{p}$ $<0,001$ ), CA3 (Teste-t, $\mathrm{p}<0,001$ ), CA2 (Mann-Whitney, $\mathrm{p}<0,001$ ), CA1 (MannWhitney, $\mathrm{p}<0,001$ ) e prosubículo (Mann-Whitney, $\mathrm{p}<0,001)$ dos pacientes com ELT, comparados com o CHR (Figura 17). Não houve diferença significativa entre as densidades neuronais de ELT e CHR no subículo (Teste-t, $p=0,929)$ 

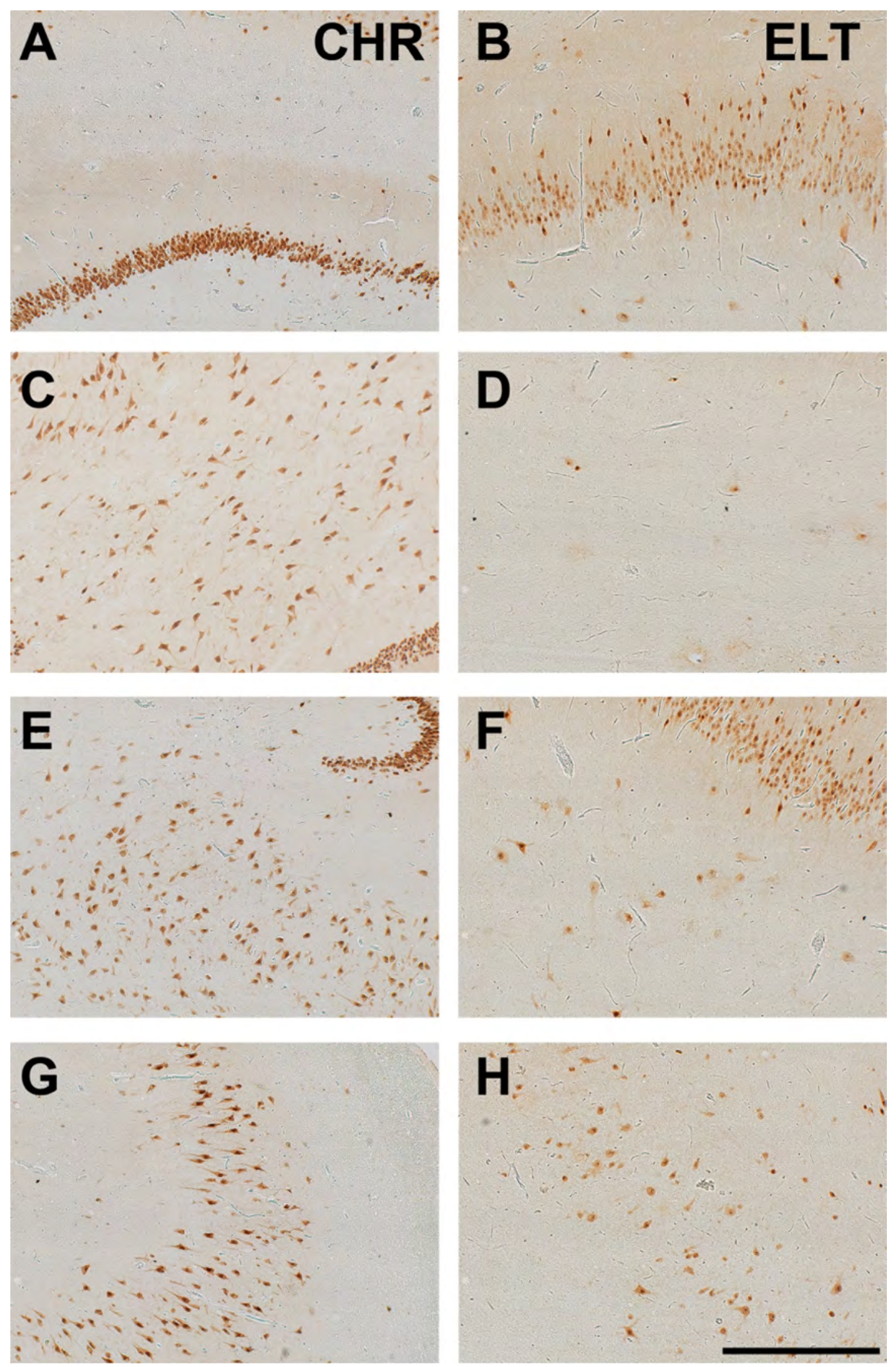

Figura 15. Fotomicrografias representativas da imuno-histoquímica para avaliação das populações neuronais em pacientes do grupo CHR (A, C, E e G) e de pacientes com ELT (B, D, F e H). Observe a perda neuronal intensa no hilo da fascia dentata (D), em CA4 (F) e CA3 (H) dos casos com ELT, quando comparados com os casos CHR (respectivamente C, E e G). Na camada granular dos pacientes do grupo ELT (B) nota-se dispersão neuronal e perda moderada, comparado com o CHR (A). A barra em F indica 500 micrômetros. 

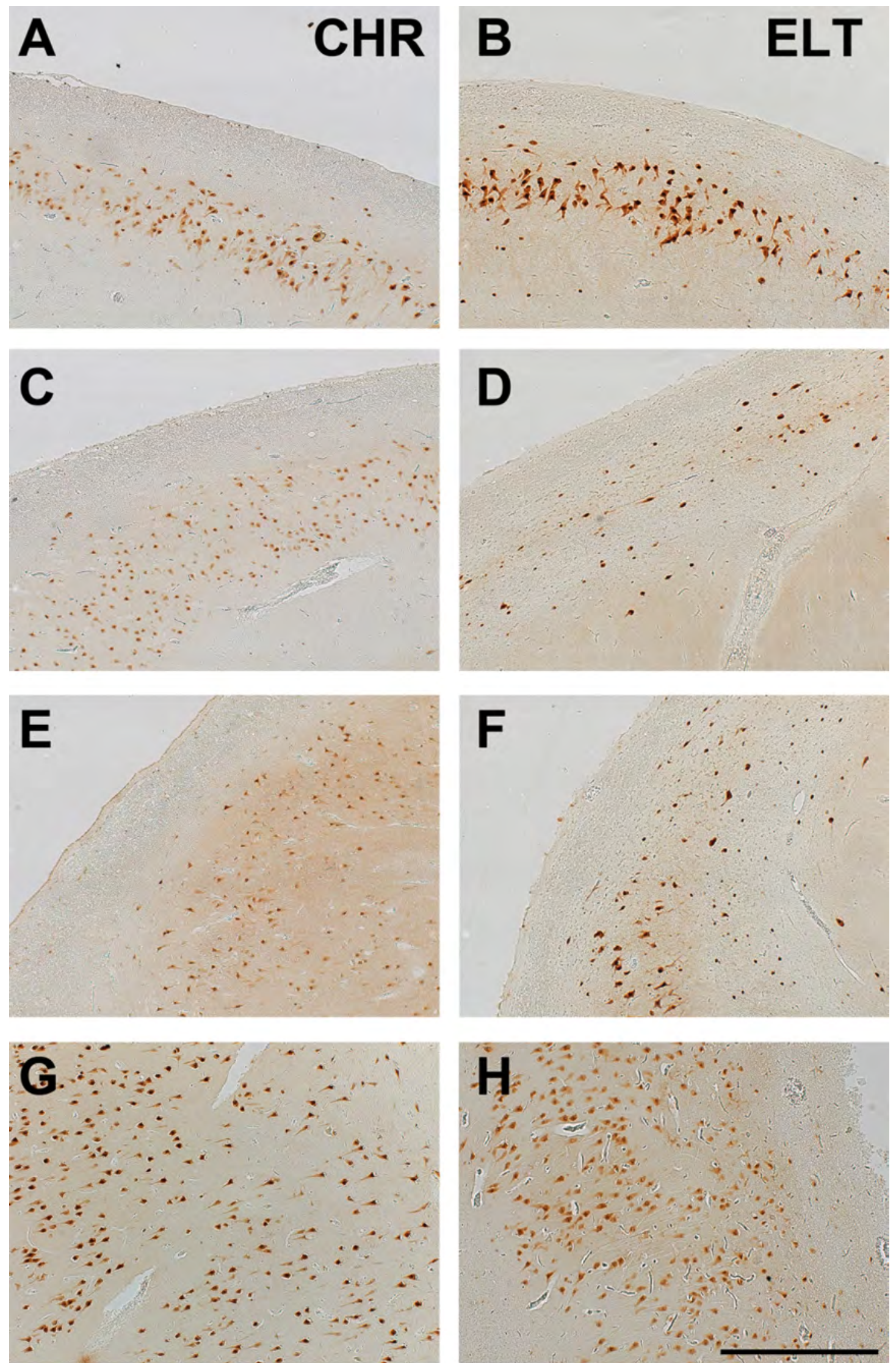

Figura 16. Fotomicrografias representativas da imuno-histoquímica para avaliação das populações neuronais em pacientes do grupo CHR (A, C, E e G) e de pacientes com ELT (B, D, F e H). Observe a perda neuronal intensa em CA1 (D) e no prosubículo (F) dos casos com ELT, quando comparados com os casos CHR (respectivamente C e E). Em CA2 dos pacientes do grupo ELT (B) há perda discreta, enquanto o subículo encontra-se preservado de perda $(\mathrm{H})$, comparado com o CHR (respectivamente A e G). A barra em F indica 500 micrômetros. 

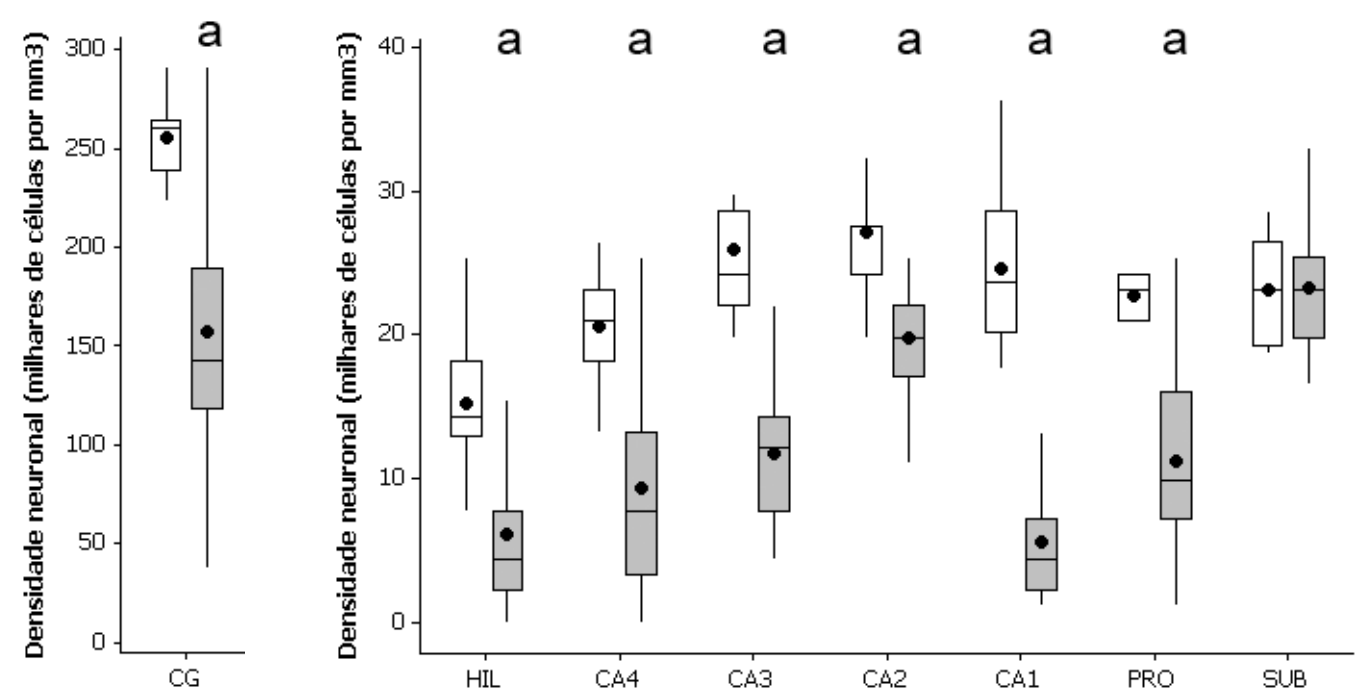

Figura 17. Densidade neuronal em casos CHR (boxplot branco) e pacientes com ELT (boxplot cinza). A letra a sobre os boxplots indica diferença em relação ao CHR. O círculo negro no boxplot indica a média. Teste-t, $p$ $<0,001$ para CA3; Mann-Whitney, $\mathrm{p}<0,001$ para CG, HIL, CA4, CA2, CA1 e PRO. CG = camada granular; $\mathrm{HIL}=$ hilo; $\mathrm{PRO}=$ prosubículo; $\mathrm{SUB}=$ subículo. 


\section{População astroglial}

As populações astrogliais, avaliadas através de fração da área imunopositiva em secções submetidas à imuno-histoquímica para detecção da proteína GFAP (Figuras 18-19) revelaram diferenças significativas, quando comparadas ao grupo CHR, nas regiões camada molecular externa (Teste-t, $p=0,010$ ), camada molecular interna (Teste-t, $p=0,025$ ), camada granular (Mann-Whitney, $\mathrm{p}=0,048$ ), CA4 (Mann-Whitney, $\mathrm{p}=0,043$ ), CA3 (Teste-t, $\mathrm{p}<0,035)$, CA2 (Mann-Whitney, $\mathrm{p}=$ 0,006), CA1 (Mann-Whitney, p < 0,001), prosubículo (Mann-Whitney, p < 0,001) e subículo (Mann-Whitney, $\mathrm{p}<0,001$ ) dos pacientes com ELT (Figuras 20-21). Não foram observadas diferenças entre os grupos ELT e CHR na zona subgranular (Teste$\mathrm{t}, \mathrm{p}=0$,204) e hilo (Teste-t, $\mathrm{p}=0,959)$. 

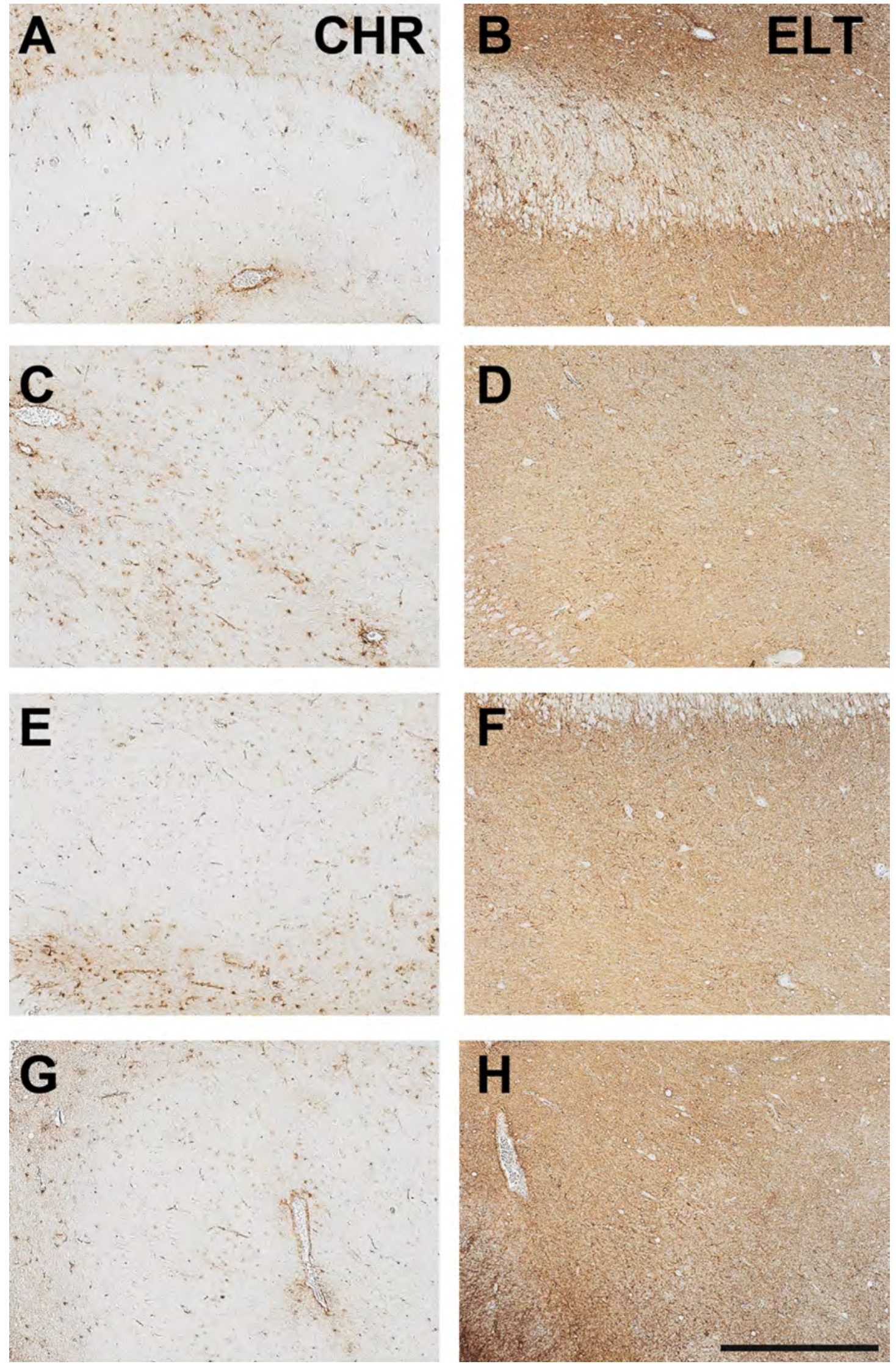

Figura 18. Fotomicrografias representativas da imuno-histoquímica para avaliação dos astrócitos reativos na camada granular (A-B), hilo (C-D), CA4 (E-F) e CA3 (G-H) de pacientes do grupo CHR (A, C, E e G) e com ELT $(\mathrm{B}, \mathrm{D}, \mathrm{F}$ e H). Observe o aumento na área imunopositiva de todas as regiões dos pacientes com ELT, quando comparados com os casos CHR. Em várias regiões (e.g. D, F e H) o aumento na imunoreatividade é tão intenso que dificulta a observação dos corpos celulares dos astrócitos. A barra em $\mathrm{H}$ indica 500 micrômetros. 

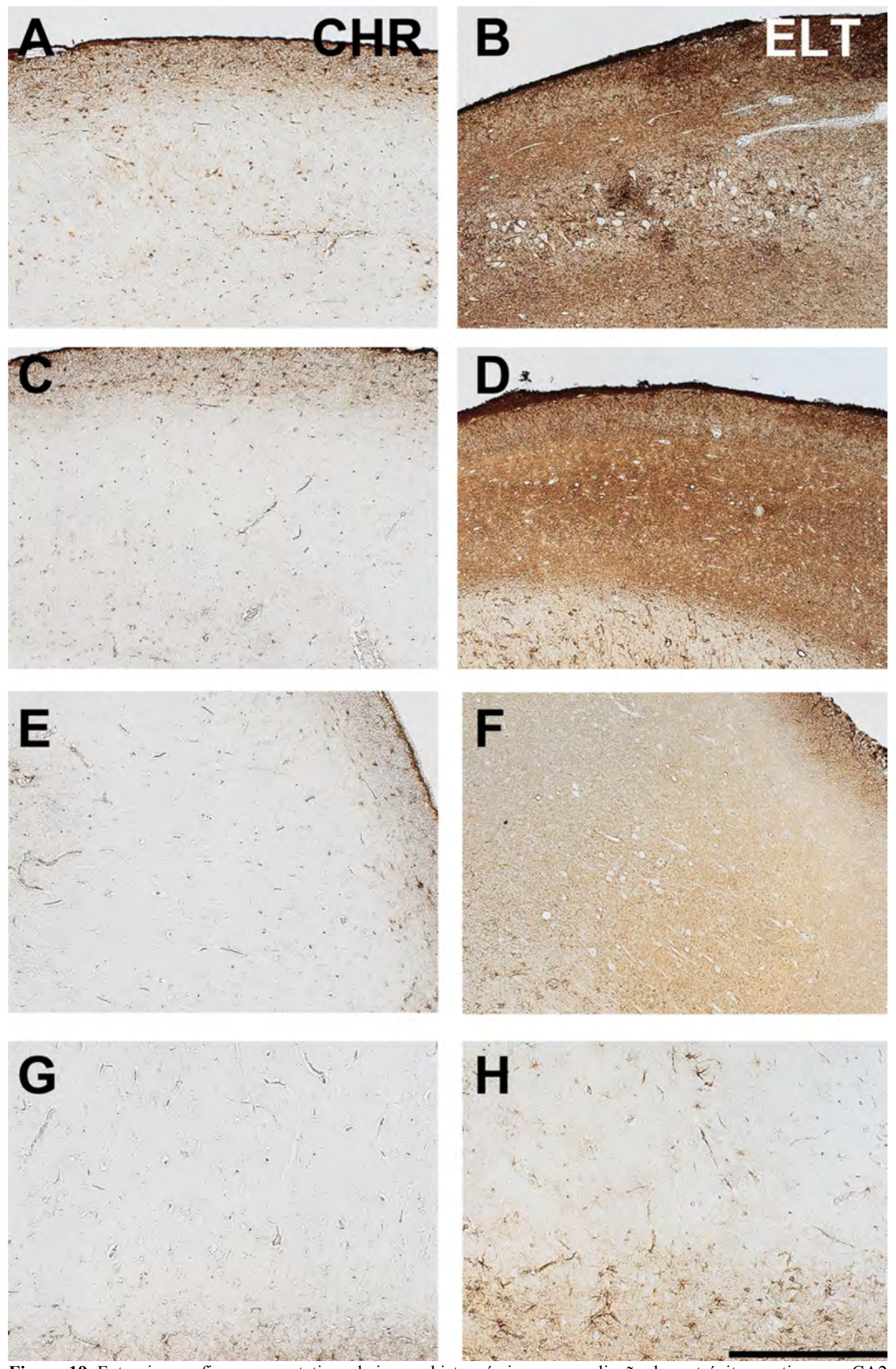

Figura 19. Fotomicrografias representativas da imuno-histoquímica para avaliação dos astrócitos reativos em CA2 (A-B), CA1 (C-D), prosubículo (E-F) e subículo (G-H) de pacientes do grupo CHR (A, C, E e G) e com ELT (B, $\mathrm{D}, \mathrm{F}$ e H). Observe o aumento na área imunopositiva das regiões dos pacientes com ELT, quando comparados com os casos CHR. A barra em H indica 500 micrômetros. 


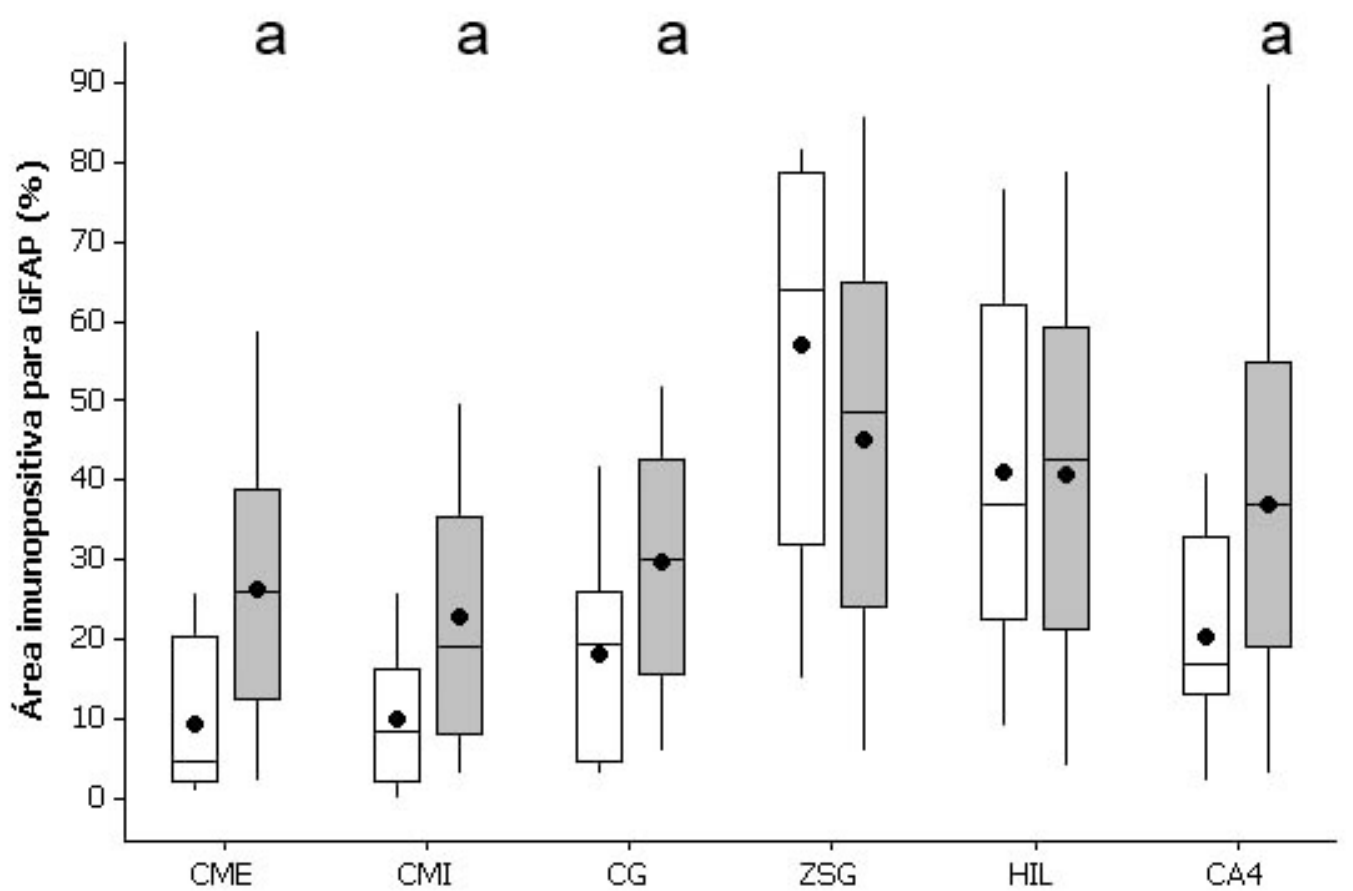

Figura 20. Área imunopositiva para GFAP em casos CHR (boxplot branco) e pacientes com ELT (boxplot cinza). A letra a sobre os boxplots indica diferença em relação ao CHR. O círculo negro no boxplot indica a média. Teste$\mathrm{t}, \mathrm{p}=0,01$ para CME e $\mathrm{p}=0,025$ para CMI; Mann-Whitney, $\mathrm{p}=0,048$ para CG e $\mathrm{p}=0,043$ para CA4. CME $=$ camada molecular externa; $\mathrm{CMI}=$ camada molecular interna; $\mathrm{CG}=$ camada granular; $\mathrm{ZSG}=$ zona subgranular; $\mathrm{HIL}=$ hilo.

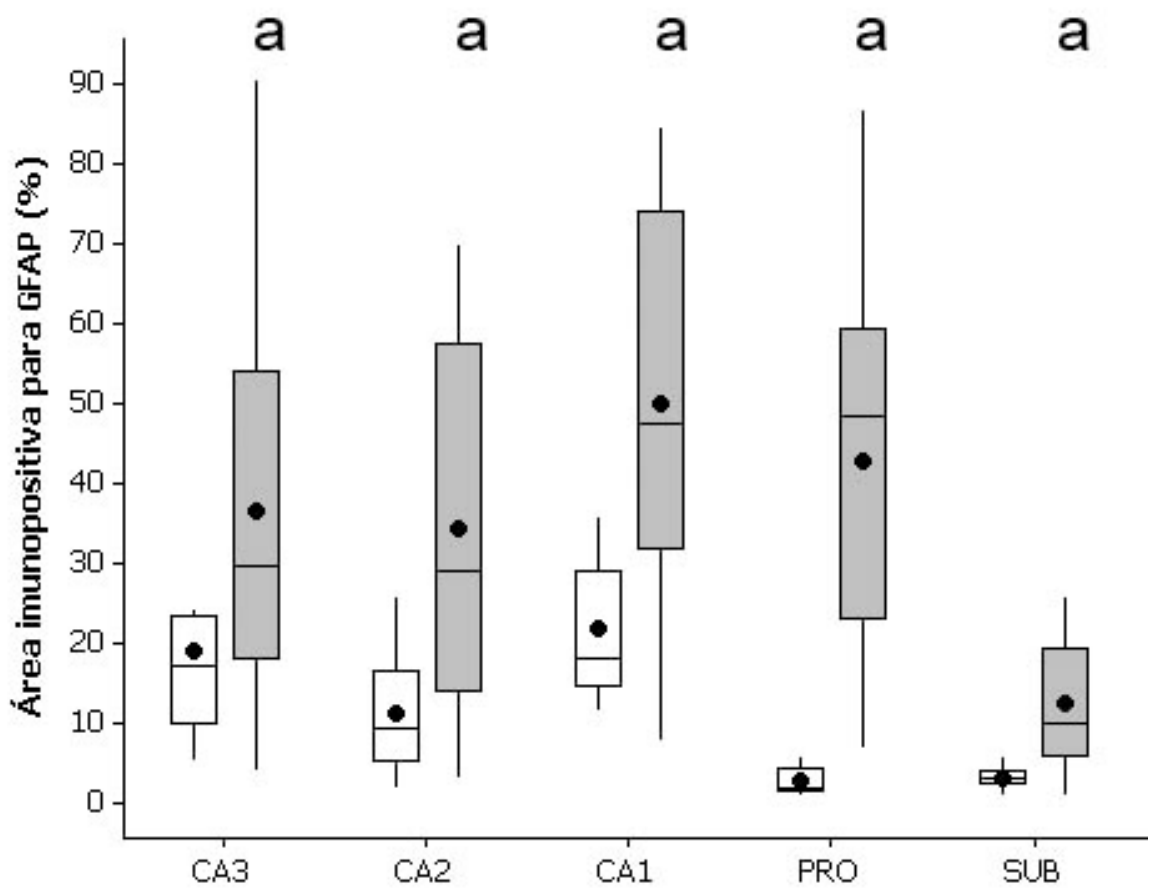

Figura 21. Área imunopositiva para GFAP em casos CHR (boxplot branco) e pacientes com ELT (boxplot cinza). A letra a sobre os boxplots indica diferença em relação ao CHR. O círculo negro no boxplot indica a média. Teste$\mathrm{t}, \mathrm{p}<0,035$ para CA3; Mann-Whitney, $\mathrm{p}=0,006$ para CA2 e $\mathrm{p}<0,001$ para CA1, PRO e SUB. PRO = prosubículo; $\mathrm{SUB}=$ subículo. 


\section{População microglial}

A avaliação da população microglial ativada, através de fração da área imunopositiva em secções submetidas à imuno-histoquímica para detecção da proteína HLA-DR (Figura 22-23) revelou diferenças significativas no grupo ELT, quando comparado ao CHR, na camada molecular externa (Mann-Whitney, $\mathrm{p}=$ 0,025), camada molecular interna (Mann-Whitney, $\mathrm{p}=0,025)$, camada granular (Mann-Whitney, $\mathrm{p}=0,006$ ), zona subgranular (Mann-Whitney, $\mathrm{p}=0,028$ ), hilo (Mann-Whitney, $\mathrm{p}=0,020$ ), CA4 (Mann-Whitney, $\mathrm{p}=$ 0,020), CA3 (Mann-Whitney, $\mathrm{p}=0,004)$, CA2 (Mann-Whitney, $\mathrm{p}=0,003)$, CA1 (Mann-Whitney, $\mathrm{p}<0,001)$ e prosubículo (Mann-Whitney, $p=0,038$ ) (Figuras 24-25). Não houve diferença significativa no subículo dos casos ELT, quando comparado ao CHR (Mann-Whitney, $\mathrm{p}=0,408)$ 

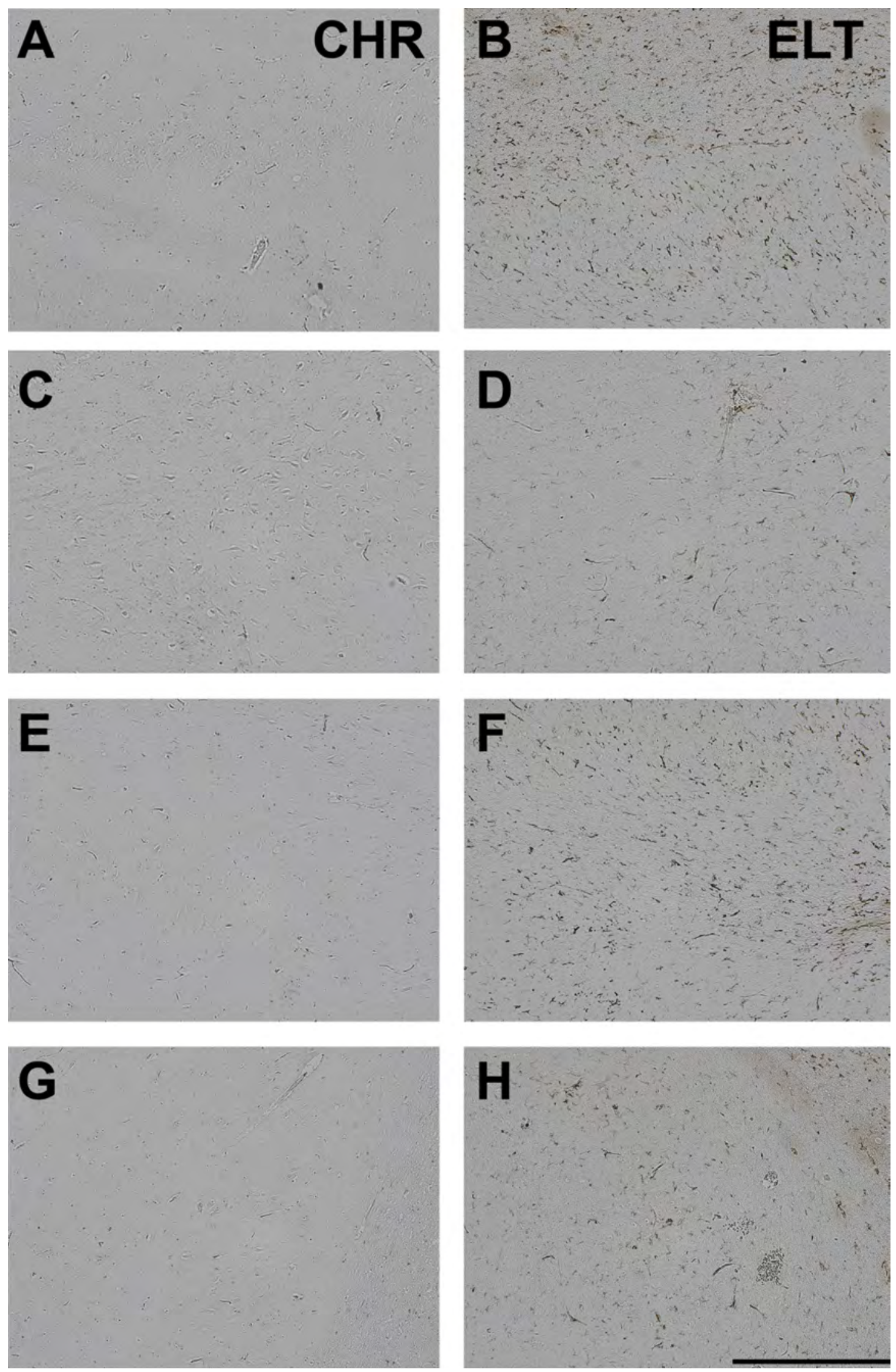

Figura 22. Fotomicrografias representativas da imuno-histoquímica para avaliação das micróglias ativadas na camada granular (A-B), hilo (C-D), CA4 (E-F) e CA3 (G-H) de pacientes do grupo CHR (A, C, E e G) e com ELT $(\mathrm{B}, \mathrm{D}, \mathrm{F}$ e H). Observe a grande quantidade de micróglias ramificadas positivas para HLA-DR em todas as regiões dos pacientes com ELT, quando comparadas com os casos CHR, onde praticamente não se observam células imunopositivas. A barra em $\mathrm{H}$ indica 500 micrômetros. 

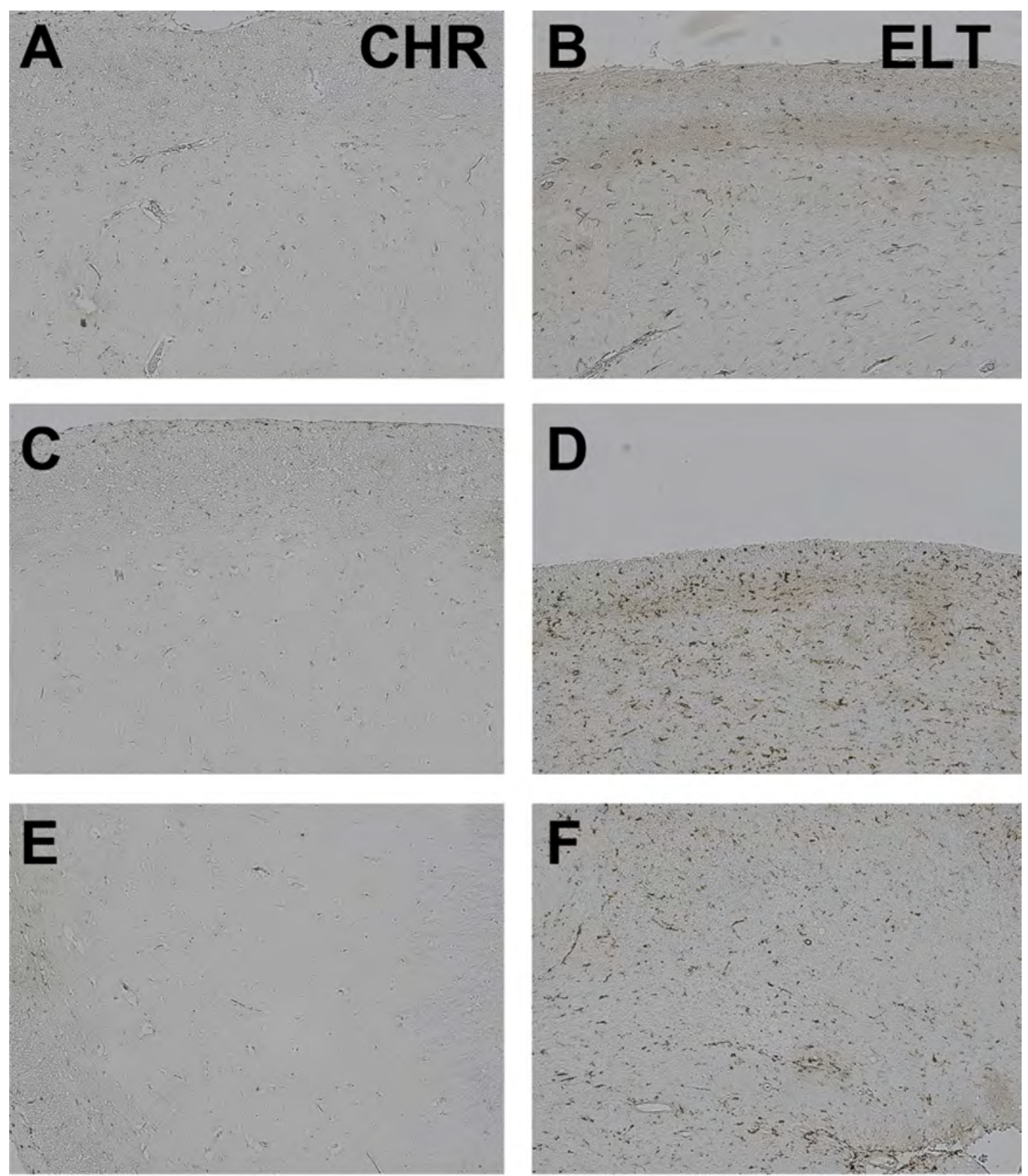

\section{G}

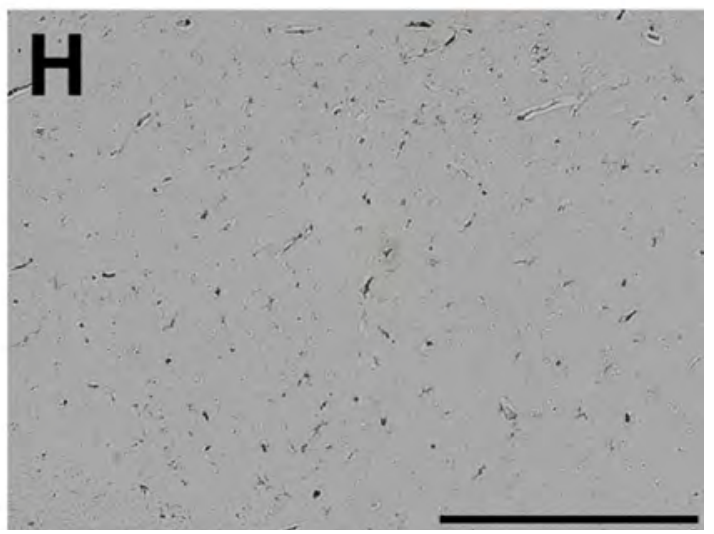

Figura 23. Fotomicrografias representativas da imuno-histoquímica para avaliação das micróglias ativadas em CA2 (A-B), CA1 (C-D), prosubículo (E-F) e subículo (G-H) de pacientes do grupo CHR (A, C, E e G) e com ELT $(\mathrm{B}, \mathrm{D}, \mathrm{F}$ e H). Observe a grande quantidade de micróglias ramificadas positivas para HLA-DR em todas as regiões dos pacientes com ELT (com destaque para CA1), quando comparadas com os casos CHR. A barra em $\mathrm{H}$ indica 500 micrômetros. 


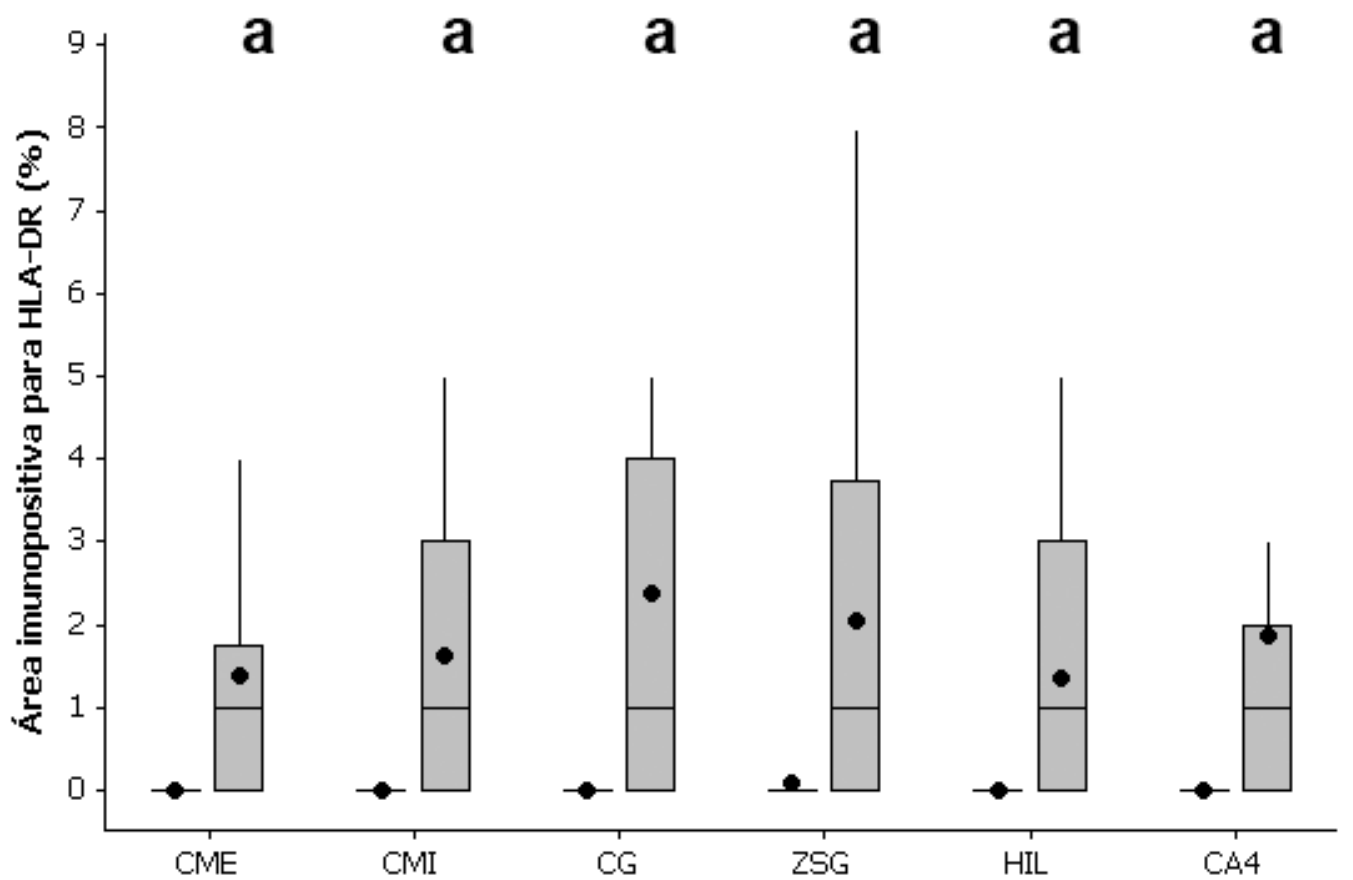

Figura 24. Área imunopositiva para HLA-DR em casos CHR (boxplot branco) e pacientes com ELT (boxplot cinza). A letra a sobre os boxplots indica diferença em relação ao CHR. O círculo negro no boxplot indica a média. Mann-Whitney, $p=0,025$ para CME e CMI, $p=0,006$ para CG, $p=0,028$ para ZSG e $p=0,02$ para HIL e CA4. $\mathrm{CME}=$ camada molecular externa; $\mathrm{CMI}=$ camada molecular interna; $\mathrm{CG}=$ camada granular; $\mathrm{ZSG}=$ zona subgranular; HIL = hilo.

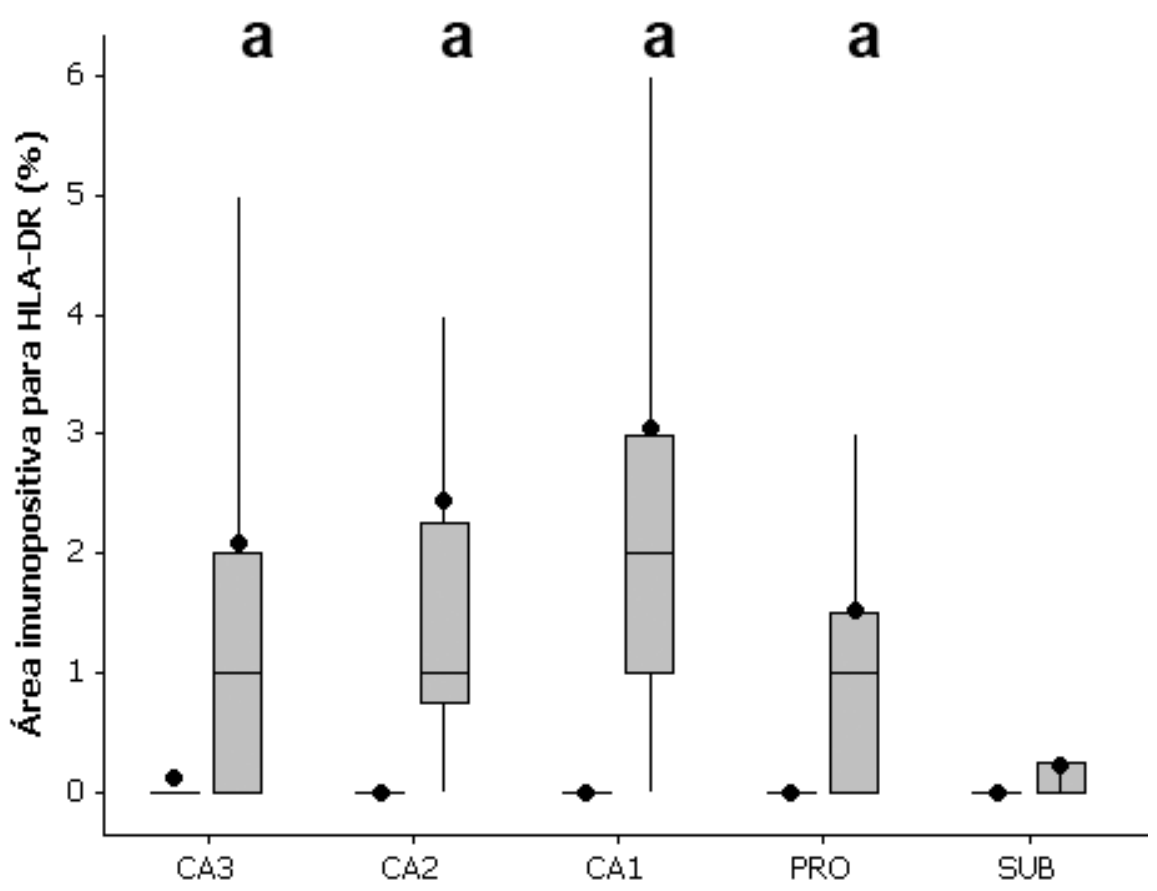

Figura 25. Área imunopositiva para HLA-DR em casos CHR (boxplot branco) e pacientes com ELT (boxplot cinza). A letra a sobre os boxplots indica diferença em relação ao CHR. O círculo negro no boxplot indica a média. Mann-Whitney, $\mathrm{p}=0,004$ para CA3, $\mathrm{p}=0,003$ para CA2, $\mathrm{p}<0,001$ para CA1 e $\mathrm{p}=0,038$ para PRO. PRO = prosubículo; SUB = subículo. 


\section{Aquaporina 4}

A avaliação da expressão da proteína aquaporina 4 perivascular, através de fração da área imunopositiva em secções submetidas à imuno-histoquímica para sua detecção (Figura 26-27) revelou redução significativa da AQP4 perivascular nos casos ELT, quando comparado ao grupo CHR, na camada molecular externa (MannWhitney, $\mathrm{p}<0,001$ ), camada molecular interna (Mann-Whitney, $\mathrm{p}=0,004$ ), camada granular (Mann-Whitney, $\mathrm{p}=0,003$ ), zona subgranular (Mann-Whitney, $\mathrm{p}<0,001$ ), hilo (Mann-Whitney, $\mathrm{p}<0,001$ ), CA4 (Mann-Whitney, $\mathrm{p}=0,001$ ), CA3 (MannWhitney, $\mathrm{p}=0,002$ ), CA2 (Mann-Whitney, $\mathrm{p}=0,016$ ), CA1 (Mann-Whitney, $\mathrm{p}=$ 0,022), no prosubículo (Mann-Whitney, $\mathrm{p}=0,03$ ) e no subículo (Mann-Whitney, $\mathrm{p}=$ 0,015) (Figuras 28-29). 

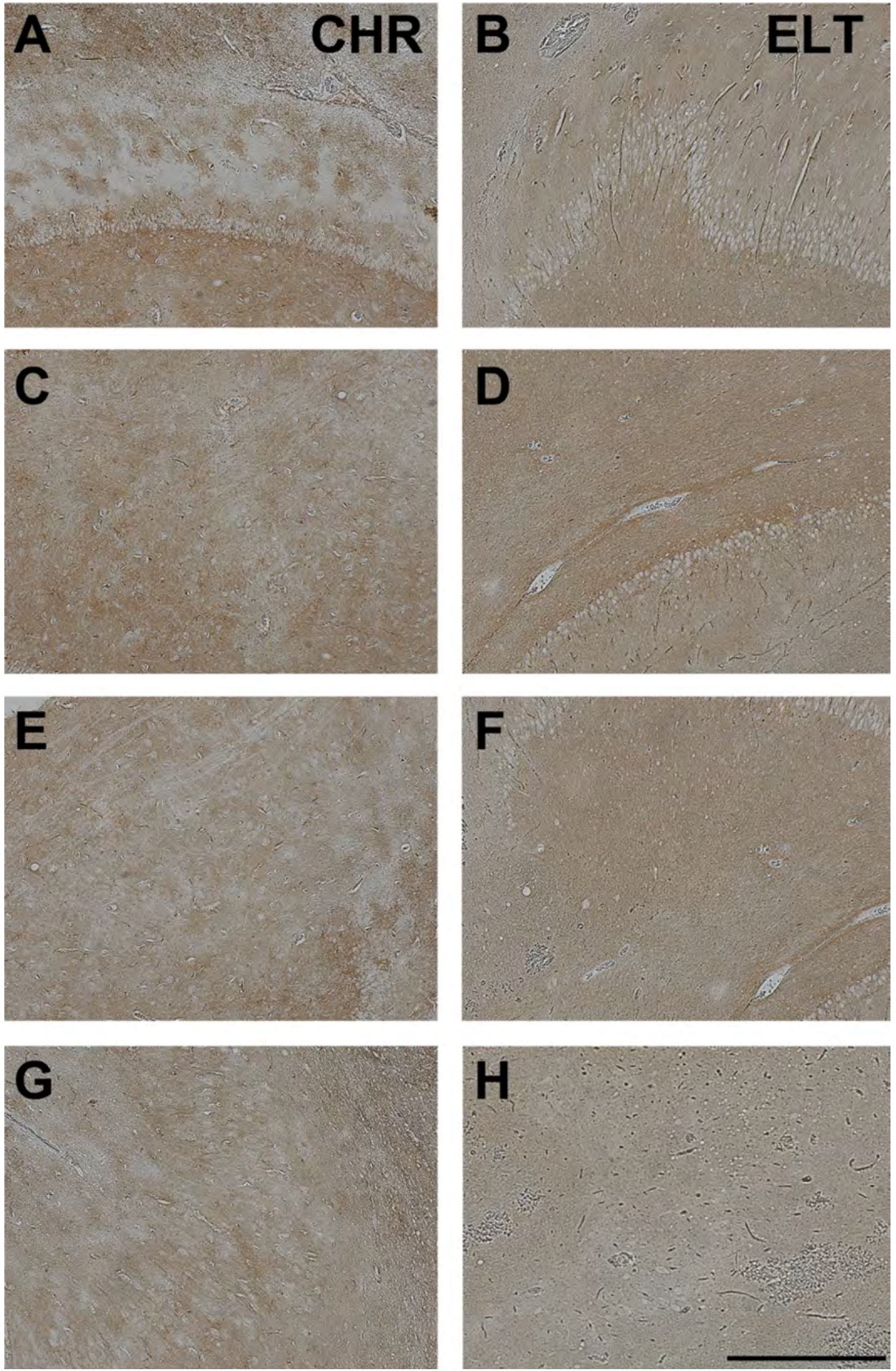

Figura 26. Fotomicrografias representativas da imuno-histoquímica para avaliação da AQP4 perivascular na camada granular (A-B), hilo (C-D), CA4 (E-F) e CA3 (G-H) de pacientes do grupo CHR (A, C, E e G) e com ELT (B, D, F e H). Note o aumento de imunoreatividade em todo o tecido, e a concomitante perda de polarização da AQP4 nos casos ELT, quando comparados com os casos CHR. A barra em H indica 500 micrômetros. 

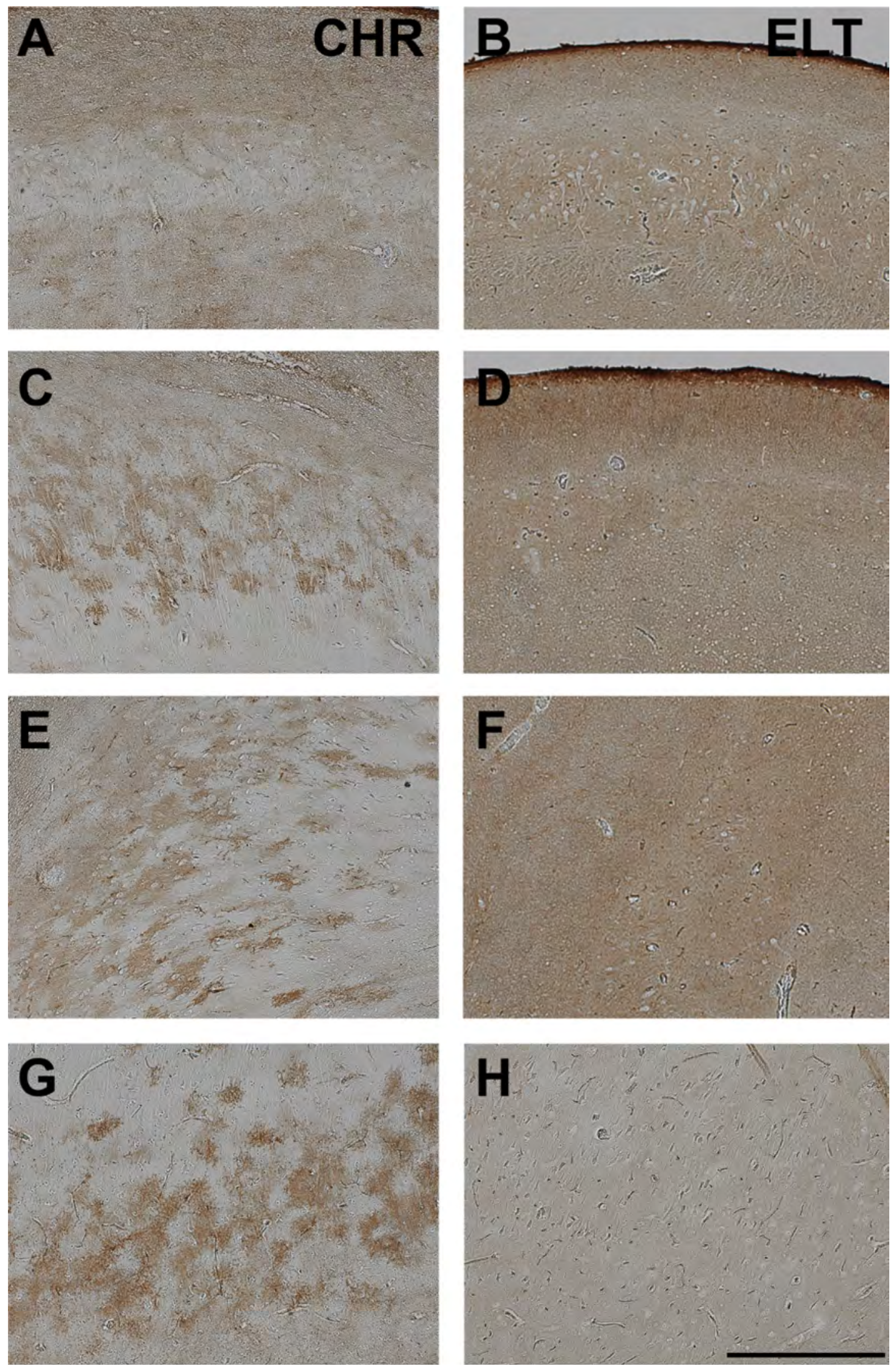

Figura 27. Fotomicrografias representativas da imuno-histoquímica para avaliação da AQP4 perivascular em CA2 (A-B), CA1 (C-D), prosubículo (E-F) e subículo (G-H) de pacientes do grupo CHR (A, C, E e G) e com ELT (B, D, F e H). Observe a perda de polaridade (especialmente visível em CA1, prosubículo e subículo) dos casos ELT, quando comparados com os casos CHR. A barra em H indica 500 micrômetros. 


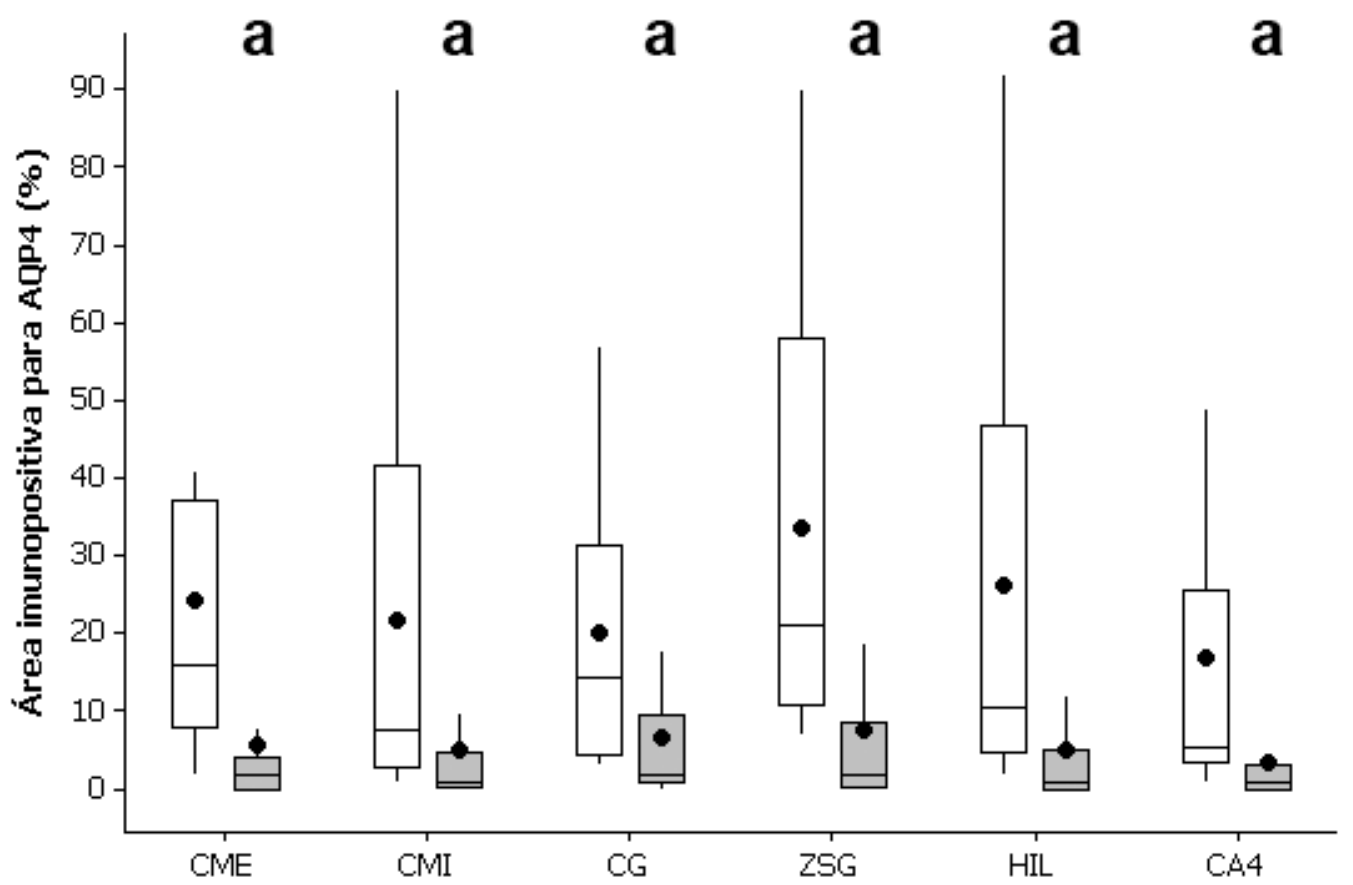

Figura 28. Área imunopositiva para AQP4 perivascular em casos CHR (boxplot branco) e pacientes com ELT (boxplot cinza). A letra a sobre os boxplots indica diferença em relação ao CHR. O círculo negro no boxplot indica a média. Mann-Whitney, $\mathrm{p}<0,001$ para CME, ZSG e HIL, $\mathrm{p}=0,004$ para CMI, $\mathrm{p}=0,003$ para CG e $\mathrm{p}=0,001$ para $\mathrm{CA} 4 . \mathrm{CME}=$ camada molecular externa; $\mathrm{CMI}=$ camada molecular interna; $\mathrm{CG}=$ camada granular; $\mathrm{ZSG}=$ zona subgranular; $\mathrm{HIL}=$ hilo.

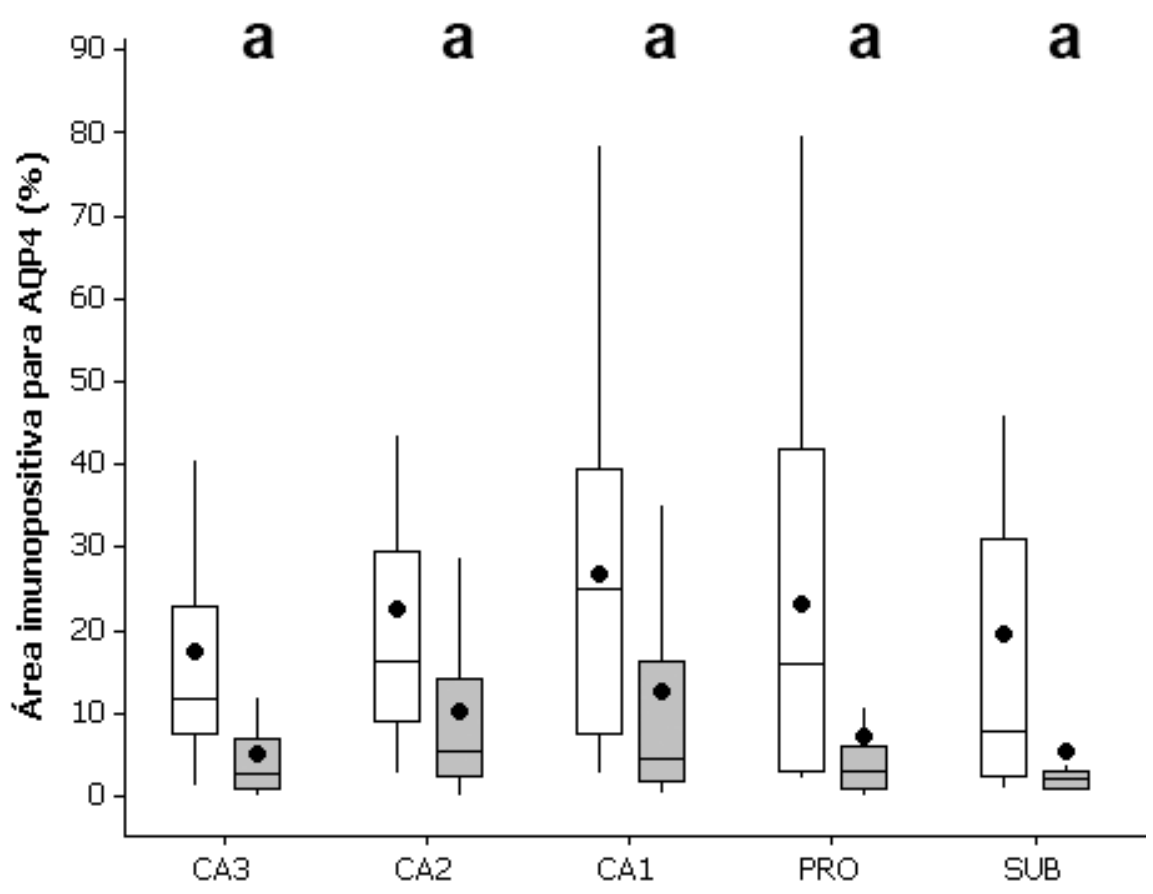

Figura 29. Área imunopositiva para AQP4 perivascular em casos CHR (boxplot branco) e pacientes com ELT (boxplot cinza). A letra a sobre os boxplots indica diferença em relação ao CHR. O círculo negro no boxplot indica a média. Mann-Whitney, $p=0,002$ para CA3, $p=0,016$ para CA2, $p=0,022$ para CA1, $p=0,03$ para PRO e $p=$ 0,015 para $\mathrm{SUB} . \mathrm{PRO}=$ prosubículo; $\mathrm{SUB}=$ subículo. 


\section{Sulfato de Condroitina}

A avaliação dos níveis do proteoglicano sulfato de condroitina, através de fração da área imunopositiva em secções submetidas à imuno-histoquímica para detecção do antígeno CS-56 (Figura 30-31) revelou aumento significativo de CS-56, quando comparado ao grupo CHR, na camada molecular externa (Mann-Whitney, $\mathrm{p}<$ 0,001), camada molecular interna (Mann-Whitney, p $<0,001$ ), zona subgranular (Mann-Whitney, $\mathrm{p}=0,002$ ), hilo (Mann-Whitney, $\mathrm{p}<0,001$ ), CA4 (Mann-Whitney, $\mathrm{p}$ $<0,001$ ), CA3 (Mann-Whitney, $\mathrm{p}<0,001$ ), CA2 (Mann-Whitney, $\mathrm{p}<0,001$ ), CA1 (Mann-Whitney, $\mathrm{p}<0,001$ ), no prosubículo (Mann-Whitney, $\mathrm{p}<0,001$ ) e no subículo (Mann-Whitney, $\mathrm{p}<0,001)$ (Figuras 32-33). Houve tendência à maior área imunopositiva na camada granular (Teste-t, $p=0,051)$ de casos ELT, comparados ao CHR. 

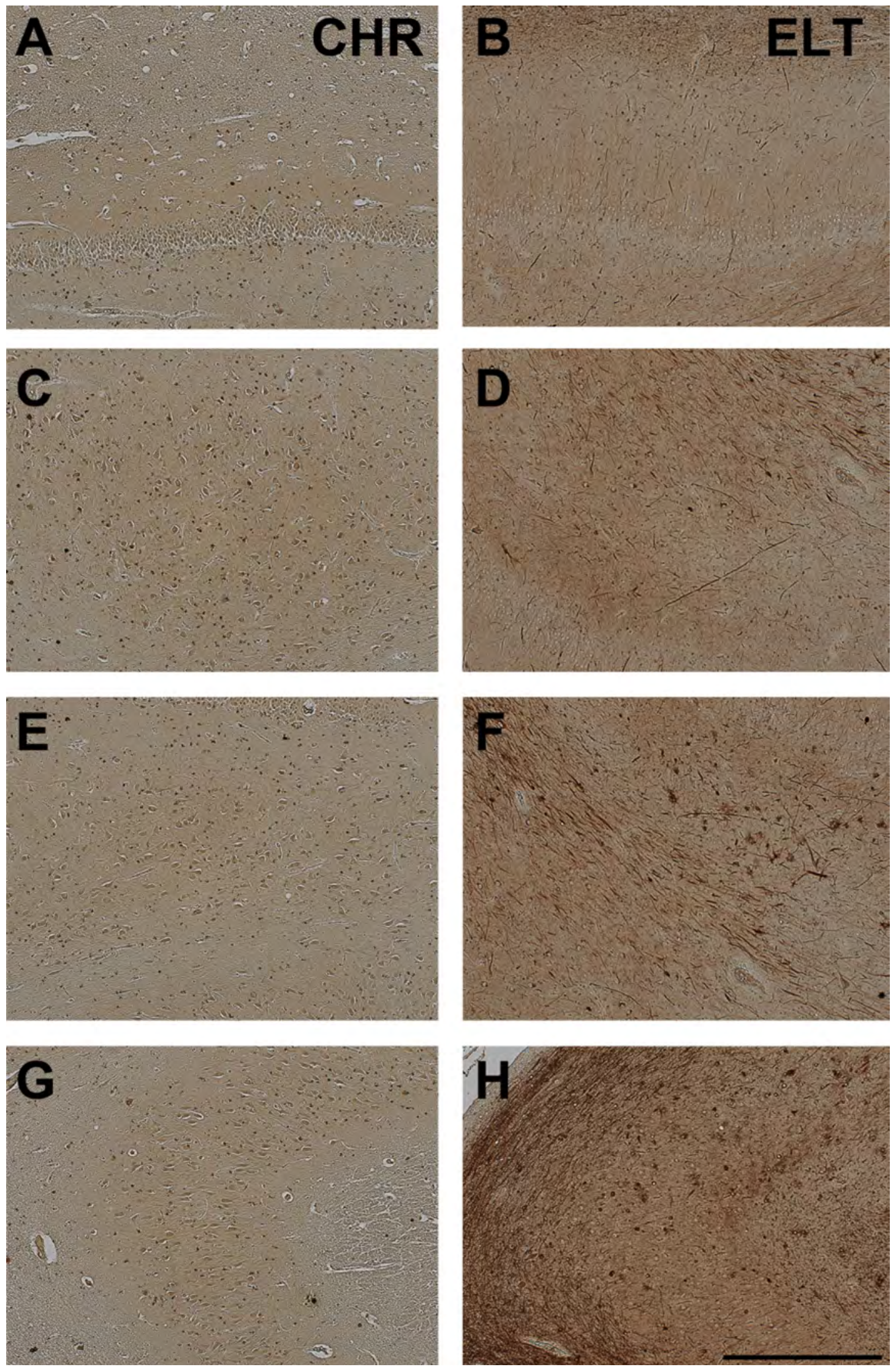

Figura 30. Fotomicrografias representativas da imuno-histoquímica para avaliação do sulfato de condroitina na camada granular (A-B), hilo (C-D), CA4 (E-F) e CA3 (G-H) de pacientes do grupo CHR (A, C, E e G) e com ELT $(\mathrm{B}, \mathrm{D}, \mathrm{F}$ e H). Note o aumento de imunoreatividade em todo o tecido e o maior número de fibras imunopositivas (com destaque para CA4) nos casos ELT, quando comparados com os casos CHR. A barra em H indica 500 micrômetros. 

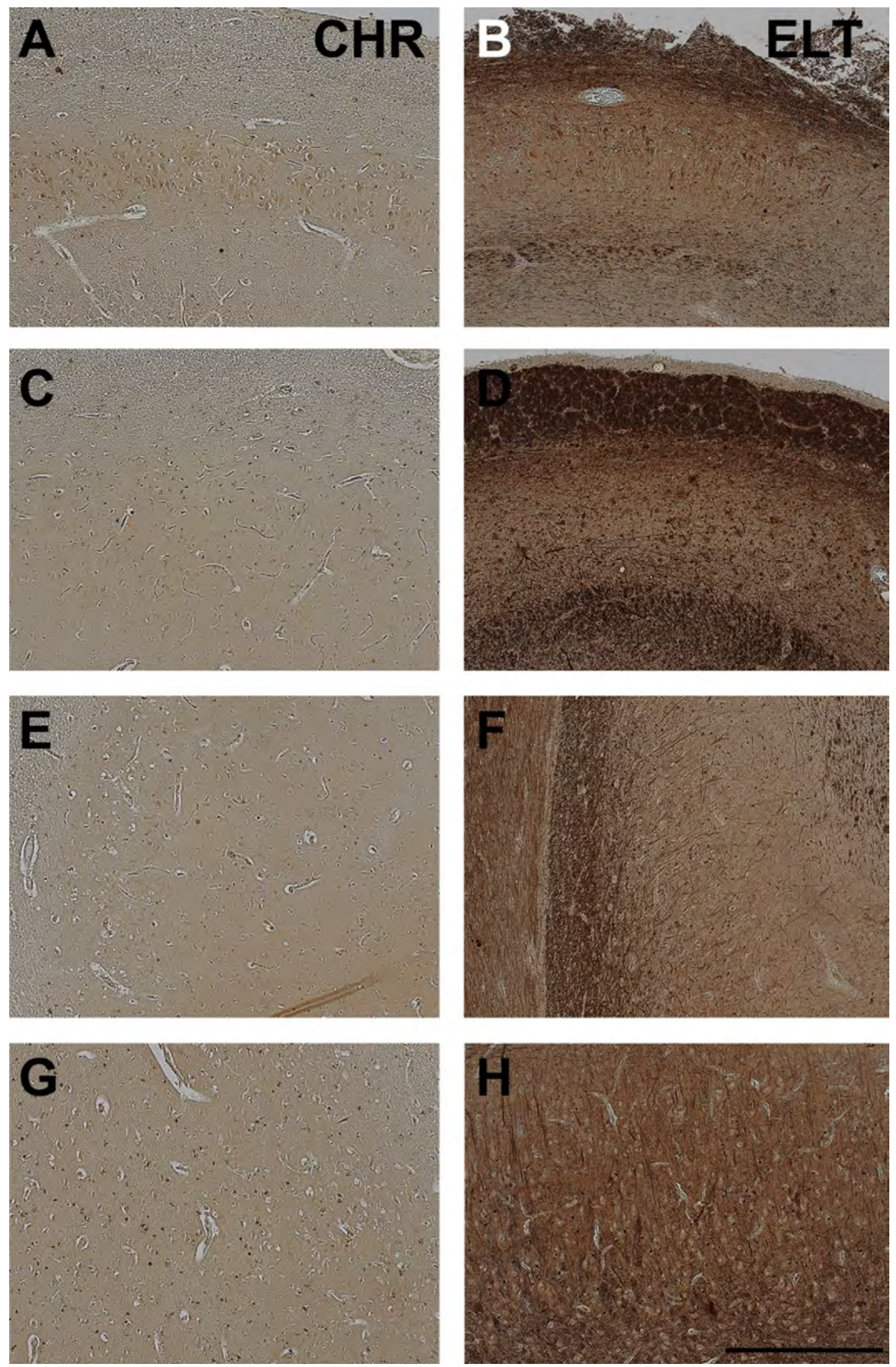

Figura 31. Fotomicrografias representativas da imuno-histoquímica para avaliação do sulfato de condroitina em CA2 (A-B), CA1 (C-D), prosubículo (E-F) e subículo (G-H) de pacientes do grupo CHR (A, C, E e G) e com ELT $(\mathrm{B}, \mathrm{D}, \mathrm{F}$ e $\mathrm{H})$. Note o aumento da intensidade e número de fibras imunopositivas nos casos ELT, quando comparados com os casos CHR. A barra em $\mathrm{H}$ indica 500 micrômetros. 


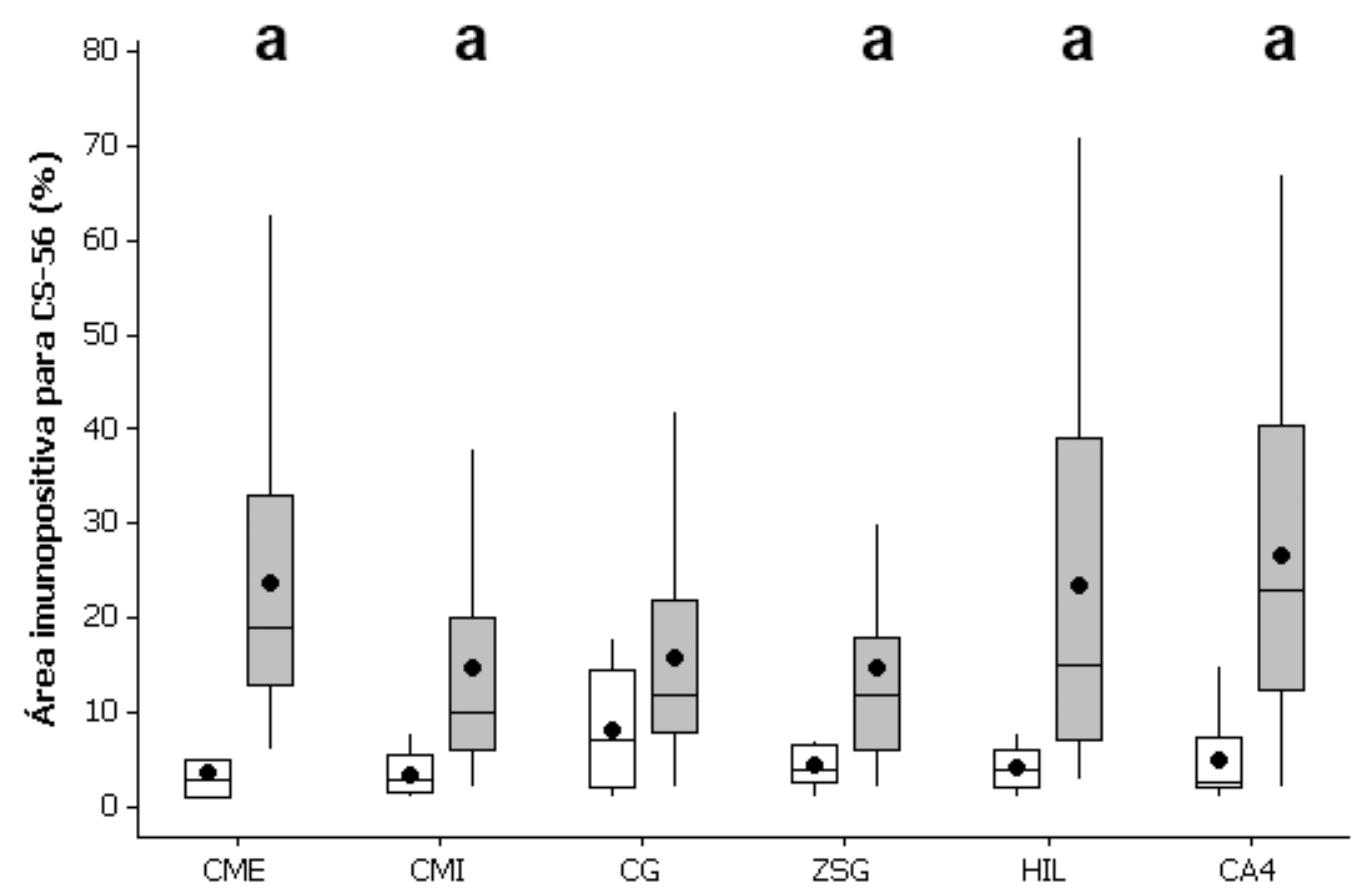

Figura 32. Área imunopositiva para CS-56 em casos CHR (boxplot branco) e pacientes com ELT (boxplot cinza). A letra a sobre os boxplots indica diferença em relação ao CHR. O círculo negro no boxplot indica a média. MannWhitney, $\mathrm{p}<0,001$ para CME, CMI, HIL e CA4, e $\mathrm{p}=0,002$ para ZSG. CME = camada molecular externa; $\mathrm{CMI}=$ camada molecular interna; $\mathrm{CG}=$ camada granular; $\mathrm{ZSG}=$ zona subgranular; $\mathrm{HIL}=$ hilo.

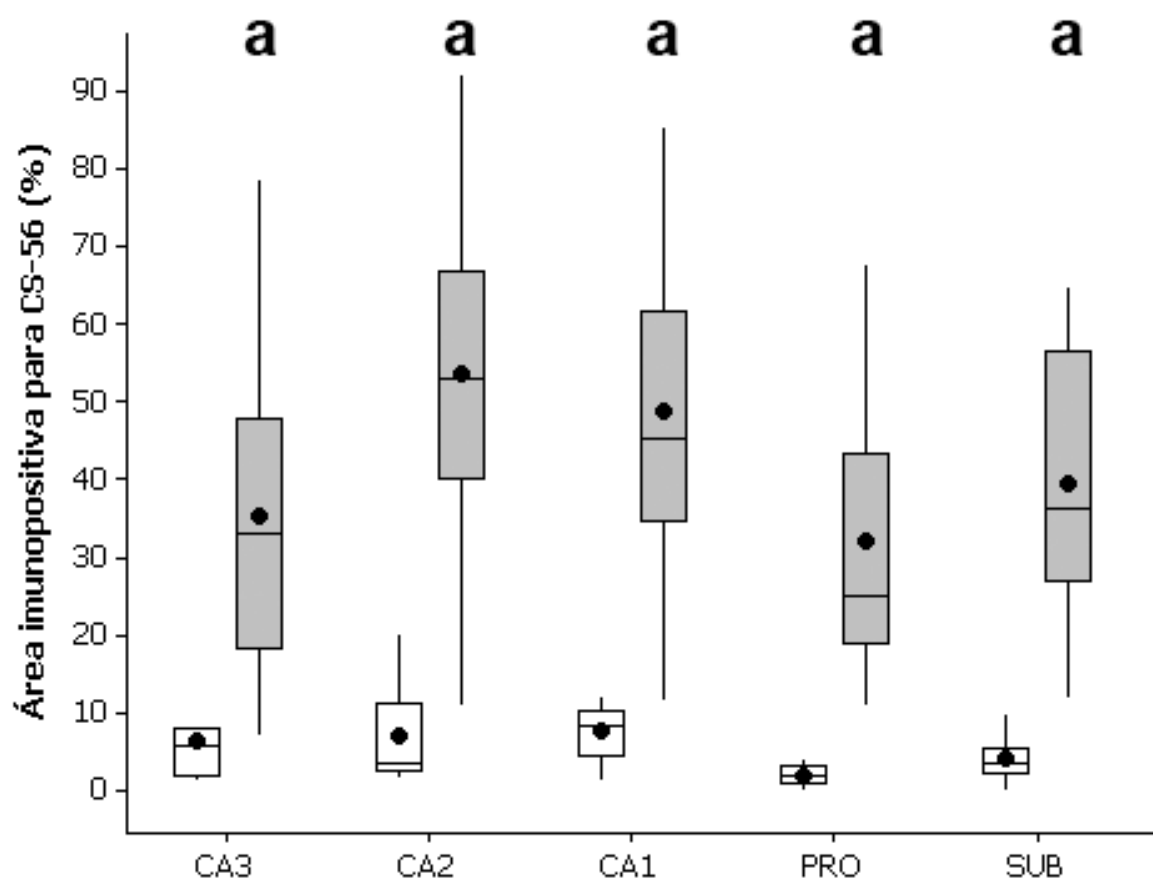

Figura 33. Área imunopositiva para CS-56 em casos CHR (boxplot branco) e pacientes com ELT (boxplot cinza). A letra a sobre os boxplots indica diferença em relação ao CHR. O círculo negro no boxplot indica a média. MannWhitney, $\mathrm{p}<0,001$ para CA3, CA2, CA1, PRO e SUB. PRO = prosubículo; SUB = subículo, 


\section{Correlações}

\section{Protocolo de ressonância in vivo e alterações histológicas no grupo ELT}

Em relação ao volume hipocampal, foram observadas correlações positivas com as densidades neuronais na camada granular $(\mathrm{R}=0,367 ; \mathrm{p}=0,0328)$ e em CA3 $(\mathrm{R}=0,436 ; \mathrm{p}=0,0261)$, e com a área imunopositiva para CS-56 em CA3 $(\mathrm{R}=0,43 ; \mathrm{p}$ $=0,0356), \mathrm{CA} 2(\mathrm{R}=0,473 ; \mathrm{p}=0,0112)$ e CA1 $(\mathrm{R}=0,427 ; \mathrm{p}=0,0187)$. Houve ainda correlação negativa entre o volume hipocampal e a área imunopositiva para HLA-DR no prosubículo $(\mathrm{R}=-0,563 ; \mathrm{p}=0,00968)$ (Figuras 34-36).

O tempo de relaxamento hipocampal correlacionou-se positivamente com a área imunopositiva para GFAP no subículo $(\mathrm{R}=0,541 ; \mathrm{p}=0,0296)$ e com a área imunopositiva para CS-56 no hilo $(\mathrm{R}=0,473 ; \mathrm{p}=0,0303)$ (Figuras 37-38).

A transferência de magnetização hipocampal correlacionou-se positivamente com a densidade neuronal em $\mathrm{CA} 3(\mathrm{R}=0,581 ; \mathrm{p}=0,00589)$ e com as áreas imunopositivas para CS-56 em CA4 $(\mathrm{R}=0,513 ; \mathrm{p}=0,0291), \mathrm{CA} 3(\mathrm{R}=0,66 ; \mathrm{p}=$ 0,00383), CA2 $(\mathrm{R}=0,486 ; \mathrm{p}=0,0297), \mathrm{CA} 1(\mathrm{R}=0,544 ; \mathrm{p}=0,0109)$ e no subículo $(\mathrm{R}=0,578 ; \mathrm{p}=0,0182)$ (Figuras 39-42). Foram observadas correlações negativas entre a taxa de transferência de magnetização e a área imunopositiva para HLA-DR em CA3 $(R=-0,566 ; p=0,0175)$, CA2 $(R=-0,636 ; p=0,00794)$ e em CA1 $(R=-$ $0,604 ; p=0,0103)$ 


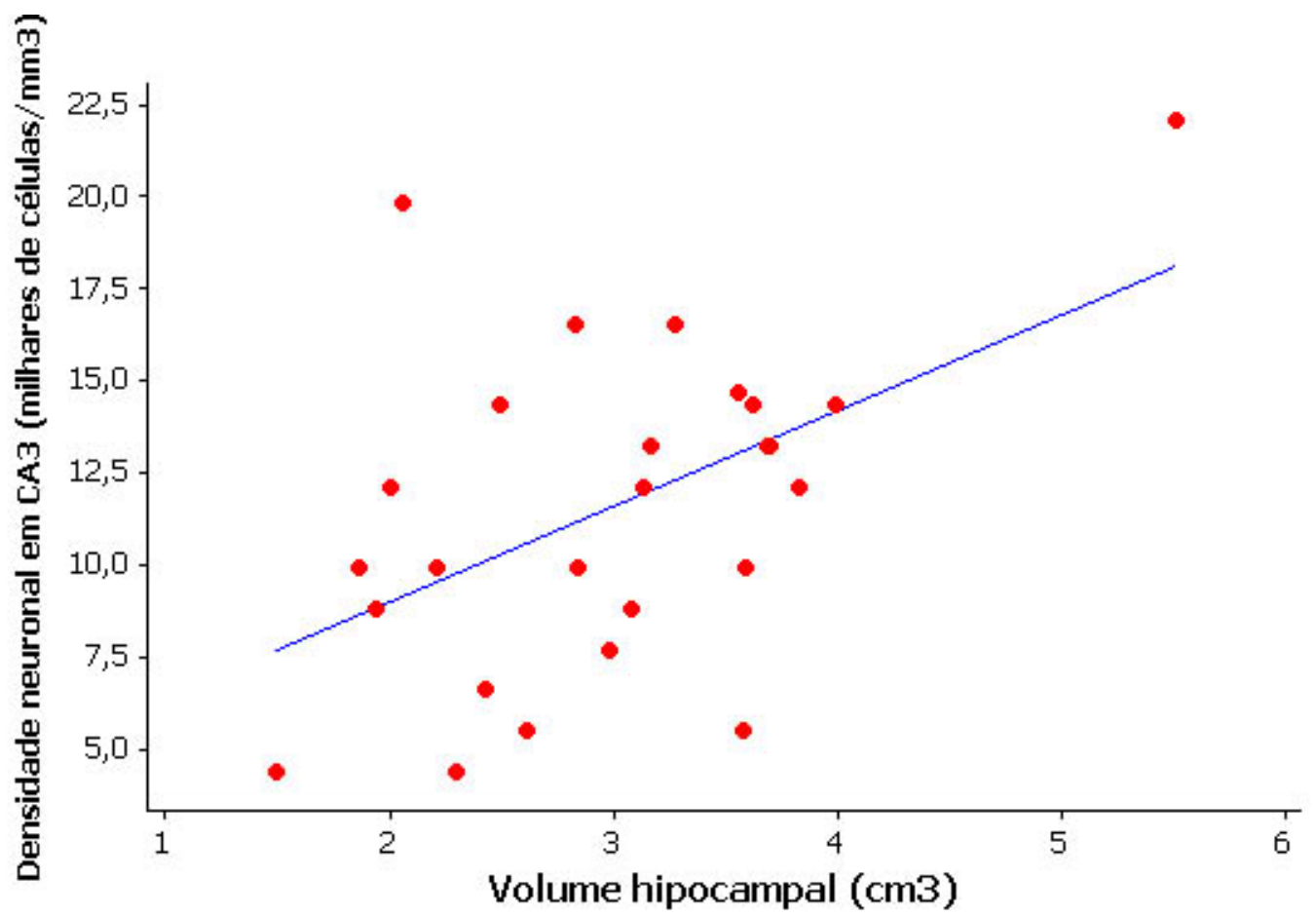

Figura 34. Gráfico de pontos com regressão linear entre volume hipocampal e a densidade neuronal em CA3. Teste de Spearman, $\mathrm{R}^{2}=0,190 ; \mathrm{p}=0,0261 ; \mathrm{n}=24$.

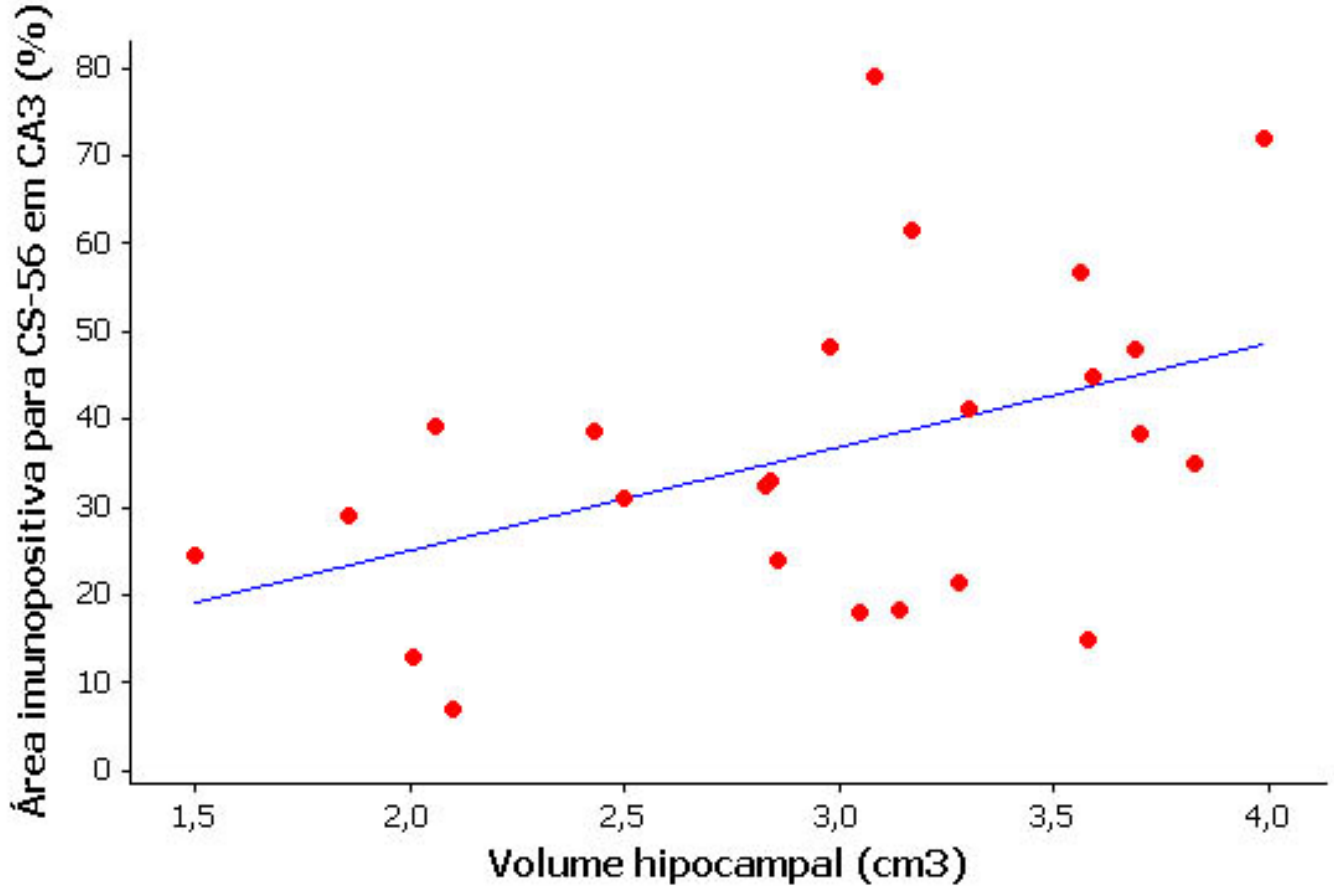

Figura 35. Gráfico de pontos com regressão linear entre volume hipocampal e a área imunopositiva para sulfato de condroitina em CA3. Teste de Spearman, $R^{2}=0,185 ; p=0,0356 ; n=24$. 


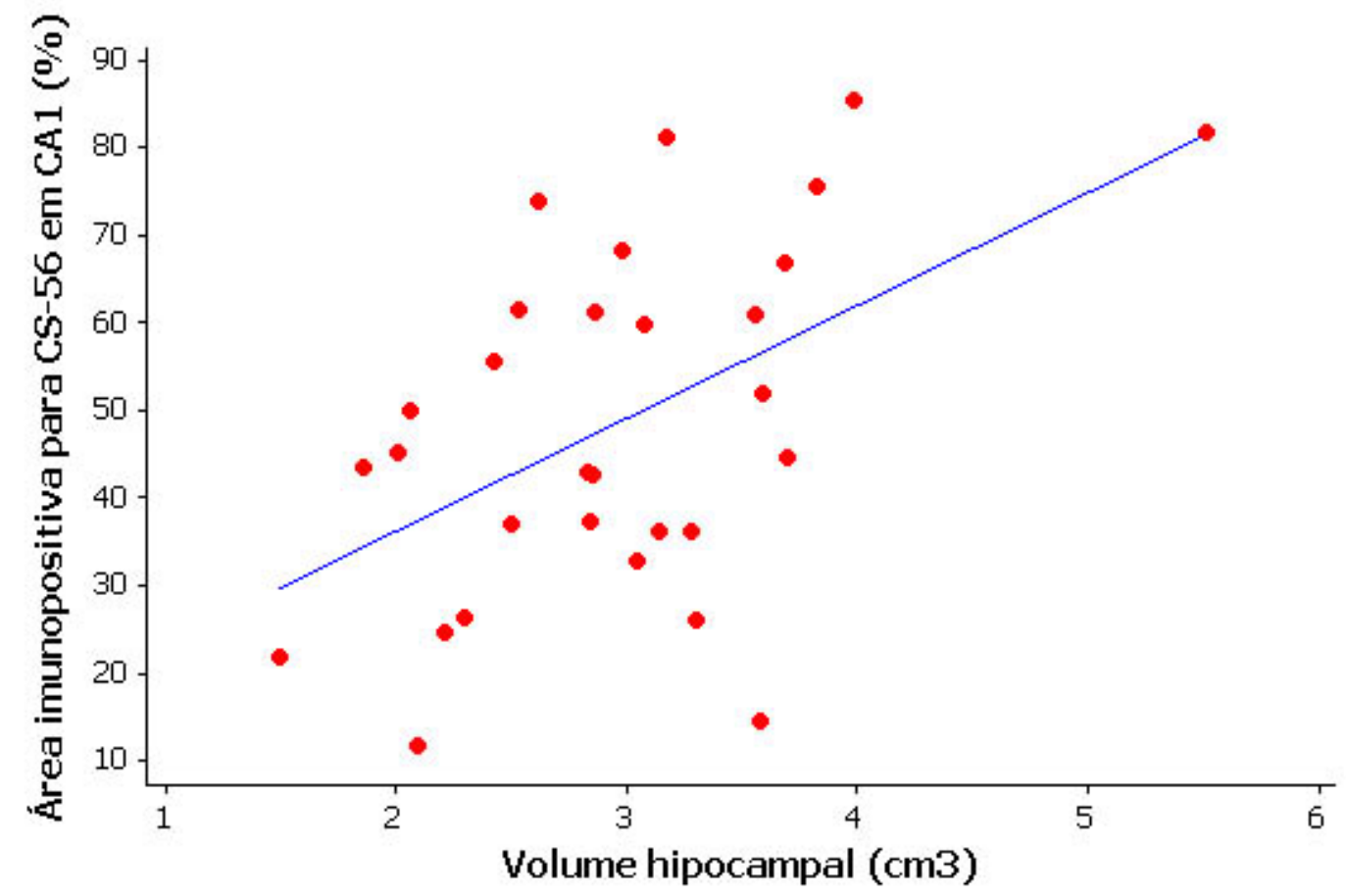

Figura 36. Gráfico de pontos com regressão linear entre volume hipocampal e a área imunopositiva para sulfato de condroitina em CA1. Teste de Spearman, $R^{2}=0,182 ; p=0,0187 ; n=30$.

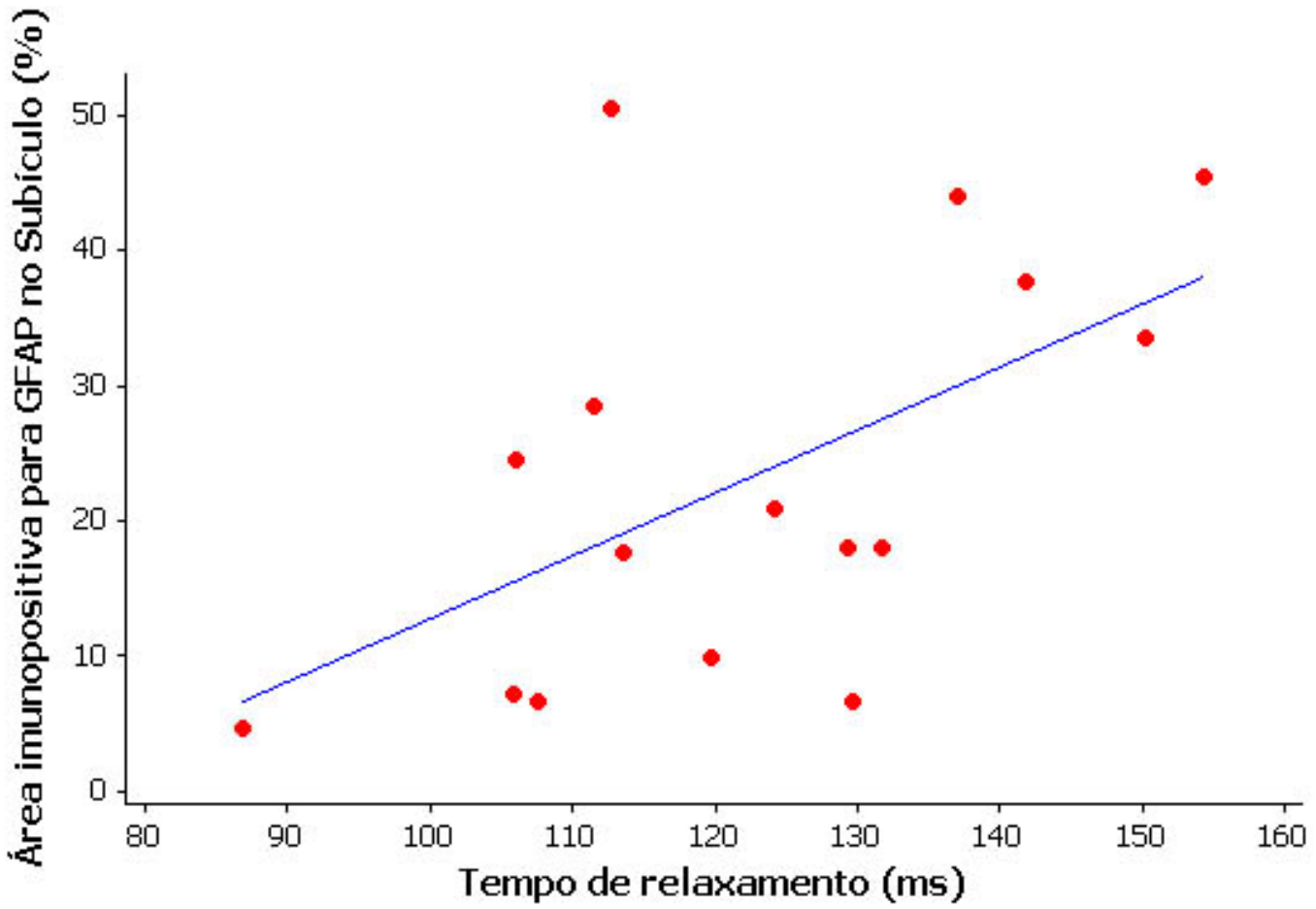

Figura 37. Gráfico de pontos com regressão linear entre o tempo de relaxamento hipocampal e a área imunopositiva para GFAP no subículo. Teste de Spearman, $R^{2}=0,293 ; p=0,0296 ; n=16$. 


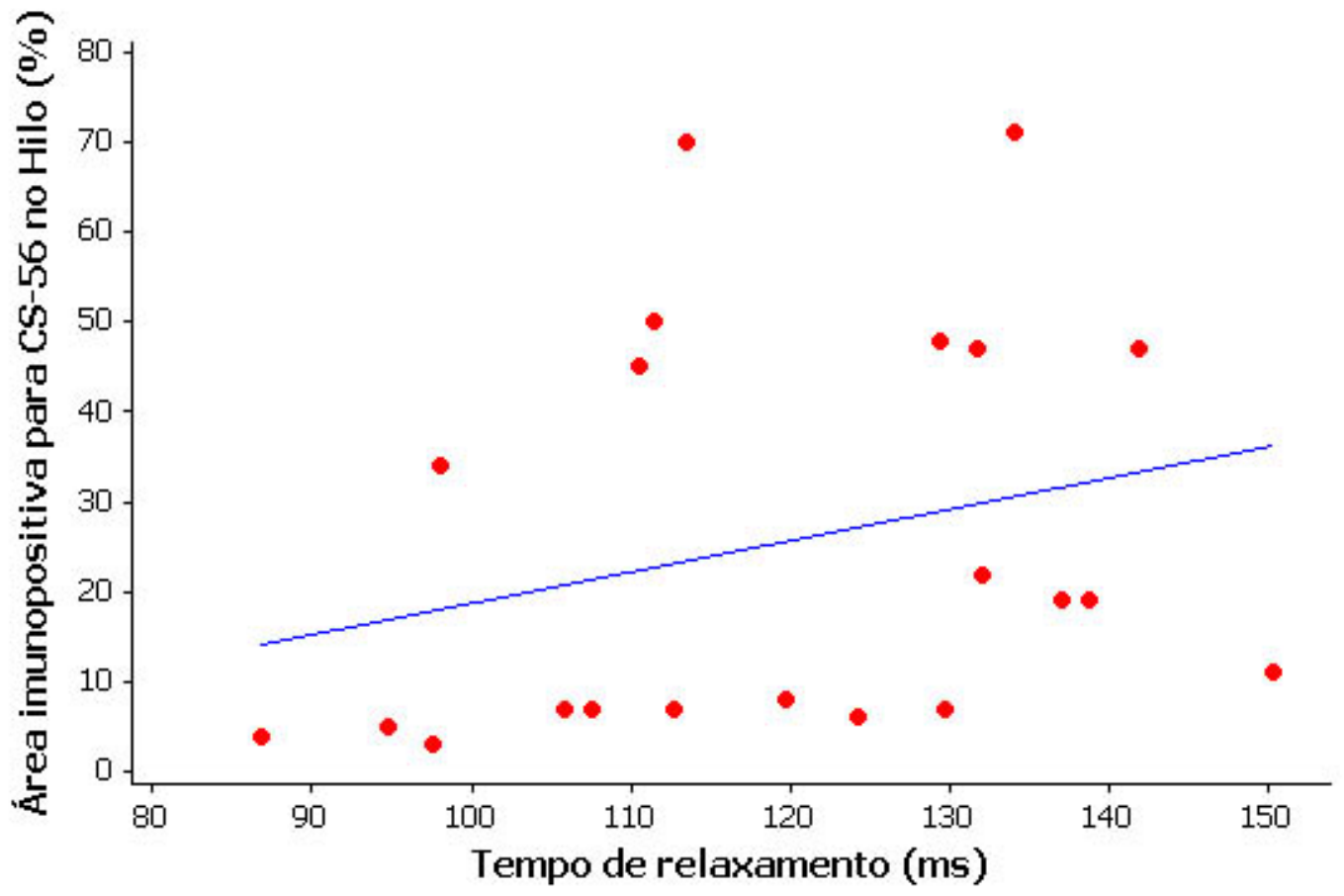

Figura 38. Gráfico de pontos com regressão linear entre o tempo de relaxamento hipocampal e a área imunopositiva para sulfato de condroitina no hilo. Teste de Spearman, $R^{2}=0,224 ; p=0,0303 ; n=21$.

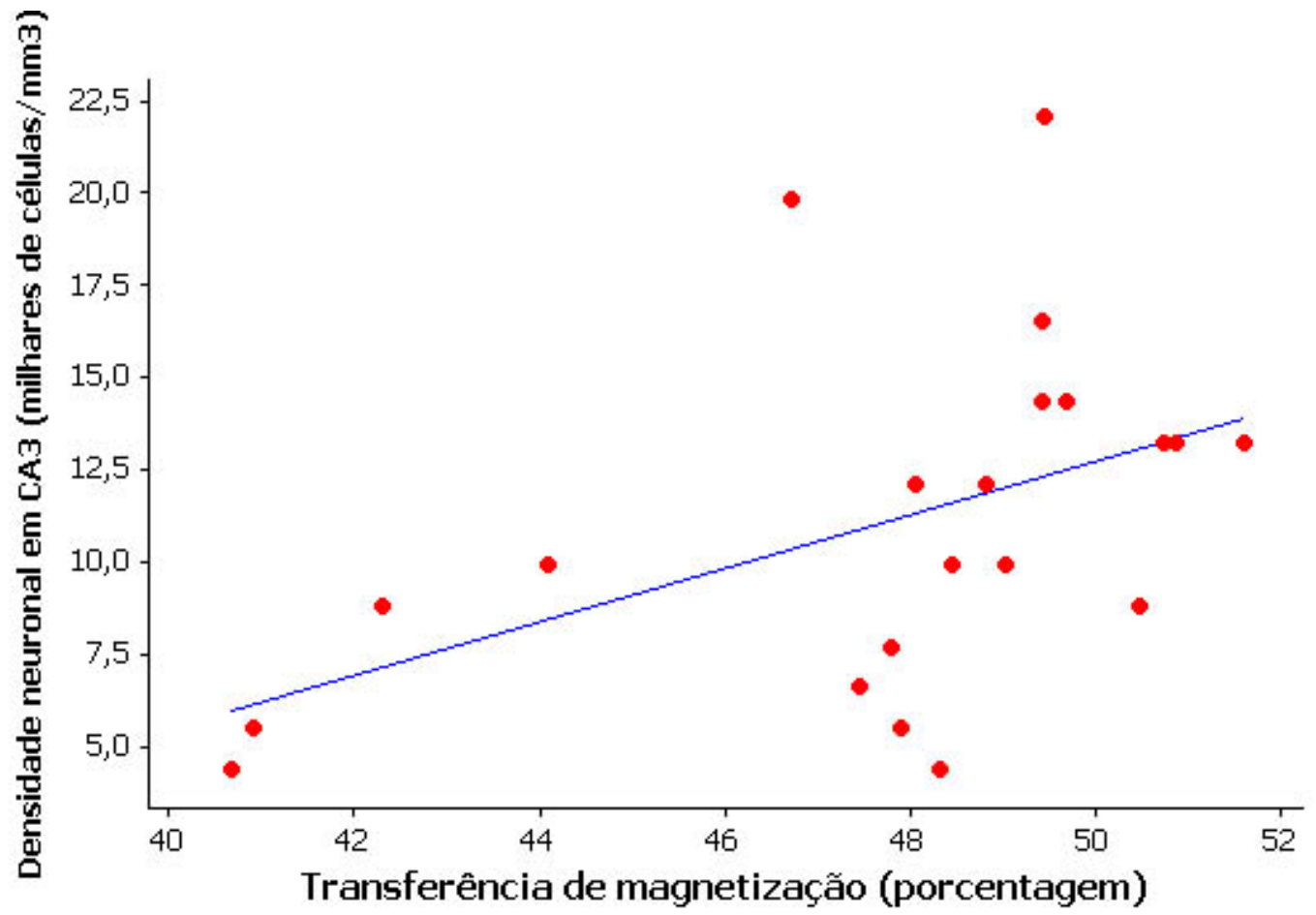

Figura 39. Gráfico de pontos com regressão linear entre a taxa de transferência de magnetização hipocampal e a densidade neuronal em CA3. Teste de Spearman, $\mathrm{R}^{2}=0,338 ; \mathrm{p}=0,00589 ; \mathrm{n}=21$. 


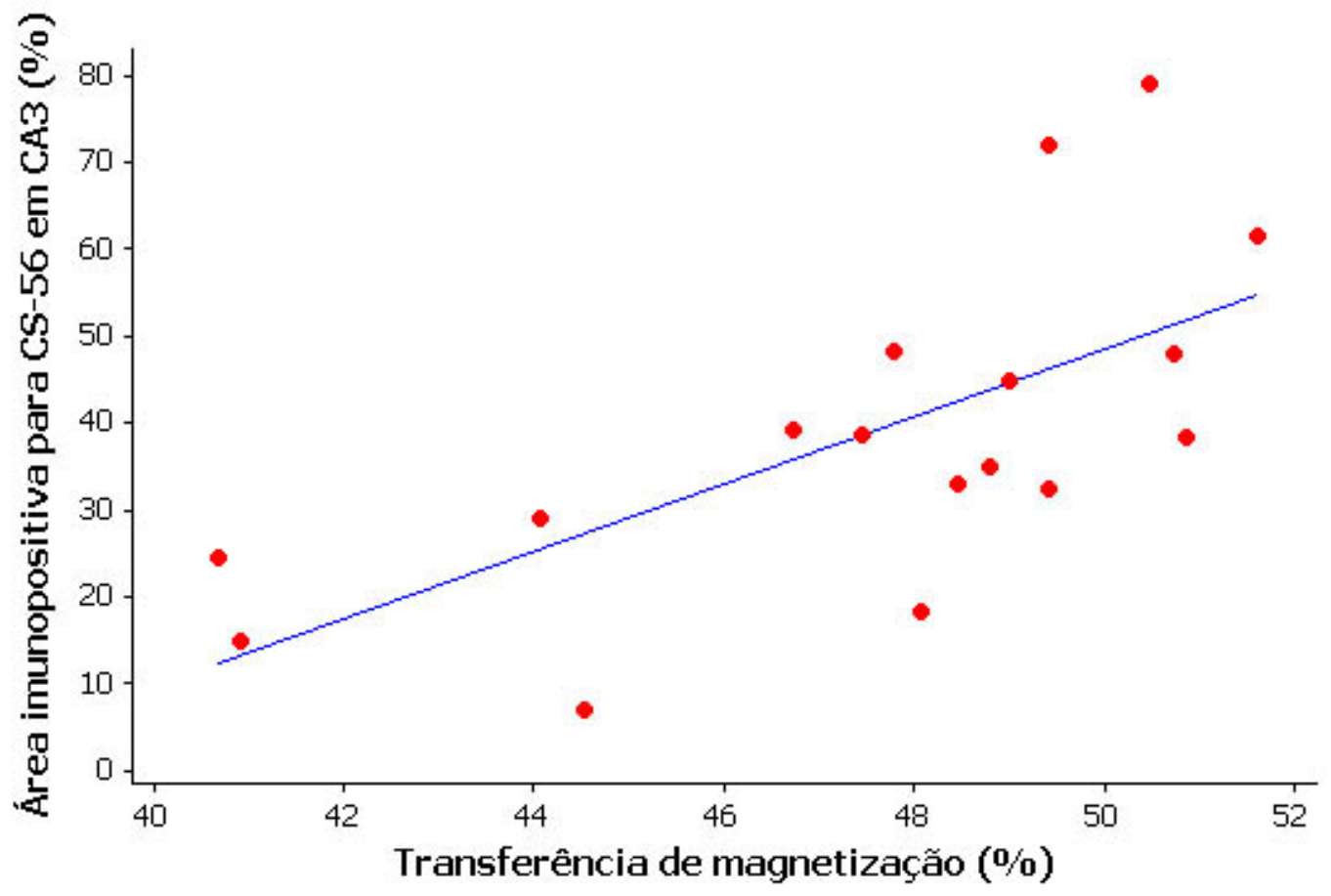

Figura 40. Gráfico de pontos com regressão linear entre a taxa de transferência de magnetização hipocampal e a área imunopositiva para sulfato de condroitina em CA3. Teste de Spearman, $\mathrm{R}^{2}=0,436 ; \mathrm{p}=0,00383 ; \mathrm{n}=17$.

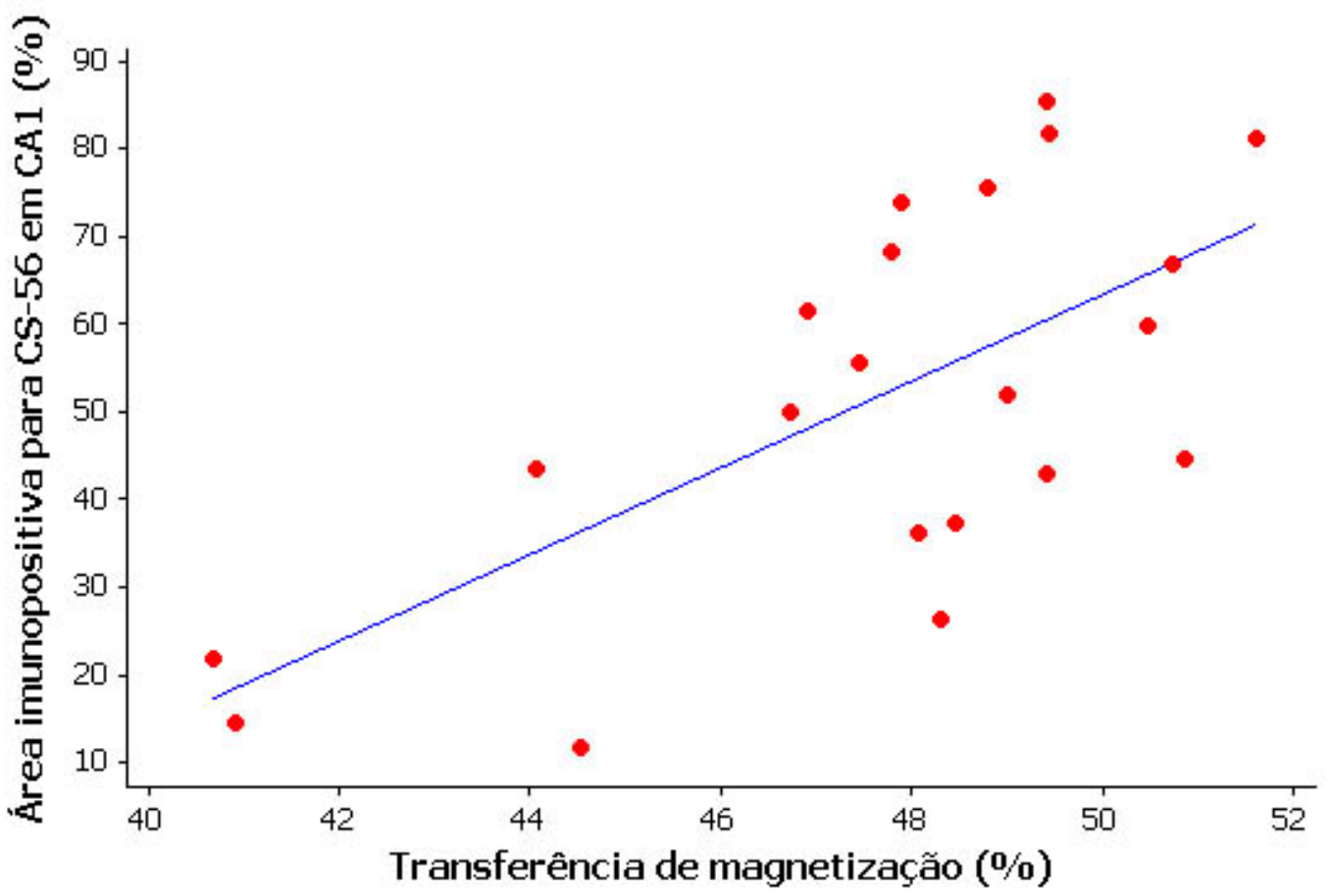

Figura 41. Gráfico de pontos com regressão linear entre a taxa de transferência de magnetização hipocampal e a área imunopositiva para sulfato de condroitina em CA1. Teste de Spearman, $R^{2}=0,296 ; p=0,0109 ; n=21$. 


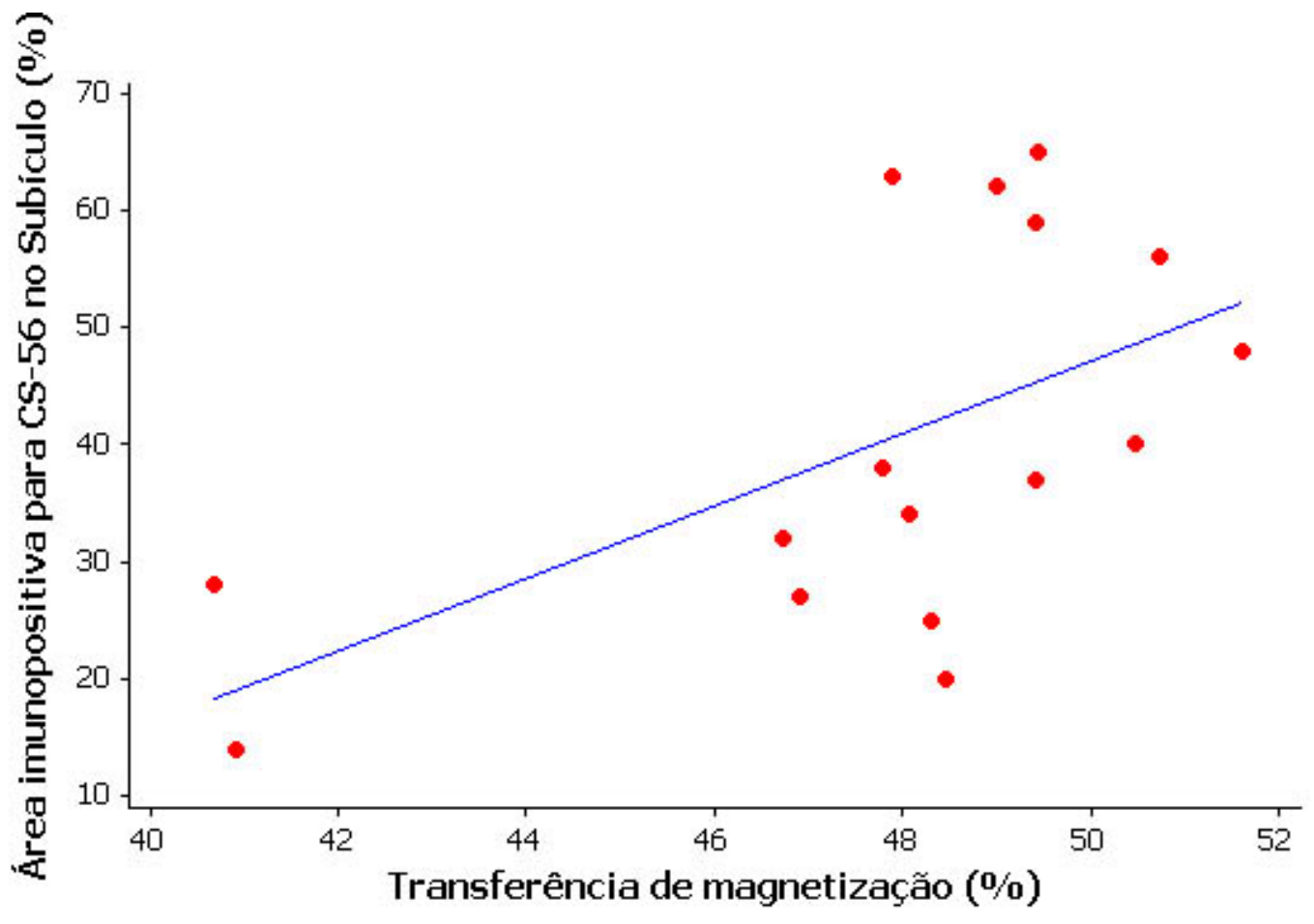

Figura 42. Gráfico de pontos com regressão linear entre a taxa de transferência de magnetização hipocampal e a área imunopositiva para sulfato de condroitina no subículo. Teste de Spearman, $R^{2}=0,334 ; p=0,0182 ; n=16$.

\section{Protocolo de ressonância ex vivo e alterações histológicas no grupo ELT}

O tempo de relaxamento $\mathrm{T} 2$ correlacionou-se positivamente com a área imunopositiva para GFAP na camada molecular externa $(\mathrm{R}=0,44 ; \mathrm{p}=0,0108)$, camada molecular interna $(\mathrm{R}=0,408 ; \mathrm{p}=0,0186)$, zona subgranular $(\mathrm{R}=0,488 ; \mathrm{p}=$ 0,00558), hilo $(R=0,434 ; p=0,0149)$, CA4 $(R=0,383 ; p=0,0444)$ e no subículo $(R$ $=0,383 ; \mathrm{p}=0,0485)$ e com a área imunopositiva para HLA-DR em CA1 $(\mathrm{R}=0,45 ; \mathrm{p}$ $=0,0406)$ (Figuras 43-48). Foi ainda observada correlação negativa entre o tempo de relaxamento e a densidade neuronal em CA3 $(R=-0,446 ; p=0,0289)$. 


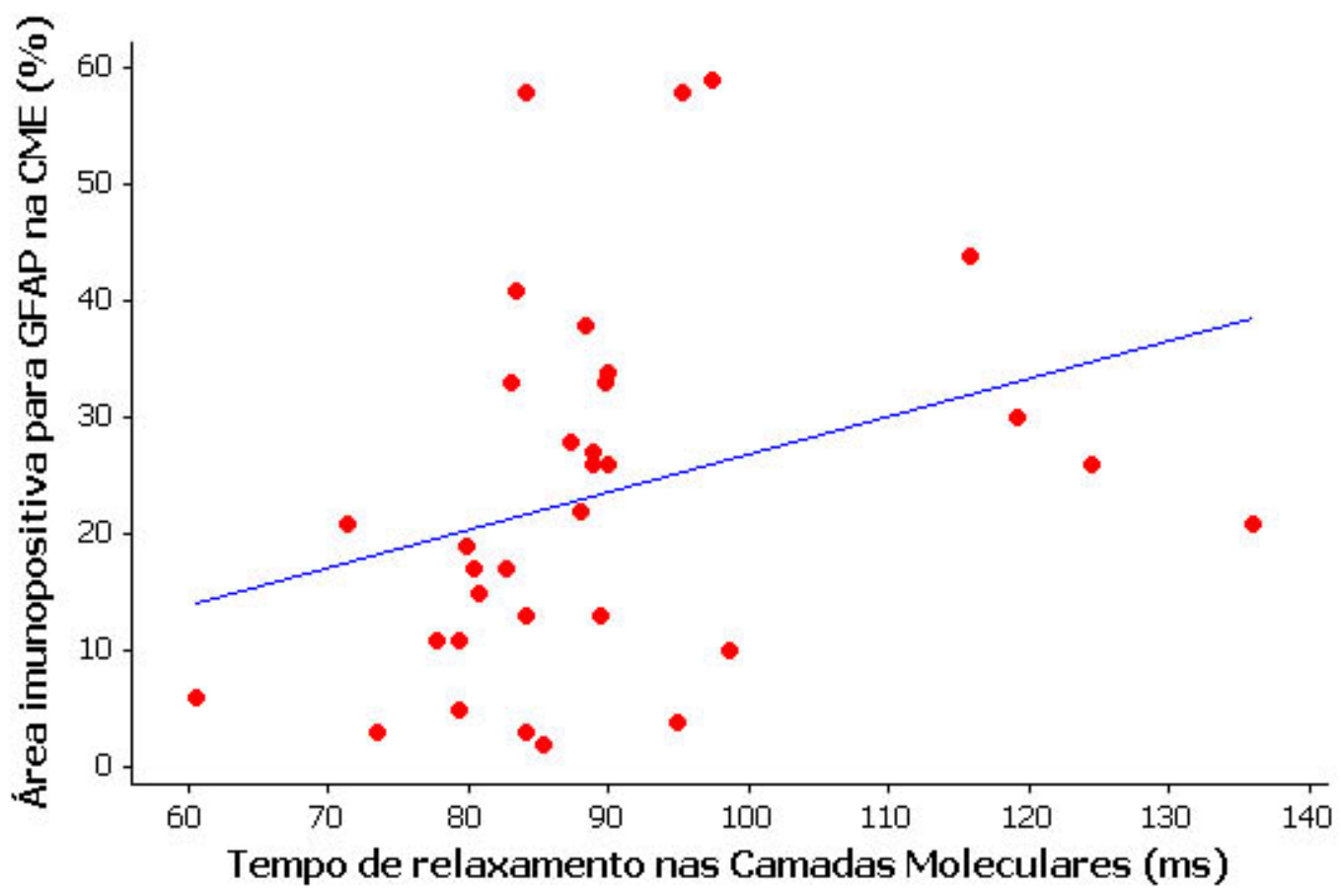

Figura 43. Gráfico de pontos com regressão linear entre o tempo de relaxamento na camada molecular da fascia dentata e a área imunopositiva para GFAP na camada molecular externa da fascia dentata. Teste de Spearman, $\mathrm{R}^{2}$ $=0,194 ; \mathrm{p}=0,0182 ; \mathrm{n}=33$.

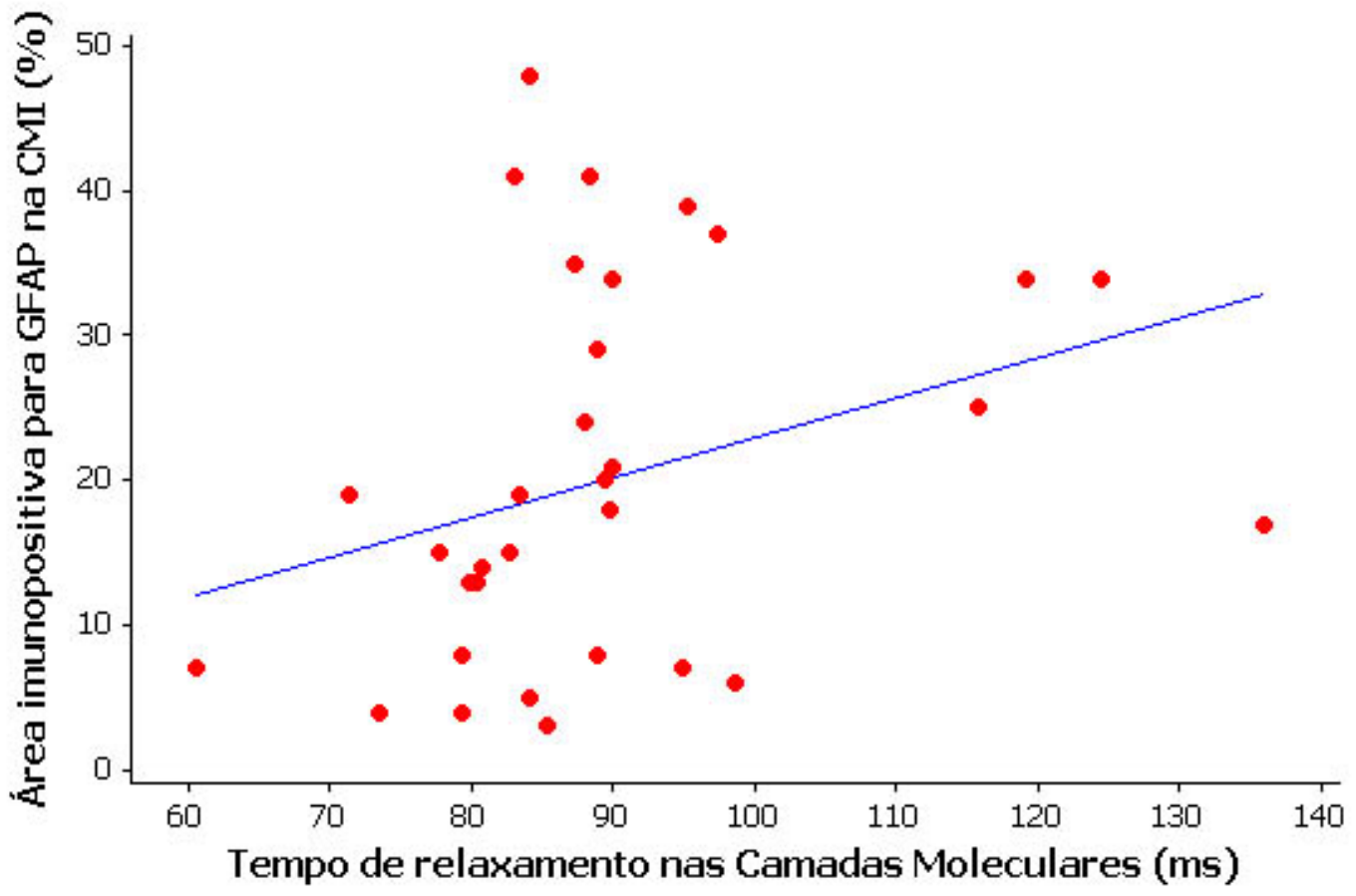

Figura 44. Gráfico de pontos com regressão linear entre o tempo de relaxamento na camada molecular da fascia dentata e a área imunopositiva para GFAP na camada molecular interna da fascia dentata. Teste de Spearman, $\mathrm{R}^{2}$ $=0,166 ; \mathrm{p}=0,0186 ; \mathrm{n}=33$. 


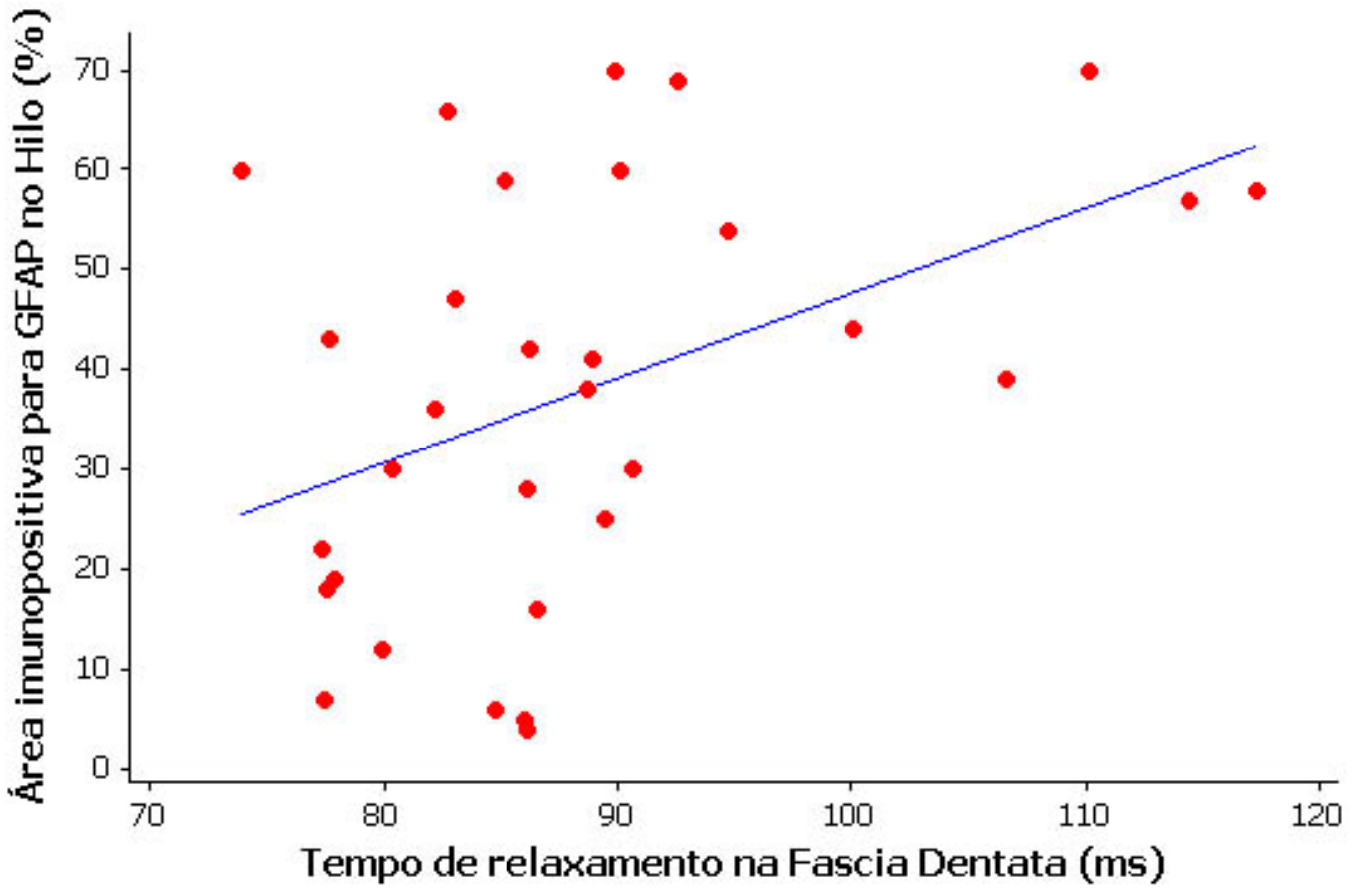

Figura 45. Gráfico de pontos com regressão linear entre o tempo de relaxamento na fascia dentata e a área imunopositiva para GFAP no hilo. Teste de Spearman, $R^{2}=0,188 ; p=0,0149 ; n=31$.

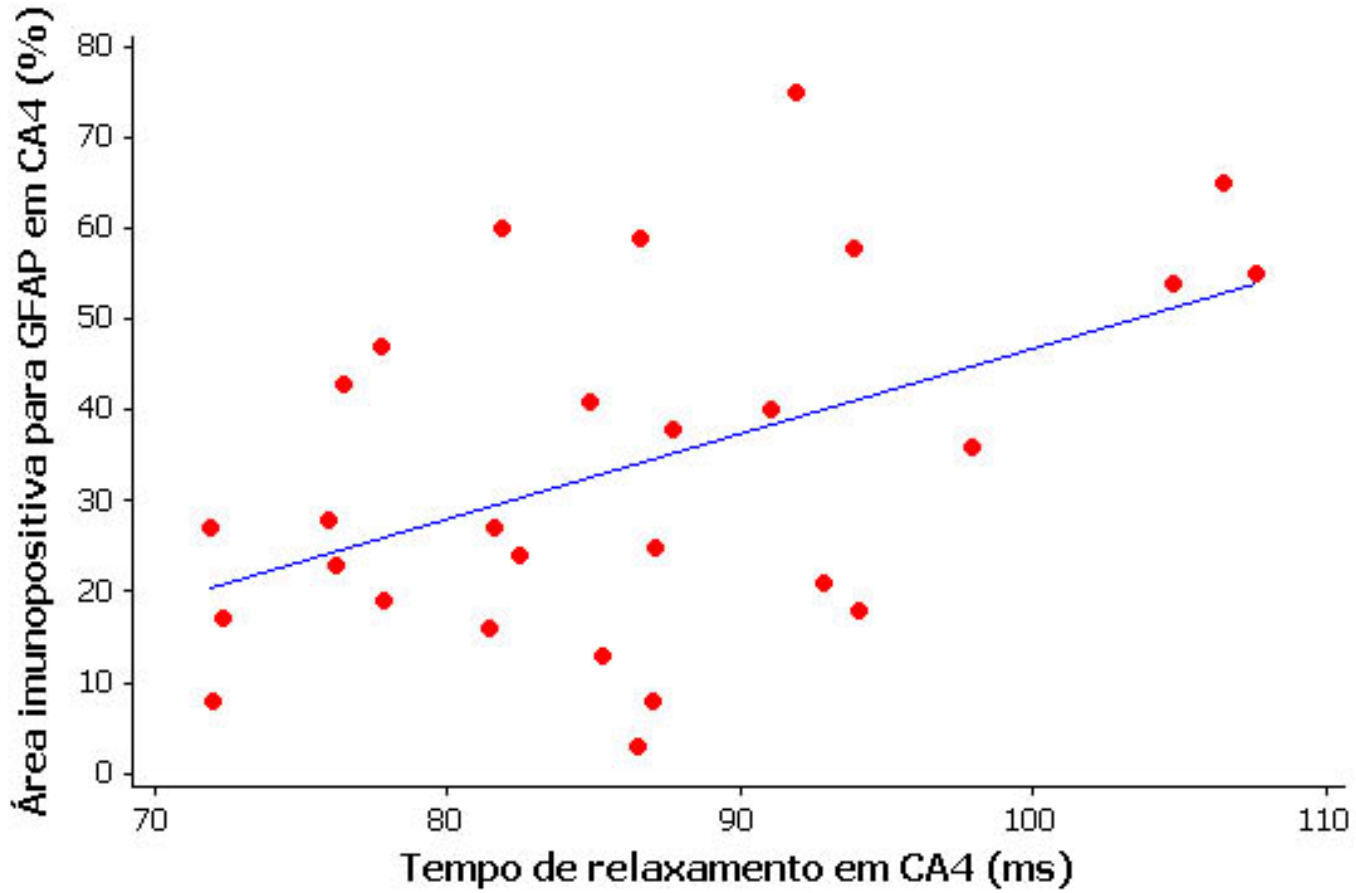

Figura 46. Gráfico de pontos com regressão linear entre o tempo de relaxamento em CA4 e a área imunopositiva para GFAP em CA4. Teste de Spearman, $\mathrm{R}^{2}=0,147 ; \mathrm{p}=0,0444 ; \mathrm{n}=28$. 


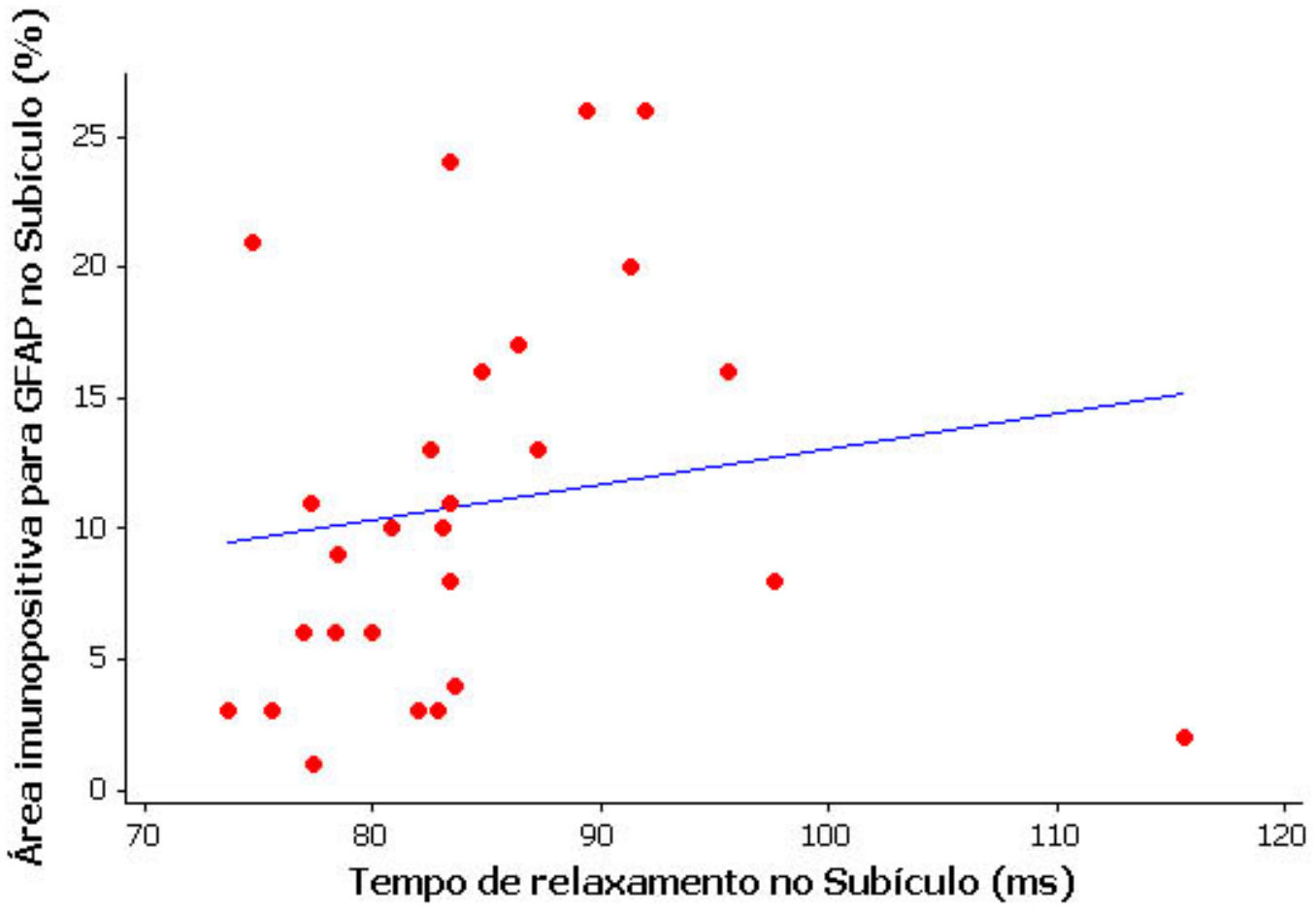

Figura 47. Gráfico de pontos com regressão linear entre o tempo de relaxamento no subículo e a área imunopositiva para GFAP no subículo. Teste de Spearman, $R^{2}=0,147 ; \mathrm{p}=0,0485 ; \mathrm{n}=27$.

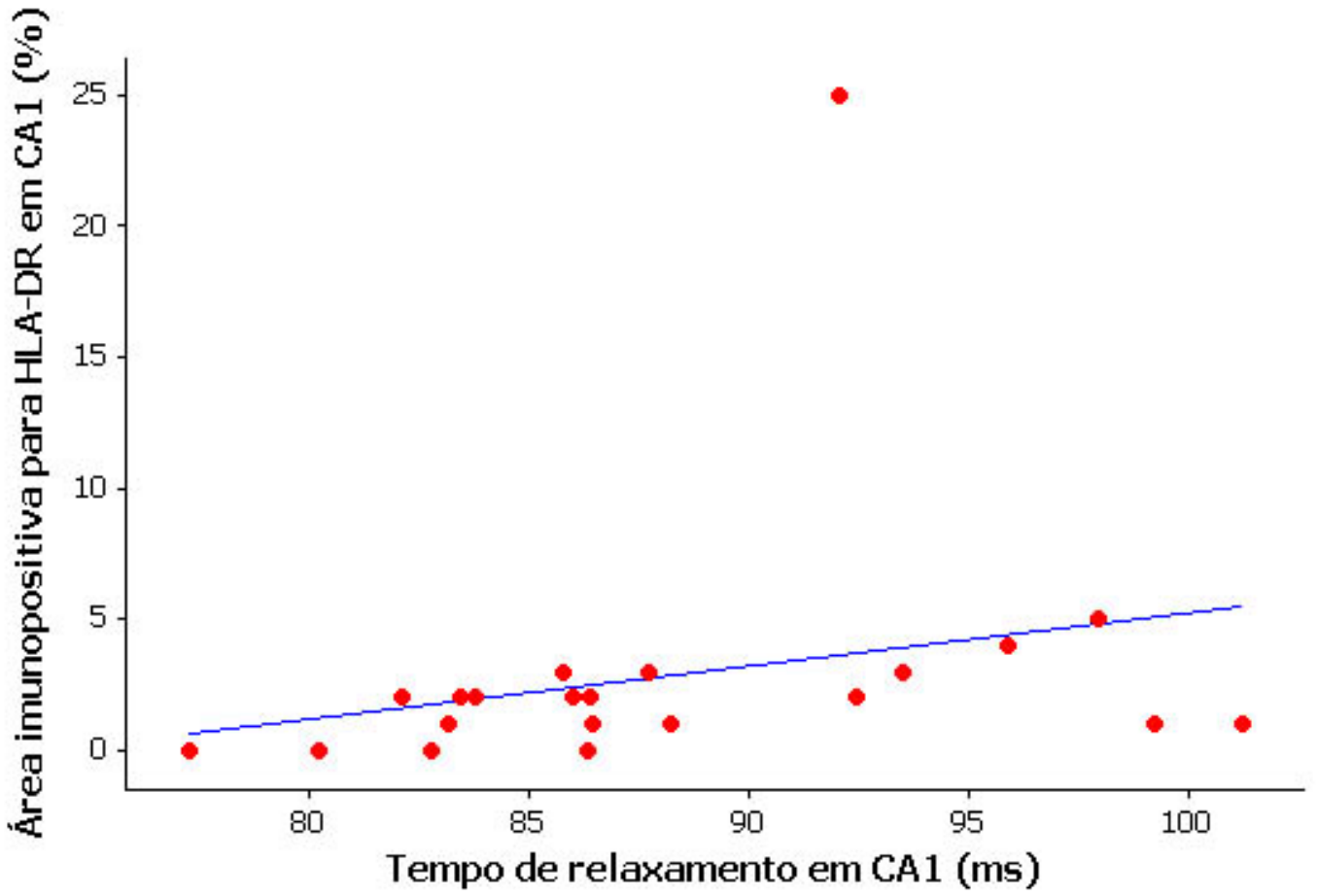

Figura 48. Gráfico de pontos com regressão linear entre o tempo de relaxamento em $\mathrm{CA} 1 \mathrm{e}$ a área imunopositiva para HLA-DR em CA1. Teste de Spearman, $R^{2}=0,203 ; p=0,0406 ; n=21$. 


\section{Variação no tempo de relaxamento, difusibilidade da água e alterações}

\section{histológicas em ELT}

Dada a diferença entre os valores do tempo de relaxamento in vivo e ex vivo, foi calculada a variação no tempo de relaxamento subtraindo-se o valor do tempo de relaxamento ex vivo do valor in vivo. Observou-se correlação positiva entre a variação no tempo de relaxamento e a difusibilidade da água, medida através de imagem por tensor de difusão $(\mathrm{R}=0,488 ; \mathrm{p}=0,0337)$ (Figura 49). A variação no tempo de relaxamento correlacionou-se positivamente com a área imunopositiva para CS-56 na camada molecular interna $(\mathrm{R}=0,477 ; \mathrm{p}=0,0382)$ e no hilo $(\mathrm{R}=0,487 ; \mathrm{p}=0,0291)$ (Figuras 50).

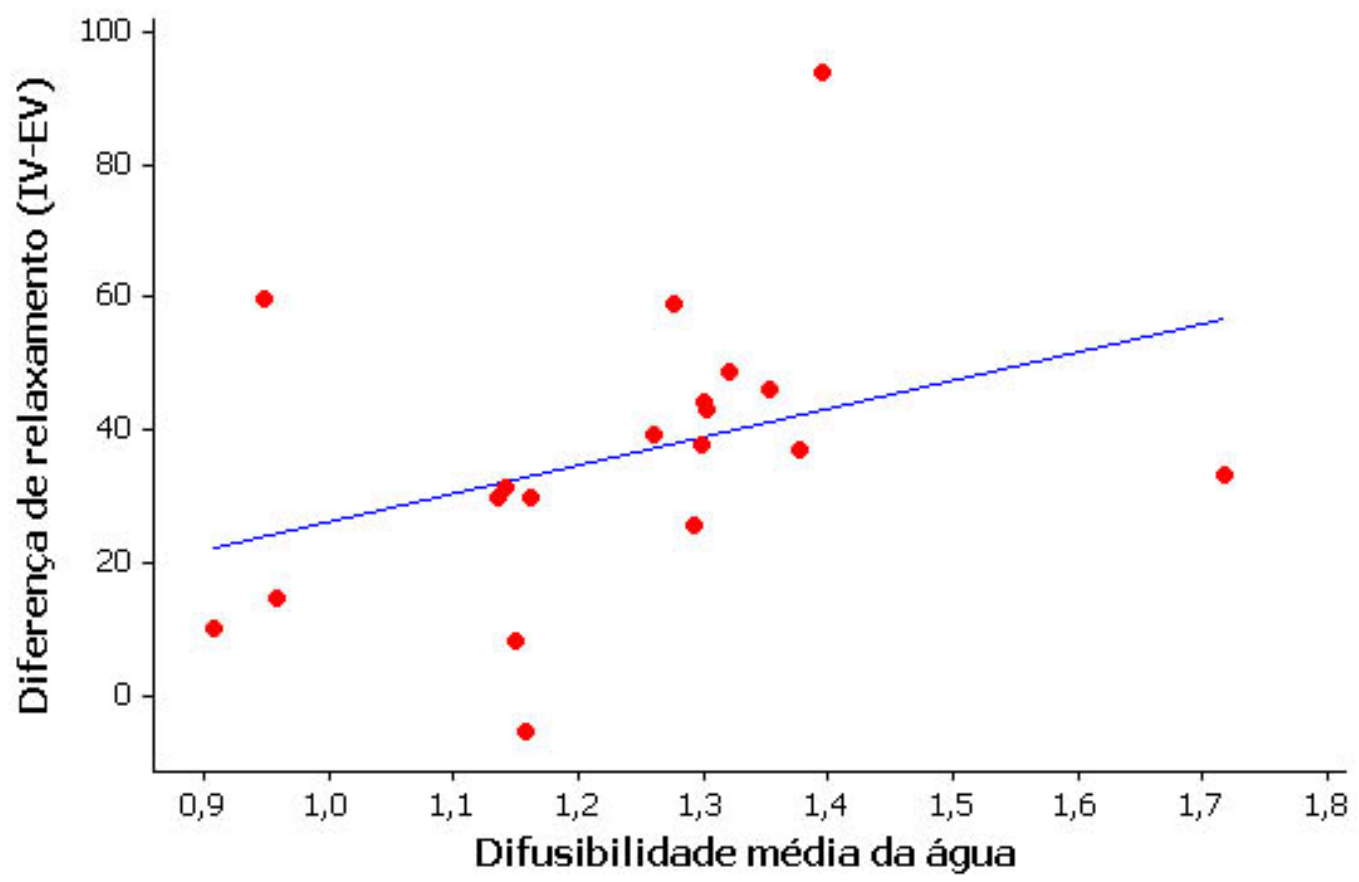

Figura 49. Gráfico de pontos com regressão linear entre a variação no tempo de relaxamento hipocampal e difusibilidade média da água. Teste de Spearman, $R^{2}=0,238 ; p=0,0337 ; n=19$. 


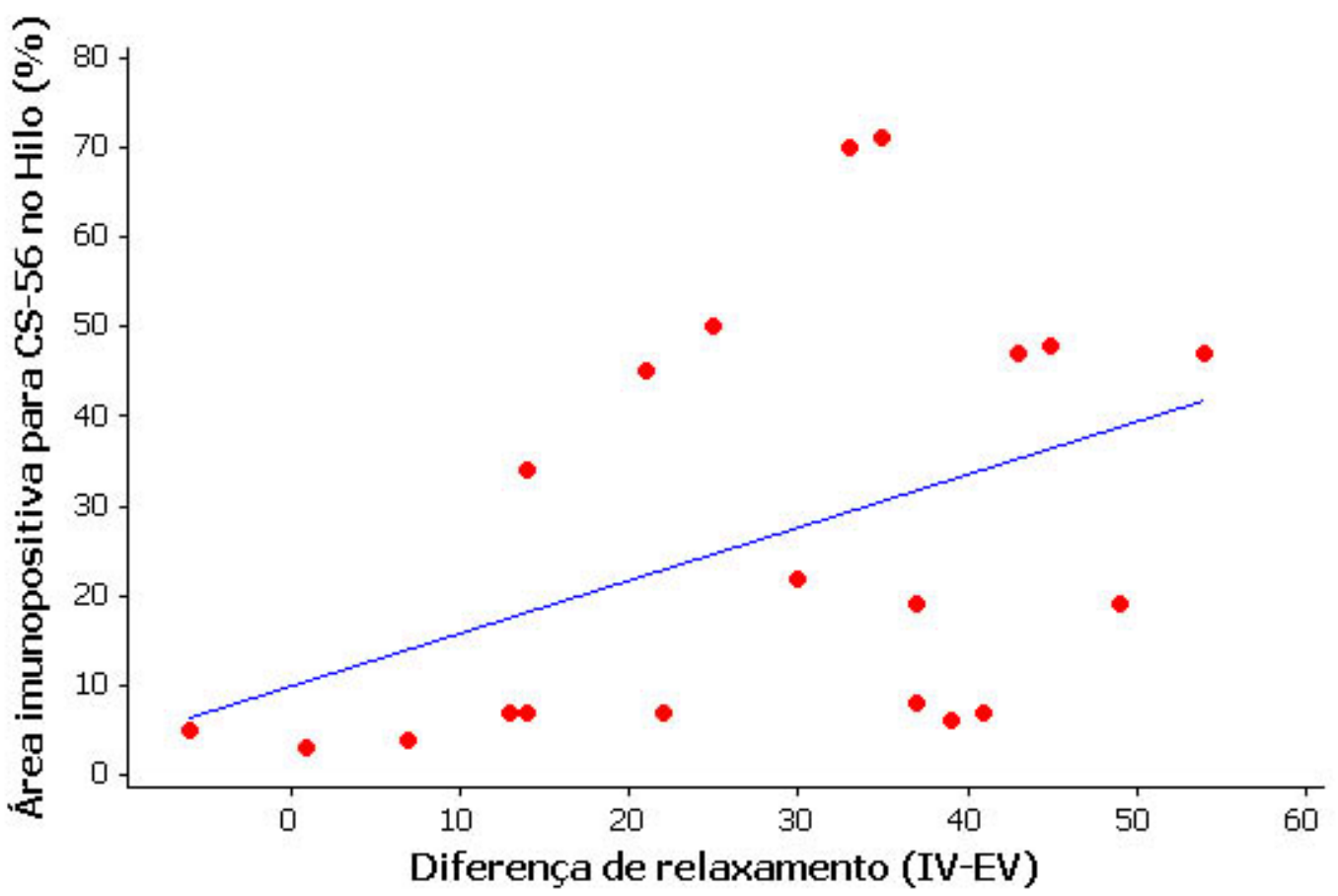

Figura 50. Gráfico de pontos com regressão linear entre a variação no tempo de relaxamento hipocampal e a área imunopositiva para sulfato de condroitina no hilo. Teste de Spearman, $R^{2}=0,228 ; p=0,0382 ; n=19$. 


\section{Discussão}

\section{Ressonância in vivo}

Em termos gerais, nossos achados estão de acordo com a literatura, que indica redução do volume hipocampal em imagens ponderadas em T1, aumento de tempo de relaxamento em imagens ponderadas em T2 e redução na taxa de transferência de magnetização nos pacientes com ELT (Berkovic et al., 1991; Cendes et al., 1993; Briellmann et al., 2002; Rugg-Gunn et al., 2003).

Em termos de localização do foco, observamos que a volumetria hipocampal, se analisada como índice de assimetria, é o melhor método para identificar o hipocampo associado à epileptogênese em casos com volume hipocampal de valores dentro da normalidade, indicando corretamente o foco em $85 \%$ dos casos, sendo seguida pelo tempo de relaxamento, com $59 \%$ de definição do foco, e pela taxa de transferência de magnetização, com 48\%. Estas observações concordam com a literatura, que indica a volumetria hipocampal como um ótimo método quantitativo para definir a lateralização do hipocampo epileptogênico (Cendes et al., 1997). Em relação à relaxometria, o aumento no tempo de relaxamento é observado em 74 a 100\% dos hipocampos escleróticos (Van Paesschen et al., 1997; Scott et al., 2003; Briellmann, Jackson, et al., 2004; Pell et al., 2004; Coan et al., 2006), valor próximo ao observado em nossos dados. Das imagens de RM avaliadas, a taxa de transferência de magnetização identificou o hipocampo epileptogênico em menos de $50 \%$ dos casos. Li e colaboradores (2000) indicaram que a transferência de magnetização acertou a lateralização hipocampal em apenas $10 \%$ dos casos de ELT unilateral, enquanto Tofts e colaboradores (1995) indicam grande correspondência entre redução 
da transferência de magnetização e a atrofia hipocampal. Nossos dados indicam um meio-termo entre os achados destes dois trabalhos.

\section{Ressonância ex vivo}

Estudos com ressonância ex vivo foram realizados em várias doenças do sistema nervoso (Schumann et al., 2001; Blezer et al., 2007; Sun et al., 2009; Schmierer et al., 2010; Siddique et al., 2010; Garbelli et al., 2011). Trabalhos ex vivo indicam que sinais de ressonância apresentam redução de seus valores como resultado da fixação do tecido (Blamire et al., 1999; Pfefferbaum et al., 2004; Blezer et al., 2007; Siddique et al., 2010) e que o decaimento do sinal cessa com uma semana de fixação (Blamire et al., 1999; Blezer et al., 2007). Nossos dados de relaxometria e transferência de magnetização ex vivo confirmaram esta redução de valores em relação aos exames in vivo. Apesar desta redução de sinal, dados de Garbelli e colaboradores (2011) e Rane e Duong (2011) indicam que uma boa fixação do tecido garante boa qualidade da imagem, e imagens ex vivo de tecidos com boa fixação podem até garantir melhores resultados que as imagens in vivo (Rane e Duong, 2011).

O tempo de relaxamento ex vivo indicou diferença entre os pacientes com ELT e o grupo CHR. Alterações em imagens ponderadas em T2 e na transferência de magnetização ex vivo foram relacionadas a alterações neuropatológicas teciduais em alguns estudos. $\mathrm{Na}$ esclerose múltipla, foi observada correspondência entre as alterações em T2 e transferência de magnetização e as lesões tanto da substância cinzenta (Schmierer et al., 2010) como da substância branca (Blezer et al., 2007). Em pacientes com ELT, foi observada alteração em imagens ponderadas em T2 em regiões com displasia cortical (Garbelli et al., 2011), e casos com borramento da transição entre as substâncias cinzenta e branca (Garbelli et al., 2012). 
Em relação à volumetria individual dos subcampos hipocampais, nossos dados indicam importante contribuição dos subcampos CA1, subículo e da fascia dentata (i.e., hilo, camada granular e camadas moleculares) sobre o volume da formação hipocampal. Vários estudos foram realizados de modo a observar a contribuição dos diferentes subcampos hipocampais, utilizando-se de várias metodologias de delimitação e definição de estruturas. Nas delimitações manuais, é comum a delimitação dos subcampos de acordo com Duvernoy (2005). Entretanto, Duvernoy não considera o prosubículo como subcampo. Como resultado, a região CA1 de Duvernoy engloba não apenas CA1 mas também o prosubículo e parte inicial do subículo, causando a superestimação do volume de CA1 e subestimação do volume subicular. Outro problema comum nos estudos dos subcampos em ressonância magnética é a definição dos subcampos na cabeça e cauda do hipocampo. Esta dificuldade leva alguns estudos, tanto manuais como de delimitação semiautomática, a avaliar os subcampos hipocampais apenas no corpo do hipocampo (Yushkevich et al., 2010; Mueller et al., 2011). Um outro problema é que muitos estudos adotam, para estas medidas, a fusão de vários subcampos, pela dificuldade em se definir bordas em imagens de ressonância clínicas (Van Leemput et al., 2009; Cole et al., 2010; La Joie et al., 2010; Malykhin et al., 2010; Neylan et al., 2010; Mueller et al., 2011; Lim et al., 2012; Francis et al., 2013; Huang et al., 2013; Li et al., 2013; Travis et al., 2014; Wisse et al., 2014). Finalmente, em relação aos estudos de delimitação automática, a grande maioria utiliza o algoritmo de Van Leemput, desenvolvido para o programa Freesurfer (Van Leemput et al., 2009; Lim et al., 2012; Francis et al., 2013; Li et al., 2013). Este algoritmo, entretanto, apresenta erros grosseiros na delimitação dos subcampos, diferindo das delimitações propostas por Duvernoy, Lorente de Nó ou Gloor (Lorente De Nó, 1934; Gloor, 1997; Duvernoy, 2005). Como 
resultado, o algoritmo de Van Leemput indica que as regiões CA3 e CA2, que são agrupadas pela análise em uma região única, apresentam um volume três vezes maior que a região CA1. A razão desta discrepância deve-se ao fato da região $\mathrm{CA} 3+\mathrm{CA} 2$ delimitada automaticamente pelo algoritmo englobar porções significantes de CA1. De todos os estudos, nossos dados se assemelham mais aos achados do grupo de Malykhin (Malykhin et al., 2010; Huang et al., 2013; Travis et al., 2014). Estes estudos analisam o hipocampo como fascia dentata, corno de Amon e subículo, indicando volumes entre 1,281 e 0,791 para a fascia dentata, 1,713 e 1,115 para o corno de Amon e 0,790 e 0,574 para o subículo. Realizando o mesmo agrupamento em nossos dados, obtivemos 0,680 para a fascia dentata, 1,240 para o corno de Amon e 0,920 para o subículo.

\section{Comparação entre ressonância in vivo e ex vivo}

Em geral, a literatura mostra que os exames ex vivo seguem o mesmo padrão dos exames in vivo (Gupta et al., 2001; Blezer et al., 2007; Kim et al., 2007; Siddique et al., 2010) mas raramente é realizada correlação entre os resultados in vivo e ex vivo. Blezer e colaboradores (2007) observaram correlação entre os valores de transferência de magnetização in vivo e ex vivo, mas não entre tempo de relaxamento in vivo e ex vivo.

Nos exames in vivo, tanto características estruturais (i.e., matriz extracelular, populações celulares, mielinização) quanto características funcionais (água tecidual, crises, etc) afetam as imagens de RM (Van Paesschen et al., 1997; Namer et al., 1998; Scott et al., 2002; Fabene et al., 2006; Blezer et al., 2007; Parekh et al., 2010). Nos exames ex vivo, entretanto, apenas as características estruturais estão presentes e afetam o sinal. Deste modo, é possível que a perda dos componentes teciduais 
dinâmicos com a fixação, além da alteração na microestrutura tecidual causada pela fixação (Fagan et al., 2008), podem ser responsáveis pela falta de correlação entre os exames in vivo e ex vivo.

Visando avaliar os possíveis componentes dinâmicos, como a água livre que hidrata o tecido, que afetem o tempo de relaxamento, calculamos a variação de tempo de relaxamento (delta relaxamento) dos pacientes com ELT avaliados. Observamos correlação positiva entre o delta relaxamento e os níveis de sulfato de condroitina no hilo e na camada molecular, indicando que esta molécula de matriz tem importante contribuição na manutenção da água no parênquima cerebral vivo. Ainda observamos correlação positiva entre uma maior diferença entre os dois tempos de relaxamento e a difusibilidade da água no tecido, medida com exame in vivo. Uma vez que os casos com maior difusibilidade apresentaram maior diferença entre o relaxamento in vivo e o ex vivo, acreditamos que nestes pacientes com maior volume havia maior quantidade de água tecidual. Tanto a redução da tortuosidade do espaço extracelular, devido à perda celular, quanto a presença de edema vasogênico (causado por abertura da barreira hematoencefálica) produzem aumento da difusibilidade cerebral (Van Putten et al., 2005). Dado que crises podem promover a abertura da barreira hematoencefálica e permitir o extravasamento de plasma sanguíneo no parênquima (Van Vliet et al., 2007), é possível que este edema afete a difusibilidade e promova um aumento no tempo de relaxamento observado pelo exame in vivo.

Fagan e colaboradores (2008) mostraram queda de sinal T2 nas primeiras 24 horas post mortem (hpm). Nas primeiras $10 \mathrm{hpm}$, esta queda acompanharia a queda de temperatura corporal, porém ela continua mesmo quando o corpo já apresenta temperatura estável. Deste modo, as alterações decorrentes da morte, provavelmente ligadas à desorganização tecidual por decomposição, afetam o sinal da imagem. Em 
contraposição, Schmierer e colaboradores (2010) observaram que a transferência de magnetização e o sinal T2 correlacionam-se com o tempo de fixação, não com o tempo entre a morte e a fixação. Além deste trabalho, Pfefferbaum e colaboradores (2004) não observaram diferenças qualitativas entre imagens ex vivo de um cérebro fixado após $6 \mathrm{hpm}$ e um fixado após $24 \mathrm{hpm}$. Como os pacientes do grupo CHR apresentam maior tempo entre a morte e a fixação do que o tempo entre cirurgia e fixação dos pacientes do grupo ELT (238 versus 30 minutos, respectivamente), realizamos teste de correlação para observar o efeito do tempo entre a morte e o início da fixação e os sinais de ressonância. Em concordância com os achados de Schmierer e colaboradores (2010), não houve correlação entre o tempo de relaxamento ex vivo e o tempo entre morte e o início da fixação $(p=0,782)$ ou entre este tempo e a transferência de magnetização ex vivo $(\mathrm{P}=0,194)$.

\section{Ressonância magnética e as alterações teciduais hipocampais}

\section{População neuronal}

Como comentado anteriormente, a perda neuronal é uma das principais alterações histológicas presentes no hipocampo de pacientes com ELT. Nossos achados de perda neuronal intensa em prosubículo, CA1, CA3, CA4 e Hilo, perda moderada na camada granular e CA2 e preservação do subículo estão de acordo com os dados de trabalhos de outros centros (Margerison e Corsellis, 1966; Babb et al., 1984; Babb et al., 1991; Mathern et al., 1996).

Em geral, estudos com RM indicam que a perda neuronal está ligada à redução no volume hipocampal. Briellmann e colaboradores (2002) observaram correlação entre o volume hipocampal e a camada granular, enquanto Van Paesschen e 
colaboradores (1997) e Kuzniecky e colaboradores (2001) apontaram correlações significativas entre as alterações patológicas no Corno de Amon e o volume hipocampal. Diehl e colaboradores (2002) observaram correlações entre o volume hipocampal e a gravidade da perda neuronal tanto na camada granular como em CA1. Em estudo anterior, observamos correlações entre o volume hipocampal e a densidade neuronal em CA1 e no prosubículo (artigo submetido, ver Anexo II). Na casuística atual, observamos correlação entre densidade neuronal em CA3 e o volume hipocampal, corroborando a importância da densidade neuronal para o volume hipocampal medido em imagens de RM.

Observamos correlação negativa entre o tempo de relaxamento ex vivo e a densidade neuronal apenas na região CA3. Estudos indicaram tanto uma correlação forte (Van Paesschen et al., 1997) quanto a ausência de correlação (Briellmann et al., 2002) entre a população neuronal em CA1 e o tempo de relaxamento in vivo. Eriksson e colaboradores (2007) observaram, no córtex temporal de pacientes com ELT, correlação negativa entre a densidade neuronal e o sinal T2. Uma vez que a intensidade da perda neuronal está diretamente ligada à severidade da gliose, e que a maioria dos estudos associa gliose e relaxamento T2, é possível que a correlação negativa entre a densidade neuronal e o relaxamento observada por Van Paesschen e colaboradores (1997) e por Eriksson e colaboradores (2007) sejam um indício indireto que a gliose mais severa, que acompanha dano neuronal mais intensa, esteja associada ao aumento no tempo de relaxamento. Discutiremos com mais propriedade as associações entre gliose e tempo de relaxamento no tópico seguinte.

Quanto à taxa de transferência de magnetização, defende-se a correlação entre esta medida e a perda neuronal na ELT (Flugel et al., 2006). Estudos post mortem em casos de esclerose múltipla indicaram que não apenas a perda da mielina, mas 
também a redução na densidade axonal, estão associados à redução na transferência de magnetização (Van Waesberghe et al., 1999; Mottershead et al., 2003; Fisher et al., 2007). Segundo dados de Mottershead e colaboradores (2003), a densidade axonal contribui de forma mais importante para a transferência de magnetização do que a mielinização. Um estudo com modelo de encefalomielite autoimune indicou que a redução na transferência de magnetização é maior na região onde há perda neuronal associada à desmielinização do que na zona onde só ocorre desmielinização (Rausch et al., 2009). Em um estudo com córtex temporal de pacientes com ELT, não foi observada nenhuma correlação entre a população neuronal e a transferência de magnetização (Eriksson et al., 2007). Observamos correlação significante entre a densidade neuronal em CA3 e a transferência de magnetização nos pacientes com ELT, indicando que a população neuronal é importante para a transferência de magnetização.

\section{Gliose}

Observamos reação astroglial e ativação microglial em todas as regiões da formação hipocampal dos pacientes com ELT. A gliose é comumente observada na esclerose hipocampal (Van Paesschen et al., 1997; Salanova et al., 1999; Crespel et al., 2002; Swartz et al., 2006; Prayson e Yoder, 2007; Choi e Koh, 2008). Imediatamente após um insulto, as micróglias em repouso passam por processo de ativação, aumentando seu grau de ramificação e expressando moléculas de reconhecimento de antígenos e várias moléculas pró e anti-inflamatórias (Drage et al., 2002; Bonde et al., 2006; Choi e Koh, 2008). Em sequência, a população astroglial sofre processo hiperplasia e hipertrofia na área de dano, gerando uma rede altamente 
emaranhada de processos astrocíticos interligados por junções comunicantes (Khurgel e Ivy, 1996; Fawcett e Asher, 1999; Crespel et al., 2002; Silver e Miller, 2004; Martinian et al., 2009).

Em geral, as regiões com maior redução na densidade neuronal apresentaram maiores níveis de reação astroglial. Crespel e colaboradores (2002) observaram maior grau de reação astroglial na região CA1, onde houve perda neuronal mais grave, e no hilo apenas dos casos onde havia morte neuronal em CA4, indicando assim que a reação astroglial segue a gravidade da perda neuronal. Entretanto, também observamos astrogliose significativa no subículo, região onde não houve perda neuronal. Uma vez que estudos com abrasamento indicam ligação entre intensidade das crises e intensidade da reação astroglial (Khurgel e Ivy, 1996) e que o camundongo EL apresenta gliose mas não perda neuronal ou brotamento axonal (Drage et al., 2002), a presença de gliose no subículo deve estar relacionada às crises epilépticas apresentadas pelos pacientes com ELT.

Observamos correlações entre a astrogliose e o tempo de relaxamento nos pacientes com ELT. Apesar de amplamente defendida, poucos trabalhos apresentaram correlação entre o tempo de relaxamento e a gliose. Em um estudo que avaliou a gravidade da esclerose hipocampal, através de razão glia/neurônio, houve a indicação de que a gravidade da esclerose em CA1 e no hilo correlaciona-se positivamente com o aumento do tempo de relaxamento (Van Paesschen et al., 1997). Quanto avaliadas separadamente, porém, a população neuronal apresentou maior correlação com a relaxometria do que a população glial (Van Paesschen et al., 1997). Outro estudo (Briellmann et al., 2002) observou correlação positiva entre a população glial na camada granular e o sinal T2, mas não correlação com a população glial em CA1. De modo similar, nosso exame in vivo indicou correlação entre o tempo de relaxamento e 
a astrogliose no subículo. No exame ex vivo dos pacientes com ELT, entretanto, observamos correlações não apenas entre o tempo de relaxamento e a astrogliose no subículo mas também entre o relaxamento T2 e a astrogliose nas camadas moleculares da fascia dentata, na zona subgranular, no hilo e em CA4. No exame ex vivo, a maior qualidade anatômica das imagens permitiu a subdivisão do hipocampo em seus subcampos. Conforme ficou evidenciado, tanto o aumento no tempo de relaxamento como a gliose observadas na ELT não são homogêneos em todos os subcampos do hipocampo. Deste modo, a subdivisão permitiu relacionar diretamente o tempo de relaxamento à respectiva alteração tecidual observada em cada subcampo, conferindo maior associação entre a patologia e a respectiva alteração no sinal de RM.

Em relação às micróglias ativadas, observamos aumento significativo em todos os subcampos hipocampais exceto no subículo. Estudos indicam que, na ELT, a ativação microglial precede a morte neuronal (Jansson et al., 2009) e as micróglias podem permanecer ativadas por tempo prolongado (Jansson et al., 2009; Kirkman et al., 2010; Yang et al., 2010). Nossa avaliação da ativação microglial foi realizada com anticorpo anti-HLA-DR. Este anticorpo, além de marcar micróglias ativadas, pode marcar endotélio de capilares. Por isto, tivemos especial cuidado em não incluir vasos imunopositivos em nossas áreas amostrais.

Nos estudos de neuroimagem, a ativação microglial é geralmente estudada por tomografia por emissão de pósitrons (PET) com uso do radiofármaco ${ }^{11} \mathrm{C}-\mathrm{PK} 11195$, um ligante específico do receptor benzodiazepínico periférico, que está presente apenas em micróglias ativadas (Banati et al., 2000). Estes estudos apontam que a marcação pelo radiofármaco tem boa correspondência com áreas com presença de gliose (Kumar et al., 2008), porém a correspondência com alterações observadas em RM é parcial (Banati et al., 1999) ou mesmo inexistente (Kumar et al., 2008; 
Doorduin et al., 2009). Estudos visando avaliar a associação entre micróglias ativadas e sinal T2, até o momento, apresentam achados discrepantes. Hipersinal T2 foi observado em lesões na substância branca de pacientes idosos. Todas as lesões apresentaram perda de mielina, porém apenas algumas apresentaram micróglias ativadas e nenhuma apresentou astrogliose (Simpson et al., 2007). Enquanto um estudo com ratos Wistar submetidos à isquemia indica associação entre hiposinal T2 e astrogliose e microgliose (Fujioka et al., 1999), outro não observou nenhuma sobreposição entre a distribuição temporal de micróglias ativadas e as alterações na RM (Schroeter et al., 2001). Camundongos com predisposição genética para a formação de depósitos de proteína amiloide apresentaram micróglias ativadas nas regiões de depósito e queda do sinal T2 (Teipel et al., 2011). Apesar de ratos SpragueDawley submetidos à trauma encefálico apresentarem astrogliose e microgliose na região do trauma, houve aumento de sinal T2 nos animais cujo trauma foi causado por impacto cortical e redução do sinal naqueles cujo trauma se deu por percussão de fluido (Obenaus et al., 2007). Estudo com ratos submetidos às crises por cainato indicaram ligação entre presença de microgliose e aumento do sinal T2 (Wolf et al., 2002; Luna-Medina et al., 2007). Em modelo experimental de esclerose múltipla, observou-se correlação positiva entre astrogliose e microgliose perilesional e o sinal T2 (Nessler et al., 2007). Observamos correlação positiva entre o tempo de relaxamento ex vivo e a área imunopositiva para HLA-DR em CA1, reforçando a importância da gliose para o aumento de sinal T2 no hipocampo dos pacientes com ELT.

Ainda sobre a gliose e o tempo de relaxamento, apesar de a maioria dos pacientes com ELTM e esclerose hipocampal na histologia também apresentarem aumento no tempo de relaxamento, alguns pacientes com esclerose apresentam 
relaxamento dentro dos padrões normais (Van Paesschen et al 1997; Scott et al, 2003). Ademais, apesar de tanto pacientes com ELT como pacientes com doença de Alzheimer apresentarem gliose no hipocampo, apenas os primeiros possuem tempo de relaxamento hipocampal significantemente acima dos valores considerados normais (Pitkanen et al., 1996). Em um estudo sobre alterações no polo temporal, gliose foi observada tanto nos casos com aumento de sinal nas imagens com TR longo como nos casos sem alteração, sendo que os casos com aumento de sinal a gliose era mais conspícua (Mitchell et al., 1999). Portanto, é possível que seja necessário um grau mínimo de gliose para que esta impacte significantemente o tempo de relaxamento.

\section{Aquaporina 4}

Observamos redução de AQP4 perivascular em algumas regiões do hipocampo de pacientes com ELT. Em condições fisiológicas, a AQP4 é expressa por astrócitos, sendo concentrada em grandes agrupamentos na membrana astrocítica que envolve vasos e forma a glia limitans (Rash et al., 1998). Estudos mostraram que, nos casos de ELT com esclerose hipocampal, há aumento da expressão da AQP4, acompanhando a gravidade da reação astroglial (Lee et al., 2004; Eid et al., 2005). Entretanto, este aumento da expressão de AQP4 é acompanhado pela perda de sua polarização, ocorrendo diminuição dos níveis de AQP4 perivascular e um aumento geral na presença desta proteína por toda a superfície astroglial e, por conseguinte, por toda a área de gliose (Eid et al., 2005). Estudos em animais nocaute para a-sintrofina, proteína importante para a polarização da AQP4 nos pés perivasculares, indicam que a perda da polaridade da AQP4 leva à alteração na homeostase da água e de íons potássio (Amiry-Moghaddam et al., 2003). Assim, a alteração nos níveis de expressão 
e na localização celular da AQP4 na epilepsia pode ser importante para a excitabilidade exacerbada encontrada no foco epileptogênico.

Em neuroimagem, estudos tentaram avaliar a associação entre a AQP4 e alterações no sinal T2 e no coeficiente de difusão aparente. Estudos em modelos de isquemia indicaram aumento da expressão de AQP4, aumento de sinal T2 e redução do coeficiente de difusão aparente (Meng et al., 2004; Badaut et al., 2007). Um estudo com modelo de glioma em ratas Fischer indicou que, entre a gliose e o aumento de AQP4, esta última foi a alteração que melhor se sobrepôs as áreas com aumento de sinal T2 (Engelhorn et al., 2009). Por outro lado, animais nocaute para AQP4 submetidos à status por cainato apresentam aumento de sinal T2 na mesma proporção dos animais selvagens, porém este aumento é mais lento (Lee et al., 2012). Outros dois estudos não observaram nenhuma possível ligação entre a expressão de AQP4 e o sinal T2 (Fukuda et al., 2012; Wachter et al., 2012). Uma vez que o sinal T2 é afetado por edema, nossa hipótese era que a alteração na expressão de AQP4 contribuiria para o aumento do sinal hipocampal. Nossos dados, entretanto, não indicaram nenhuma associação entre a expressão de AQP4 e o tempo de relaxamento em T2 ou a transferência de magnetização in vivo. Uma vez que estudos animais indicam a formação de edema após crises graves (Binder et al., 2004; Van Vliet et al., 2007; Lee et al., 2012), é possível que a influência da AQP4 sobre o sinal T2 ocorra logo no pós crise, e que o sinal T2 que está constantemente aumentado nos pacientes seja relacionado mais diretamente à gliose, como evidenciado pelos nossos achados e por estudos publicados por outros grupos. 


\section{Sulfato de Condroitina}

Com exceção da camada granular e do subículo, observamos aumento significativo dos níveis de sulfato de condroitina em todos os subcampos da formação hipocampal dos pacientes com ELT, quanto comparados ao CHR. O aumento de sulfato de condroitina já foi relatado em pacientes com ELT (Perosa et al., 2002) e em modelos de crises epileptiformes (Schwarzacher et al., 2006). Dentre os fatores que podem levar ao aumento dos níveis de sulfato de condroitina, estudos apontam neurotransmissores, citocinas e fatores de crescimento (Stichel et al., 1995; Smith e Strunz, 2005; Yin et al., 2009; Pantazopoulos et al., 2010), sendo que os astrócitos e as micróglias são as principais células produtoras da matriz extracelular (Fawcett e Asher, 1999; Yin et al., 2009).

Em geral, estudos sobre matriz extracelular no sistema nervoso central focam na interação entre níveis de diferentes moléculas e a plasticidade tecidual (Silver e Miller, 2004; Smith e Strunz, 2005; Huang et al., 2006; Yiu e He, 2006; Lin et al., 2008; Liu et al., 2008). Estudos indicam uma possível associação entre redução do coeficiente de difusão aparente do tecido e o aumento dos níveis de sulfato de condroitina (Roitbak e Sykova, 1999; Vorisek et al., 2002). Um estudo com neuroimagem ante e post mortem em fetos humanos observou que a intensidade do sinal T2 na zona intermediária apresentou tendência à correlação positiva com a idade fetal (Widjaja et al., 2010). Nesta mesma região, os proteoglicanos apresentam dinâmica de aumento semelhante ao do sinal (i.e., aumentam com a idade). Entretanto, nenhuma correlação entre histologia e neuroimagem foi avaliada no estudo. Por outro lado, na subplaca cortical os níveis de proteoglicanos reduzem com a idade, enquanto que o sinal T2 continua a manter uma correlação positiva com a idade fetal (Widjaja et al., 2010). Outros estudos associaram os níveis de moléculas 
de matriz a alterações no sinal T2. Estudos com fantomas indicaram correlação inversa entre os níveis de sulfato de condroitina e o sinal T2 (Laurent et al., 2001). Em cartilagem umeral de porcos, a degradação de proteoglicanos promove redução do sinal T2 (Toffanin et al., 2001). Tertti e colaboradores (1991) observaram que discos intervertebrais com menores níveis de sulfato de condroitina apresentaram menor sinal T2. Nossos dados indicaram correlação positiva entre o tempo de relaxamento in vivo e os níveis de sulfato de condroitina no hilo, e entre a diferença do tempo de relaxamento e os níveis de sulfato de condroitina no hilo e na camada molecular, indicando que moléculas de matriz influenciam imagens ponderadas em T2.

Em relação à transferência de magnetização, observamos correlações positivas com os níveis de sulfato de condroitina em todos os subcampos do corno de Amon (CA4 a CA1) e no subículo. A relação entre proteoglicanos e a transferência de magnetização foi estudada principalmente em trabalhos que visaram definir estágios iniciais de danos em cartilagens, e produziram resultados conflitantes. Seo e colaboradores (1996), estudando fantomas com diferentes concentrações de sulfato de condroitina ou colágeno, observaram que apenas o colágeno, mas não o sulfato de condroitina, apresentava correlação com alterações na transferência de magnetização. Wachsmuth e colaboradores (1997) observaram correlação negativa entre a transferência de magnetização e os níveis de ácido hialurônico em cartilagens bovinas tratadas com hialuronidase. Contrário aos achados de Seo e colaboradores, Laurent e colaboradores (2001) observaram que a concentração de sulfato de condroitina em fantomas afeta a transferência de magnetização, sendo que quanto maior a concentração deste proteoglicano, maior é a transferência de magnetização. Apoiando este efeito dos proteoglicanos sobre a transferência de magnetização, a remoção de proteoglicanos de cartilagem umeral de porcos promoveu redução da transferência de 
magnetização. Nossos dados indicam que o proteoglicano sulfato de condroitina tem importante papel sobre o sinal de transferência de magnetização no hipocampo de pacientes com ELT.

Finalmente, observamos correlações positivas entre o volume hipocampal e os níveis de sulfato de condroitina em CA3, CA2 e CA1. Uma vez que a matriz extracelular constitui até $20 \%$ do volume do parênquima cerebral e é rica em sulfato de condroitina (Davson e Spaziani, 1959; Sykova, 2004; Vitellaro-Zuccarello et al., 2005), o aumento nos níveis desta molécula impactariam o volume hipocampal. Em nossos estudos prévios (dado submetido para publicação, veja artigo em anexo), realizados em uma casuística sem sobreposição com a do atual trabalho, também observamos correlação entre os níveis de sulfato de condroitina em CA1 e o volume hipocampal. Assim, reafirmamos a importância do sulfato de condroitina para a manutenção do volume hipocampal em pacientes com ELT. 


\section{Conclusões}

Nossos dados ex vivo mostraram concordância parcial com as imagens correspondentes in vivo, indicando que as alterações patológicas existentes em pacientes com ELT podem ser estudadas com ressonância ex vivo. Adicionalmente, a grande qualidade das imagens ex vivo permitiu correlações mais diretas entre alterações patológicas teciduais estruturais e imagens de ressonância magnética.

As correlações observadas entre patologia e o tempo de relaxamento in vivo e ex vivo indicam que alterações tanto funcionais como estruturais afetam o sinal T2 no hipocampo dos pacientes com ELT. Em especial, astrogliose e os níveis de sulfato de condroitina parecem ter uma associação mais próxima com o tempo de relaxamento $\mathrm{T} 2$, enquanto que apenas sulfato de condroitina e densidade neuronal correlacionaram-se com a transferência de magnetização. 


\section{Referências Bibliográficas}

ABERCROMBIE, M. Estimation of nuclear population from microtome sections. Anat Rec, v. 94, p. 239-47, Feb 1946.

AMARAL, D. G.; INSAUSTI, R. Hippocampal Formation. In: (Ed.). The Human Nervous System. San Diego: Academic Press, 1990. cap. 21, p.711-756.

AMIRY-MOGHADDAM, M. et al. Delayed K+ clearance associated with aquaporin-4 mislocalization: phenotypic defects in brains of alpha-syntrophinnull mice. Proc Natl Acad Sci U S A, v. 100, n. 23, p. 13615-20, Nov 112003.

BABB, T. L. et al. Temporal lobe volumetric cell densities in temporal lobe epilepsy. Epilepsia, v. 25, n. 6, p. 729-40, Dec 1984.

BABB, T. L. et al. Synaptic reorganization by mossy fibers in human epileptic fascia dentata. Neuroscience, v. 42, n. 2, p. 351-63, 1991.

BADAUT, J. et al. Temporal and regional evolution of aquaporin-4 expression and magnetic resonance imaging in a rat pup model of neonatal stroke. Pediatr Res, v. 62, n. 3, p. 248-54, Sep 2007.

BAGARY, M. S. et al. Gray and white matter brain abnormalities in first-episode schizophrenia inferred from magnetization transfer imaging. Arch Gen Psychiatry, v. 60, n. 8, p. 779-88, Aug 2003.

BANATI, R. B. et al. [11C](R)-PK11195 positron emission tomography imaging of activated microglia in vivo in Rasmussen's encephalitis. Neurology, v. 53, n. 9, p. 2199-203, Dec 101999.

BANATI, R. B. et al. The peripheral benzodiazepine binding site in the brain in multiple sclerosis: quantitative in vivo imaging of microglia as a measure of disease activity. Brain, v. 123 ( Pt 11), p. 2321-37, Nov 2000.

BENKOVIC, S. A.; O'CALlAGHAN, J. P.; MILlER, D. B. Regional neuropathology following kainic acid intoxication in adult and aged C57BL/6J mice. Brain Res, v. 1070, n. 1, p. 215-31, Jan 272006.

BERKOVIC, S. F. et al. Hippocampal sclerosis in temporal lobe epilepsy demonstrated by magnetic resonance imaging. Ann Neurol, v. 29, n. 2, p. 17582, Feb 1991.

BERNASCONI, A. et al. T2 relaxometry can lateralize mesial temporal lobe epilepsy in patients with normal MRI. Neuroimage, v. 12, n. 6, p. 739-46, Dec 2000.

BINDER, D. K. et al. In vivo measurement of brain extracellular space diffusion by cortical surface photobleaching. J Neurosci, v. 24, n. 37, p. 8049-56, Sep 15 2004. 
BINDER, D. K.; STEINHAUSER, C. Functional changes in astroglial cells in epilepsy. Glia, v. 54, n. 5, p. 358-68, Oct 2006.

BLAMIRE, A. M. et al. Optimising imaging parameters for post mortem MR imaging of the human brain. Acta Radiol, v. 40, n. 6, p. 593-7, Nov 1999.

BLEZER, E. L. et al. Quantitative MRI-pathology correlations of brain white matter lesions developing in a non-human primate model of multiple sclerosis. NMR Biomed, v. 20, n. 2, p. 90-103, Apr 2007.

BLOCK, M. L.; ZECCA, L.; HONG, J. S. Microglia-mediated neurotoxicity: uncovering the molecular mechanisms. Nat Rev Neurosci, v. 8, n. 1, p. 57-69, Jan 2007.

BLUMCKE, I. et al. Defining clinico-neuropathological subtypes of mesial temporal lobe epilepsy with hippocampal sclerosis. Brain Pathol, v. 22, n. 3, p. 402-11, May 2012.

BLUMCKE, I. et al. A new clinico-pathological classification system for mesial temporal sclerosis. Acta Neuropathol, v. 113, n. 3, p. 235-44, Mar 2007.

BOER, K. et al. Evidence of activated microglia in focal cortical dysplasia. J Neuroimmunol, v. 173, n. 1-2, p. 188-95, Apr 2006.

BONDE, S.; EKDAHL, C. T.; LINDVALL, O. Long-term neuronal replacement in adult rat hippocampus after status epilepticus despite chronic inflammation. Eur J Neurosci, v. 23, n. 4, p. 965-74, Feb 2006.

BORGES, K. et al. Neuronal and glial pathological changes during epileptogenesis in the mouse pilocarpine model. Exp Neurol, v. 182, n. 1, p. 21-34, Jul 2003.

BRIELLMANN, R. S. et al. Structural abnormalities remote from the seizure focus: a study using T2 relaxometry at 3 T. Neurology, v. 63, n. 12, p. 2303-8, Dec 28 2004.

BRIELLMANN, R. S. et al. Hippocampal pathology in refractory temporal lobe epilepsy: T2-weighted signal change reflects dentate gliosis. Neurology, v. 58, n. 2, p. 265-71, Jan 222002.

BRIELLMANN, R. S. et al. Increased anterior temporal lobe T2 times in cases of hippocampal sclerosis: a multi-echo T2 relaxometry study at 3 T. AJNR Am J Neuroradiol, v. 25, n. 3, p. 389-94, Mar 2004.

BROWN, M. A.; SEMELKA, R. C. MRI Basic Principles and Applications. 3rd. Hoboken: John Wiley and Sons, 2003. 265 ISBN 0-471-43310-1.

CASCINO, G. D. Surgical treatment for epilepsy. Epilepsy Res, v. 60, n. 2-3, p. 17986, Jul-Aug 2004. 
CENDES, F. et al. Early childhood prolonged febrile convulsions, atrophy and sclerosis of mesial structures, and temporal lobe epilepsy: an MRI volumetric study. Neurology, v. 43, n. 6, p. 1083-7, Jun 1993.

CENDES, F. et al. Proton magnetic resonance spectroscopic imaging and magnetic resonance imaging volumetry in the lateralization of temporal lobe epilepsy: a series of 100 patients. Ann Neurol, v. 42, n. 5, p. 737-46, Nov 1997.

CHAKIR, A. et al. Drug resistance and hippocampal damage after delayed treatment of pilocarpine-induced epilepsy in the rat. Brain Res Bull, v. 71, n. 1-3, p. 12738, Dec 112006.

CHOI, J.; KOH, S. Role of brain inflammation in epileptogenesis. Yonsei Med J, v. 49, n. 1, p. 1-18, Feb 292008.

CHOI, J. et al. Cellular injury and neuroinflammation in children with chronic intractable epilepsy. J Neuroinflammation, v. 6, p. 38, 2009.

COAN, A. C. et al. T2-weighted and T2 relaxometry images in patients with medial temporal lobe epilepsy. J Neuroimaging, v. 16, n. 3, p. 260-5, Jul 2006.

COLE, J. et al. Subregional hippocampal deformations in major depressive disorder. J Affect Disord, v. 126, n. 1-2, p. 272-7, Oct 2010.

COSTA, C. et al. Mapping of aggrecan, hyaluronic acid, heparan sulphate proteoglycans and aquaporin 4 in the central nervous system of the mouse. J Chem Neuroanat, v. 33, n. 3, p. 111-23, May 2007.

CRANDALL, P. H. Cortical Resections. In: (Ed.). Surgical Treatment of the Epilepsies. New York: Raven Press, 1987. p.377-404.

CRESPEL, A. et al. Inflammatory reactions in human medial temporal lobe epilepsy with hippocampal sclerosis. Brain Res, v. 952, n. 2, p. 159-69, Oct 182002.

DAVSON, H.; SPAZIANI, E. The blood-brain barrier and the extracellular space of brain. J Physiol, v. 149, p. 135-43, Dec 1959.

DIEHL, B. et al. Interictal EEG, hippocampal atrophy, and cell densities in hippocampal sclerosis and hippocampal sclerosis associated with microscopic cortical dysplasia. J Clin Neurophysiol, v. 19, n. 2, p. 157-62, Apr 2002.

DOORDUIN, J. et al. Neuroinflammation in schizophrenia-related psychosis: a PET study. J Nucl Med, v. 50, n. 11, p. 1801-7, Nov 2009.

DRAGE, M. G.; HOLMES, G. L.; SEYFRIED, T. N. Hippocampal neurons and glia in epileptic EL mice. J Neurocytol, v. 31, n. 8-9, p. 681-92, Sep-Nov 2002.

DUVERNOY, H. M. The Human Hippocampus. Berlin: Springer-Verlag, 2005. ISBN 3-540-23191-9. 
EID, T. et al. Loss of perivascular aquaporin 4 may underlie deficient water and $\mathrm{K}+$ homeostasis in the human epileptogenic hippocampus. Proc Natl Acad Sci U S A, v. 102, n. 4, p. 1193-8, Jan 252005.

ENGEL, J., JR. Concepts of epilepsy. Epilepsia, v. 36 Suppl 1, p. S23-9, 1995.

ENGEL, J., JR.; CASCINO, G. P.; SHIELDS, W. D. Surgically Remediable Syndromes. In: (Ed.). Epilepsy: A Comprehensive Textbook. Philadelphia: Lippincott-Raven, 1997. p.1687-1696.

ENGEL J., J. Protocols for the University of California, Los Angeles. In: (Ed.). Surgical Treatment of the Epilepsies. New York: Raven Press, 1993. p.743745.

ENGEL J., J. L., M.; CRANDALL, P. H.; SHEWMAN, A.; RAUSH, R.; SUTULA, T. The Epilepsies. In: (Ed.). Principals of Neurosurgery. New York: Raven Press, 1991. p.319-358.

ENGELHORN, T. et al. Cellular characterization of the peritumoral edema zone in malignant brain tumors. Cancer Sci, v. 100, n. 10, p. 1856-62, Oct 2009.

ERIKSSON, S. H. et al. Correlation of quantitative MRI and neuropathology in epilepsy surgical resection specimens--T2 correlates with neuronal tissue in gray matter. Neuroimage, v. 37, n. 1, p. 48-55, Aug 12007.

FABENE, P. F. et al. Structural and functional MRI following 4-aminopyridineinduced seizures: a comparative imaging and anatomical study. Neurobiol Dis, v. 21, n. 1, p. 80-9, Jan 2006.

FAGAN, A. J. et al. Serial postmortem relaxometry in the normal rat brain and following stroke. J Magn Reson Imaging, v. 27, n. 3, p. 469-75, Mar 2008.

FALCONER, M. A. et al. Treatment of temporal-lobe epilepsy by temporal lobectomy; a survey of findings and results. Lancet, v. 268, n. 6869, p. 827-35, Apr 231955.

FAWCETT, J. W.; ASHER, R. A. The glial scar and central nervous system repair. Brain Res Bull, v. 49, n. 6, p. 377-91, Aug 1999.

FISHER, E. et al. Imaging correlates of axonal swelling in chronic multiple sclerosis brains. Ann Neurol, v. 62, n. 3, p. 219-28, Sep 2007.

FLUGEL, D. et al. A neuropsychological study of patients with temporal lobe epilepsy and chronic interictal psychosis. Epilepsy Res, v. 71, n. 2-3, p. 117-28, Oct 2006.

FOONG, J. et al. Neuropathological abnormalities in schizophrenia: evidence from magnetization transfer imaging. Brain, v. 124, n. Pt 5, p. 882-92, May 2001. 
FRANCIS, A. N. et al. Reduced subicular subdivisions of the hippocampal formation and verbal declarative memory impairments in young relatives at risk for schizophrenia. Schizophr Res, v. 151, n. 1-3, p. 154-7, Dec 2013.

FRENCH, J. A. et al. Characteristics of medial temporal lobe epilepsy: I. Results of history and physical examination. Ann Neurol, v. 34, n. 6, p. 774-80, Dec 1993.

FUJIOKA, M. et al. Novel brain ischemic change on MRI. Delayed ischemic hyperintensity on T1-weighted images and selective neuronal death in the caudoputamen of rats after brief focal ischemia. Stroke, v. 30, n. 5, p. 1043-6, May 1999.

FUKUDA, A. M. et al. Delayed increase of astrocytic aquaporin 4 after juvenile traumatic brain injury: possible role in edema resolution? Neuroscience, v. 222, p. 366-78, Oct 112012.

FURMAN, C. S. et al. Aquaporin-4 square array assembly: opposing actions of M1 and M23 isoforms. Proc Natl Acad Sci U S A, v. 100, n. 23, p. 13609-14, Nov 112003.

GALTREY, C. M.; FAWCETT, J. W. The role of chondroitin sulfate proteoglycans in regeneration and plasticity in the central nervous system. Brain Res Rev, v. 54, n. 1, p. 1-18, Apr 2007.

GARBELLI, R. et al. Blurring in patients with temporal lobe epilepsy: clinical, highfield imaging and ultrastructural study. Brain, v. 135, n. Pt 8, p. 2337-49, Aug 2012.

GARBELLI, R. et al. Combined 7-T MRI and histopathologic study of normal and dysplastic samples from patients with TLE. Neurology, v. 76, n. 13, p. 1177-85, Mar 292011.

GASTAUT, H. et al. Relative frequency of different types of epilepsy: a study employing the classification of the International League Against Epilepsy. Epilepsia, v. 16, n. 3, p. 457-61, Sep 1975.

GE, Y. et al. Magnetization transfer ratio histogram analysis of gray matter in relapsing-remitting multiple sclerosis. AJNR Am J Neuroradiol, v. 22, n. 3, p. 470-5, Mar 2001.

GLOOR, P. The Hippocampal System. In: GLOOR, P. (Ed.). The Temporal Lobe and Limbic System: Oxford University Press, 1997. p.888. ISBN 0195092724.

GUERIN, C. F.; REGLI, L.; BADAUT, J. [Roles of aquaporins in the brain]. Med Sci (Paris), v. 21, n. 8-9, p. 747-52, Aug-Sep 2005.

GUPTA, R. K. et al. Magnetization transfer MR imaging correlation with histopathology in intracranial tuberculomas. Clin Radiol, v. 56, n. 8, p. 656-63, Aug 2001. 
HAWKINS, B. T.; DAVIS, T. P. The blood-brain barrier/neurovascular unit in health and disease. Pharmacol Rev, v. 57, n. 2, p. 173-85, Jun 2005.

HECK, N. et al. Differential upregulation of extracellular matrix molecules associated with the appearance of granule cell dispersion and mossy fiber sprouting during epileptogenesis in a murine model of temporal lobe epilepsy. Neuroscience, v. 129, n. 2, p. 309-24, 2004.

HILL, D. et al. Discussion on the surgery of temporal lobe epilepsy. Proc R Soc Med, v. 46, n. 11, p. 965-76, Nov 1953.

HIREMATH, G. K.; NAJM, I. M. Magnetic resonance spectroscopy in animal models of epilepsy. Epilepsia, v. 48 Suppl 4, p. 47-55, 2007.

HOLLINGWORTH, W. et al. The diagnostic and therapeutic impact of MRI: an observational multi-centre study. Clin Radiol, v. 55, n. 11, p. 825-31, Nov 2000.

HUANG, W. C. et al. Chondroitinase ABC promotes axonal re-growth and behavior recovery in spinal cord injury. Biochem Biophys Res Commun, v. 349, n. 3, p. 963-8, Oct 272006.

HUANG, Y. et al. Structural changes in hippocampal subfields in major depressive disorder: a high-field magnetic resonance imaging study. Biol Psychiatry, v. 74, n. 1, p. 62-8, Jul 12013.

JANSSON, L. et al. Glial cell activation in response to electroconvulsive seizures. Prog Neuropsychopharmacol Biol Psychiatry, v. 33, n. 7, p. 1119-28, Oct 1 2009.

KANG, T. C. et al. Epileptogenic roles of astroglial death and regeneration in the dentate gyrus of experimental temporal lobe epilepsy. Glia, v. 54, n. 4, p. 258-71, Sep 2006.

KAWAKITA, K. et al. Expression of matrix metalloproteinase-9 in thrombininduced brain edema formation in rats. J Stroke Cerebrovasc Dis, v. 15, n. 3, p. 88-95, May-Jun 2006.

KHURGEL, M.; IVY, G. O. Astrocytes in kindling: relevance to epileptogenesis. Epilepsy Res, v. 26, n. 1, p. 163-75, Dec 1996.

KIM, J. H. et al. Postmortem delay does not change regional diffusion anisotropy characteristics in mouse spinal cord white matter. NMR Biomed, v. 20, n. 3, p. 352-9, May 2007.

KIRKMAN, N. J. et al. Innate but not adaptive immune responses contribute to behavioral seizures following viral infection. Epilepsia, v. 51, n. 3, p. 454-64, Mar 2010.

KNUDSON, C. B.; KNUDSON, W. Hyaluronan-binding proteins in development, tissue homeostasis, and disease. FASEB J, v. 7, n. 13, p. 1233-41, Oct 1993. 
KRALIC, J. E.; LEDERGERBER, D. A.; FRITSCHY, J. M. Disruption of the neurogenic potential of the dentate gyrus in a mouse model of temporal lobe epilepsy with focal seizures. Eur J Neurosci, v. 22, n. 8, p. 1916-27, Oct 2005.

KUMAR, A. et al. Epilepsy surgery in a case of encephalitis: use of 11C-PK11195 positron emission tomography. Pediatr Neurol, v. 38, n. 6, p. 439-42, Jun 2008.

KUMAR, R. et al. Magnetization transfer MR imaging in patients with posttraumatic epilepsy. AJNR Am J Neuroradiol, v. 24, n. 2, p. 218-24, Feb 2003.

KUZNIECKY, R. et al. Magnetic resonance spectroscopic imaging in temporal lobe epilepsy: neuronal dysfunction or cell loss? Arch Neurol, v. 58, n. 12, p. 204853, Dec 2001.

LA JOIE, R. et al. Differential effect of age on hippocampal subfields assessed using a new high-resolution 3 T MR sequence. Neuroimage, v. 53, n. 2, p. 506-14, Nov 12010.

LAURENT, D. et al. Quantitative and qualitative assessment of articular cartilage in the goat knee with magnetization transfer imaging. Magn Reson Imaging, v. 19, n. 10, p. 1279-86, Dec 2001.

LAURENT, T. C.; FRASER, J. R. Hyaluronan. FASEB J, v. 6, n. 7, p. 2397-404, Apr 1992.

LEE, D. J. et al. Aquaporin-4-dependent edema clearance following status epilepticus. Epilepsy Res, v. 98, n. 2-3, p. 264-8, Feb 2012.

LEE, T. S. et al. Aquaporin-4 is increased in the sclerotic hippocampus in human temporal lobe epilepsy. Acta Neuropathol, v. 108, n. 6, p. 493-502, Dec 2004.

LEITE, J. P. et al. Calcified neurocysticercotic lesions and postsurgery seizure control in temporal lobe epilepsy. Neurology, v. 55, n. 10, p. 1485-91, Nov 28 2000 .

LI, L. M. et al. Magnetization transfer ratio is unable to lateralize epileptic foci in patients with temporal lobe epilepsy. AJNR Am J Neuroradiol, v. 21, n. 10, p. 1853-6, Nov-Dec 2000.

LI, Y. D. et al. Discriminative analysis of mild Alzheimer's disease and normal aging using volume of hippocampal subfields and hippocampal mean diffusivity: an in vivo magnetic resonance imaging study. Am J Alzheimers Dis Other Demen, v. 28, n. 6, p. 627-33, Sep 2013.

LIM, H. K. et al. Automated hippocampal subfields segmentation in late life depression. J Affect Disord, v. 143, n. 1-3, p. 253-6, Dec 202012. 
LIN, R. et al. Chondroitinase ABC has a long-lasting effect on chondroitin sulphate glycosaminoglycan content in the injured rat brain. J Neurochem, v. 104, n. 2, p. 400-8, Jan 2008.

LIU, W. L. et al. Methylprednisolone inhibits the expression of glial fibrillary acidic protein and chondroitin sulfate proteoglycans in reactivated astrocytes. Glia, v. 56, n. 13, p. 1390-400, Oct 2008.

LORENTE DE NÓ, R. Studies on the structure of the cerebral cortex. II. Continuation of the study of ammonic system. Journal für Psychologie und Neurologie, v. 46, p. 65, 1934.

LUNA-MEDINA, R. et al. NP031112, a thiadiazolidinone compound, prevents inflammation and neurodegeneration under excitotoxic conditions: potential therapeutic role in brain disorders. J Neurosci, v. 27, n. 21, p. 5766-76, May 23 2007.

MALYKHIN, N. V. et al. In vivo quantification of hippocampal subfields using 4.7 T fast spin echo imaging. Neuroimage, v. 49, n. 2, p. 1224-30, Jan 152010.

MARGERISON, J. H.; CORSELLIS, J. A. Epilepsy and the temporal lobes. A clinical, electroencephalographic and neuropathological study of the brain in epilepsy, with particular reference to the temporal lobes. Brain, v. 89, n. 3, p. 499-530, Sep 1966.

MARTINIAN, L. et al. Expression patterns of glial fibrillary acidic protein (GFAP)delta in epilepsy-associated lesional pathologies. Neuropathol Appl Neurobiol, v. 35, n. 4, p. 394-405, Aug 2009.

MATHERN, G. W. et al. Hippocampal neuron damage in human epilepsy: Meyer's hypothesis revisited. Prog Brain Res, v. 135, p. 237-51, 2002.

MATHERN, G. W. et al. The pathogenic and progressive features of chronic human hippocampal epilepsy. Epilepsy Res, v. 26, n. 1, p. 151-61, Dec 1996.

MCLEAN, M. A. et al. Magnetization transfer effect on human brain metabolites and macromolecules. Magn Reson Med, v. 54, n. 5, p. 1281-5, Nov 2005.

MCNAMARA, J. O. Cellular and molecular basis of epilepsy. J Neurosci, v. 14, n. 6, p. 3413-25, Jun 1994.

MENG, S. et al. Correspondence of AQP4 expression and hypoxic-ischaemic brain oedema monitored by magnetic resonance imaging in the immature and juvenile rat. Eur J Neurosci, v. 19, n. 8, p. 2261-9, Apr 2004.

MITCHELL, L. A. et al. Anterior temporal abnormality in temporal lobe epilepsy: a quantitative MRI and histopathologic study. Neurology, v. 52, n. 2, p. 327-36, Jan 151999. 
MOTTERSHEAD, J. P. et al. High field MRI correlates of myelin content and axonal density in multiple sclerosis--a post-mortem study of the spinal cord. $\mathbf{J}$ Neurol, v. 250, n. 11, p. 1293-301, Nov 2003.

MUELLER, S. G. et al. Evidence for functional specialization of hippocampal subfields detected by MR subfield volumetry on high resolution images at $4 \mathrm{~T}$. Neuroimage, v. 56, n. 3, p. 851-7, Jun 12011.

NAGELhUS, E. A.; MATHiISEN, T. M.; OTTERSEN, O. P. Aquaporin-4 in the central nervous system: cellular and subcellular distribution and coexpression with KIR4.1. Neuroscience, v. 129, n. 4, p. 905-13, 2004.

NAMER, I. J. et al. Contribution of T2 relaxation time mapping in the evaluation of cryptogenic temporal lobe epilepsy. Neuroimage, v. 7, n. 4 Pt 1, p. 304-13, May 1998.

NESSLER, S. et al. Early MRI changes in a mouse model of multiple sclerosis are predictive of severe inflammatory tissue damage. Brain, v. 130, n. Pt 8, p. 218698, Aug 2007.

NEYLAN, T. C. et al. Insomnia severity is associated with a decreased volume of the CA3/dentate gyrus hippocampal subfield. Biol Psychiatry, v. 68, n. 5, p. 494-6, Sep 12010.

OBENAUS, A. et al. Multi-modal magnetic resonance imaging alterations in two rat models of mild neurotrauma. J Neurotrauma, v. 24, n. 7, p. 1147-60, Jul 2007.

PANTAZOPOULOS, $\mathrm{H}$. et al. Extracellular matrix-glial abnormalities in the amygdala and entorhinal cortex of subjects diagnosed with schizophrenia. Arch Gen Psychiatry, v. 67, n. 2, p. 155-66, Feb 2010.

PAPADOPOULOS, M. C. et al. Aquaporin-4 facilitates reabsorption of excess fluid in vasogenic brain edema. FASEB J, v. 18, n. 11, p. 1291-3, Aug 2004.

PAPADOPOULOS, M. C.; VERKMAN, A. S. Aquaporin-4 gene disruption in mice reduces brain swelling and mortality in pneumococcal meningitis. J Biol Chem, v. 280, n. 14, p. 13906-12, Apr 82005.

PAREKH, M. B. et al. Early MR diffusion and relaxation changes in the parahippocampal gyrus precede the onset of spontaneous seizures in an animal model of chronic limbic epilepsy. Exp Neurol, v. 224, n. 1, p. 258-70, Jul 2010.

PEIXOTO-SANTOS, J. E. et al. Increased Metallothionein I/II Expression in Patients with Temporal Lobe Epilepsy. PLoS One, v. 7, n. 9, p. e44709, 2012.

PELL, G. S. et al. Voxel-based relaxometry: a new approach for analysis of T2 relaxometry changes in epilepsy. Neuroimage, v. 21, n. 2, p. 707-13, Feb 2004. 
PEROSA, S. R. et al. Glycosaminoglycan levels and proteoglycan expression are altered in the hippocampus of patients with mesial temporal lobe epilepsy. Brain Res Bull, v. 58, n. 5, p. 509-16, Sep 152002.

PFEFFERBAUM, A. et al. Postmortem MR imaging of formalin-fixed human brain. Neuroimage, v. 21, n. 4, p. 1585-95, Apr 2004.

PITKANEN, A. et al. Severity of hippocampal atrophy correlates with the prolongation of MRI T2 relaxation time in temporal lobe epilepsy but not in Alzheimer's disease. Neurology, v. 46, n. 6, p. 1724-30, Jun 1996.

PITKANEN, A.; SUTULA, T. P. Is epilepsy a progressive disorder? Prospects for new therapeutic approaches in temporal-lobe epilepsy. Lancet Neurol, v. 1, n. 3, p. 173-81, Jul 2002.

PRAYSON, R. A.; YODER, B. J. Clinicopathologic findings in mesial temporal sclerosis treated with gamma knife radiotherapy. Ann Diagn Pathol, v. 11, n. 1, p. 22-6, Feb 2007.

PROPER, E. A. et al. A grading system for hippocampal sclerosis based on the degree of hippocampal mossy fiber sprouting. Acta Neuropathol, v. 101, n. 4, p. 405-9, Apr 2001.

RANE, S.; DUONG, T. Q. Comparison of in vivo and ex vivo diffusion tensor imaging in rhesus macaques at short and long diffusion times. Open Neuroimag J, v. 5, p. 172-8, 2011.

RASH, J. E. et al. Direct immunogold labeling of aquaporin-4 in square arrays of astrocyte and ependymocyte plasma membranes in rat brain and spinal cord. Proc Natl Acad Sci U S A, v. 95, n. 20, p. 11981-6, Sep 291998.

RAUSCH, M. et al. Characterization of white matter damage in animal models of multiple sclerosis by magnetization transfer ratio and quantitative mapping of the apparent bound proton fraction f. Mult Scler, v. 15, n. 1, p. 16-27, Jan 2009.

ROITBAK, T.; SYKOVA, E. Diffusion barriers evoked in the rat cortex by reactive astrogliosis. Glia, v. 28, n. 1, p. 40-8, Oct 1999.

RUGG-GUNN, F. J. et al. Magnetization transfer imaging in focal epilepsy. Neurology, v. 60, n. 10, p. 1638-45, May 272003.

SALANOVA, V. et al. Presurgical evaluation and surgical outcome of temporal lobe epilepsy. Pediatr Neurol, v. 20, n. 3, p. 179-84, Mar 1999.

SALMENPERA, T. M. et al. Evaluation of quantitative magnetic resonance imaging contrasts in MRI-negative refractory focal epilepsy. Epilepsia, v. 48, n. 2, p. 22937, Feb 2007. 
SCHMIERER, K. et al. High field (9.4 Tesla) magnetic resonance imaging of cortical grey matter lesions in multiple sclerosis. Brain, v. 133, n. Pt 3, p. 858-67, Mar 2010 .

SCHROETER, $M$. et al. Dynamic changes of magnetic resonance imaging abnormalities in relation to inflammation and glial responses after photothrombotic cerebral infarction in the rat brain. Acta Neuropathol, v. 101, n. 2, p. 114-22, Feb 2001.

SCHUMANN, C. M.; BUONOCORE, M. H.; AMARAL, D. G. Magnetic resonance imaging of the post-mortem autistic brain. J Autism Dev Disord, v. 31, n. 6, p. 561-8, Dec 2001.

SCHWARZACHER, S. W. et al. Neuronal hyperactivity induces astrocytic expression of neurocan in the adult rat hippocampus. Glia, v. 53, n. 7, p. 704-14, May 2006.

SCOTT, R. C. et al. Abnormalities in hippocampi remote from the seizure focus: a T2 relaxometry study. Brain, v. 126, n. Pt 9, p. 1968-74, Sep 2003.

SCOTT, R. C. et al. Magnetic resonance imaging findings within 5 days of status epilepticus in childhood. Brain, v. 125, n. Pt 9, p. 1951-9, Sep 2002.

SEO, G. S. et al. Hyaline cartilage: in vivo and in vitro assessment with magnetization transfer imaging. Radiology, v. 201, n. 2, p. 525-30, Nov 1996.

SIDDIQUE, D. et al. Magnetization transfer ratio may be a surrogate of spongiform change in human prion diseases. Brain, v. 133, n. 10, p. 3058-68, Oct 2010.

SILVER, J.; MILLER, J. H. Regeneration beyond the glial scar. Nat Rev Neurosci, v. 5, n. 2, p. 146-56, Feb 2004.

SIMPSON, J. E. et al. White matter lesions in an unselected cohort of the elderly: astrocytic, microglial and oligodendrocyte precursor cell responses. Neuropathol Appl Neurobiol, v. 33, n. 4, p. 410-9, Aug 2007.

SMITH, G. M.; STRUNZ, C. Growth factor and cytokine regulation of chondroitin sulfate proteoglycans by astrocytes. Glia, v. 52, n. 3, p. 209-18, Nov 152005.

STICHEL, C. C. et al. Differential expression of the small chondroitin/dermatan sulfate proteoglycans decorin and biglycan after injury of the adult rat brain. Brain Res, v. 704, n. 2, p. 263-74, Dec 181995.

SUN, S. W. et al. Fixation, not death, reduces sensitivity of DTI in detecting optic nerve damage. Neuroimage, v. 44, n. 3, p. 611-9, Feb 12009.

SWANN, K. et al. Peripheral thermal injury causes blood-brain barrier dysfunction and matrix metalloproteinase (MMP) expression in rat. Brain Res, v. 1129, n. 1, p. 26-33, Jan 192007. 
SWARTZ, B. E. et al. Hippocampal cell loss in posttraumatic human epilepsy. Epilepsia, v. 47, n. 8, p. 1373-82, Aug 2006.

SYKOVA, E. Diffusion properties of the brain in health and disease. Neurochem Int, v. 45, n. 4, p. 453-66, Sep 2004.

SYKOVA, E. et al. Reduced extracellular space in the brain of tenascin-R- and HNK-1-sulphotransferase deficient mice. Eur J Neurosci, v. 22, n. 8, p. 1873-80, Oct 2005.

TEIPEL, S. J. et al. Automated detection of amyloid-beta-related cortical and subcortical signal changes in a transgenic model of Alzheimer's disease using high-field MRI. J Alzheimers Dis, v. 23, n. 2, p. 221-37, 2011.

TERTTI, M. et al. Disc degeneration in magnetic resonance imaging. A comparative biochemical, histologic, and radiologic study in cadaver spines. Spine (Phila Pa 1976), v. 16, n. 6, p. 629-34, Jun 1991.

TOFFANIN, R. et al. Proteoglycan depletion and magnetic resonance parameters of articular cartilage. Arch Biochem Biophys, v. 390, n. 2, p. 235-42, Jun 152001.

TOFTS, P. S. et al. MR magnetization transfer measurements in temporal lobe epilepsy: a preliminary study. AJNR Am J Neuroradiol, v. 16, n. 9, p. 1862-3, Oct 1995.

TRAVIS, S. G. et al. High field structural MRI reveals specific episodic memory correlates in the subfields of the hippocampus. Neuropsychologia, v. 53, p. 23345, Jan 2014.

UHLMANN, E. J. et al. Astrocyte-specific TSC1 conditional knockout mice exhibit abnormal neuronal organization and seizures. Ann Neurol, v. 52, n. 3, p. 285-96, Sep 2002.

VAN LEEMPUT, K. et al. Automated segmentation of hippocampal subfields from ultra-high resolution in vivo MRI. Hippocampus, v. 19, n. 6, p. 549-57, Jun 2009.

VAN PAESSCHEN, W. et al. Quantitative neuropathology and quantitative magnetic resonance imaging of the hippocampus in temporal lobe epilepsy. Ann Neurol, v. 42, n. 5, p. 756-66, Nov 1997.

VAN PUTTEN, H. P. et al. Diffusion-weighted imaging of edema following traumatic brain injury in rats: effects of secondary hypoxia. J Neurotrauma, v. 22, n. 8, p. 857-72, Aug 2005.

VAN VLIET, E. A. et al. Blood-brain barrier leakage may lead to progression of temporal lobe epilepsy. Brain, v. 130, n. Pt 2, p. 521-34, Feb 2007. 
VAN WAESBERGHE, J. H. et al. Axonal loss in multiple sclerosis lesions: magnetic resonance imaging insights into substrates of disability. Ann Neurol, v. 46, n. 5, p. 747-54, Nov 1999.

VERKMAN, A. S. et al. Three distinct roles of aquaporin-4 in brain function revealed by knockout mice. Biochim Biophys Acta, v. 1758, n. 8, p. 1085-93, Aug 2006.

VESSAL, M. et al. Might astrocytes play a role in maintaining the seizure-prone state? Brain Res, v. 1044, n. 2, p. 190-6, May 242005.

VITELLARO-ZUCCARELLO, L. et al. Distribution of Aquaporin 4 in rodent spinal cord: relationship with astrocyte markers and chondroitin sulfate proteoglycans. Glia, v. 51, n. 2, p. 148-59, Aug 12005.

VORISEK, I. et al. Water ADC, extracellular space volume, and tortuosity in the rat cortex after traumatic injury. Magn Reson Med, v. 48, n. 6, p. 994-1003, Dec 2002.

WACHSMUTH, L.; JURETSCHKE, H. P.; RAISS, R. X. Can magnetization transfer magnetic resonance imaging follow proteoglycan depletion in articular cartilage? MAGMA, v. 5, n. 1, p. 71-8, Mar 1997.

WACHTER, B. et al. 6-Hydroxydopamine leads to T2 hyperintensity, decreased claudin-3 immunoreactivity and altered aquaporin 4 expression in the striatum. Behav Brain Res, v. 232, n. 1, p. 148-58, Jun 152012.

WANG, F. et al. Aquaporins as potential drug targets. Acta Pharmacol Sin, v. 27, n. 4, p. 395-401, Apr 2006.

WIDDESS-WALSH, P.; DIEHL, B.; NAJM, I. Neuroimaging of focal cortical dysplasia. J Neuroimaging, v. 16, n. 3, p. 185-96, Jul 2006.

WIDJAJA, E. et al. Alteration of human fetal subplate layer and intermediate zone during normal development on MR and diffusion tensor imaging. AJNR Am J Neuroradiol, v. 31, n. 6, p. 1091-9, Jun 2010.

WISSE, L. E. et al. Hippocampal subfield volumes at 7T in early Alzheimer's disease and normal aging. Neurobiol Aging, v. 35, n. 9, p. 2039-45, Sep 2014.

WOLF, O. T. et al. Volumetric structural magnetic resonance imaging (MRI) of the rat hippocampus following kainic acid (KA) treatment. Brain Res, v. 934, n. 2, p. 87-96, May 32002.

WONG, M. et al. Impaired glial glutamate transport in a mouse tuberous sclerosis epilepsy model. Ann Neurol, v. 54, n. 2, p. 251-6, Aug 2003.

YANG, F. et al. Roles of astrocytes and microglia in seizure-induced aberrant neurogenesis in the hippocampus of adult rats. J Neurosci Res, v. 88, n. 3, p. 519-29, Feb 152010. 
YIN, J. et al. Transforming growth factor-betal upregulates keratan sulfate and chondroitin sulfate biosynthesis in microglias after brain injury. Brain Res, v. 1263, p. 10-22, Mar 312009.

YIU, G.; HE, Z. Glial inhibition of CNS axon regeneration. Nat Rev Neurosci, v. 7, n. 8, p. 617-27, Aug 2006.

YUSHKEVICH, P. A. et al. Nearly automatic segmentation of hippocampal subfields in in vivo focal T2-weighted MRI. Neuroimage, v. 53, n. 4, p. 1208-24, Dec 2010 . 


\section{Anexos}

\section{Cálculos dos mapas e medidas nas ressonâncias ex vivo}

O cálculo do mapa de relaxamento foi realizado através do seguinte comandos:

relaxon16.pl

onde calcula-se o tempo de relaxamento DP/T2 pelas variações do brilho em imagens ponderadas em DP ou T2 consecutivas. Este comando calcula o tempo de relaxamento em séries de até 16 ecos diferentes.

mincmath -pd -const 5 (nome da imagem sem o pulso de saturação) (nome da imagem com o pulso de saturação reformatada) (nome que se quer para o mapa de MTR)

onde calcula-se o mapa de transferência de magnetização. mincmath = operação matemática; $\mathrm{pd}=$ diferença de percentil entre as duas imagens; const $=$ valor constante

Os cálculos do tempo de relaxamento e da transferência de magnetização, realizados no XQuartz, foram feitos a partir do seguinte comando:

mincstats (nome do mapa) -mask (nome do label reformatado) -mask_binvalue

$n$

onde: mincstats $=$ cálculo das estatísticas da imagem/mapa selecionado; -mask $=$ região dentro da imagem será quantificada (no caso, o label demarcado manualmente); -mask_binvalue = qual dos labels será analisado (cada label de cor diferente no programa tem por nome um número diferente; e.g., 1 equivale ao label vermelho, 2 equivale ao label verde, 3 equivale ao label azul). Por esta linha de 
comando, obtém-se o valor médio da região de interesse no mapa, sendo que este valor tem a unidade de medida referente ao mapa (i.e., milissegundos para o tempo de relaxamento e porcentagem para a transferência de magnetização). 
Artigos publicados e submetidos para publicação 


\title{
Increased Metallothionein I/II Expression in Patients with Temporal Lobe Epilepsy
}

\author{
José Eduardo Peixoto-Santos ${ }^{1}$, Orfa Yineth Galvis-Alonso ${ }^{4}$, Tonicarlo Rodrigues Velasco ${ }^{1}$, \\ Ludmyla Kandratavicius ${ }^{1}$, João Alberto Assirati ${ }^{2}$, Carlos Gilberto Carlotti ${ }^{2}$, Renata Caldo Scandiuzzi ${ }^{1}$, \\ Luciano Neder Serafini ${ }^{3}$, João Pereira Leite ${ }^{1 *}$
}

1 Department of Neuroscience and Behavior, Ribeirão Preto School of Medicine, University of São Paulo, Ribeirão Preto - São Paulo, Brazil, 2 Department of Neurosurgery, Ribeirão Preto School of Medicine, University of São Paulo, Ribeirão Preto - São Paulo, Brazil, 3 Department of Pathology, Ribeirão Preto School of Medicine, University of São Paulo, Ribeirão Preto - São Paulo, Brazil, 4 Department of Molecular Biology, São José do Rio Preto Medical School, São José do Rio Preto - São Paulo, Brazil

\begin{abstract}
In the central nervous system, zinc is released along with glutamate during neurotransmission and, in excess, can promote neuronal death. Experimental studies have shown that metallothioneins I/II (MT-I/II), which chelate free zinc, can affect seizures and reduce neuronal death after status epilepticus. Our aim was to evaluate the expression of MT-I/II in the hippocampus of patients with temporal lobe epilepsy (TLE). Hippocampi from patients with pharmacoresistant mesial temporal lobe epilepsy (MTLE) and patients with TLE associated with tumor or dysplasia (TLE-TD) were evaluated for expression of MT-I/II, for the vesicular zinc levels, and for neuronal, astroglial, and microglial populations. Compared to control cases, MTLE group displayed widespread increase in MT-I/II expression, astrogliosis, microgliosis and reduced neuronal population. In TLE-TD, the same changes were observed, except that were mainly confined to fascia dentata. Increased vesicular zinc was observed only in the inner molecular layer of MTLE patients, when compared to control cases. Correlation and linear regression analyses indicated an association between increased MT-I/II and increased astrogliosis in TLE. MT-I/II levels did not correlate with any clinical variables, but MTLE patients with secondary generalized seizures (SGS) had less MT-I/II than MTLE patients without SGS. In conclusion, MT-I/II expression was increased in hippocampi from TLE patients and our data suggest that it is associated with astrogliosis and may be associated with different seizure spread patterns.
\end{abstract}

Citation: Peixoto-Santos JE, Galvis-Alonso OY, Velasco TR, Kandratavicius L, Assirati JA, et al. (2012) Increased Metallothionein I/II Expression in Patients with Temporal Lobe Epilepsy. PLoS ONE 7(9): e44709. doi:10.1371/journal.pone.0044709

Editor: Stefano L. Sensi, University G. D’Annunzio, Italy

Received June 17, 2012; Accepted August 7, 2012; Published September 18, 2012

Copyright: (c) 2012 Peixoto-Santos et al. This is an open-access article distributed under the terms of the Creative Commons Attribution License, which permits unrestricted use, distribution, and reproduction in any medium, provided the original author and source are credited.

Funding: The present work was supported by Fundação de Amparo à Pesquisa do Estado de São Paulo (FAPESP, research grants 2005/56447-7 and 2009/534477 to JPL and master's grant 2008/52657-5 to JEPS), Conselho Nacional de Desenvolvimento Científico e Tecnológico (CNPq) and Coordenação de Aperfeiçoamento de Pessoal de Nível Superior (CAPES). The funders had no role in study design, data collection and analysis, decision to publish, or preparation of the manuscript.

Competing Interests: The authors have declared that no competing interests exist.

* E-mail: jpleite@fmrp.usp.br

\section{Introduction}

Zinc $\left(\mathrm{Zn}^{2+}\right)$ is an important modulator of glutamatergic transmission in the central nervous system (CNS) [1], [2], [3]. $\mathrm{Zn}^{2+}$ is concentrated in presynaptic vesicles, along with glutamate, and released during normal neurotransmission [4], [5], [6], [7], [8]. Hippocampal neurons are specially rich in vesicular $\mathrm{Zn}^{2+}$, particularly in the axonal boutons of granule cells, CA3 and CA1 pyramidal cells and prosubicular neurons [5], [6], [7], [9], [10]. In temporal lobe epilepsy (TLE), one of the most frequent drugresistant epilepsies in adults, the hippocampus is associated with seizure generation [11], [12]. The intense neuronal activity during seizures can induce high amounts of $\mathrm{Zn}^{2+}$ in the synaptic cleft, [13], [14] promoting reactive oxygen species (ROS) production, [15] which can ultimately lead to hippocampal neuronal death [16], [17], [14], [15], [13]. In fact, studies in hippocampi from TLE patients who underwent epilepsy surgery have shown neuronal loss [18], [19], [20], increased glial reaction [21], [22], [23], [24] and reorganization of mossy fibers axon collaterals into the inner molecular layer of the granule cell dendrites [25], [19]. This synaptic reorganization of $\mathrm{Zn}^{2+}$-enriched terminals has been hypothesized to contribute to synchronous firing and epileptiform activity [19]. Besides the vesicular $\mathrm{Zn}^{2+}$, other intracellular $\mathrm{Zn}^{2+}$ pools are present in neurons [26], [27], which can also contribute to neuronal death after an insult [28], [29], [27].

Metallothioneins (MTs) are low molecular weight, cysteinenriched proteins that bound $\mathrm{Zn}^{2+}$ and cadmium. They can be found in various tissues, in four isoforms [30]. Isoforms I, II and III are found in the central nervous system (CNS), where the isoforms I and II are expressed in astrocytes and the isoform III is expressed only in neurons [31], [32]. MTs participate in $\mathrm{Zn}^{2+}$ homeostasis, scavenging ROS in the brain [33] and stimulate the expression of several neurotrophic and antiinflamatory factors [34]. Studies on rodent models of TLE have shown that MT expression is increased in the hippocampal formation shortly after seizures [35], [36] and that high levels of MTs I and II are associated with reduced neuronal death after seizure-induced damage [37], [36], [38]. However, some studies with neuronal MT (MT-III) indicate that MTs could also contribute to neuronal death in some circumstances [39], [29]. 
Since MT-I/II levels may be associated with neuron survival after seizures, we hypothesize that MT-I/II expression is altered in TLE and can be associated with the preservation of neuronal density in the hippocampus of TLE patients. Therefore, in this study we evaluated the immunoexpression of MT-I/II and its correlation with hippocampal neuron density in hippocampi of patients with chronic TLE.

\section{Materials and Methods}

\section{Patients and clinical data}

Patients with drug-resistant epilepsy were evaluated at the University of São Paulo Epilepsy Surgical Centre in Ribeirão Preto (Brazil), according to standard protocols published elsewhere [40]. The presurgical evaluation protocol included interviews for epilepsy history, neurological examination, EEG recording, videoEEG assessment, T1- and T2-weighted MRI, ictal and interictal single-photon emission computed tomography (SPECT) scans and neuropsychological tests. Drug resistance was defined according to previous published literature [41].

TLE patients were divided in two groups: (i) mesial TLE (MTLE) and (ii) TLE associated with extrahippocampal tumor or dysplasia (TLE-TD). MTLE group $(\mathrm{n}=69)$ were patients with hippocampal atrophy or with normal hippocampal volume at MRI without other lesions associated with TLE. TLE-TD $(\mathrm{n}=17)$ were TLE patients with tumor or cortical dysplasia in temporal lobe structures other than the hippocampus. From all TLE-TD patients, 4 had non-Taylor focal cortical dysplasia and the remaining had tumors. The tumors observed were grade I ganglioglioma $(\mathrm{n}=3)$, grade I dysembryoplastic neuroepithelial tumor $(\mathrm{n}=3)$, hamartoma $(\mathrm{n}=3)$, teratoma $(\mathrm{n}=2)$, grade III astrocytoma $(\mathrm{n}=1)$ and angioma $(\mathrm{n}=1)$.

For comparison purposes in the neuropathology studies, autopsy controls $(\mathrm{Ctrl}, \mathrm{n}=19)$ were obtained from autopsy cases without history of neurological diseases, with no sign of CNS pathologies in post mortem pathological evaluation and no history of hypoxic episodes during agony. Post mortem time (i.e., time between death and hippocampal fixation) was of $5.15 \pm 1.43$ hours, ranging from 3.16 to 9 hours. The causes of death were pulmonary insuficiency $(\mathrm{n}=6)$, cardiomyopathy $(\mathrm{n}=3)$, cardiogenic shock $(\mathrm{n}=2)$, sepsis $(\mathrm{n}=3)$, hepatic failure $(\mathrm{n}=3)$, acute lymphoblastic leukemia $(n=1)$ and gastric adenocarcinoma $(n=1)$.

Medical records of all evaluated patients were assessed for clinical data analysis. The clinical variables investigated were age at death and cause of death for Ctrl patients and age at surgery, epilepsy duration, age at the first recurrent seizure, seizure frequency per month, presence of secondary generalized seizures, and neuropathological evaluation for TLE patients. This study followed the principles of the Declaration of Helsinki, was registered in Brazilian's Health Ministry and was approved by the Research Ethics Committee of the Hospital das Clínicas, where this study was performed (process HCRP 2634/2008). Written informed consent was obtained from all patients used in this study, and the Research Ethics Committee also approved the Consent Term. Tissue from autopsy cases came from a Brain Bank approved by the Research Ethics Committee of Hospital das Clínicas (process HCRP 9370/2003).

\section{Tissue collection and histological techniques}

Hippocampi from surgery or autopsy were cut in coronal sections and placed in 10\% (vol/vol) buffered formaldehyde for one week, followed by paraffin embedding. Immunohistochemistry was performed in $8 \mu \mathrm{m}$ sections at the level of hippocampal body for evaluation of neuronal, astroglial and activated microglial populations and for MT-I/II expression with antibodies against, respectively, NeuN, GFAP, HLA-DR and MT-I/II. The sections were submitted to endogenous peroxidase blocking with $4.5 \%$

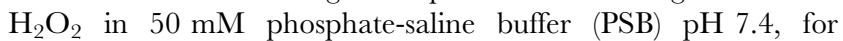
15 minutes, followed by microwave antigenic retrieval in $10 \mathrm{mM}$ sodium citrate buffer $\mathrm{pH} 6.0$ (for GFAP) or $50 \mathrm{mM}$ Tris-HCl pH 9.6 (for NeuN, HLA-DR and MT-I/II). After achieving room temperature, the sections went through blocking free aldehyde groups with Tris-glycine $0.1 \mathrm{M} \mathrm{pH} 7.4$ for 45 minutes, followed by blocking buffer with $5 \%$ defatted milk and $15 \%$ goat serum (\#S-1000, Vector) in Triton buffer (PTB, $20 \mathrm{mM}$ phosphate $+0.45 \mathrm{M} \mathrm{NaCl}, \mathrm{pH} 7.4$, with $0.3 \%$ Triton X-100) for four hours. The sections were then incubated with primary antibodies in blocking buffer for 16 hours. We used primary monoclonal antibodies raised in mouse anti-human GFAP (clone 6F2, \#M0761, Dako), anti-murine NeuN (clone A60, \#MAB377, Chemicon), anti-human HLA-DR (clone TAL.1B5, \#M0746, Dako) and anti-equine MT-I/II (clone E9, \#M0639, Dako), diluted in blocking buffer at concentrations of 1:500, 1:500, 1:100 and 1:500, respectively. The primary antibodies were detected using biotinylated rabbit anti-murine IgG (\#E0354, Dako), at 1:200 dilution in blocking buffer, for one hour, followed by revelation with avidin-biotin-peroxidase system (Vectastain Elite ABC kit, \#PK6100, Vector) and diaminobenzidine as chromogen (DAB, \#34001, Pierce Biotechnology). The development times in DAB solution were 12 minutes for HLA-DR, 10.5 minutes for NeuN and 8 minutes for MT-I/II and GFAP. In order to assure that the different times of fixation of autopsy hippocampi and surgical tissue were comparable, an additional experiment was performed with temporal cortical tissue from one TLE patient. Briefly, a cortical sample was removed during surgery, sectioned in 5 fragments which were kept at room temperature for 1, 2, 4, 6 and 8 hours before immersion-fixation in $10 \%$ buffered formaldehyde. Sections of these cortical fragments with different prefixation times were mounted on slides and processed in the same manner as the surgical and autopsy hippocampi.

Vesicular $\mathrm{Zn}^{2+}$ was evaluated in a subset of cases by neo-Timm histochemistry [19]. Briefly, a fresh hippocampal section was placed in buffered fixative solution (4\% glutaraldehyde and $0.1 \%$ sodium sulfite) at $4{ }^{\circ} \mathrm{C}$ for one week, followed by water removal with $20 \%$ buffered saccarose for one day. The fragment was dried and frozen in cryostat. Thirty $\mu \mathrm{m}$ sections were utilized for neoTimm technique, according to previously published protocols [19], [42], [43].

\section{Immunofluorescence}

Colocalization of MT-I/II with neuronal and astroglial markers was performed with the same protocol described above. Endogenous peroxidase blocking and the revelation procedure were omitted. Primary antibodies were raised in mouse anti-equine for MT-I/II (clone E9, \#M0639, Dako), in rabbit anti-cow for GFAP (\#Z0334, Dako) and anti-human for MAP2 (\#sc-20172, Santa Cruz Biotechnology). Sections were submitted to MT-I/II plus GFAP or MT-I/II plus MAP2 incubation, with antibodies diluted in blocking buffer at 1:100 for MT-I/II, 1:1000 for GFAP and 1:50 for MAP2, for 20 hours. The primary antibodies were detected using goat anti-mouse IgG conjugated with Alexa Fluor 488 (\#A11001, Molecular Probes) and goat anti-rabbit IgG conjugated with Texas Red (\#T2767, Molecular Probes), diluted in blocking buffer, at 1:300 each, for 2 hours. Following incubation, the sections were submitted to Hoechst 33342 staining (\#H1399, Molecular Probes) for 4 minutes, and were mounted in Fluoromount-G (\#17984-25, EMS). With this procedure, GFAP and MAP2 were observed in red, MT-I/II in green and cell 
nucleus in blue. All images were captured in Leica SP5 confocal microscope.

\section{Histological analysis}

Images of all hippocampal regions were obtained with a video monochrome charge-coupled device camera (CCD; Hamamatsu Photonics Model 2400, Japan) attached to an Olympus microscope (Model BX60, Melville, NY), and captured, averaged, and digitized using a frame grabber (Scion Corporation, Frederick, MD) on a Macintosh computer (Model G3, Cupertino, CA). Illumination exposure was uniformly maintained and regularly checked using optical density standards (Kodak, Rochester, NY) in order to prevent any distortion of measurements (immunopositive area, gray level) between the samples. After captured, the image was analyzed using image system software (Image J, version $1.37 \mathrm{c}$ ).

Quantification of the immunohistochemistry was performed with threshold tool, with the investigator blind to the group allocation. After the selection of the region of interest (ROI), the software calculated the immunopositive area by counting all pixels with gray intensity equal or superior to the threshold of staining. A complete protocol for threshold tool can be found at rsbweb.nih.gov/ij/docs/examples/stained-sections/index.html. The threshold was defined for each protein evaluated, based on the mean immunopositivity of all control cases. The evaluated regions were the fascia dentata (outer molecular layer, inner molecular layer, granule cell layer, subgranular zone), the hilus and the stratus piramidale of CA4, CA3, CA2, CA1, prosubiculum and subiculum (Figure 1). The characterization of hippocampal regions was based on the Lorente de Nós classification [44]. Results were shown as percentage of immunopositive area/total area.

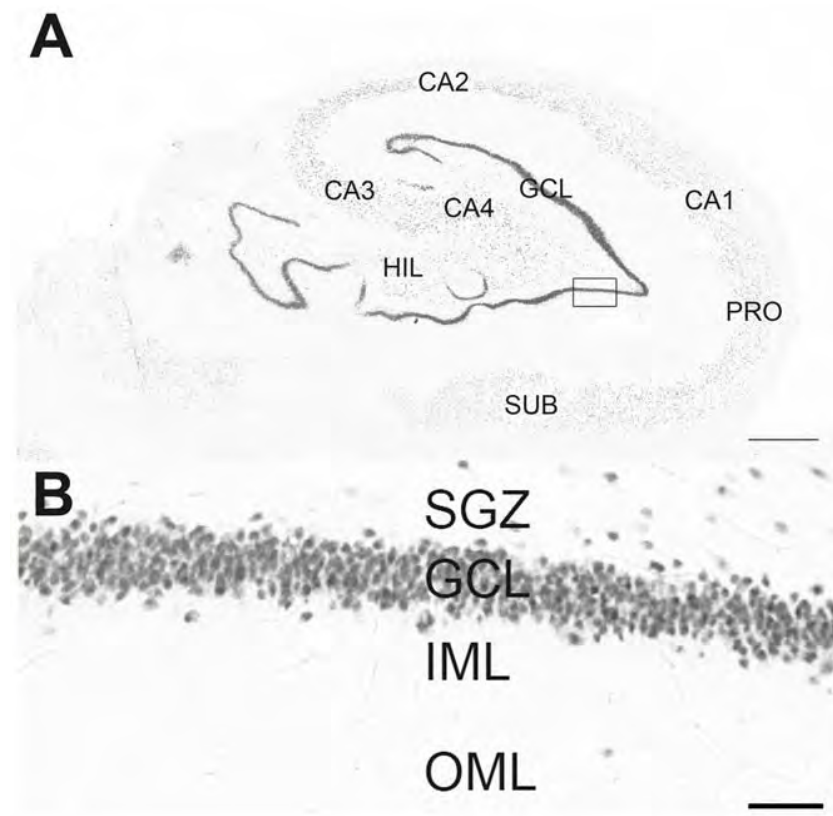

Figure 1. Subfields in the hippocampal formation under NeuN immunohistochemistry. In A can be seen: the granule cell layer of fascia dentata (GCL, composed by granular neurons) and the hilus (HIL, composed by several types of interneurons); pyramidal neuronal layers of the hippocampus (CA4-CA1); the subicular formation, composed by prosubiculum (PRO) and subiculum (SUB). In B, a higher magnification of the fascia dentate (marked as a black square in A), composed by subgranule zone (SGZ), granule cell layer (GCL), inner molecular layer (IML) and outer molecular layer (OML). Bar in A indicates 1 millimeter and in $\mathrm{B}$ indicates 50 micrometers.

doi:10.1371/journal.pone.0044709.g001
Additionally, neuronal density was evaluated in the NeuN stained sections. Neuronal count was processed in Image J $1.37 \mathrm{c}$ software with a $520 \times$ magnification for granule cell layer and $260 \times$ for pyramidal neurons of CA4, CA3, CA2, CA1, prosubiculum and subiculum. Neuronal densities were estimated with the correction of Abercrombie [45], which permits to estimate the neuronal density through mathematical method, and the results were shown as thousands of cells per cubic millimeter.

Quantification of neo-Timm sections was done by measurement of mean gray value, which varied from 0 to 255 , of the hippocampal regions in Image J software. The evaluated regions comprised outer molecular layer, inner molecular layer, granule cell layer, subgranule zone and hilus/CA4.

\section{Statistical analysis}

Statistics were carried out in SigmaStat 3.1 software for all tests except for simple regression models, which were performed with SPSS 20. Tests for normality and homogeneity of variances were performed to define data distribution. For parametric variables, One Way ANOVA with Bonferroni post hoc or t-test was performed. For the non-parametric variables, Kruskal-Wallis with Dunn post hoc or Mann-Whitney tests were used. Fisher's exact test was performed to evaluate categorical data. Correlation between MT expression and cellular populations was performed using the Spearman's test, when $\mathrm{n} \leq 30$, or Pearson's test, for $\mathrm{n}>30$. Multiple linear regressions were used to define associations between age, neuronal and astroglial populations over MT-I/II expression. All results were considered significant at $\mathrm{p}<0.05$.

\section{Results}

\section{Clinical data}

The clinical characteristics of study participants are summarized in Table 1 . The mean age at evaluation was significantly lower in TLE-TD group than Ctrl and MTLE groups (Kruskal-Wallis, $\mathrm{p}=0.001)$. Epilepsy duration was lower in TLE-TD group than in MTLE group (Mann-Whitney, $p=0.002$ ). Recurrent seizures onset (t-test, $p=0.651$ ), minimal seizure frequency in a month (Mann-Whitney, $\mathrm{p}=0.397$ ) and frequency of secondary generalized seizures per month (Mann-Whitney, $\mathrm{p}=0.557$ ) were similar in MTLE and TLE-TD groups. Fisher's exact test showed that the prevalence of secondary generalized seizures was similar between MTLE and TLE-TD $(\mathrm{p}=1.0)$.

Changes in immunoreactivity in different fixation times

Quantification of MT-I/II, NeuN, GFAP and HLA-DR immunostaining in sections of cortical fragment in different fixation times revealed that a delay on fixation time was not associated with a decrease of immunoreactivity for all antibodies evaluated (Figure S1).

\section{Neuronal density}

NeuN immunopositive cells (Figure 2) were counted to estimate the neuronal density in the hippocampal subfields. The quantification studies (Figure 3) revealed reduced neuronal density in granule cell layer (Kruskal-Wallis, $p<0.001$ ), CA4 (Kruskal-Wallis, $\mathrm{p}<0.001$ ), CAl (Kruskal-Wallis, $\mathrm{p}<0.001$ ) and prosubiculum (ANOVA, $\mathrm{p}<0.001$ ) of the MTLE group, when compared to Ctrl and TLE-TD groups. In CA2 subfield, the neuronal densities of MTLE and TLE-TD groups were reduced when compared to Ctrl (ANOVA, p<0.001). In CA3, MTLE and TLE-TD had reduced neuronal density when compare to each other and to the Ctrl group (ANOVA, $\mathrm{p}<0.001$ ). No differences in 
Table 1. Clinical history of patients with TLE (MTLE and TLE-TD) and Ctrl cases.

\begin{tabular}{lllll}
\hline Group & & & & \\
\hline Age at evaluation 1 (years) & Ctrl & MTLE & TLE-TD & P value \\
Epilepsy duration (years) & $42 \pm 16^{\#}$ & $38 \pm 10^{\#}$ & $26 \pm 12$ & 0.001 \\
Age at epilepsy onset (years) & - & $25 \pm 10^{\#}$ & $15 \pm 12$ & 0.002 \\
Minimal seizure frequency (per month) & - & $13 \pm 9$ & $12 \pm 7$ & 0.651 \\
Number of secondary generalizations (per month) & - & $16 \pm 23$ & $25 \pm 36$ & 0.397 \\
Frequency of secondary generalization (\%) & - & $4 \pm \pm$ & $4 \pm 9$ & 0.557 \\
\hline
\end{tabular}

${ }^{1}$ age of death for Ctrl and age at surgery for TLE.

\# = statistical difference to TLE-TD; Ctrl=control; MTLE= mesial temporal lobe epilepsy; TLE-TD=temporal lobe epilepsy associated with tumor or dysplasia.

doi:10.1371/journal.pone.0044709.t001

neuronal density were found in the subiculum (ANOVA, $\mathrm{p}=0.08$ ). All hippocampal regions of MTLE group showed reduced NeuN immunopositive area when compared with Ctrl, in agreement with neuron density measurements (Data not shown).

\section{Vesicular $\mathrm{Zn}^{2+}$ evaluation}

Vesicular $\mathrm{Zn}^{2+}$ content (Figures 2 and $\mathbf{4}$ ), estimated by gray value of neo-Timm staining, was increased only in the inner molecular layer of MTLE patients, compared to Ctrl $(\mathrm{p}<0.001)$. No differences were observed between Ctrl, MTLE and TLE-TD in the outer molecular layer $(\mathrm{p}=0.275)$, granule cell layer $(p=0.196)$, subgranule zone $(p=0.467)$ or hilus $/$ CA4 $(p=0.843)$.

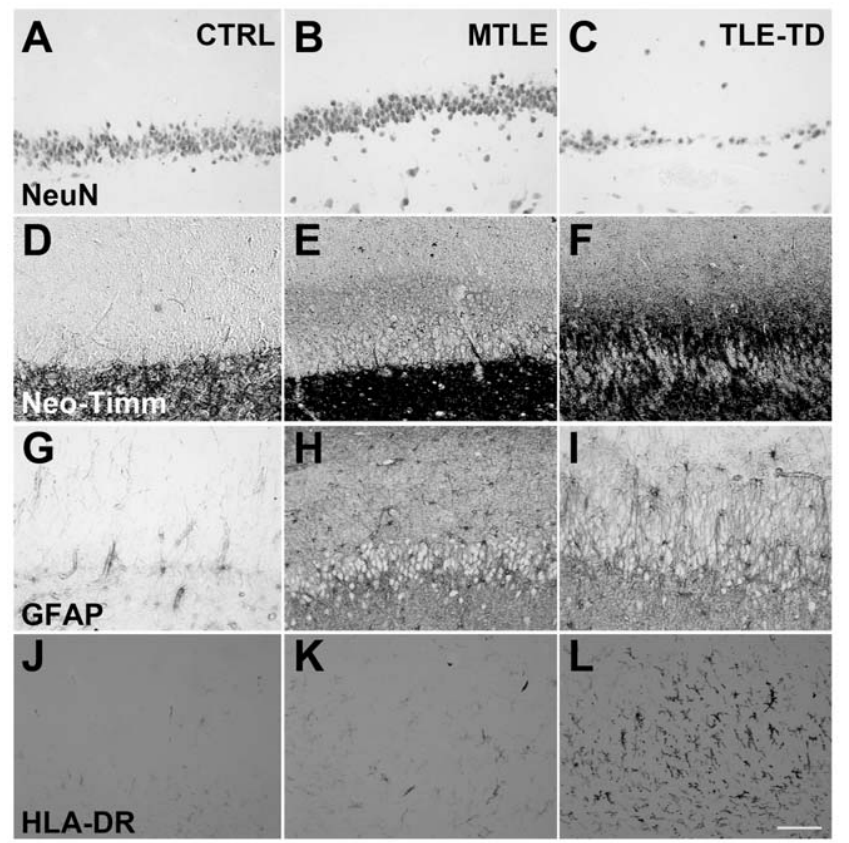

Figure 2. Representative images of NeuN, neo-Timm, GFAP and HLA-DR staining in the Fascia dentata of Ctrl, TLE-TD and MTLE patients. The pattern of NeuN staining is the same in Ctrl (A), TLE-TD (B) and MTLE (C) groups, but MTLE shows reduced neuronal population in this subfield. Compared to Ctrl (D), increased neo-Timm staining was observed in the inner molecular layer of fascia dentata in MTLE patients (F), but not in TLE-TD (E). As for the astroglial population, both hyperplasia and hypertrophy are observed in MTLE (I) and TLE-TD (H), compared to Ctrl (G). Hyperplasia is also observed in microglial cells in TLE-TD (K) and, more notable, in MTLE (L), compared to Ctrl (J). Bar in L indicates 100 micrometers.

doi:10.1371/journal.pone.0044709.g002

\section{Reactive astroglial population}

GFAP immunopositive area, shown in Figures 2 and $\mathbf{5}$, indicated increased GFAP immnunoreactivity labeling in the outer and inner molecular layers, granule cell layer, subgranule zone, hilus and CA4 of MTLE and TLE-TD, when compared to Ctrl (ANOVA for granule cell layer and Kruskal-Wallis for the remaining regions, $\mathrm{p}<0.001)$. In $\mathrm{CA} 2$, Sommer sector $(\mathrm{CA} 1$ and prosubiculum) and the subiculum, there was increased GFAP immnunoreactivity labeling of the MTLE group, when compared to Ctrl and TLE-TD (Kruskal-Wallis, $\mathrm{p}<0.001$ ). Increased reactive astrogliosis was also observed in CA3 of MTLE (Kruskal-Wallis, $\mathrm{p}<0.001$ ), when compared to Ctrl.

\section{Activated microglial population}

HLA-DR immunopositive area, shown in Figures 2 and $\mathbf{6}$, indicated increased labeling in subgranule zone (Kruskal-Wallis, $\mathrm{p}=0.002$ ), hilus (Kruskal-Wallis, $\mathrm{p}=0.017)$, CA3 (Kruskal-Wallis, $\mathrm{p}<0.001$ ), CA2 (Kruskal-Wallis, $\mathrm{p}<0.001$ ), prosubiculum (Kruskal-Wallis, $\mathrm{p}<0.001$ ) and subiculum (Kruskal-Wallis, $\mathrm{p}=0.009)$ of MTLE group, when compared to Ctrl. In outer molecular layer, granule cell layer and CA4 (Kruskal-Wallis, $\mathrm{p}<0.001$ ) HLA-DR immunopositivity was increased in MTLE and TLE-TD groups, when compared to Ctrl. MTLE group showed increased staining in the inner molecular layer and CAl when compared to both TLE-TD and Ctrl groups (Kruskal-Wallis, $\mathrm{p}<0.001$ ).

\section{Metallothionein I/II immunoreactivity}

MT-I/II staining revealed both cellular and neuropil staining (Figure 7A-F). MT-I/II-positive cells had astrocyte morphology, with small round soma and radial processes (Figure 7A-D). The staining was present in nucleus, cytoplasm and the proximal portion of the cytoplasmic processes. In two individuals of the Ctrl group and in one MTLE patient, some cells with neuronal morphology and size were also stained for MT-I/II (Figure 7E, F). No microglia-like cells were stained for MT-I/II. Neuropil staining showed a granular pattern in all hippocampal subfields (Figure 7A-F). Confocal microscopy confirmed the expression of MT-I/II in astrocytes by GFAP-positive labeling (Figure 8). A comparison between MT-I/II expression in Ctrl, TLE-TD and MTLE groups is shown in Figure 9.

Higher MT-I/II immunoreactivity area (Figure 10) was observed in both TLE groups, when compared to Ctrl group. The increase in MT-I/II immunoreactivity area observed in TLE was due to an increased number of MT-I/II-positive cells and to increased neuropil staining. MTLE group showed increased immunopositive area when compared to Ctrl in granule cell layer (Kruskal-Wallis, $\mathrm{p}=0.028$ ), hilus (Kruskal-Wallis, $\mathrm{p}<0.001$ ), CA3 

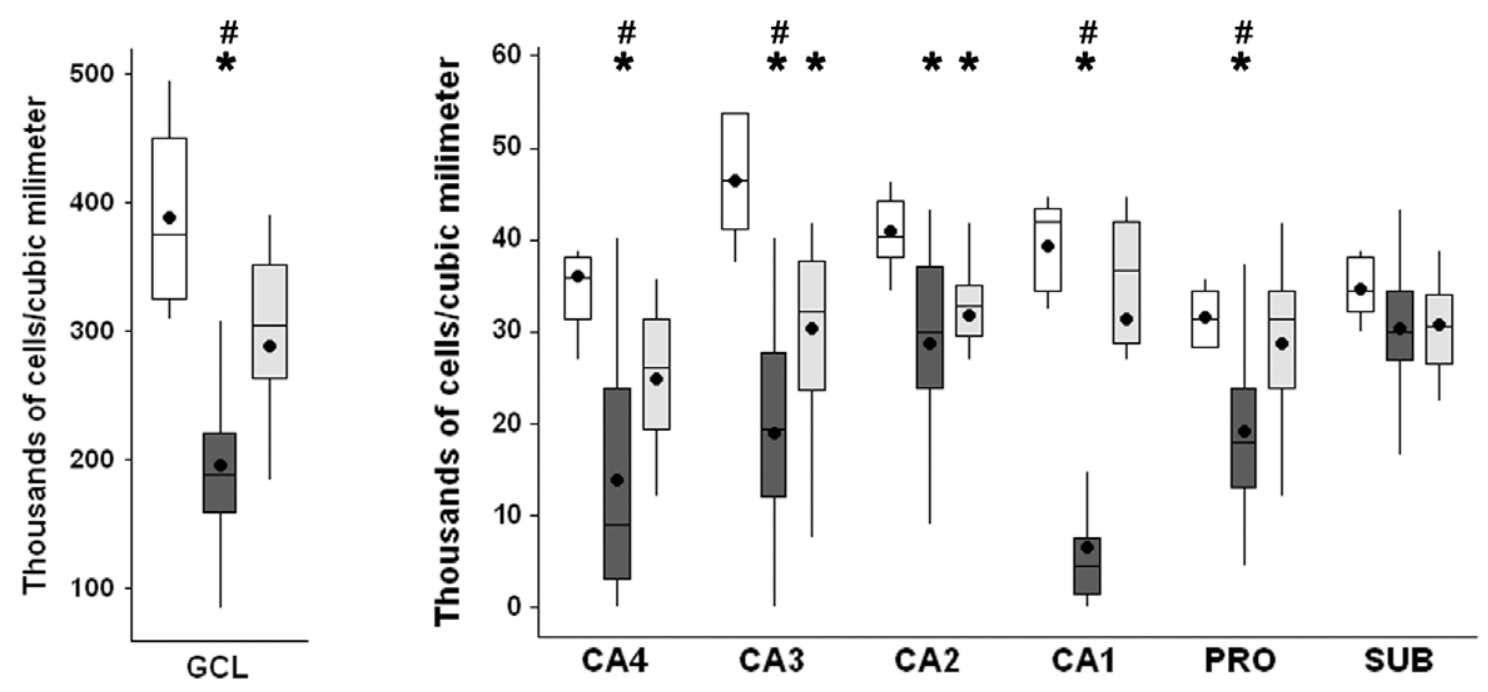

Figure 3. Neuronal density in hippocampal subfields of Ctrl, MTLE and TLE-TD groups. MTLE (dark gray boxplots) had reduced neuronal density (showed as thousands of cells per cubic millimeter), when compared to Ctrl (white boxplots) and TLE-TD (light gray boxplots), in granule cell layer (GCL), CA4, CA3, CA1 and prosubiculum, and in CA2, when compared to $C \operatorname{trl}(p<0.001)$. TLE-TD presented decreased neuronal density only in CA3 and CA2, compared to $\mathrm{Ctrl}(\mathrm{p}<0.001)$. The ${ }^{*}$ indicate difference from $\mathrm{Ctrl}$ and ${ }^{*}$ difference from TLE-TD. The dark circles indicate mean. doi:10.1371/journal.pone.0044709.g003

(ANOVA, $\mathrm{p}=0.003)$, GA2 (Kruskal-Wallis, $\mathrm{p}<0.001$ ) and subiculum (Kruskal-Wallis, $\mathrm{p}<0.001)$ and in CA4 when compared to TLE-TD (Kruskal-Wallis, $\mathrm{p}=0.041$ ). Both MTLE and TLE-TD groups had increased MT-I/II immunopositive area when compared to Ctrl in outer molecular layer (Kruskal-Wallis, $p=0.002)$, inner molecular layer (Kruskal-Wallis, $p=0.023)$, and subgranule zone (Kruskal-Wallis, $\mathrm{p}<0.001$ ). In $\mathrm{CAl}$ and the prossubiculum, the immunopositive area was increased in MTLE when compared with both TLE-TD and Ctrl (ANOVA, $\mathrm{p}<0.001)$.

\section{MT-I/II immunoreactivity and seizures}

In MTLE group, patients without secondary generalized seizures (SGS) had increased MT-I/II immunopositivity, when

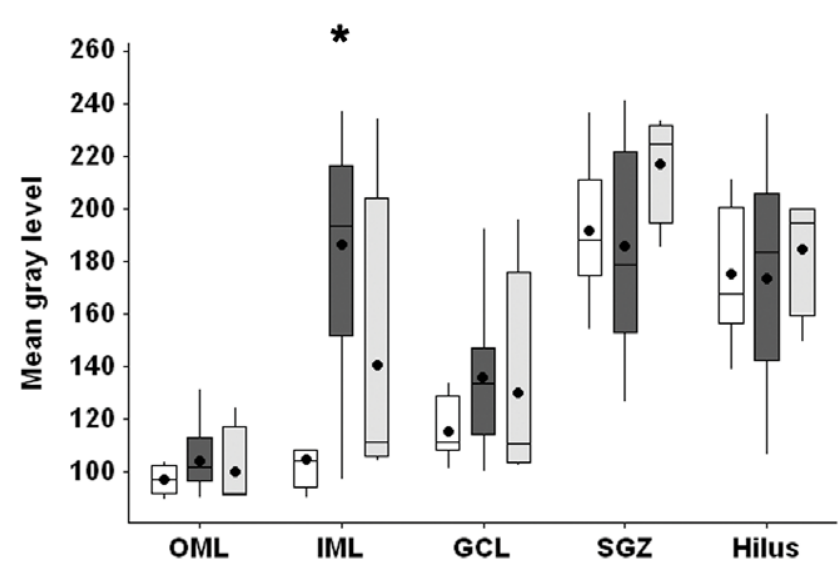

Figure 4. Vesicular zinc staining in the Fascia dentata of Ctrl, MTLE and TLE-TD groups. MTLE (dark gray boxplots) had increased neo-Timm staining (showed as gray level intensity), when compared to Ctrl (white boxplots), in the inner molecular layer (IML, $\mathrm{p}<0.001$ ). No difference was observed between TLE-TD (light gray boxplots) and Ctrl or MTLE. The * indicate difference from Ctrl. The dark circles indicate mean.

doi:10.1371/journal.pone.0044709.g004 compared with patients with SGS, in the inner molecular layer ( $\mathrm{t}$ test, $p=0.037$ ), granule cell layer ( $t$-test, $p=0.018$ ), subgranule zone (t-test, $\mathrm{p}=0.004), \mathrm{CA} 2$ (Mann-Whitney, $\mathrm{p}=0.039)$ and CA1 (t-test, $\mathrm{p}=0.043)$ (Figure 11). No differences in neuronal, astroglial or microglial populations were observed between MTLE patients with or without SGS. In TLE-TD patients, no differences in hippocampal MT-I/II immunopositivity, neuronal, astroglial or microglial populations were observed between patients with and without SGS. Frequency of seizures did not correlate with MT-I/ II immunopositivity in all hippocampal subfields.

Correlations between MT-I/II immunoreactivity, cellular populations and vesicular $\mathrm{Zn}^{2+}$

Considering all TLE patients, correlation analysis revealed that MT-I/II immunoreactivity correlated with GFAP immunoreactivity in CA4 $(\mathrm{r}=0.312 ; \mathrm{p}=0.012 ; \mathrm{n}=65)$, CA2 $(\mathrm{r}=0.275$; $\mathrm{p}=0.038 ; \mathrm{n}=57)$ and CAl $(\mathrm{r}=0.319 ; \mathrm{p}=0.004 ; \mathrm{n}=78)$ and with NeuN in CAl $(r=-0.241 ; p=0.034 ; n=78)$. No correlation was found between MT-I/II immunoreactivity and HLA-DR immunoreactivity or neo-Timm staining. In CA4, multiple linear regression revealed a trend to association between MT-I/II expression and GFAP immunopositivity $(\mathrm{r}=0.347 ; \mathrm{p}=0.061$, with $p=0.753$ for NeuN, $p=0.02$ for GFAP and $p=0.111$ for age; $n=53$ ). In CA2, multiple regression model revealed that MT expression was significantly explained by GFAP and age $(\mathrm{r}=0.574 ; \mathrm{p}<0.001$, with $\mathrm{p}=0.533$ for NeuN, $\mathrm{p}=0.018$ for GFAP, $\mathrm{p}<0.001$ for age; $\mathrm{n}=55$ ). In CAl, MT-I/II expression has a trend to be explained by increased GFAP immunoreactivity $(\mathrm{r}=0.364 ; \mathrm{p}=0.015$, with $\mathrm{p}=0.817$ for NeuN, $\mathrm{p}=0.069$ for GFAP and $p=0.107$ for age; $n=77$ ). In summary, in some hippocampal subfields (CA4, CA2, and CA1) there was a positive correlation between MT-I/II immunoreactivity and GFAP immunoreactivity. Different regressions models did not provided a best fit for any of the variables evaluated.

In TLE-TD, there was a positive correlation between NeuN and MT-I/II expression in CA4 $(r=0.543 ; p=0.0353 ; n=15)$. No correlation was observed between MT-I/II expression and GFAP, HLA-DR area or neo-Timm density in TLE-TD. Multiple linear 


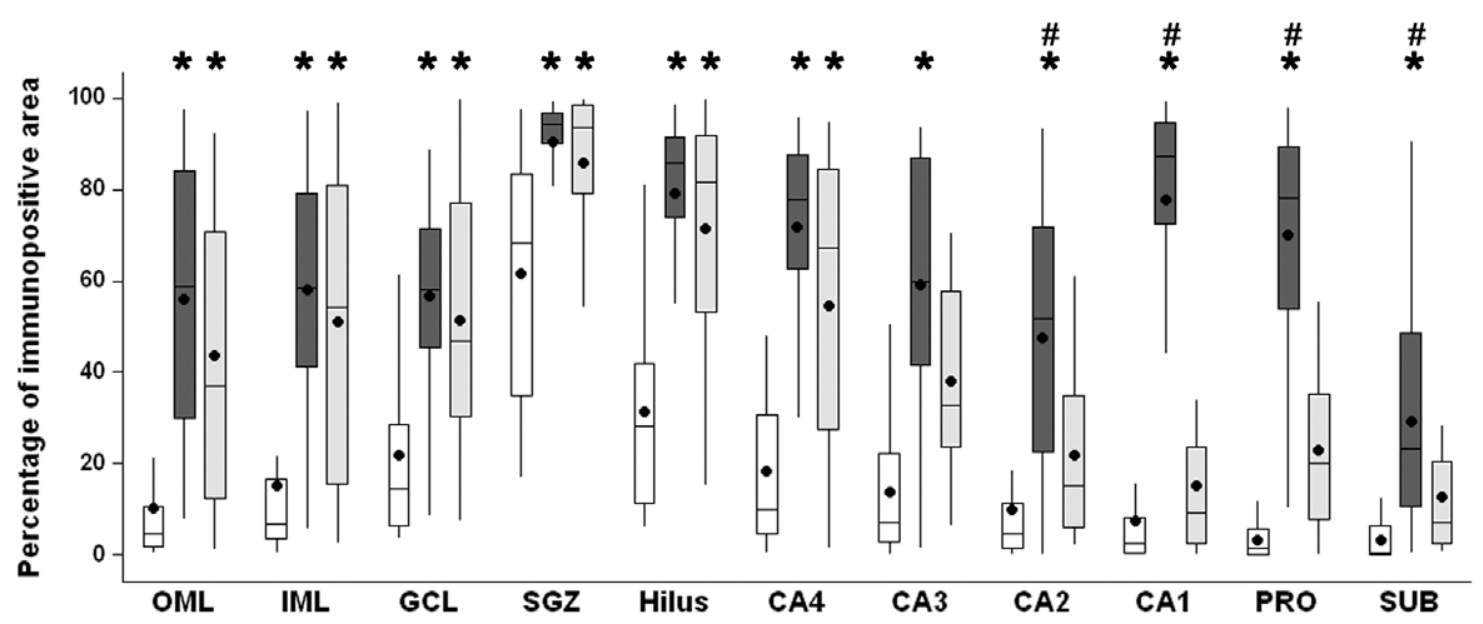

Figure 5. GFAP immunopositive area in hippocampal subfields of Ctrl, MTLE and TLE-TD groups. Compared to Ctrl (white boxplots), MTLE (dark gray boxplots) and TLE-TD (light gray boxplots) groups had increased GFAP immunoreactivity (showed as percentage of immunopositive area) in outer molecular layer (OML), inner molecular layer (IML), granule cell layer (GCL), subgranule zone (SGZ), hilus, CA4 and CA3 ( $<<0.001)$, and MTLE groups had increased GFAP immunopositivity in CA2, CA1, prosubiculum (PRO) and subiculum (SUB), compared to Ctrl and TLE-TD ( $<<0.001$ ). In the subiculum (SUB), TLE-TD had increased GFAP immunoreactivity, compared to Ctrl $(p<0.001)$. The ${ }^{*}$ indicate difference from Ctrl and ${ }^{*}$ difference from TLE-TD.

doi:10.1371/journal.pone.0044709.g005

regression model was not significant in CA4 $(\mathrm{r}=0.590 ; \mathrm{p}=0.179$ $\mathrm{n}=15)$, but NeuN was significantly associated with MT-I/II in this region $(\mathrm{p}=0.046$ for NeuN, $\mathrm{p}=0.662$ for GFAP and $\mathrm{p}=0.486$ for age). For the relation between neuronal population and MT-I/II expression in CA4, the quadratic model provided a better fit, when compared to the linear model $\left(r^{2}=0.48\right.$ and $p=0.014$ for the quadratic model versus $\mathrm{r}^{2}=0.333$ and $\mathrm{p}=0.019$ for the linear model)

In MTLE, MT-I/II immunoreactivity area correlated with GFAP area in CA4 (Pearson's test; $\mathrm{r}=0.319 ; \mathrm{p}=0.0241 ; \mathrm{n}=50$ ). No correlations were observed between MT expression and NeuN, HLA-DR or neo-Timm in MTLE. Multiple linear regression revealed no significance in CA4, although GFAP expression was significantly associated with MT expression $(\mathrm{r}=0.332 ; \mathrm{p}=0$. 175, with $\mathrm{p}=0.703$ for NeuN, $\mathrm{p}=0.042$ for
GFAP and $p=0.269$ for age; $n=46$ ). No other regression model than the linear provided a best fit for the variables evaluated.

\section{Discussion}

In the present study, we found an increased MT-I/II expression in all hippocampal subfields of MTLE patients and in the fascia dentata of patients with TLE-TD. In MTLE patients, MT-I/II expression correlated with astroglial population but not with neuronal population. In TLE-TD group, MT-I/II expression correlated positively with neuronal population only in CA4. In the CNS, MT-I/II are expressed mainly by astrocytes [46] and, when the tissue suffers an injury, increased MT-I/II expression is observed in astrocytes and microglias [46], [32]. In our study, an increased expression of MT-I/II was observed in astrocytes and

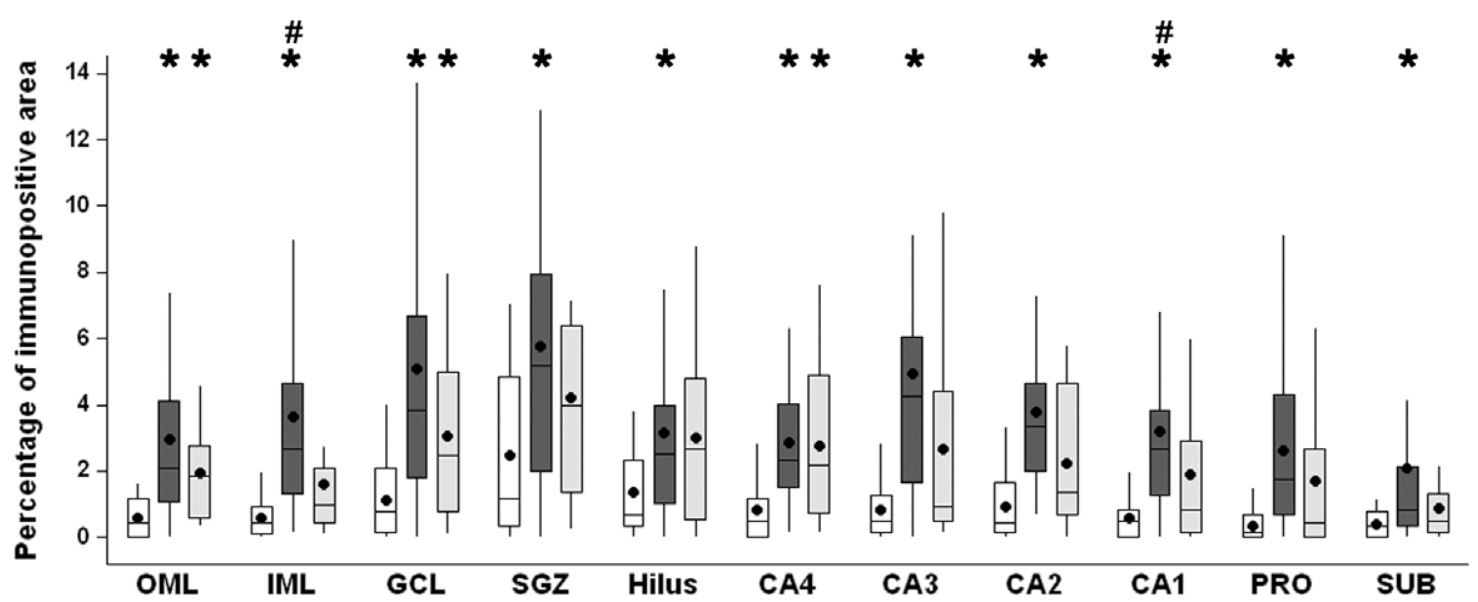

Figure 6. HLA-DR immunopositive area in hippocampal subfields of Ctrl, MTLE and TLE-TD groups. Compared to Ctrl (white boxplots), TLE groups had increased HLA-DR immunoreactivity (showed as percentage of immunopositive area) in outer molecular layer (OML), granule cell layer (GCL), CA4, and CA1 subfields $(p<0.001)$. MTLE (dark gray boxplots) had increased HLA-DR immunoreactivity in inner molecular layer (IML), subgranule zone (SGZ), hilus, CA3, CA2, prosubiculum (PRO) and subiculum (SUB) $(p<0.01$ ). In IML, MTLE also presented increased HLA-DR immunoreactivity when compared to TLE-TD $(p<0.001)$. The * indicate difference from Ctrl and ${ }^{*}$ difference from TLE-TD. doi:10.1371/journal.pone.0044709.g006 


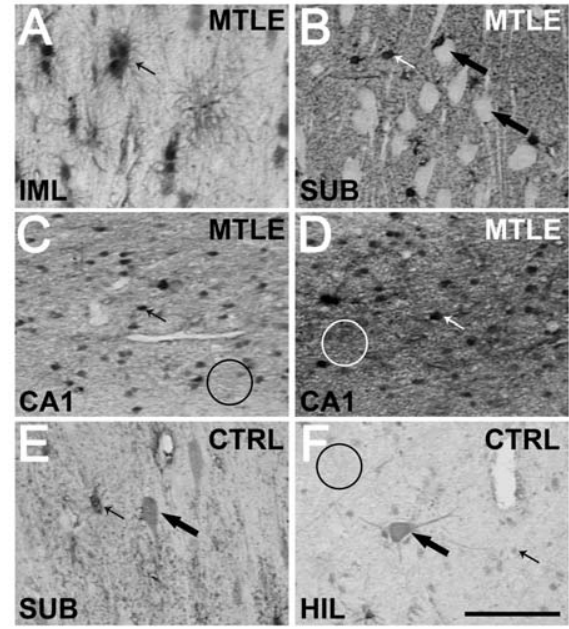

Figure 7. Representative images of $M T-I / I I$ staining in several hippocampal subfields. Almost all stained cells have astrocyte morphology (indicated by small arrows in A-F), while neurons remained unstained (white cells pointed by large arrows in B). Only in few cases from $\mathrm{Ctrl}(\mathrm{E}$ and $\mathrm{F}$ ) and in one region of one case of TLE were observed cells with neuron morphology (large arrows in $\mathrm{E}$ and F). No stained neuron presented the strong staining of astrocytes. In Ctrl, neuropil presented a weak staining (indicated by black circle in F). In TLE the neuropil staining level was heterogeneous, as can be seen in CA1 sections depicted in C and D (indicated by white circles). The representative images shown are from the fascia dentate (A), subiculum ( $\mathrm{B}$ and $\mathrm{E}), \mathrm{CA} 1$ ( $\mathrm{C}$ and $\mathrm{D})$ and hilus $(\mathrm{F})$ of $\mathrm{Ctrl}(\mathrm{E}$ and $\mathrm{F})$ and TLE cases ( $\mathrm{A}-$ D). Bar in $\mathrm{F}$ indicates 100 micrometers. doi:10.1371/journal.pone.0044709.g007

occasionally in neurons of autopsy and TLE patients. Confocal microscopy in our TLE patients corroborated the finding that MT-I/II are expressed by astrocytes. We also observed an increased expression of MT-I/II in the neuropil of TLE patients. Studies in tissue obtained from animal models of CNS injury have shown that increased MT-I/II expression in the neuropil is most likely the result of higher release of MT-I/II from the astrocytes [47], [48]. Therefore, our data support the notion that MT-I/II changes are essentially related to astroglial population.

Gliosis is a common finding in TLE [21], [22], [23], [24] and is associated with the degree of neuronal death [22], [49], [23], [24]. Similarly with MT-I/II expression, gliosis was more intense and widespread in MTLE than in TLE-TD groups. Furthermore, correlations between the degree of astrogliosis and the expression of MT-I/II observed in TLE patients indicate that MT-I/II expression in TLE is a phenomenon associated with the astrogliosis and, consequently, with the degree of tissue damage. In agreement with this hypothesis, an association between the severity of tissue damage and the increase in MT-I/II expression has been reported in mice subjected to soman-induced SE [35].

Studies in rodents with kainic acid-induced SE showed an association between MT-I/II expression and neuronal survival. Transgenic mice over-expressing MT-I/II have reduced neuronal death, compared to wild type animals [38]. In addition, mice with reduced MT-I/II expression [36] or in knockouts for MT-I/II [37] had increased neuronal death following SE, compared to wild type mice. In our study, MT-I/II expression correlated positively with neuronal population only in CA4 of TLE-TD patients. In MTLE group, where neuronal death and MT-I/II expression are more pronounced, no correlation between neuronal death and MT-I/II was observed. These findings contradict the hypothesis that an increased MT-I/II expression could be related with

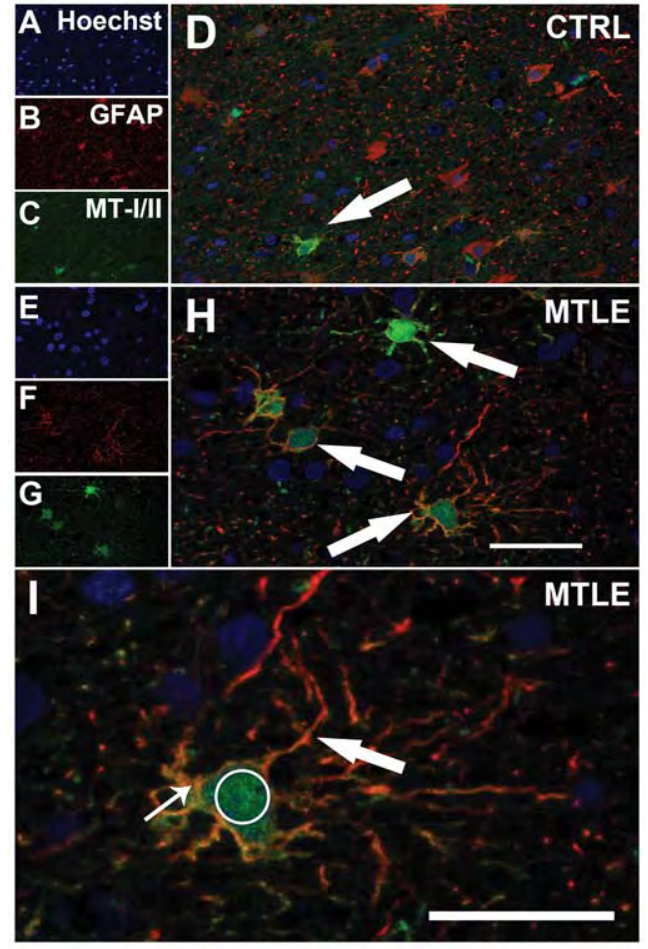

Figure 8. Confocal images of astrocytes expressing MT-I/II in Ctrl and TLE cases. TLE (E-H) patients presented more astrocytes (GFAP immunoreactive cells, red in $\mathrm{B}, \mathrm{F}, \mathrm{D}, \mathrm{H}$ and I) expressing MT-I/II (green in $C, G, D, H$ and $I$, indicated by white arrows in $D$ and $H$ ) than Ctrl (A-D). In a detailed view of $\mathrm{H}(\mathrm{I}), \mathrm{MT}-\mathrm{I} / \mathrm{Il}$ expression can be observed in radial branches (large arrow), soma (small arrow) and nucleus (Hoeschst 33342 staining, white circle) of astrocytes. Astrocytes are GFAP immunoreactivity) Bars in $\mathrm{H}$ and $\mathrm{I}$ indicate 50 micrometers. doi:10.1371/journal.pone.0044709.g008

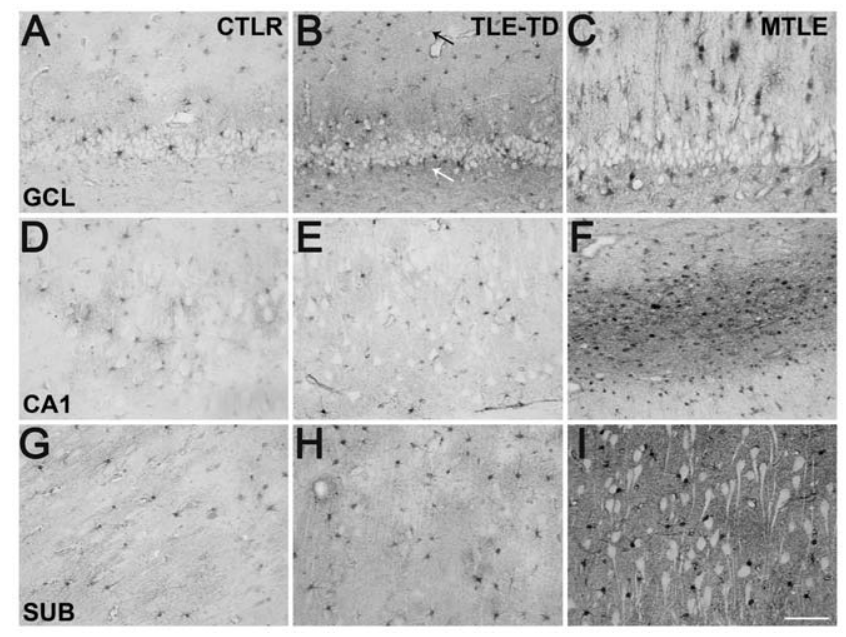

Figure 9. Representative sections of MT-I/II immunohistochemistry in hippocampal subfields from Ctrl, TLE-TD and MTLE patients. MTLE patients had widespread increase in MT-I/II when compared to Ctrl, demonstrated by increased cellular and neuropil staining in C, F and I. In TLE-TD patients, increased MT-I/II expression was observed only in the fascia dentata (B) outer molecular layer (small black arrow) and subgranule zone (small white arrow), the entry point of the hippocampus. The representative images shown are from the fascia dentata (A-C), CA1 (D-F) and subiculum (G-I). Bar in I indicates 100 micrometers.

doi:10.1371/journal.pone.0044709.g009 


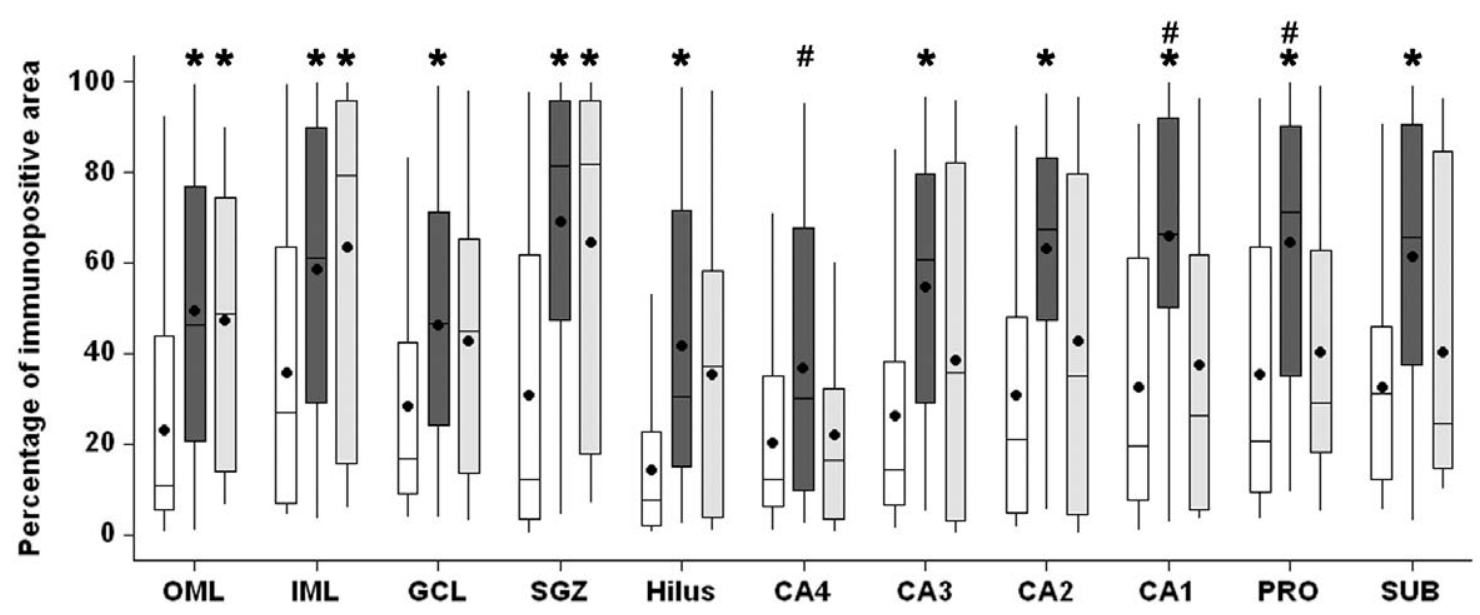

Figure 10. MT-I/II immunopositive area in hippocampal subfields of Ctrl, MTLE and TLE-TD groups. Compared to Ctrl (white boxplots), TLE groups had higher MT-I/II immunopositive area (showed as percentage of immunopositive area) in outer molecular layer (OML), inner molecular layer (IML) and subgranule zone (SGZ) $(p<0.01)$. MTLE (dark gray boxplots) had increased MT-I/II immunoreactivity in granule cell layer $(G C L)$, hilus, CA4, CA3, CA2, CA1, prosubiculum (PRO) and subiculum (SUB) $(p<0.05)$, compared to Ctrl, and also in CA1 when compared to TLE-TD ( $p<0.001)$. The * indicate difference from $\mathrm{Ctrl}$ and ${ }^{*}$ difference from TLE-TD.

doi:10.1371/journal.pone.0044709.g010

neuronal survival. Different mechanisms contribute to neuronal death that occurs in the hippocampus of MTLE and TLE-TD patients. In TLE-TD patients, evidence has been shown that neuronal death is a consequence of the recurrent seizures [50]. Although neuronal death in MTLE can also be caused by recurrent seizures [50], the bulk of neuronal death is rather a consequence of an initial precipitating insult (IPI), which usually occurs several years before the epilepsy onset [50], [51]. The neuronal death is also severe in MTLE, often resulting in hippocampal sclerosis, while TLE-TD patients generally have preserved neuronal density [18], [52]. In addition, data indicate that hippocampal atrophy may be determined by a strong genetic predisposition and occur in individuals who never had seizures [53]. Therefore, it is possible that the differential increase in MTI/II expression in TLE-TD and MTLE is also the result of the different mechanisms associated with neuronal death in such epileptic syndromes.
According to other studies, MTs could also be responsible to neuronal damage and death following SE. In mice knockout for $\mathrm{ZnT}$, a protein responsible to stock $\mathrm{Zn}^{2+}$ in synaptic vesicles, SE increases damage in CAl [39], [28], [29] and other cerebral regions [29], when compared to wild type mice. In these knockout mice lacking vesicular $\mathrm{Zn}^{2+}$, damage in CAl can be prevented by chelating extracellular $\mathrm{Zn}^{2+}$ [28], [29] or by knocking out MT-III gene [39], [29]. However, knocking out MT-III gene in mice with [54] or without vesicular $\mathrm{Zn}^{2+}$ [29] increases damage in CA3 after SE. Since all studies that associated MT-I/II with neuronal survival after SE studied mainly the CA3 region, where MT-III is also known to protect from damage [54], [29], one could argue that, in CAl and other hippocampal regions, MT-I/II could cause damage, similarly to MT-III. We did not find any positive association between increased MT-I/II expression and reduced neuronal population in all hippocampal subfields. Furthermore, mice with reduced levels of MT-I/II [36] have increased damage in CAl after SE. It is known that MT-I/II binds $\mathrm{Zn}^{2+}$ more

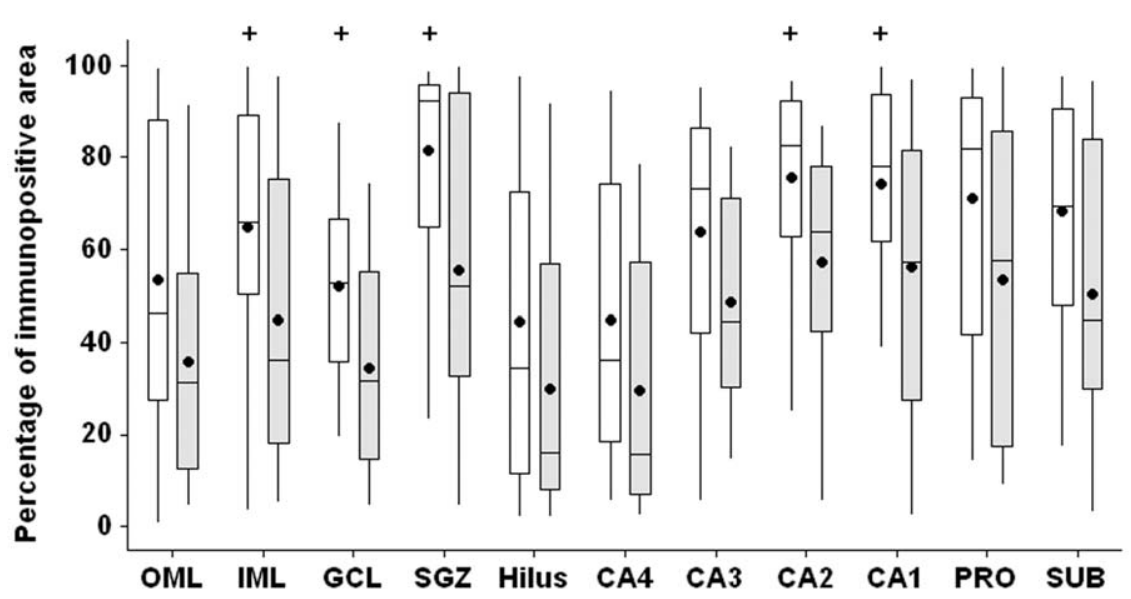

Figure 11. MT-I/II immunopositive area in MTLE patients without and with secondary generalized seizures. Patients without secondary generalization (white boxplots) present increased MT-I/II immunopositivity $(p<0.05)$ in the inner molecular layer (IML), granule cell layer $(G C L)$, subgranule zone (SGZ), CA2 and CA1, when compared with patients that present secondary generalization (light gray boxplots). The ${ }^{+}$indicates difference between the groups.

doi:10.1371/journal.pone.0044709.g011 
strongly that MT-III [55], [56]. These observations make us believe that MT-I/II do not contribute to the neuronal damage observed in the hippocampus of TLE patients. Further studies must be performed to better address this issue.

Several developmental studies have indicated that MT-I/II levels increase with the age, [57], [58], [59], [60], [61], [62], [63], [64]. On the other hand, reduced MT-I/II expression has also been reported in the adult rat brain when compared to young brain [65], and no differences were observed in aged and adult brain specimens of rat [66] and calf [67]. Also, it is already known that longer epilepsy duration can increase the neuronal death observed in hippocampal sclerosis and is associated with the neuronal death in non-sclerosis cases [50]. Therefore, we must also account for age and epilepsy duration as factors for the changes observed in MT-I/II expression. We did not see relation between epilepsy duration and MT expression in our multivariate analysis. However, in some regions, age at evaluation was significantly associated with MT-I/II expression. For example, in CA2 of all TLE patients and in CA4 of TLE-TD age at evaluation predicted MT-I/II expression. Although our findings indicate that age can contribute to the increased MT-I/II expression observed in TLE, the pathological changes associated to the epileptic condition (i.e., gliosis and neuronal death) are still the main factors related to the increased MT-I/II expression in the hippocampus of TLE patients.

Reorganization of vesicular $\mathrm{Zn}^{2+}$ in the hippocampus is often observed in TLE [19], [20], and $\mathrm{Zn}^{2+}$ can trigger MT-I/II expression [59]. Then, it is also important to consider the effect of the $\mathrm{Zn}^{2+}$ pool over MT-I/II expression. In agreement with other studies [68], [69], [19], we only observed significant increase in vesicular $\mathrm{Zn}^{2+}$ in the inner molecular layer of MTLE patients. No correlation was observed between MT-I/II expression and vesicular $\mathrm{Zn}^{2+}$ in our TLE cases. This does not exclude an association between MT-I/II expression and $\mathrm{Zn}^{2+}$, provided that only $10 \%$ of all $\mathrm{Zn}^{2+}$ in the brain is located in vesicles [70], [7] and only a small fraction of the $\mathrm{Zn}^{2+}$ released during neurotransmission will reach the astrocytes to induce MT-I/II expression.

Data have shown that the increased MT-I/II immunoreactivity observed in animal models of TLE can also be a factor associated with the seizure generation process. Transgenic mice overexpressing MT-I, have increased seizure duration, a tendency to reduced latency, but similar number of seizures after kainic acid administration [38]. Since MT-I/II act chelating free $\mathrm{Zn}^{2+}$ [31], [14] and $\mathrm{Zn}^{2+}$ chelation increases tissue excitability and facilitates seizure generation [71], excessive MT-I/II levels can reduce free $\mathrm{Zn}^{2+}$ in the synaptic cleft, increasing neuronal excitability and affecting seizure generation. Our data showed a similar frequency of seizure between MTLE and TLE-TD patients. In agreement with previous studies, we found no correlation between seizure frequency and MT-I/II expression in TLE [38].

In MTLE, we found increased levels of MT-I/II expression in patients without SGS, when compared with those with SGS. This could indicate that MT-I/II expression is associated with different seizure spread patterns from the epileptogenic hippocampus to other brain regions. It is important to point out that no difference in neurons or glial cells was observed between MTLE with and without SGS. Studies from different groups also observed no association between changes in the hippocampus and SGS [72], [73], [74]. These observations suggest that the increased MT-I/II expression in patients without SGS is not an effect of gliosis, but it is independently associated with SGS. Further studies with animal models of TLE should evaluate more closely the relationship between MT-I/II expression and seizure susceptibility.
The differential pattern of increase in MT-I/II expression in MTLE and TLE-TD patients may also be associated with the site of seizure generation. Seizures are known to induce MT-I/II expression in the epileptic hippocampus [75]. In MTLE patients, where MT-I/II increase was widespread, most focal seizures are generated within the hippocampus [76]. In TLE-TD, the seizures are generally generated in the cerebral cortex surrounding the tumor or in the cortical dysplasia and hence propagate to the hippocampus [18], [77], [78]. The main area of input entry in the hippocampus is the molecular layer of the fascia dentata [10], where increased MT-I/II expression was observed in the TLE-TD patients of our study.

Some limitations of our study must be pointed out. So far, studies about MT-I/II expression in animal models of TLE only evaluated the acute period following SE. Considering that our study was performed in patients with chronic epilepsy, it is difficult to establish comparisons between human and animal data. Besides, the reduced number of patients in the TLE-TD group can be the reason why only in one hippocampal subfields the neuronal density correlated with MT-I/II expression. The lack of correlation between seizure frequency and MT-I/II expression does not exclude an association between seizures and MT-I/II expression. Other seizure characteristics, such as seizure duration and time between the last seizure and the surgery, could better correlate with MT-I/II expression than isolated seizure frequency.

Finally, our study may have translational implications in the future. The role of MTs in antiinflamatory response, neurotrophic factor expression, and protection against ROS and heavy metals make those proteins interesting for clinical applications. Studies have shown that EmtinB, a syntethic peptide that mimics the actions of MTs, attenuates kainic acid-induced seizures and protects neurons from excitotoxic death [34]. Further studies with EmtinB and MTs in acute and chronic models of epilepsy might assess, in more detail, the role of these proteins in neuronal survival and seizure susceptibility.

In summary, our data indicate that increased MT-I/II expression is a plastic alteration of chronic TLE, primarily related to the astrogliosis, a common finding in chronic TLE. In opposition to other studies, MT-I/II expression was not associated with significant neuronal survival in TLE. Nevertheless, our findings suggest that increased MT-I/II expression may contribute to the control of the brain hyperexcitability.

\section{Supporting Information}

Figure S1 Representative images of immunohistochemistries in the temporal cortex from a MTLE patient. After surgery, tissue fragments were maintained in saline solution during 1 hour (A, F, K and P), 4 hours (B, G, L and Q $)$ and 8 hour $(\mathrm{C}, \mathrm{H}$, $\mathrm{M}$ and $\mathrm{R}$ ) prior to fixation in formaline. Note that no difference can be seen regardless of waiting time prior to fixation for MT-I/II (A-C), GFAP (F-H), HLA-DR $(\mathrm{K}-\mathrm{M})$ and NeuN (P-R) immunoreactivities. Statistical analyses did not revealed difference in immunopositive area (D, I, N and S) or gray level (E, J, O and $\mathrm{T})$ between tissues fixed after 1 (white boxplot), 2 (very light gray boxplot), 4 (light gray boxplot), 6 (medium gray boxplot) or 8 (dark gray boxplot) hours post surgery for MT-I/II (D and E), GFAP (I and J), HLA-DR ( $\mathrm{N}$ and $\mathrm{O}$ ) or NeuN ( $\mathrm{S}$ and $\mathrm{T}$ ). Bar in $\mathrm{R}$ indicates 100 micrometers.

(TIF)

\section{Author Contributions}

Conceived and designed the experiments: JEPS OYGA JPL. Performed the experiments: JEPS TRV LK RCS. Analyzed the data: JEPS OYGA. 
Contributed reagents/materials/analysis tools: JEPS LK JAA GGC RCS LNS JPL. Wrote the paper: JEPS TRV JPL.

\section{References}

1. Peters S, Koh J, Choi DW (1987) Zinc selectively blocks the action of N-methylD-aspartate on cortical neurons. Science 236 (4801): 589-593.

2. Westbrook GL, Mayer ML (1987) Micromolar concentrations of Zn2+ antagonize NMDA and GABA responses of hippocampal neurons. Nature 328 (6131): 640-643.

3. Rassendren FA, Lory P, Pin JP, Nargeot J (1990) Zinc has opposite effects on NMDA and non-NMDA receptors expressed in Xenopus oocytes. Neuron 4 (5): 733-740.

4. Haug FMS (1967) Electron microscopic localization of the zinc in hippocampal mossy fiber synapses by a modified sulphide silver procedure. Histochemie 8 : 355-368.

5. Frederickson CJ, Hernandez MD, McGinty JF (1989) Translocation of zinc may contribute to seizure-induced death of neurons. Brain Res 480 (1-2): 317-321.

6. Perez-Clausell J (1996) Distribution of terminal fields stained for zinc in the neocortex of the rat. J Chem Neuroanat 11 (2): 99-111.

7. Frederickson CJ, Suh SW, Silva D, Frederickson CJ, Thompson RB (2000) Importance of zinc in the central nervous system: the zinc-containing neuron. J Nutr 130 (5S Suppl): 1471S-1483S.

8. Brown CE, Dyck RH (2004) Distribution of zincergic neurons in the mouse forebrain. J Comp Neurol 479 (2): 156-167.

9. Takeda A, Itoh H, Tamano H, Oku N (2006) Responsiveness to kainate in young rats after 2-week zinc deprivation. Biometals 19 (5): 565-572.

10. Amaral D, Lavenex P (2006) Hippocampal Neuroanatomy. The Hippocampus Book: Oxford University Press. pp. 37-114

11. Mathern GW, Babb TL, Leite JP, Pretorius K, Yeoman KM, et al. (1996) The pathogenic and progressive features of chronic human hippocampal epilepsy. Epilepsy Res 26 (1): 151-161.

12. Pitkanen A (2002) Efficacy of current antiepileptics to prevent neurodegeneration in epilepsy models. Epilepsy Res 50 (1-2): 141-160.

13. Weiss JH, Sensi SL, Koh JY (2000) Zn(2+): a novel ionic mediator of neural injury in brain disease. Trends Pharmacol Sci 21 (10): 395-401.

14. Colvin RA, Fontaine CP, Laskowski M, Thomas D (2003) Zn2+ transporters and Zn2+ homeostasis in neurons. Eur J Pharmacol 479 (1-3): 171-185.

15. Kim EY, Koh JY, Kim YH, Sohn S, Joe E, et al. (1999) Zn2+ entry produces oxidative neuronal necrosis in cortical cell cultures. Eur J Neurosci 11 (1): 327334.

16. Treiber C (2005) Metals on the brain. Sci Aging Knowledge Environ 2005 (36): e27-

17. Frederickson CJ, Koh JY, Bush AI (2005) The neurobiology of zinc in health and disease. Nat Rev Neurosci 6 (6): 449-462.

18. Babb TL, Brown WJ, Pretorius J, Davenport C, Lieb JP, et al. (1984) Temporal lobe volumetric cell densities in temporal lobe epilepsy. Epilepsia 25 (6): 729 740.

19. Babb TL, Kupfer WR, Pretorius JK, Crandall PH, Levesque MF (1991) Synaptic reorganization by mossy fibers in human epileptic fascia dentata. Neuroscience 42 (2): 351-363.

20. Mathern GW, Leite JP, Babb TL, Pretorius JK, Kuhlman PA, et al. (1996) Aberrant hippocampal mossy fiber sprouting correlates with greater NMDAR2 receptor staining. Neuroreport 7 (5): 1029-1035.

21. Salanova V, Markand O, Worth R, Garg B, Patel H, et al. (1999) Presurgical evaluation and surgical outcome of temporal lobe epilepsy. Pediatr Neurol 20 (3): 179-184.

22. Proper EA, Jansen GH, van Veelen CW, van Rijen PG, Gispen WH, et al. (2001) A grading system for hippocampal sclerosis based on the degree of hippocampal mossy fiber sprouting. Acta Neuropathol (Berl) 101 (4): 405-409.

23. Swartz BE, Houser CR, Tomiyasu U, Walsh GO, DeSalles A, et al. (2006) Hippocampal cell loss in posttraumatic human epilepsy. Epilepsia 47 (8): 13731382.

24. Prayson RA, Yoder BJ (2007) Clinicopathologic findings in mesial temporal sclerosis treated with gamma knife radiotherapy. Ann Diagn Pathol 11 (1): 2226 .

25. Sutula T, Cascino G, Cavazos J, Parada I, Ramirez L (1989) Mossy fiber synaptic reorganization in the epileptic human temporal lobe. Ann Neurol 26 (3): $321-330$.

26. Sensi SL, Ton-That D, Sullivan PG, Jonas EA, Gee KR, et al. (2003) Modulation of mitochondrial function by endogenous $\mathrm{Zn} 2+$ pools. Proc Natl Acad Sci U S A 100 (10): 6157-6162.

27. Sensi SL, Paoletti P, Koh JY, Aizenman E, Bush AI, et al. (2011) The neurophysiology and pathology of brain zinc. J Neurosci 31 (45): 16076-16085.

28. Lee JY, Cole TB, Palmiter RD, Koh JY (2000) Accumulation of zinc in degenerating hippocampal neurons of ZnT3-null mice after seizures: evidence against synaptic vesicle origin. J Neurosci 20 (11): RC79

29. Lee JY, Kim JH, Palmiter RD, Koh JY (2003) Zinc released from metallothionein-iii may contribute to hippocampal CA1 and thalamic neuronal death following acute brain injury. Exp Neurol 184 (1): 337-347.

30. Kille P, Hemmings A, Lunney EA (1994) Memories of metallothioneis. Biochim Biophys Acta 1205 : 151-161.
31. Aschner M, Cherian MG, Klaassen CD, Palmiter RD, Erickson JC, et al. (1997) Metallothioneins in brain-the role in physiology and pathology. Toxicol Appl Pharmacol 142 (2): 229-242.

32. Wiese L, Kurtzhals JA, Penkowa M (2006) Neuronal apoptosis, metallothionein expression and proinflammatory responses during cerebral malaria in mice. Exp Neurol 200 (1): 216-226.

33. Ebadi M, Brown-Borg H, El RH, Singh BB, Garrett S, et al. (2005) Metallothionein-mediated neuroprotection in genetically engineered mouse models of Parkinson's disease. Brain Res Mol Brain Res 134 (1): 67-75.

34. Sonn K, Pankratova S, Korshunova I, Zharkovsky A, Bock E, et al. (2010) A metallothionein mimetic peptide protects neurons against kainic acid-induced excitotoxicity. J Neurosci Res 88 (5): 1074-1082.

35. Pazdernik TL, Emerson MR, Cross R, Nelson SR, Samson FE (2001) Somaninduced seizures: limbic activity, oxidative stress and neuroprotective proteins. J Appl Toxicol 21 Suppl 1 : S87-S94.

36. Penkowa M, Molinero A, Carrasco J, Hidalgo J (2001) Interleukin-6 deficiency reduces the brain inflammatory response and increases oxidative stress and neurodegeneration after kainic acid-induced seizures. Neuroscience 102 (4): 805-818.

37. Carrasco J, Penkowa M, Hadberg H, Molinero A, Hidalgo J (2000) Enhanced seizures and hippocampal neurodegeneration following kainic acid-induced seizures in metallothionein-I+II-deficient mice. Eur J Neurosci 12 (7): 23112322.

38. Penkowa M, Florit S, Giralt M, Ouintana A, Molinero A, et al. (2005) Metallothionein reduces central nervous system inflammation, neurodegeneration, and cell death following kainic acid-induced epileptic seizures. J Neurosci Res 79 (4): 522-534.

39. Cole TB, Robbins CA, Wenzel HJ, Schwartzkroin PA, Palmiter RD (2000) Seizures and neuronal damage in mice lacking vesicular zinc. Epilepsy Res 39 (2): 153-169.

40. Leite JP, Terra-Bustamante VC, Fernandes RM, Santos AC, Chimelli L, et al. (2000) Calcified neurocysticercotic lesions and postsurgery seizure control in temporal lobe epilepsy. Neurology 55 (10): 1485-1491.

41. Berg AT (2009) Identification of pharmacoresistant epilepsy. Neurol Clin 27 (4): 1003-1013.

42. Mathern GW, Leite JP, Pretorius JK, Quinn B, Peacock WJ, et al. (1994) Children with severe epilepsy: evidence of hippocampal neuron losses and aberrant mossy fiber sprouting during postnatal granule cell migration and differentiation. Brain Res Dev Brain Res 78 (1): 70-80.

43. Kandratavicius L, Hallak JE, Young LT, Assirati JA, Carlotti GG Jr, et al. (2012) Differential aberrant sprouting in temporal lobe epilepsy with psychiatric comorbidities. Psychiatry Res 195 (3): 144-150.

44. Lorente de Nó R (1934) Studies on the structure of the cerebral cortex. II. Continuation of the study of the ammoniac system. Journal of Psychologie und Neurologie $45: 113-177$.

45. Abercrombie M (1946) Estimation of nuclear population from microtome sections. Anat Rec 94 : 239-147.

46. Hidalgo J (2004) Metallothioneins and Brain Injury: What Transgenic Mice Tell Us. Environ Health Prev Med : 87-94.

47. Chung RS, West AK (2004) A role for extracellular metallothioneins in CNS injury and repair. Neuroscience 123 (3): 595-599.

48. Chung RS, Penkowa M, Dittmann J, King CE, Bartlett C, et al. (2008) Redefining the role of metallothionein within the injured brain: extracellular metallothioneins play an important role in the astrocyte-neuron response to injury. J Biol Chem 283 (22): 15349-15358.

49. Crespel A, Coubes P, Rousset MC, Brana C, Rougier A, et al. (2002) Inflammatory reactions in human medial temporal lobe epilepsy with hippocampal sclerosis. Brain Res 952 (2): 159-169.

50. Mathern GW, Adelson PD, Cahan LD, Leite JP (2002) Hippocampal neuron damage in human epilepsy: Meyer's hypothesis revised. Prog Brain Res 135 : 237-251.

51. Pitkanen A, Sutula TP (2002) Is epilepsy a progressive disorder? Prospects for new therapeutic approaches in temporal-lobe epilepsy. Lancet Neurol 1 (3): 173181.

52. Kim JH, Guimaraes PO, Shen MY, Masukawa LM, Spencer DD (1990) Hippocampal neuronal density in temporal lobe epilepsy with and without gliomas. Acta Neuropathol 80 (1): 41-45.

53. Kobayashi E, Li LM, Lopes-Cendes I, Cendes F (2002) Magnetic resonance imaging evidence of hippocampal sclerosis in asymptomatic, first-degree relatives of patients with familial mesial temporal lobe epilepsy. Arch Neurol 59 (12): 1891-1894.

54. Erickson JC, Hollopeter G, Thomas SA, Froelick GJ, Palmiter RD (1997) Disruption of the metallothionein-III gene in mice: analysis of brain zinc, behavior, and neuron vulnerability to metals, aging, and seizures. J Neurosci 17 (4): 1271-1281.

55. Frederickson CJ, Maret W, Cuajungco MP (2004) Zinc and excitotoxic brain injury: a new model. Neuroscientist 10 (1): 18-25. 
56. Palumaa P, Tammiste I, Kruusel K, Kangur L, Jornvall H, et al. (2005) Metal binding of metallothionein-3 versus metallothionein-2: lower affinity and higher plasticity. Biochim Biophys Acta 1747 (2): 205-211.

57. Natale JE, Knight JB, Cheng Y, Rome JE, Gallo V (2004) Metallothionein I and II mitigate age-dependent secondary brain injury. J Neurosci Res 78 (3): 303314.

58. Waalkes MP, Klaassen CD (1984) Postnatal ontogeny of metallothionein in various organs of the rat. Toxicol Appl Pharmacol 74 (3): 314-320.

59. Ebadi M, Iversen PL, Hao R, Cerutis DR, Rojas P, et al. (1995) Expression and Regulation of Brain Metallothionein. Neurochem Int 27 (1): 1-22.

60. Suzuki K, Nakajima K, Otaki N, Kimura M (1994) Metallothionein in developing human brain. Biol Signals 3 (4): 188-192.

61. Marijic VF, Raspor B (2006) Age- and tissue-dependent metallothionein and cytosolic metal distribution in a native Mediterranean fish, Mullus barbatus, from the Eastern Adriatic Sea. Comp Biochem Physiol C Toxicol Pharmacol 143 (4): 382-387.

62. Lu T, Pan Y, Kao SY, Li C, Kohane I, et al. (2004) Gene regulation and DNA damage in the ageing human brain. Nature 429 (6994): 883-891.

63. Suzuki K, Nakajima K, Kawaharada U, Uehara K, Hara F, et al. (1992) Metallothionein in the human brain. Acta Histochem Cytochem 25 (6): $617-$ 622.

64. Mocchegiani E, Bertoni-Freddari C, Marcellini F, Malavolta M (2005) Brain, aging and neurodegeneration: role of zinc ion availability. Prog Neurobiol 75 (6): 367-390.

65. Nishimura N, Nishimura H, Ghaffar A, Tohyama C (1992) Localization of metallothionein in the brain of rat and mouse. J Histochem Cytochem 40 (2): 309-315.

66. Gomi F, Nakano S, Uchida Y (2005) Tolerance of aged rat brains to mild hyperoxia: possible involvement of higher GIF content. Brain Res 1033 (1): 113116.

67. Zatta P, Drago D, Zambenedetti P, Bolognin S, Nogara E, et al. (2008) Accumulation of copper and other metal ions, and metallothionein I/II expression in the bovine brain as a function of aging. J Chem Neuroanat 36 (1): $1-5$.
68. Mathern GW, Pretorius JK, Babb TL, Quinn B (1995) Unilateral hippocampal mossy fiber sprouting and bilateral asymmetric neuron loss with episodic postictal psychosis. J Neurosurg 82 (2): 228-233.

69. Mathern GW, Pretorius JK, Babb TL (1995) Quantified patterns of mossy fiber sprouting and neuron densities in hippocampal and lesional seizures. J Neurosurg $82(2): 211-219$.

70. Frederickson CJ, Hernandez MD, Goik SA, Morton JD, McGinty JF (1988) Loss of zinc staining from hippocampal mossy fibers during kainic acid induced seizures: a histofluorescence study. Brain Res 446 (2): 383-386.

71. Dominguez MI, Blasco-Ibanez JM, Crespo C, Nacher J, Marques-Mari AI, et al. (2006) Neural overexcitation and implication of NMDA and AMPA receptors in a mouse model of temporal lobe epilepsy implying zinc chelation. Epilepsia 47 (5): 887-899.

72. Bernasconi N, Natsume J, Bernasconi A (2005) Progression in temporal lobe epilepsy: differential atrophy in mesial temporal structures. Neurology 65 (2): 223-228.

73. Szabo CA, Lancaster JL, Lee S, Xiong JH, Cook C, et al. (2006) MR imaging volumetry of subcortical structures and cerebellar hemispheres in temporal lobe epilepsy. AJNR Am J Neuroradiol 27 (10): 2155-2160.

74. O'Dwyer R, Silva Cunha JP, Vollmar C, Mauerer C, Feddersen B, et al. (2007) Lateralizing significance of quantitative analysis of head movements before secondary generalization of seizures of patients with temporal lobe epilepsy. Epilepsia 48 (3): 524-530.

75. Montpied P, de Bock F, Baldy-Moulinier M, Rondouin G (1998) Alterations of metallothionein II and apolipoprotein J mRNA levels in kainate-treated rats. Neuroreport 9 (1): 79-83.

76. Wennberg R, Arruda F, Quesney LF, Olivier A (2002) Preeminence of extrahippocampal structures in the generation of mesial temporal seizures: evidence from human depth electrode recordings. Epilepsia 43 (7): 716-726.

77. Engel J Jr (1996) Introduction to temporal lobe epilepsy. Epilepsy Res 26 (1): $141-150$.

78. Surges R, Schulze-Bonhage A, Altenmuller DM (2008) Hippocampal involvement in secondarily generalised seizures of extrahippocampal origin. J Neurol Neurosurg Psychiatry 79 (8): 924-929. 


\title{
Journal of \\ Epilepsy and \\ Clinical \\ Neurophysiology
}

J Epilepsy Clin Neurophysiol 2012;18(1):16-20

Trabalho vencedor do Prêmio Cesare Lombroso - XXXIV Congresso Brasileiro de Epilepsia -2012

\section{Different Levels of MT-I/II Between Patients With MTLE With or Without Seizure Generalization: Does Hippocampal MT-I/II Affects Seizure Spread, or Does Seizure Spread Promotes Differential Expression of MT-I/II?}

\author{
José Eduardo Peixoto-Santos ${ }^{\mathrm{a}}$, Orfa Yineth Galvis-Alonso ${ }^{\mathrm{b}}$, Tonicarlo R. Velasco ${ }^{\mathrm{a}}$, \\ Ludmyla Kandratavicius ${ }^{a}$, João Alberto Assirati Jrc ${ }^{c}$, Carlos Gilberto Carlottic, Renata Caldo Scandiuzzi ${ }^{\text {a }}$, \\ Luciano Neder Serafinid ${ }^{d}$, João Pereira Leite ${ }^{a}$ \\ Ribeirão Preto School of Medicine, University of São Paulo
}

\begin{abstract}
In the central nervous system, zinc is released along with glutamate during neurotransmission and, in excess, can promote neuronal death. Experimental studies have shown that metallothioneins I/II (MT-I/II), which chelate free zinc, can affect seizures and reduce neuronal death after status epilepticus. Our aim was to evaluate the expression of MT-I/II in the hippocampus of patients with temporal lobe epilepsy (TLE). Hippocampi from patients with pharmacoresistant mesial temporal lobe epilepsy (MTLE) were evaluated for expression of MT-I/II and for neuronal, astroglial, and microglial populations. Compared to control cases, MTLE group displayed widespread increase in MT-I/II expression, astrogliosis and reduced neuronal population. MT-I/II levels did not correlate with any clinical variables, but patients with secondary generalized seizures (SGS) had less MT-I/II than patients without SGS. In conclusion, MT-I/II expression was increased in hippocampi from MTLE patients and our data suggest that it may be associated with different seizure spread patterns.
\end{abstract}

Keywords: Metallothioneins; zinc homeostasis; gliosis; epilepsy; neuronal density.

\section{RESUMO}

Níveis diferentes de MT-I/II entre pacientes com MTLE com ou sem crise generalizada: os níveis hipocampais de MT-I/II afetam o alastramento das crises, ou o alastramento das crises promove expressão diferencial de MT-I/II?

No sistema nervoso central, o zinco é liberado juntamente com o glutamato durante a neurotransmissão e, quando liberado em excesso, pode promover morte neuronal. Estudos indicam que as metalotioneínas I/II (MT-I/II), proteínas quelantes de zinco livre, podem afetar parâmetros relacionados às crises e reduzir a morte neuronal subsequente a um status epilepticus. Nosso objetivo foi avaliar a expressão de MT-I/II no hipocampo de pacientes com epilepsia do lobo temporal (ELT). Hipocampos de pacientes com ELT mesial (ELTM) resistente ao tratamento farmacológico foram avaliados para a expressão de MT-I/II e para as populações neuronal e astroglial. Quando comparadas com o grupo controle, pacientes com ELTM apresentaram aumento na expressão de MT-I/II, astrogliose e redução na densidade neuronal. Não foram observadas correlações entre os níveis de MT-I/II e as características clínicas dos pacientes, mas pacientes com crises secundariamente generalizadas apresentaram um aumento menor nos níveis de MT-I/II que os pacientes sem estas crises. Em resumo, um aumento na expressão de MT-I/II é observado em pacientes com ELTM e nossos dados sugerem que o aumento pode estar associado a diferentes padrões de crises epilépticas.

Unitermos: Metalotioneínas; homeostase do zinco; gliose; epilepsia; densidade neuronal.

\footnotetext{
a Department of Neuroscience and Behavior, Ribeirão Preto School of Medicine, University of São Paulo.

${ }^{b}$ Department of Molecular Biology, São José do Rio Preto Medical School.

c Department of Neurosurgery, Ribeirão Preto School of Medicine, University of São Paulo.

d Department of Pathology, RibeirãoPreto School of Medicine, University of São Paulo.

Received Apr. 28, 2012; accepted Apr. 30, 2012.
} 


\section{INTRODUCTION}

Zinc $\left(\mathrm{Zn}^{2+}\right)$ is an important modulator of glutamatergic transmission in the central nervous system $(\mathrm{CNS}){ }^{1-3} \mathrm{Zn}^{2+}$ is concentrated in presynaptic vesicles, along with glutamate, and released during normal neurotransmission. ${ }^{4-8}$ Hippocampal neurons are specially rich in vesicular $\mathrm{Zn}^{2+}$, particularly in the axonal boutons of granule cells, CA3 and CA1 pyramidal cells and prosubicular neurons. . $^{5,9,10}$ In temporal lobe epilepsy (TLE), one of the most frequent drug-resistant epilepsies in adults, the hippocampus is associated with seizure generation. ${ }^{11,12}$ The intense neuronal activity during seizures can release high amounts of $\mathrm{Zn}^{2+}$ in the synaptic cleft, ${ }^{13,14}$ promoting reactive oxygen species (ROS) production, ${ }^{15}$ which can ultimately lead to hippocampal neuronal death. ${ }^{13-17} \mathrm{In}$ fact, studies in hippocampi from TLE patients who underwent epilepsy surgery have shown neuronal loss, ${ }^{18-20}$ increased glial reaction ${ }^{21-24}$ and reorganization of mossy fibers axon collaterals into the inner molecular layer of the granule cell dendrites. ${ }^{19,25}$ This synaptic reorganization of $\mathrm{Zn}^{2+}$, enriched terminals has been hypothesized to contribute to synchronous firing and epileptiform activity. ${ }^{19}$

Metallothioneins (MTs) are low molecular weight, cystein-enriched proteins that bound $\mathrm{Zn}^{2+}$ and cadmium. They can be found in various tissues, in four isoforms. ${ }^{26}$ Isoforms I, II and III are found in the central nervous system (CNS), where the isoforms I and II are coexpressed in astrocytes and the isoform III is expressed in neurons. ${ }^{27,28}$ MTs participate in $\mathrm{Zn}^{2+}$ homeostasis, scavenging ROS in the brain $^{29}$ and stimulate the expression of several neurotrophic and antiinflamatory factors. ${ }^{30}$ Studies on rodent models of TLE have shown that MT expression is increased in the hippocampal formation shortly after seizures ${ }^{31,32}$ and that high levels of MTs I and II are associated with reduced neuronal death after seizure-induced damage. ${ }^{32-34}$

Since MT-I/II levels may be associated with neuron survival after seizures, we hypothesize that MT-I/II expression is altered in TLE and can be associated with the preservation of neuronal density in the hippocampus of TLE patients. Therefore, in this study we evaluated the immunoexpression of MT-I/II and its correlation with hippocampal neuron density in hippocampi of patients with chronic TLE.

\section{MATERIALS AND METHODS}

\section{Patients and clinical data}

Patients with drug-resistant epilepsy were evaluated at the University of São Paulo Epilepsy Surgical Centre in Ribeirão Preto (Brazil), according to standard protocols published elsewhere. ${ }^{35}$ MTLE patients $(n=69)$ were patients with hippocampal atrophy or with normal hippocampal volume at MRI without other lesions associated with TLE.
For comparison purposes in the neuropathology studies, autopsy controls (Ctrl, $\mathrm{n}=20$ ) were obtained from autopsy cases without history of neurological diseases, with no sign of CNS pathologies in post mortem pathological evaluation, and with less than 10 hours post mortem.

Medical records of all evaluated patients were assessed for clinical data analysis. The clinical variables investigated were age at death and cause of death for Ctrl patients and age at surgery, epilepsy duration, age at the first recurrent seizure, seizure frequency per month, presence of secondary generalized seizures, and neuropathological evaluation for MTLE patients. This study followed the principles of the Declaration of Helsinki, was registered in Brazilian's Health Ministry and was approved by our local ethics committee (processes HCRP 9370/2003 and HCRP 2634/2008).

\section{Tissue collection and immunohistochemistry}

Hippocampi from surgery or autopsy were cut in coronal sections and placed in 10\% (vol/vol) buffered formaldehyde for one week, followed by paraffin embedding. Immunohistochemistry was performed in $8 \mu \mathrm{m}$ sections at the level of hippocampal body for evaluation of neuronal and astroglial populations and for MT-I/II expression with antibodies against, respectively, NeuN, GFAP and MT-I/II. The sections were submitted to endogenous peroxidase blocking with $4.5 \% \mathrm{H}_{2} \mathrm{O}_{2}$ in $50 \mathrm{mM}$ phosphate-saline buffer (PSB) pH 7.4, for 15 minutes, followed by microwave antigenic retrieval in $10 \mathrm{mM}$ sodium citrate buffer $\mathrm{pH} 6.0$ (for GFAP) or $50 \mathrm{mM}$ Tris-HCl pH 9.6 (for NeuN and MT-I/II). After achieving room temperature, the sections went through blocking free aldehyde groups with Tris-glycine $0.1 \mathrm{M} \mathrm{pH} 7.4$ for 45 minutes, followed by blocking buffer with $5 \%$ defatted milk and 15\% goat serum (\# S-1000, Vector) in Triton buffer (PTB, $20 \mathrm{mM}$ phosphate $+0.45 \mathrm{M} \mathrm{NaCl}, \mathrm{pH}$ 7.4 , with $0.3 \%$ Triton X-100) for four hours. The sections were then incubated with primary antibodies in blocking buffer for 16 hours. We used primary monoclonal antibodies raised in mouse anti-human GFAP (clone 6F2, \#M0761, Dako), anti-murine NeuN (clone A60, \#MAB377, Chemicon) and anti-equine MT-I/II (clone E9, \#M0639, Dako), diluted in blocking buffer at concentrations of 1:500. The primary antibodies were detected using biotinylated rabbit anti-murine IgG (\#E0354, Dako), at 1:200 dilution in blocking buffer, for one hour, followed by revelation with avidin-biotin-peroxidase system (Vectastain Elite ABC kit, \#PK6100, Vector) and diaminobenzidine as chromogen (DAB, \#34001, Pierce Biotechnology). The development times in DAB solution were 10.5 minutes for NeuN and 8 minutes for MT-I/II and GFAP.

\section{Immunohistochemistry analysis}

Images of all hippocampal regions were obtained with a video monochrome charge-coupled device camera (CCD; 
Hamamatsu Photonics Model 2400, Japan) attached to an Olympus microscope (Model BX60, Melville, NY), and captured, averaged, and digitized using a frame grabber (Scion Corporation, Frederick, MD) on a Macintosh computer (Model G3, Cupertino, CA). Illuminance was uniformly maintained and regularly checked using optical density standards (Kodak, Rochester, NY). After captured, the image was analyzed using image system software (ImageJ, version 1.37c).

Quantification of the immunohistochemistry was performed with threshold tool, with the investigator blind to the group allocation. After the selection of the region of interest (ROI), the software calculated the immunopositive area by counting all pixels with gray intensity equal or superior to the threshold of staining. A complete protocol for threshold tool can be found at rsbweb.nih.gov/ij/docs/ examples/stained-sections/index.html. The threshold was defined for each protein evaluated, based on the mean immunopositivity of all control cases. The evaluated regions were outer molecular layer (OML), inner molecular layer (IML), granule cell layer (GCL), subgranular zone (SGZ), the hilus (HIL) and the stratus piramidale of CA4, CA3, CA2, CA1, prosubiculum (PRO) and subiculum (SUB). The characterization of hippocampal regions was based on the Lorente de Nós classification. ${ }^{36}$ Results were shown as percentage of immunopositive area/total area.

Additionally, neuronal density was evaluated in the NeuN stained sections. Neuronal count was processed in Image 1.37 c software with a 520x magnification for granule cell layer and 260x for pyramidal neurons of CA4, CA3, CA2, CA1, prosubiculum and subiculum. Neuronal densities were estimated with the correction of Abercrombie ${ }^{37}$, which permits to estimate the neuronal density through mathematical method, and the results were shown as thousands of cells per cubic millimeter.

\section{Statistical analysis}

Statistics were carried out in SigmaStat 3.1 software. Tests for normality and homogeneity of variances were performed to define data distribution. For parametric variables, t-test was performed and, for the non-parametric variables, MannWhitney test was used. Correlation between MT expression and clinical variables was performed using Pearson's test. All results were considered significant at $p<0.05$.

\section{RESULTS}

\section{Clinical data}

The clinical characteristics of study participants are summarized in Table 1. Patients with MTLE and Ctrl patients have the same age $(p=0.175)$. Epilepsy duration was $25 \pm 10$ years, and the age at onset was $13 \pm 1$. MTLE patients had seven seizures by month, being one of those a secondary generalized seizure (SGS).

Table 1. Clinical history of patients with MTLE and Ctrl cases

\begin{tabular}{lcc}
\hline \multicolumn{1}{c}{ Group } & Ctrl & MTLE \\
\hline Age at evaluation* (years) & $42 \pm 16$ & $38 \pm 10$ \\
Epilepsy duration (years) & - & $25 \pm 10$ \\
Age at epilepsy onset (years) & - & $13 \pm 1$ \\
Minimal seizure frequency (per month) & - & 7 \\
Number of secondary generalizations (per month) & - & 1 \\
Frequency of secondary generalization (\%) & - & 59 \\
\hline
\end{tabular}

* Age of death for Ctrl and age at surgery for TLE.

\section{Immunohistochemistry evaluation}

Neuronal density, estimated with the count of NeuN positive cells, was reduced in the granule cell layer, CA4, CA3, CA2, CA1, prosubiculum and subiculum of the MTLE group, when compared to Ctrl $(p<0.03)$. Increased astrogliosis was observed in all hippocampal regions of MTLE, compared to Ctrl $(p<0.001)$. MT-I/II expression, observed in astrocyte-like cells, was increased in all hippocampal subfields evaluated $(p<0.032)$. For further details, see Table 2 .

Table 2. Neuronal density and percentage of immunopositive area for GFAP and MT-I/II in patients with MTLE and Ctrl

\begin{tabular}{lccccccccc}
\hline \multirow{2}{*}{ Region } & \multicolumn{3}{c}{ NeuN $^{*}$} & \multicolumn{3}{c}{ GFAP** $^{* *}$} & \multicolumn{3}{c}{ MT-I/II** $^{*}$} \\
\cline { 2 - 10 } OML & MTLE & Ctrl & $\boldsymbol{p}$ & MTLE & Ctrl & $\boldsymbol{p}$ & MTLE & Ctrl & $\boldsymbol{p}$ \\
IML & - & - & - & 59 & 4 & $<0.001$ & 46 & 10 & $<0.001$ \\
GCL & 187.5 & 375 & $<0.001$ & $57 \pm 18$ & $22 \pm 18$ & $<0.001$ & $46 \pm 26$ & $28 \pm 26$ & 0.008 \\
SGZ & - & - & - & 90 & 69 & $<0.001$ & 48 & 11 & $<0.001$ \\
HIL & - & - & - & 86 & 28 & $<0.001$ & 30 & 7 & $<0.001$ \\
CA4 & 9.0 & 35.9 & $<0.001$ & $72 \pm 22$ & $18 \pm 21$ & $<0.001$ & 30 & 12 & 0.031 \\
CA3 & $19 \pm 11$ & $47 \pm 6$ & $<0.001$ & 60 & 6 & $<0.001$ & $55 \pm 28$ & $27 \pm 28$ & $<0.001$ \\
CA2 & $29 \pm 9$ & $41 \pm 4$ & $<0.001$ & 52 & 5 & $<0.001$ & $62 \pm 25$ & $30 \pm 29$ & $<0.001$ \\
CA1 & 4.5 & 41.9 & $<0.001$ & 87 & 2 & $<0.001$ & $66 \pm 28$ & $31 \pm 31$ & $<0.001$ \\
PRO & $19 \pm 8$ & $32 \pm 3$ & $<0.001$ & 78 & 1 & $<0.001$ & $64 \pm 29$ & $34 \pm 32$ & $<0.001$ \\
SUB & $30 \pm 6$ & $35 \pm 3$ & 0.029 & 23 & 0.2 & $<0.001$ & 66 & 31 & $<0.001$ \\
\hline
\end{tabular}

* Neuronal density, as thousands of cells per cubic millimeter.

** Percentage of immunopositive area in the amostral area. 
The results are shown as median (for Mann Whitney test) or mean \pm standard deviation (for Student's t-test). $\mathrm{OML}=$ outer molecular layer; $\mathrm{IML}=$ inner molecular layer; $\mathrm{GCL}=$ granule cell layer; $\mathrm{SGZ}=$ subgranule zone; $\mathrm{HIL}=$ hilus; $\mathrm{PRO}=$ prosubiculum $\mathrm{SUB}=$ subiculum .

\section{Tissue alterations and seizures}

In MTLE group, patients without SGS had increased MT-I/II immunopositivity, when compared with patients with SGS, in the inner molecular layer $(p=0.037)$, granule cell layer $(p=0.018)$, subgranule zone $(p=0.004)$, CA2 $(p=0.039)$ and CA1 $(p<0.043)$. A trend to increased MT-I/II immunopositivity was observed in the outer molecular layer $(p=0.072)$, CA4 $(p=0.076)$ and subiculum $(p=0.068)$. No differences in neuronal or astroglial populations were observed between MTLE patients with or without SGS. Frequency of seizures did not correlate with NeuN, GFAP or MT-I/II in all hippocampal subfields.

\section{DISCUSSION}

In the present study, we found an increased MT-I/II expression in all hippocampal subfields of MTLE patients. In the CNS, MT-I/II are expressed mainly by astrocytes ${ }^{38}$ and, when the tissue suffers an injury, increased MT-I/II expression is observed in astrocytes and microglias. ${ }^{28,38}$ We also observed that higher degree of MT-I/II expression was observed in regions with higher astrogliosis. Increased glial population is a common finding in TLE $21-24$ and is associated with the degree of neuronal death. ${ }^{22-24,39}$ In our study, an increased expression of MT-I/II was observed in astrocytes and in a few neurons of some patients. Thus, our data support the notion that MT-I/II changes are essentially related to astroglial population.

Studies in rodents with kainic acid-induced SE showed an association between MT-I/II expression and neuronal protection. Transgenic mice over-expressing MT-I/II have reduced neuronal death, compared to wild type animals. ${ }^{34}$ In addition, mice with reduced MT-I/II expression ${ }^{32}$ or knockouts for MT-I/II ${ }^{33}$ had increased neuronal death following SE, compared to wild type mice. In our study, however, the higher MT-I/II expression was observed in regions with lower neuronal density, indicating that MT-I/II was not associated with neuronal survival. In agreement with our data, an association between the severity of tissue damage and the increase in MT-I/II expression has been reported in mice subjected to soman-induced status epilepticus (SE). ${ }^{31}$

Data have shown that the increased MT-I/II immunoreactivity observed in animal models of TLE can also be a factor associated with the seizure generation process. Transgenic mice over-expressing MT-I, have increased seizure duration, a tendency to reduced latency, but similar number of seizures after KA administration. ${ }^{34}$
Since MT-I/II act chelating free $\mathrm{Zn}^{2+14,27}$ and $\mathrm{Zn}^{2+}$ chelation increases tissue excitability and facilitates seizure generation ${ }^{40}$, excessive MT-I/II levels can reduce free $\mathrm{Zn}^{2+}$ in the synaptic cleft, increasing neuronal excitability and affecting seizure generation. We found no correlation between seizure frequency and MT-I/II expression in TLE. ${ }^{34}$

In MTLE, we found increased levels of MT-I/II in patients without SGS, when compared with those with SGS. This could indicate that MT-I/II is associated with different seizure spread patterns from the epileptogenic hippocampus to other brain regions. It is important to point out that no difference in neurons or glial cells was observed between MTLE with and without SGS. Studies from different groups also observed no association between changes in the hippocampus and SGS. ${ }^{41-43}$ All those observations suggest that the increased MT-I/II expression in patients without SGS is not an effect of gliosis, but it is independently associated with SGS. Further studies with animal models of TLE must evaluate more closely the relationship between MT-I/II expression and seizure susceptibility.

Some limitations of our study must be pointed out. So far, studies about MT-I/II expression in animal models of TLE only evaluated the acute period following SE. Considering that our study was performed in patients with chronic epilepsy, it is difficult to establish comparisons between human and animal data. The lack of correlation between seizure frequency and MT-I/II expression does not exclude an association between seizures and MT-I/II expression. Other seizure characteristics, such as seizure duration and time between the last seizure and the surgery, could better correlate with MT-I/II expression than isolate seizure frequency.

Finally, our study may have translational implications in the future. The role of MTs in antiinflamatory response, neurotrophic factor expression, and protection against ROS and heavy metals make those proteins interesting for clinical applications. Studies have shown that EmtinB, a syntethic peptide that mimics the actions of MTs, attenuates KA-induced seizures and protects neurons from excitotoxic death. ${ }^{30}$ Further studies with EmtinB and MTs should be done to evaluate the role of these proteins in neuronal survival and seizure susceptibility.

In summary, our data indicate that increased MT-I/II expression is a plastic alteration of chronic TLE, primarily related to the astrogliosis, a common finding in chronic TLE. Our findings suggest that increase MT-I/II expression may contribute to the control of the brain hyperexcitability.

\section{ACKNOWLEDGMENTS}

The present work was supported by FAPESP (Research grants 2005/56447-7 and 2009/53447-7 to JPL and Master's grant 2008/52657-5 to JEPS), CNPq and CAPES. 


\section{REFERENCES}

1. Peters S, Koh J, Choi DW. Zinc selectively blocks the action of $\mathrm{N}$-methyl-D-aspartate on cortical neurons. Science 1987;236:589-93.

2. Westbrook GL, Mayer ML. Micromolar concentrations of $\mathrm{Zn}^{2+}$ antagonize NMDA and GABA responses of hippocampal neurons. Nature 1987;328:640-643.

3. Rassendren FA, Lory P, Pin JP, Nargeot J. Zinc has opposite effects on NMDA and non-NMDA receptors expressed in Xenopus oocytes. Neuron 1990;4:733-40.

4. Haug FMS. Electron microscopic localization of the zinc in hippocampal mossy fiber synapses by a modified sulphide silver procedure. Histochemie 1967;8:355-68.

5. Frederickson CJ, Hernandez MD, McGinty JF. Translocation of zinc may contribute to seizure-induced death of neurons. Brain Res 1989;480:317-21.

6. Perez-Clausell J. Distribution of terminal fields stained for zinc in the neocortex of the rat. J Chem Neuroanat 1996;11:99-111.

7. Frederickson CJ, Suh SW, Silva D, Frederickson CJ, Thompson RB. Importance of zinc in the central nervous system: the zinc-containing neuron. J Nutr 2000;130:1471S-83S.

8. Brown CE, Dyck RH.Distribution of zincergic neurons in the mouse forebrain. J Comp Neurol 2004;479:156-67.

9. Takeda $\mathrm{A}$, Itoh $\mathrm{H}$, Tamano $\mathrm{H}, \mathrm{Oku} \mathrm{N}$. Responsiveness to kainate in young rats after 2-week zinc deprivation. Biometals 2006;19:565-72.

10. Amaral D, Lavenex P. Hippocampal Neuroanatomy. The Hippocampus Book. 1를 ed. Oxford University Press; 2006. p.37-114.

11. Mathern GW, Babb TL, Leite JP, Pretorius K, Yeoman KM, Kuhlman PA. The pathogenic and progressive features of chronic human hippocampal epilepsy. Epilepsy Res 1996;26:151-61.

12. Pitkanen A. Efficacy of current antiepileptics to prevent neurodegeneration in epilepsy models. Epilepsy Res 2002;50:141-60.

13. Weiss JH, Sensi SL, Koh JY. $\mathrm{Zn}^{(2+)}$ : a novel ionic mediator of neural injury in brain disease. Trends Pharmacol Sci 2000;21:395-401.

14. Colvin RA, Fontaine CP, Laskowski M, Thomas D. $\mathrm{Zn}^{2+}$ transporters and Zn2+ homeostasis in neurons. Eur J Pharmacol 2003;479:171-85.

15. Kim EY, Koh JY, Kim YH, Sohn S, Joe E, Gwag BJ. Zn ${ }^{2+}$ entry produces oxidative neuronal necrosis in cortical cell cultures. Eur J Neurosci 1999;11:327-34.

16. Treiber C. Metals on the brain.Sci Aging Knowledge Environ 2005;2005:e27.

17. Frederickson CJ, Koh JY, Bush AI. The neurobiology of zinc in health and disease. Nat Rev Neurosci 2005;6:449-62.

18. Babb TL, Brown WJ, Pretorius J, Davenport C, Lieb JP, Crandall PH. Temporal lobe volumetric cell densities in temporal lobe epilepsy. Epilepsia 1984;25:729-40.

19. Babb TL, Kupfer WR, Pretorius JK, Crandall PH, Levesque MF. Synaptic reorganization by mossy fibers in human epileptic fascia dentata. Neuroscience 1991;42:351-63.

20. Mathern GW, Leite JP, Babb TL, Pretorius JK, Kuhlman PA, Mendoza $\mathrm{D}$ et al. Aberrant hippocampal mossy fiber sprouting correlates with greater NMDAR2 receptor staining. Neuroreport 1996;7: 1029-35.

21. Salanova V, Markand O, Worth R, Garg B, Patel H, Asconape J et al. Presurgical evaluation and surgical outcome of temporal lobe epilepsy. Pediatr Neurol 1999;20:179-84.

22. Proper EA, Jansen GH, van Veelen CW, van Rijen PC, Gispen WH, de Graan PN. A grading system for hippocampal sclerosis based on the degree of hippocampal mossy fiber sprouting. ActaNeuropathol (Berl) 2001;101:405-9.

23. Swartz BE, Houser CR, Tomiyasu U, Walsh GO, DeSalles A, Rich JR et al. Hippocampal cell loss in posttraumatic human epilepsy. Epilepsia 2006;47:1373-82.

24. Prayson RA, Yoder BJ. Clinicopathologic findings in mesial temporal sclerosis treated with gamma knife radiotherapy. Ann Diagn Pathol 2007;11:22-26.

25. Sutula T, Cascino G, Cavazos J, Parada I, Ramirez L. Mossy fiber synaptic reorganization in the epileptic human temporal lobe. Ann Neurol 1989;26:321-30.
26. Kille P, Hemmings A, Lunney EA. Memories of metallothioneis. Biochim Biophys Acta 1994;1205:151-61.

27. Aschner M, Cherian MG, Klaassen CD, Palmiter RD, Erickson JC, Bush AI. Metallothioneins in brain - the role in physiology and pathology. Toxicol Appl Pharmacol 1997;142:229-42.

28. Wiese L, Kurtzhals JA, Penkowa M. Neuronal apoptosis, metallothionein expression and proinflammatory responses during cerebral malaria in mice. Exp Neurol 2006;200:216-26.

29. Ebadi M, Brown-Borg H, El RH, Singh BB, Garrett S, Shavali S et al. Metallothionein-mediated neuroprotection in genetically engineered mouse models of Parkinson's disease. Brain Res Mol Brain Res 2005;134:67-75.

30. Sonn K, Pankratova S, Korshunova I, Zharkovsky A, Bock E, Berezin $\mathrm{V}$ et al. A metallothionein mimetic peptide protects neurons against kainic acid-induced excitotoxicity. J Neurosci Res 2010;88: 1074-82.

31. Pazdernik TL, Emerson MR, Cross R, Nelson SR, Samson FE. Somaninduced seizures: limbic activity, oxidative stress and neuroprotective proteins. J ApplToxicol 2001;21Suppl 1:S87-S94.

32. Penkowa M, Molinero A, Carrasco J, Hidalgo J. Interleukin-6 deficiency reduces the brain inflammatory response and increases oxidative stress and neurodegeneration after kainic acid-induced seizures. Neuroscience 2001;102:805-18.

33. Carrasco J, Penkowa M, Hadberg H, Molinero A, Hidalgo J. Enhanced seizures and hippocampal neurodegeneration following kainic acidinduced seizures in metallothionein-I + II-deficient mice. Eur J Neurosci 2000;12:2311-22.

34. Penkowa M, Florit S, Giralt M, Quintana A, Molinero A, Carrasco J et al. Metallothionein reduces central nervous system inflammation, neurodegeneration, and cell death following kainic acid-induced epileptic seizures. J Neurosci Res 2005;79:522-34.

35. Leite JP, Terra-Bustamante VC, Fernandes RM, Santos AC, Chimelli $\mathrm{L}$, Sakamoto AC et al. Calcified neurocysticercotic lesions and postsurgery seizure control in temporal lobe epilepsy. Neurology 2000;55:1485-91.

36. Lorente de Nó R. Studies on the structure of the cerebral cortex. II. Continuation of the study of the ammoniac system. Journal of Psychologie und Neurologie 1934;45:113-77.

37. Abercrombie M. Estimation of nuclear population from microtome sections. Anat Rec 1946;94:239-147.

38. Hidalgo J. Metallothioneins and Brain Injury: What Transgenic Mice Tell Us. Environ Health Prev Med 2004;87-94.

39. Crespel A, Coubes P, Rousset MC, Brana C, Rougier A, Rondouin G et al. Inflammatory reactions in human medial temporal lobe epilepsy with hippocampal sclerosis. Brain Res 2002;952:159-69.

40. Dominguez MI, Blasco-Ibanez JM, Crespo C, Nacher J, Marques-Mari AI, Martinez-Guijarro FJ. Neural overexcitation and implication of NMDA and AMPA receptors in a mouse model of temporal lobe epilepsy implying zinc chelation. Epilepsia 2006;47:887-99.

41. Bernasconi N, Natsume J, Bernasconi A. Progression in temporal lobe epilepsy: differential atrophy in mesial temporal structures. Neurology 2005;65:223-28.

42. Szabo CA, Lancaster JL, Lee S, Xiong JH, Cook C, Mayes BN et al. MR imaging volumetry of subcortical structures and cerebellar hemispheres in temporal lobe epilepsy. AJNR Am J Neuroradiol 2006;27:2155-60.

43. O'Dwyer R, Silva Cunha JP, Vollmar C, Mauerer C, Feddersen $\mathrm{B}$, Burgess RC et al. Lateralizing significance of quantitative analysis of head movements before secondary generalization of seizures of patients with temporal lobe epilepsy. Epilepsia 2007;48: 524-30.

Corresponding author:

João Pereira Leite

Department of Neuroscience and Behavior

Ribeirão Preto School of Medicine, University of São Paulo

Av. Bandeirantes, 3900

ZIP Code 14049-900, Ribeirão Preto, SP, Brazil

Phone/Fax: $(+55-16) 3602-2556$

E-mail: <jpleite@fmrp.usp.br> 


\section{Neuronal density and chondroitin sulfate immunoreactivity in CA1 correlate with MRI hippocampal volume in patients with temporal lobe epilepsy}

José Eduardo Peixoto-Santos ${ }^{1}$ BSc MSc, Tonicarlo R. Velasco ${ }^{1}$ MD PhD, Orfa Yineth Galvis-Alonso ${ }^{2}$ MD PhD,

David Araújo ${ }^{3}$ MD PhD, João Alberto Assirati $\mathrm{Jr}^{4} \mathrm{MD} \mathrm{PhD}$, Carlos Gilberto Carlotti ${ }^{4}$ MD PhD, Renata Caldo

Scandiuzzi ${ }^{1}$ BSc, Antônio Carlos dos $\operatorname{Santos}^{5} \mathrm{MD} \mathrm{PhD}$ and João Pereira Leite ${ }^{1 *}$ MD PhD

Affiliations:

${ }^{1}$ Department of Neuroscience and Behavior, Ribeirao Preto School of Medicine, University of Sao Paulo

${ }^{2}$ Department of Molecular Biology, Sao Jose do Rio Preto Medical School

${ }^{3}$ Montreal Neurological Institute, McGill University

${ }^{4}$ Department of Neurosurgery, Ribeirao Preto School of Medicine, University of Sao Paulo

${ }^{5}$ Department of Internal Medicine, Ribeirao Preto School of Medicine, University of Sao Paulo

* Corresponding author:

João Pereira Leite, $\mathrm{MD} \mathrm{PhD}$

Department of Neuroscience and Behavior

Ribeirão Preto School of Medicine, University of São Paulo

Avenida Bandeirantes, 3900 - ZIP Code 14049-900

Ribeirão Preto - São Paulo - Brazil

Phone/Fax: +55-16-36022556

Email: jpleite@fmrp.usp.br

Keywords: Magnetic Resonance Imaging; Hippocampal Volumetry; Gliosis; Epilepsy; Neuronal density; Extracellular Matrix 


\begin{abstract}
Background and Purpose: HS is a common finding in TLE patients, and MRI studies associate the reduction of hippocampal volume with the neuron loss, observed in the histological evaluation. Astrogliosis and increased CSPG, a major component of brain ECM, are also observed in HS. Our aim was to evaluate, in TLE patients, the association between hippocampal volume and levels of CSPG, as well as neuronal and astroglial populations.
\end{abstract}

Materials and Methods: Patients with drug-resistant TLE were subdivided, according to hippocampal volume, measured on MRI, in HA or NV cases. Hippocampi from TLE patients and age-matched controls were submitted to immunohistochemistry for the evaluation of neuronal population, astroglial population, and chondroitin sulfate.

Results: No clinical difference was observed between TLE groups. NV cases had higher hippocampal volume, both ipsilateral and contralateral, when compared to HA. TLE patients had reduced neuron density, increased GFAP immunopositive area, and increased CSPG immunopositive area, when compared to controls, with no difference between NV and HA groups. Hippocampal volume correlated with neuron density in CA1 and prosubiculum, and with immunopositive areas for GFAP and CSPG in CA1. Linear regression indicated that both neuron density and CS-56 immunopositive area in CA1 are predictors of hippocampal volume.

Conclusions: Our findings support the notion that neuron density and chondroitin sulfate levels in the CA1 subfield are crucial for the hippocampal volume.

\footnotetext{
Abreviations: TLE = temporal lobe epilepsy; GFAP = glial fibrilary acidic protein; $\mathrm{CSPG}=$ chondroitin sulfate proteoglycan; ECM = extracellular matrix; $\mathrm{NV}=$ normal hippocampal volume; HA = hippocampal atrophy; HS = hippocampal sclerosis; IPI = initial precipitanting injury.
} 


\section{Introduction}

TLE is the most frequent focal epilepsy in adults and is often drug resistant [1]. HS is a common pathological finding in TLE patients [2], observed in up to $48 \%$ of cases [3]. The most common patterns are classic and severe HS. Classic HS is characterized by intense neuronal loss in CA1 and CA4, moderate loss in granule cell layer and CA3 and preservation of CA2 and subiculum [4-7]. In severe HS, there is intense neuronal loss in all Ammon's horn [3, 8]. More rare forms of HS are CA1 and endfolium HS $[3,8]$, in which neuronal loss is confined to CA1 and CA4, respectively. In $19 \%$ of TLE cases, however, no significant neuronal loss is observed in the hippocampal subfields [8].

MRI can detect most cases of HS by showing increased signal in T2-weighted images and reduced hippocampal volume in T1-weighted images [9-11]. However, MRI may be negative in atypical HS, such as endfolium sclerosis [12], and 5-10\% of the cases with normal hippocampal volume can have significant neuronal loss through several hippocampal subfields [13]. What could maintain the hippocampal volume in these TLE cases with neuronal loss remains to be defined. Since different TLE substrates could be associated with differences in antiepileptic drug response and post-surgery seizure outcome $[8,14,15]$, to understand the pathological substrates associated with different MRI patterns can be important for a better treatment of these patients. Although neuron population is an important contributor to MRI hippocampal volume in HS [11], the importance of glial cells is less clear. And since astrocytes can affect the extracellular space volume with the production of components of ECM, such as CSPG, it would also be important to understand how the ECM contributes to hippocampal volume. In this study, we evaluate the association between the hippocampal volume, measured by MRI, and the neuronal and astroglial population, as well as the content of ECM chondroitin sulfate, in the hippocampus of patients 
with drug-resistant TLE. We found evidence that the histological variables that contributed the most to hippocampal volume were the neuron density and levels of chondroitin sulfate in CA1 subfield.

\section{Materials and Methods}

\section{Patients and clinical data}

Patients with drug-resistant epilepsy were evaluated at the University of São Paulo Epilepsy Surgical Centre in Ribeirão Preto (Brazil), according to standard protocols published elsewhere $[16,17]$. Inclusion criteria were diagnosis of TLE not involving tumor, dysplasia or cortical malformations; age between 18 and 70 years; and digital 3D T1-weighted MRI at $1.5 \mathrm{~T}$ scanning.

For definition of histopathological changes, TLE hippocampi were compared to control hippocampi $(\mathrm{n}=19)$, obtained from autopsy cases without history of neurological diseases, with no sign of brain pathologies in post mortem pathological evaluation, and with less than 10 hours post mortem.

Medical records of all patients were assessed for clinical data analysis. The clinical variables investigated were age at death and cause of death for control and age at surgery, epilepsy duration, age at epilepsy onset, seizure frequency, presence of IPI, and age at IPI for TLE patients. This study was registered in Brazilian's Health Ministry and was approved by our local ethics committee (processes HCRP 9370/2003 and HCRP 2634/2008).

TLE patients were further divided, according to hippocampal volume in: 1) Normal volume (NV), patients with MRI hippocampal volume above $2.5 \mathrm{~cm}^{3}(\mathrm{n}=22)$; and 2) Hippocampal atrophy (HA), patients with MRI hippocampal volume equal or bellow $2.5 \mathrm{~cm}^{3}(\mathrm{n}=45)$. This classification was adapted from a previous study from our institution [18]. 


\section{MRI acquisition}

3D T1-weighted MRI was performed in a 1.5T Siemens Magneton Vision (Germany) with a 25mT circular polarization gradient coil. The 3D T1 MRI was a gradient-echo sequence (TR: 9.7 ms; TE: 4 ms; flip angle: 12 degrees; FOV: 256; matrix: 256x256; voxel: $1 \mathrm{~mm}^{3}$ ). The volumetry was measured with the software Display (McConnel Brain Imaging Centre, Canada).

Hippocampal boundaries were defined according to previous studies [19, 20]. The hippocampal delineation was made manually in coronal slices and corrections, when needed, were made in sagittal and axial slices. After delineation the program calculates the hippocampal volume. The volumetry was made in a blind way regarding the presurgical qualitative evaluation.

\section{Immunohistochemistry}

Hippocampi from surgery or autopsy were cut in coronal sections and placed in $10 \%$ buffered formaldehyde for one week, followed by paraffin embedding. Following previously described protocols [21, 22], immunohistochemistry were performed in $8 \mu \mathrm{m}$ sections from hippocampal body with antibodies anti-NeuN, anti-GFAP, and anti-CS-56 for evaluation of, respectively, neuronal population, astroglial population, and for the levels of CSPG. Briefly, the sections were submitted to endogenous peroxidase blocking, followed by microwave antigenic retrieval and blocking solution. The sections were then incubated with primary antibodies in blocking solution for 16 hours. We used primary monoclonal antibodies raised in mouse anti-human GFAP (clone 6F2, M0761, Dako), anti-mouse NeuN (clone A60, MAB377, Chemicon) and anti-chicken CS56 (clone CS-56, C8035, Sigma), at concentrations of, respectively, 1:500, 1:500 and 1:100 (antibody:blocking solution). The primary antibodies were detected using biotinylated rabbit antimouse IgG (E0354, Dako), at 1:200 dilution in blocking buffer, for one hour, followed by 
amplification with avidin-biotin-peroxidase system (Vectastain Elite ABC kit, \#PK6100, Vector) and revelation with diaminobenzidine as chromogen (\#34001, Pierce Biotechnology).

\section{Immunohistochemistry analysis}

Images of all hippocampal regions were obtained with a video monochrome camera (CCD; Hamamatsu Photonics Model 2400, Japan) attached to an Olympus microscope (Model BX60, USA), and captured, averaged, and digitized using the software Scion (Scion Corporation, USA) on a Macintosh computer (Model G3, USA). Luminance was uniformly maintained and regularly checked using optical density standards (Kodak, USA).

Immunohistochemistry quantification was made with ImageJ software (version 1.45s). Quantification of immunohistochemistries for GFAP and CS-56was performed with threshold tool, following previous published protocols [22], with the investigator blind to the groups. The threshold was defined for each protein evaluated, according to the pattern of staining observed in control cases. The evaluated regions were: GCL of fascia dentate, hilus, and the stratus piramidale of CA4, CA3, CA2, CA1, prosubiculum and subiculum. The characterization of hippocampal regions was based on the Lorente de Nó's classification [23]. Results were shown as immunopositive area, in squared micrometers.

Additionally, neuronal density was evaluated in the NeuN stained sections. Neuronal count was processed in ImageJ software at 200x magnification for GCL and pyramidal neurons of CA4, CA3, CA2, CA1, prosubiculum and subiculum. Neuronal densities were estimated with the correction of Abercrombie [24], and the results were shown as thousands of cells per cubic millimeter. Using the recently reviewed Wyler's score for HS [8], we further subdivided our patients in 5 groups: No HS (no significant neuronal loss; $n=2$ ), CA4 HS (neuronal loss in CA4 only; $\mathrm{n}=1$ ), CA1 HS (neuronal loss in CA1 only; $\mathrm{n}=8$ ), classic HS (with the standard neuronal 
loss; $\mathrm{n}=10$ ) and severe HS (severe neuronal loss in all hippocampus; $\mathrm{n}=29$ ). Since the Wyler's classification requires several hippocampal subfields, only some of the patients could be correctly graded.

\section{Statistical analysis}

Statistics were carried out in SigmaStat 3.1 software. For parametric variables, t-test or One Way ANOVA with Bonferroni post hoc test were performed. For the non-parametric variables, Mann-Whitney test or Kruskal-Wallis with Dunn post hoc test were performed. Correlations between histopathological variables and the hippocampal volumes were performed using the Pearson's test. All results were considered significant at $p<0.05$.

\section{Results}

\section{Clinical Data}

The clinical data of TLE patients and control cases are summarized in Table 1. Patients with TLE and controls had similar ages at evaluation $(p=0.164)$. In TLE, both groups showed similar epilepsy duration $(p=0.297)$, age at recurrence $(p=0.623)$, seizure frequency $(p=0.992)$, IPI frequency $(p=0.991)$, and age at IPI occurrence $(p=0.645)$.

\section{Hippocampal Volumetry}

The ipsilateral hippocampus (i.e., the hippocampus surgically removed) had volume ranging from 2.562 to $3.704 \mathrm{~cm}^{3}$ in NV, and 1.338 to $2.498 \mathrm{~cm}^{3}$ in HA (Fig 1). The contralateral hippocampus ranged from 2.926 to $4.827 \mathrm{~cm}^{3}$ in NV, and 2.135 to $3.748 \mathrm{~cm}^{3}$ in HA (Fig 1). The ipsilateral and contralateral hippocampi from NV had higher volume than the respective hippocampi from HA $(p<0.001)$. Qualitative analysis of MRI, made by experienced radiologists, 
revealed reduction of the hippocampal volume and increased T2 signal in the ipsilateral hippocampus of most patients (Table 2).

\section{Histological evaluation}

Neuronal cell density, evaluated in sections submitted to immunohistochemistry for NeuN (Fig 2 A-B), was reduced in both TLE groups in the GLC, CA4, CA3, CA1 and prosubiculum, when compared to controls $(p \leq 0.001)$. Astrogliosis, evaluated as GFAP immunopositive area (Fig 2 C-D), was observed in the GCL, hilus, CA4, CA3, CA2, CA1, prosubiculum and subiculum of TLE patients, when compared to controls $(p<0.001)$. The immunopositive area of CSPG, measured in sections submitted to immunohistochemistry for CS-56 antigen (Fig 2 E-F), was increased in the GCL, CA3, CA2 and CA1 of NV group $(p \leq 0.043)$, and in the prosubiculum and subiculum of both TLE groups $(p \leq 0.006)$, when compared to controls. No difference was observed between HA and NV in relation to neuronal cell density, GFAP or CS56 immunopositive areas.

Although the No HS and CA4 HS groups were only observed in NV cases, there was no significant difference between the groups NV and HA regarding Wyler's revised score (Exact test, $p=0.179$; Table 3).

\section{Correlation between MRI volumes and histological changes}

Neuronal density in CA1 $(\mathrm{R}=0.403 ; p<0.001)$ and prosubiculum $(\mathrm{R}=0.337 ; p=0,008)$ correlated positively with the hippocampal volume (Fig 3 A-B). The hippocampal volume correlated negatively with the GFAP immunopositive area in CA1 $(\mathrm{R}=-0.245 ; p=0.047$; Fig 3 C). Also in CA1, the immunopositive area of CS-56 correlated positively with the hippocampal volume $(\mathrm{R}=0.295 ; p=0.024$; Fig $3 \mathrm{D})$. No correlation was observed between hippocampal 
volume and the age at surgery $(p=0.197)$, epilepsy duration $(p=0.256)$, age at epilepsy onset $(p$ $=0.892)$, and seizure frequency $(p=0.926)$.

To evaluate the relative contributions of neuron density in CA1 and prosubiculum and the CA1 immunopositive areas for CS-56 and GFAP to hippocampal volume we performed multiple linear regression. According to the model, the higher the neuron density and CA1 levels of chondroitin sulfate in CA1, the greater the hippocampal volume $(\mathrm{R}=0.619 ; p<0.001$, with $p=$ 0.001 for neuron density and $p=0.03$ for CSPG). The prosubiculum neuron density and the CA1 immunopositive area for GFAP did not predict hippocampal volume ( $p=0.996$ and $p=0.843$, respectively).

\section{Discussion}

In this study, we evaluated the association between the MRI hippocampal volume and histopathological variables in patients with drug-resistant TLE. Our aim was to evaluate which tissue changes observed in the hippocampus of TLE patients could contribute to the hippocampal volume measured with MRI. We found that neuron density and levels of CSPG in CA1 subfield independently correlated with hippocampal volume.

Regarding the relation between MRI and pathology, previous studies have suggested that the neuron loss is the main contributor to the reduction of MRI hippocampal volume [12, 25-35]. However, most studies used qualitative data to report such association and there are few studies showing quantitative evidence. Studies using neuronal/glial ratios revealed that the severity of pathological changes (i.e., neuronal loss and gliosis) is associated with the degree of hippocampal volume reduction $[12,32]$. In agreement with our study, they found that CA1 cell changes were the main contributors for hippocampal atrophy on MRI [12]. Only one study using similar 
methods showed that neuronal density in GCL, but not in CA1, correlated with hippocampal volume [11].

Astrogliosis is observed through all hippocampal subfields in TLE [12, 22]. In MRI studies, increased astrogliosis is commonly associated with increased T2 signal [11]. Regarding MRI volumetric studies, gliosis was inversely correlated with hippocampal volume [12, 32]. Similarly, our data indicate a negative correlation between GFAP immunoreactivity in CA1 and hippocampal volume. However, it is well known that gliosis is a reactive change of glial cells in response to tissue damage [36]. Therefore, most likely the CA1 neuron loss found in patients with TLE result in reactive gliosis and reduced hippocampal volume. This conclusion seems to be the most plausible provided that when we included both neuron loss and gliosis in our regression model, gliosis was excluded as an important contributor to hippocampal volume.

In the brain, extracellular matrix accounts for up to $20 \%$ of the tissue and is rich in chondroitin sulfate proteoglycans [37-40]. Increased levels of CSPG were observed in patients with TLE [41]. We also observed an increased chondroitin sulfate levels in our TLE patients. Studies with MRI indicated that increased CSPG expression is associated with changes in water diffusion [42]. However, it is not known if increased CSPG could affect hippocampal volume. In our study, higher levels of CSPG in CA1 correlated with higher hippocampal volume in MRI. Both our quantitative and qualitative evaluations of the neuronal population showed that patients with normal volume on MRI could have cell loss as high as patients with severe hippocampal atrophy. We believe that the levels of chondroitin sulfate are important to maintain the hippocampal volume in cases that, otherwise, would have hippocampal atrophy, as observed by the severe neuronal loss.

Volumetric studies also point the Sommer sector (CA1 subfield and prosubiculum) as the most determinant region to hippocampal volume $[12,27]$. We found that the combination of neuron 
density and the levels of CSPG in CA1 explain more than $38 \%$ of hippocampal volume. The multiple regression models also excluded the astroglial population effect over hippocampal volume, thus indicating that the astrogliosis follows the severity of the neuronal death, as discussed earlier.

The reader should know that for the extracellular matrix evaluations, we used the broadspectrum antibody anti-CS-56 epitope to quantify most chondroitin sulfate proteins. However, brain ECM is also constituted by hyaluronic acid. Therefore, we did not evaluate the contribution of hyaluronic acid to the hippocampal volume.

\section{Conclusion}

The present study showed that the CA1 subfield is critical to hippocampal volume in TLE. Our data indicate that neuron density and levels of the extracellular matrix molecule CSPG in CA1 correlate positively with hippocampal volume, whereas the reactive astrocyte population correlates negatively. Linear regressions further confirmed that the combination of neuron population and levels of CSPG in the CA1 subfield are important contributors for hippocampal volume in TLE.

\section{References}

1. Gastaut H, Gastaut JL, Goncalves e Silva GE, Fernandez Sanchez GR: Relative frequency of different types of epilepsy: a study employing the classification of the International League Against Epilepsy. Epilepsia 1975, 16(3):457-461.

2. Beach TG, Woodhurst WB, MacDonald DB, Jones MW: Reactive microglia in hippocampal sclerosis associated with human temporal lobe epilepsy. Neuroscience letters 1995, 191(1-2):27-30.

3. Blumcke I, Coras R, Miyata H, Ozkara C: Defining clinico-neuropathological subtypes of mesial temporal lobe epilepsy with hippocampal sclerosis. Brain Pathol 2012, 22(3):402-411.

4. Margerison JH, Corsellis JA: Epilepsy and the temporal lobes. A clinical, electroencephalographic and neuropathological study of the brain in epilepsy, with 
particular reference to the temporal lobes. Brain : a journal of neurology 1966, 89(3):499-530.

5. Babb TL, Brown WJ, Pretorius J, Davenport C, Lieb JP, Crandall PH: Temporal lobe volumetric cell densities in temporal lobe epilepsy. Epilepsia 1984, 25(6):729-740.

6. Babb TL, Kupfer WR, Pretorius JK, Crandall PH, Levesque MF: Synaptic reorganization by mossy fibers in human epileptic fascia dentata. Neuroscience 1991, 42(2):351-363.

7. Mathern GW, Leite JP, Babb TL, Pretorius JK, Kuhlman PA, Mendoza D, Fried I, Sakamoto AC, Assirati JA, Adelson PD et al: Aberrant hippocampal mossy fiber sprouting correlates with greater NMDAR2 receptor staining. Neuroreport 1996, 7(5):1029-1035.

8. Blumcke I, Pauli E, Clusmann H, Schramm J, Becker A, Elger C, Merschhemke M, Meencke HJ, Lehmann T, von Deimling A et al: A new clinico-pathological classification system for mesial temporal sclerosis. Acta neuropathologica 2007, 113(3):235-244.

9. Berkovic SF, Andermann F, Olivier A, Ethier R, Melanson D, Robitaille Y, Kuzniecky R, Peters T, Feindel W: Hippocampal sclerosis in temporal lobe epilepsy demonstrated by magnetic resonance imaging. Annals of neurology 1991, 29(2):175-182.

10. Cendes F, Andermann F, Dubeau F, Gloor P, Evans A, Jones-Gotman M, Olivier A, Andermann E, Robitaille Y, Lopes-Cendes I et al: Early childhood prolonged febrile convulsions, atrophy and sclerosis of mesial structures, and temporal lobe epilepsy: an MRI volumetric study. Neurology 1993, 43(6):1083-1087.

11. Briellmann RS, Kalnins RM, Berkovic SF, Jackson GD: Hippocampal pathology in refractory temporal lobe epilepsy: $\mathrm{T} 2$-weighted signal change reflects dentate gliosis. Neurology 2002, 58(2):265-271.

12. Van Paesschen W, Revesz T, Duncan JS, King MD, Connelly A: Quantitative neuropathology and quantitative magnetic resonance imaging of the hippocampus in temporal lobe epilepsy. Annals of neurology 1997, 42(5):756-766.

13. King D, Spencer SS, Bouthillier A, Kim J, de Lanerolle N, Bronen RA, McCarthy G, Luby M, Spencer DD: Medial temporal lobe epilepsy without hippocampal atrophy. Journal of Epilepsy 1996, 9(4):291-297.

14. Semah F, Picot MC, Adam C, Broglin D, Arzimanoglou A, Bazin B, Cavalcanti D, Baulac M: Is the underlying cause of epilepsy a major prognostic factor for recurrence? Neurology 1998, 51(5):1256-1262.

15. Bell ML, Rao S, So EL, Trenerry M, Kazemi N, Stead SM, Cascino G, Marsh R, Meyer FB, Watson RE et al: Epilepsy surgery outcomes in temporal lobe epilepsy with a normal MRI. Epilepsia 2009, 50(9):2053-2060.

16. Leite JP, Terra-Bustamante VC, Fernandes RM, Santos AC, Chimelli L, Sakamoto AC, Assirati JA, Takayanagui OM: Calcified neurocysticercotic lesions and postsurgery seizure control in temporal lobe epilepsy. Neurology 2000, 55(10):1485-1491.

17. Velasco TR, Wichert-Ana L, Leite JP, Araujo D, Terra-Bustamante VC, Alexandre V, Jr., Kato M, Assirati JA, Jr., Machado HR, Carlotti CG, Jr. et al: Accuracy of ictal SPECT in mesial temporal lobe epilepsy with bilateral interictal spikes. Neurology 2002, 59(2):266-271.

18. Araujo D, Santos AC, Velasco TR, Wichert-Ana L, Terra-Bustamante VC, Alexandre V, Jr., Carlotti CG, Jr., Assirati JA, Jr., Machado HR, Walz R et al: Volumetric evidence of 
bilateral damage in unilateral mesial temporal lobe epilepsy. Epilepsia 2006, 47(8):1354-1359.

19. Bonilha L, Kobayashi E, Cendes F, Min Li L: Protocol for volumetric segmentation of medial temporal structures using high-resolution 3-D magnetic resonance imaging. Human brain mapping 2004, 22(2):145-154.

20. Pruessner JC, Li LM, Serles W, Pruessner M, Collins DL, Kabani N, Lupien S, Evans $\mathrm{AC}$ : Volumetry of hippocampus and amygdala with high-resolution MRI and threedimensional analysis software: minimizing the discrepancies between laboratories. Cereb Cortex 2000, 10(4):433-442.

21. Kandratavicius L, Hallak JE, Young LT, Assirati JA, Carlotti CG, Jr., Leite JP: Differential aberrant sprouting in temporal lobe epilepsy with psychiatric comorbidities. Psychiatry research 2012, 195(3):144-150.

22. Peixoto-Santos JE, Galvis-Alonso OY, Velasco TR, Kandratavicius L, Assirati JA, Carlotti CG, Scandiuzzi RC, Serafini LN, Leite JP: Increased Metallothionein I/II Expression in Patients with Temporal Lobe Epilepsy. PloS one 2012, 7(9):e44709.

23. Lorente de Nó R: Studies on the structure of the cerebral cortex. II. Continuation of the study of ammonic system. Journal für Psychologie und Neurologie 1934, 46:65.

24. Abercrombie M: Estimation of nuclear population from microtome sections. The Anatomical record 1946, 94:239-247.

25. Bronen RA, Fulbright RK, King D, Kim JH, Spencer SS, Spencer DD, Lange RC: Qualitative MR imaging of refractory temporal lobe epilepsy requiring surgery: correlation with pathology and seizure outcome after surgery. AJR American journal of roentgenology 1997, 169(3):875-882.

26. Cascino GD, Jack CR, Jr., Parisi JE, Sharbrough FW, Hirschorn KA, Meyer FB, Marsh WR, O'Brien PC: Magnetic resonance imaging-based volume studies in temporal lobe epilepsy: pathological correlations. Annals of neurology 1991, 30(1):31-36.

27. Diehl B, Najm I, Mohamed A, Babb T, Ying Z, Bingaman W: Interictal EEG, hippocampal atrophy, and cell densities in hippocampal sclerosis and hippocampal sclerosis associated with microscopic cortical dysplasia. Journal of clinical neurophysiology : official publication of the American Electroencephalographic Society 2002, 19(2):157-162.

28. Diehl B, Najm I, LaPresto E, Prayson R, Ruggieri P, Mohamed A, Ying Z, Lieber M, Babb $\mathrm{T}$, Bingaman $\mathrm{W}$ et al: Temporal lobe volumes in patients with hippocampal sclerosis with or without cortical dysplasia. Neurology 2004, 62(10):1729-1735.

29. Garcia PA, Laxer KD, Barbaro NM, Dillon WP: Prognostic value of qualitative magnetic resonance imaging hippocampal abnormalities in patients undergoing temporal lobectomy for medically refractory seizures. Epilepsia 1994, 35(3):520-524.

30. Goncalves Pereira PM, Oliveira E, Rosado P: Relative localizing value of amygdalohippocampal MR biometry in temporal lobe epilepsy. Epilepsy research 2006, 69(2):147-164.

31. Jackson GD, Kuzniecky RI, Cascino GD: Hippocampal sclerosis without detectable hippocampal atrophy. Neurology 1994, 44(1):42-46.

32. Kuzniecky R, Palmer C, Hugg J, Martin R, Sawrie S, Morawetz R, Faught E, Knowlton $\mathrm{R}$ : Magnetic resonance spectroscopic imaging in temporal lobe epilepsy: neuronal dysfunction or cell loss? Archives of neurology 2001, 58(12):2048-2053. 
33. Lehericy S, Semah F, Hasboun D, Dormont D, Clemenceau S, Granat O, Marsault C, Baulac M: Temporal lobe epilepsy with varying severity: MRI study of 222 patients. Neuroradiology 1997, 39(11):788-796.

34. Lencz T, McCarthy G, Bronen RA, Scott TM, Inserni JA, Sass KJ, Novelly RA, Kim JH, Spencer DD: Quantitative magnetic resonance imaging in temporal lobe epilepsy: relationship to neuropathology and neuropsychological function. Annals of neurology 1992, 31(6):629-637.

35. Vossler DG, Kraemer DL, Knowlton RC, Kjos BO, Rostad SW, Wyler AR, Haltiner AM, Hasegawa H, Wilkus RJ: Temporal ictal electroencephalographic frequency correlates with hippocampal atrophy and sclerosis. Annals of neurology 1998, 43(6):756-762.

36. Fawcett JW, Asher RA: The glial scar and central nervous system repair. Brain research bulletin 1999, 49(6):377-391.

37. Vitellaro-Zuccarello L, Mazzetti S, Bosisio P, Monti C, De Biasi S: Distribution of Aquaporin 4 in rodent spinal cord: relationship with astrocyte markers and chondroitin sulfate proteoglycans. Glia 2005, 51(2):148-159.

38. Davson H, Spaziani E: The blood-brain barrier and the extracellular space of brain. The Journal of physiology 1959, 149:135-143.

39. Hawkins BT, Davis TP: The blood-brain barrier/neurovascular unit in health and disease. Pharmacological reviews 2005, 57(2):173-185.

40. Sykova E: Diffusion properties of the brain in health and disease. Neurochemistry international 2004, 45(4):453-466.

41. Perosa SR, Porcionatto MA, Cukiert A, Martins JR, Passeroti CC, Amado D, Matas SL, Nader HB, Cavalheiro EA, Leite JP et al: Glycosaminoglycan levels and proteoglycan expression are altered in the hippocampus of patients with mesial temporal lobe epilepsy. Brain research bulletin 2002, 58(5):509-516.

42. Vorisek I, Hajek M, Tintera J, Nicolay K, Sykova E: Water ADC, extracellular space volume, and tortuosity in the rat cortex after traumatic injury. Magnetic resonance in medicine : official journal of the Society of Magnetic Resonance in Medicine / Society of Magnetic Resonance in Medicine 2002, 48(6):994-1003. 
Table 1. Clinical data from TLE patients and Ctrl cases.

\begin{tabular}{|c|c|c|c|c|}
\hline & Ctrl & $\mathrm{NV}$ & $\mathrm{HA}$ & $p$ \\
\hline Age at procedure & $42 \pm 16$ & $36 \pm 11$ & $40 \pm 8$ & $0.164^{\mathrm{a}}$ \\
\hline Epilepsy duration & & $24 \pm 11$ & $26 \pm 10$ & $0.297^{b}$ \\
\hline Age at epilepsy onset ${ }^{2}$ & & $12 \pm 7$ & $13 \pm 9$ & $0.623^{b}$ \\
\hline Seizure frequency ${ }^{3}$ & & $15 \pm 22$ & $14 \pm 20$ & $0.992^{c}$ \\
\hline Presence of $\mathrm{IPI}^{4}$ & & $59 \%(13 / 22)$ & $56 \%(25 / 55)$ & $0.991^{\mathrm{d}}$ \\
\hline Age at $\mathrm{IPI}^{5}$ & & $30 \pm 25$ & $26 \pm 22$ & $0.645^{\mathrm{c}}$ \\
\hline
\end{tabular}

\footnotetext{
Age (years) at surgery for TLE patients and at autopsy for Ctrl

${ }^{2}$ Age (years) at the occurrence of the first recurrent seizure

${ }^{3}$ Minimal seizure frequency in a month

${ }^{4}$ Initial precipitating injury

${ }^{5}$ Age (months) when IPI occurred

a. Kruskal-Wallis test

b. T-Test

c. Mann-Whitney test

d. Chi-square test
}

Table 2. Qualitative MRI evaluation of TLE patients.

\begin{tabular}{lllllll}
\hline Group & \multicolumn{2}{l}{ Hippocampal volume } & \multicolumn{3}{l}{ Hippocampal long-TR* Signal } \\
\cline { 2 - 6 } & No data & Normal & Reduction & No data & Normal & Increase \\
\hline NV & 0 & $2 * *$ & 20 & 0 & $2 * *$ & 20 \\
HA & 4 & 3 & 38 & 4 & 0 & 41 \\
\hline
\end{tabular}

* Either FLAIR or T2-weighted images

** One of the two patients had both hippocampal volume and TR signal normal 
Table 3. Wyler's score in TLE patients.

\begin{tabular}{cccccc}
\hline Group & No HS & CA4 HS & CA1 HS & Classic HS & Severe HS \\
\hline NV & $10 \%(2)$ & $5 \%(1)$ & $15 \%(3)$ & $10 \%(2)$ & $60 \%(12)$ \\
HA & $0 \%(0)$ & $0 \%(0)$ & $16.7 \%(5)$ & $26.7 \%(8)$ & $56.6 \%(17)$ \\
\hline
\end{tabular}
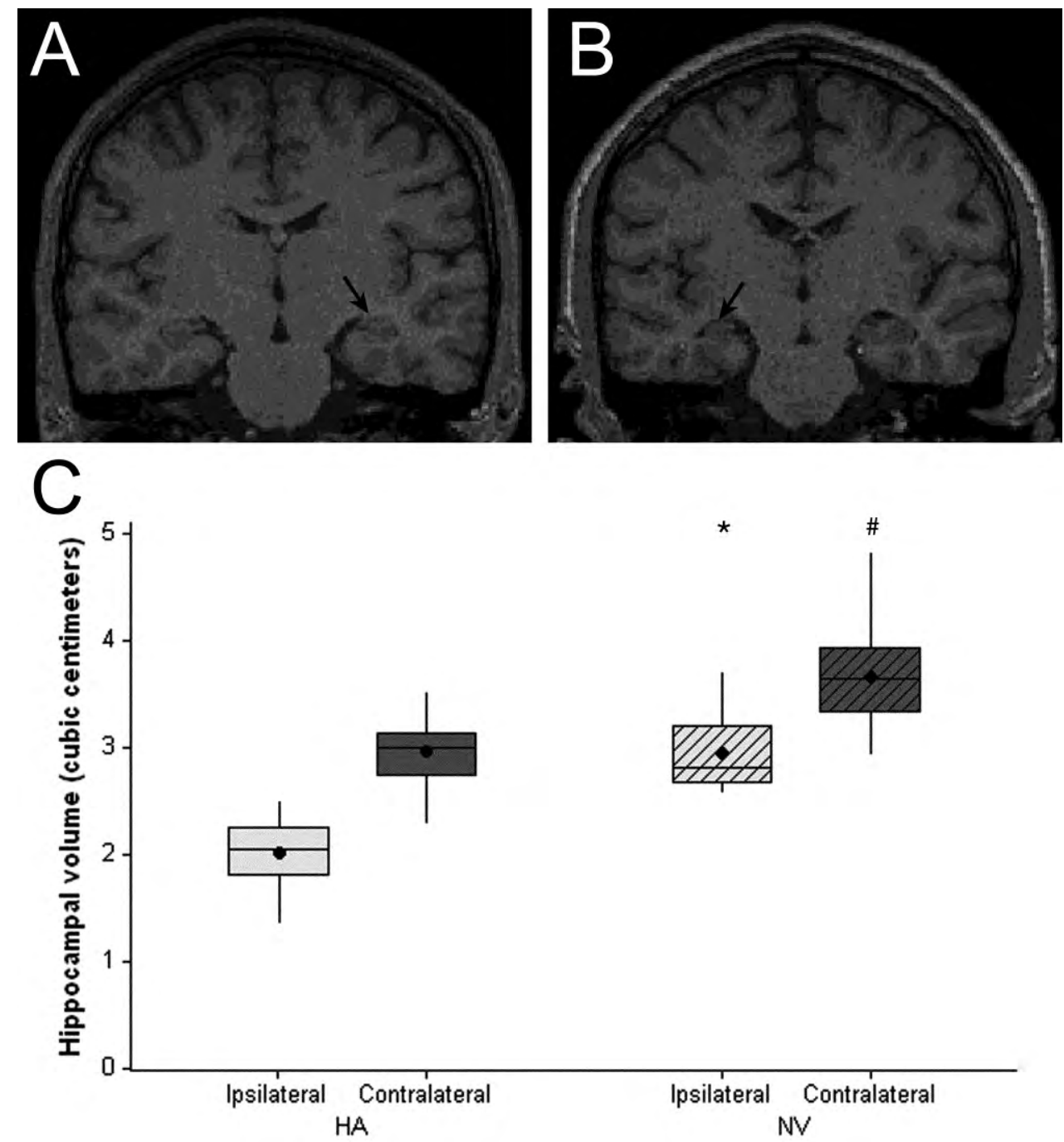

Fig. 1. Hippocampal volumes of MTLE patients with hippocampal atrophy (HA, boxplots without stripes) or normal hippocampal volume (NV, striped boxplots). The ipsilateral hippocampus of HA (light gray boxplot) had lower volume than the ipsilateral hippocampus of NV (light gray boxplot with stripes). The contralateral hippocampus of HA (dark gray boxplot) had also lower volume when compared to the contralateral hippocampus of NV (dark gray boxplot with stripes). The * indicate statistical difference from ipsilateral HA and the ${ }^{\#}$ indicate difference from contralateral HA. 


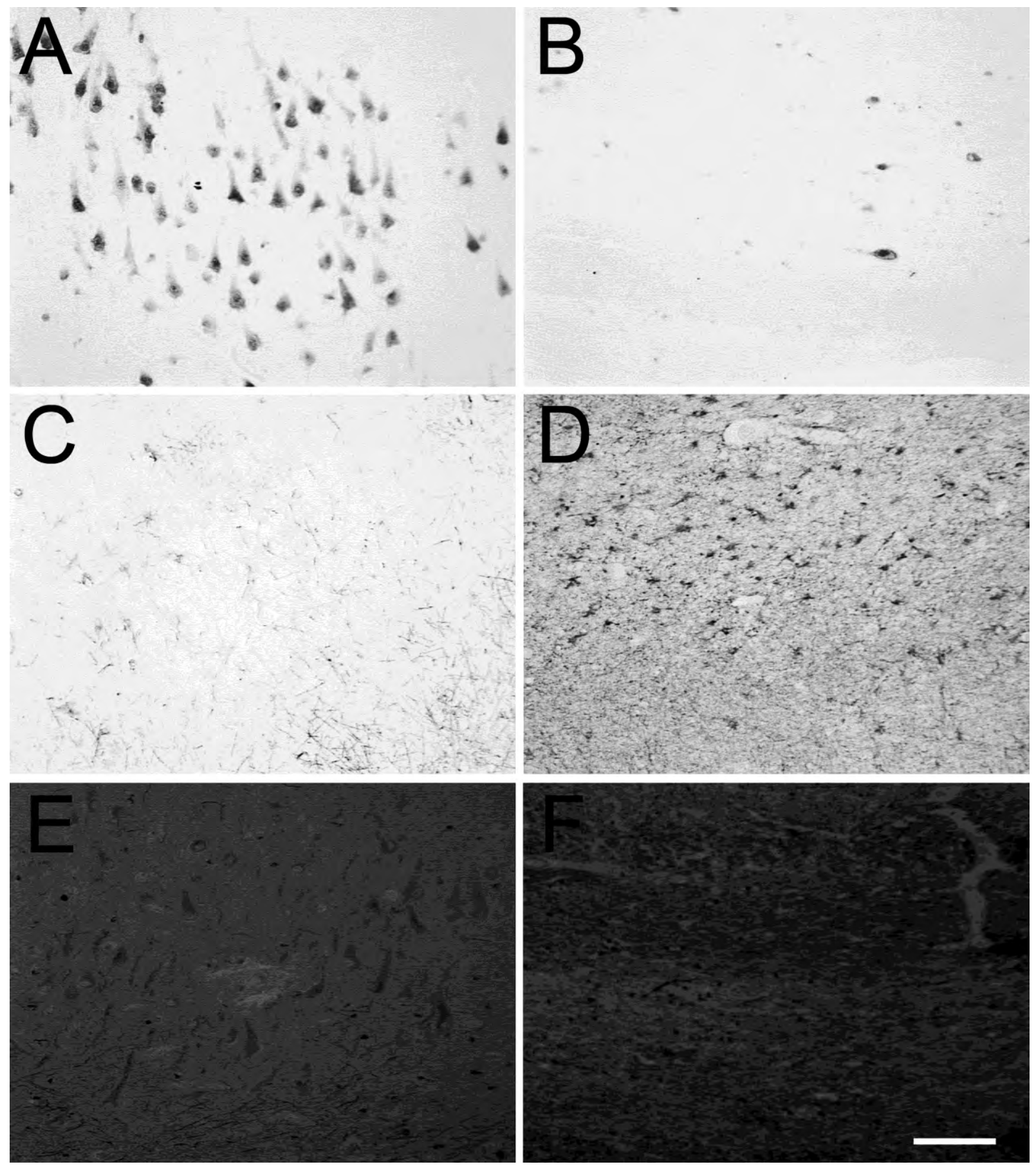

Fig. 2. Representative images of NeuN (A, B), GFAP (C, D), and CSPG (E, F) staining in the CA1 of Ctrl (A, C and E) and MTLE (B, D and F) patients. The pattern of NeuN staining is the same in Ctrl (A) and TLE (B), but MTLE shows reduced neuronal population in this subfield. Compared to Ctrl (C), GFAP staining revealed hyperplasia and hypertrophy of reactive astrocytes in TLE (D). Increased levels of fibers stained for CSPG were observed in TLE (F), compared to $\mathrm{Ctrl}(\mathrm{E})$. The bar in $\mathrm{F}$ indicates 100 micrometers. 


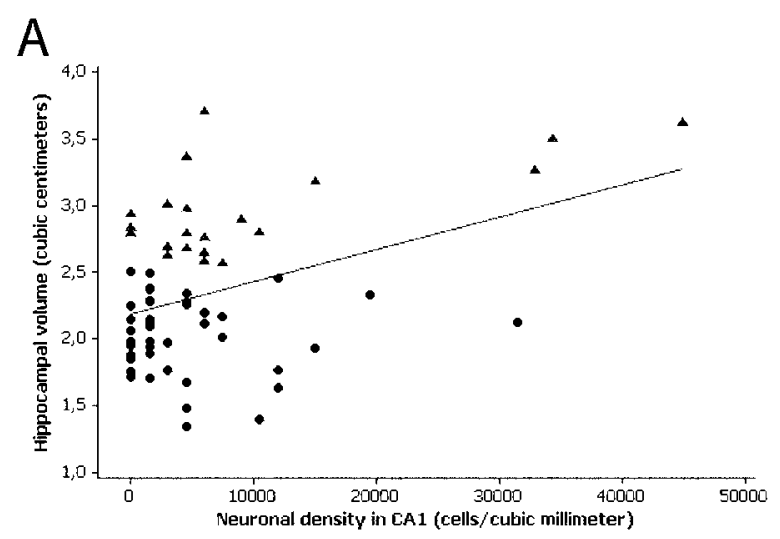

Fig. 3. Linear regressions between hippocampal volumes and the neuron density (A, B), GFAP immunopositive area (C) or CS-56 immunopositive area (D) in MTLE patients. Both neuron densities in CA1 and prosubiculum, and CS-56 immunopositive area in CA1 correlated positively with hippocampal volume. On the contrary, GFAP immunopositive area had a negative correlation with hippocampal volume. The triangles indicate patients with normal volume and the dots indicate patients with hippocampal atrophy.

B

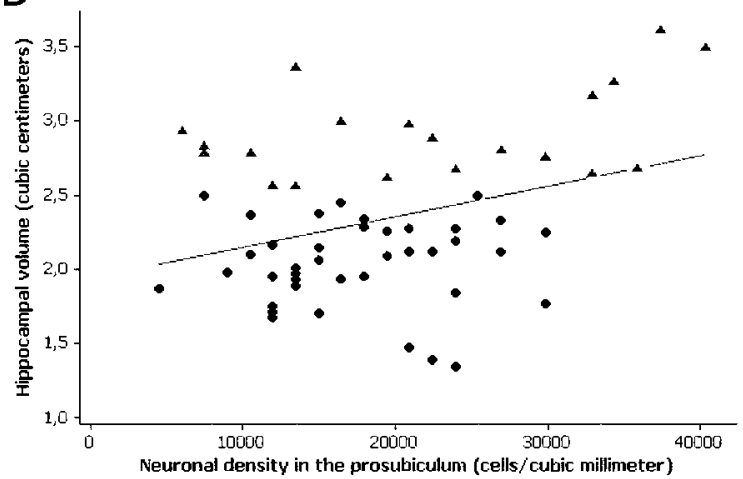

C
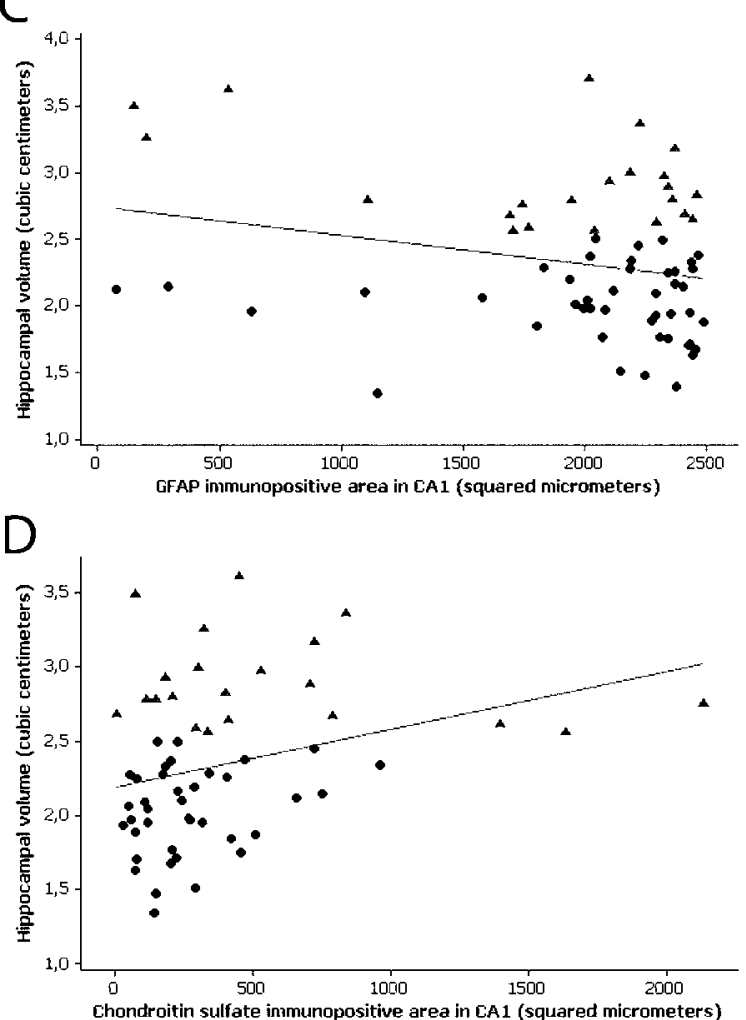
Original research

Mesial temporal lobe epilepsy with psychiatric comorbidities: a place for differential neuroinflammatory interplay

Ludmyla Kandratavicius ${ }^{\S 1,2} P h D$

E-mail: ludykandra@gmail.com

Jose Eduardo Peixoto-Santos ${ }^{\S 1} \mathrm{MSC}$

E-mail: e.peixotosantos@gmail.com

Mariana Raquel Monteiro ${ }^{1} \mathrm{MSC}$

E-mail: marianamonteiro85@gmail.com

Renata Caldo Scandiuzzi ${ }^{1}$

E-mail: renatascandiuzzi@yahoo.com.br

Carlos Gilberto Carlotti Jr ${ }^{3} M D P h D$

E-mail: carlotti@fmrp.usp.br

Joao Alberto Assirati Jr ${ }^{3} M D P h D$

E-mail: assiratijamj@uol.com.br

Jaime Eduardo Hallak ${ }^{1,2,4}$ MD PhD

E-mail: jhallak@fmrp.usp.br

Joao Pereira Leite ${ }^{* 1,2} M D P h D$

E-mail: jpleite@fmrp.usp.br

$\S:$ LK and JEPS are equally contributing authors.

Affiliations:

${ }^{1}$ Ribeirao Preto Medical School, Department of Neurosciences and Behavior, University of Sao Paulo (USP),

Brazil

${ }^{2}$ Center for Interdisciplinary Research on Applied Neurosciences (NAPNA), USP, Brazil 
${ }^{3}$ Ribeirao Preto Medical School, Department of Surgery, USP, Brazil

${ }^{4}$ National Institute of Science and Technology in Translational Medicine (INCT-TM - CNPq), Brazil

\section{* Corresponding Author:}

Joao Pereira Leite, MD PhD

Ribeirao Preto Medical School, Department of Neurosciences and Behavior, University of Sao Paulo; Av Bandeirantes 3900, CEP 14049-900, Ribeirao Preto, SP, Brazil

Phone number: +55 163602 2556; Fax number: +55 1636330866 


\section{Abstract}

Background: Despite the strong association between epilepsy and psychiatric comorbidities, few biological substrates are currently described. We have previously reported neuropathological alterations in mesial temporal lobe epilepsy (MTLE) patients with major depression and psychosis that suggest a morphological basis for psychopathological symptoms. Neuroinflammatory-related structures and molecules might be part of the altered neurochemical milieu behind the association between epilepsy and psychiatric comorbidities and such features have not been previously investigated in humans. Methods: MTLE hippocampi of subjects without psychiatric history, MTLE+major depression, and MTLE+interictal psychosis derived from epilepsy surgery and control necropsies were investigated for reactive astrocytes (GFAP), activated microglia (HLADR), glial metallothionein-I/II (MT-I/II) and aquaporin 4 (AQ4) immunohistochemistry. Results: Comparing MTLE groups, we found increased immunoreactive area of GFAP and HLA-DR, and decreased MT-I/II and AQP4 in specimens from MTLE patients with psychosis, while in specimens from patients with MTLE and major depression GFAP and MT-I/II was decreased. Differences between MTLE and control, being astrogliosis, microgliosis, increased $\mathrm{MT}-\mathrm{I} / \mathrm{II}$ and decreased perivascular AQP4 in the epileptogenic hippocampus, were coincidental to what is currently described in the literature. Conclusions: Neuroinflammatory-related molecules show in MTLE hippocampus a distinct pattern of expression when patients present with a comorbid psychiatric diagnosis, similar to what is found in the pure forms of schizophrenia and major depression. Future studies focusing on inflammatory characteristics of MTLE with psychiatric comorbidities might help in the design of better therapeutic strategies.

Key Words: temporal lobe epilepsy, psychosis, major depression, astrocytes, microglia, aquaporin-4, metallothionein. 


\section{Introduction}

Mesial temporal lobe epilepsy (MTLE) is the most common cause of intractable epilepsy in adults and is characterized by hippocampal sclerosis, neuronal loss, gliosis, and mossy fiber sprouting (Babb et al., 1991; Mathern et al., 1995; Peixoto-Santos et al., 2012; Kandratavicius et al., 2013c). Psychiatric comorbidities are frequent in MTLE patients, but their exact biological substrate is unknown (Kandratavicius et al., 2012b; Kandratavicius et al., 2012c). We have recently shown neuropathological alterations in the hippocampus of patients with epilepsy and history of major depression or interictal psychosis, which may indicate a morphological basis for psychiatric symptoms in MTLE (Kandratavicius et al., 2012a; Kandratavicius et al., 2013a; Kandratavicius et al., 2013b).

Neuroinflammation-related abnormalities such as glial pathology, glutamate dysregulation, and blood-brain-barrier dysfunction are found not only in epilepsy, but also in schizophrenia and major depression (Najjar et al., 2013a). Glial proteins such as metallothionein I and II (Rassendren et al., 1990; Ebadi et al., 1995; Colvin et al., 2003), and aquaporin 4 (AQP4), found in astrocytic endfeets, is a regulator of water homeostasis that majorly controls edema formation and tissue excitability (Binder et al., 2006; Verkman et al., 2006). In schizophrenia, upregulation of MT-I/II, astrocytes and microglia has been documented in several brain regions (Radewicz et al., 2000; Choi et al., 2008; Feresten et al., 2013). By contrast, in major depression studies indicate reduction in hippocampal GFAP astrocytes and of AQP4 and MT-I/II in frontal cortex (Shelton et al., 2011; Rajkowska \& Stockmeier, 2013). Since we have observed that protein expression in MTLE with psychiatric comorbidities tends to resemble what is found in the pure form of the correspondent psychiatric illness, we hypothesized that expression of reactive astrocytes, activated microglia, glial MT-I/II and AQ4 would be altered in the hippocampal formation of MTLE patients with major depression and interictal psychosis.

\section{Methods}




\section{Patients}

We analyzed the hippocampal formation from MTLE specimens freshly collected in the operating room and non-epileptic controls from necropsy, collected between 4-9 hours after death. $\mathrm{A}<24 \mathrm{~h}$ postmortem time limit allows comparison of necropsy tissue with freshly collected surgical specimens for their protein levels, cell morphology and tissue integrity (Gittins \& Harrison, 2004; Stan et al., 2006; PeixotoSantos et al., 2012). Tissue collection and processing were conducted according to protocol approved by our institution's Research Ethics Board (\# 2634/2008 and \# 9370/2003).

MTLE specimens were derived from 43 MTLE patients who underwent a standard en bloc anterior temporal resection (including 3-4 cm of the hippocampus) for medically intractable seizures. All had clinical neuropathological confirmation of HS. They were divided into 3 groups: 17 MTLE patients without any history of psychiatric disorder (MTLE group); 11 MTLE patients with interictal psychosis (MTLE+P group); and 15 MTLE patients with a diagnosis of major depression (MTLE+D group). For comparison purposes, 14 human non-epileptic control hippocampi from necropsies were processed and analyzed in the same manner as the surgical cases. Underlying diseases causing death were cardiomyopathy, sepsis, acute lymphoblastic leukemia, gastric adenocarcinoma, pulmonary infarct or renal-hepatic failure, with no history of hypoxic episodes during agony, seizures or neurological diseases. Furthermore, there was no evidence of brain pathological abnormalities on clinical postmortem examination of the mesial temporal structures. MTLE and control specimens were collected between 1998 and 2008. A summary of clinical characteristics of all groups is depicted in Table 1.

\section{Clinical features of MTLE patients}

All patients were referred for pre-surgical assessment due to drug-resistant seizures as defined in the literature (Berg, 2009). Patients were evaluated at the Ribeirao Preto Epilepsy Surgery Program using standardized protocols approved by the institution's Ethics Committee and a written consent form was obtained from each patient. Pre-surgical investigation at the Epilepsy Monitoring Unit included detailed 
clinical history, neurological examination, interictal and ictal scalp/sphenoidal electroencephalography (EEG), neuropsychology evaluation, and intracarotid amobarbital memory and language procedure whenever deemed clinically necessary.

Definition of MTLE followed Engel's criteria (Engel, 1996): (I) Seizure semiology consistent with MTLE, usually with epigastric/autonomic/psychic auras, followed by complex partial seizures; (II) Presurgical investigation confirming seizure onset zone in the temporal lobe; (III) Anterior and mesial temporal interictal spikes on EEG; (IV) No lesions other than uni- or bilateral hippocampal atrophy on high resolution magnetic resonance imaging scans (reduced hippocampal dimensions and increased T2 signal); (V) Clinical histopathological examination compatible with HS; (VI) No evidence of dual pathology identifiable by any of the assessment methods described (clinical, electrophysiology, neuroimaging and histopathology). Exclusion criteria were: (I) focal neurological abnormalities on physical examination; (II) generalized or extra-temporal EEG spikes; (III) marked cognitive impairment indicating dysfunction beyond the temporal regions. Information regarding antecedent of an initial precipitant injury, febrile seizures, seizure types, drug regimen and estimated monthly frequency (within the two years prior to surgery) were retrospectively collected from medical records for each patient. Psychiatric evaluations were conducted in all MTLE patients. Each diagnosis of major depression was independently established during the presurgical evaluation by two psychiatrists with experience in psychiatric disorders associated with epilepsy, using the guidelines of the Diagnostic and Statistical Manual of Mental Disorders, 4th edition. Once a consensus on the classification of psychotic syndromes associated with epilepsy was lacking at the time of collection, and neither DSM-IV nor ICD-10 has addressed this issue specifically (for a review, please see (Kandratavicius et al., 2014)), the diagnosis of psychosis associated with MTLE was established according to Sachdev (1998), meaning that patients with interictal psychosis did not experience the following: psychotic disorder temporally associated with seizures, changes in antiepileptic medications, epileptic status, delirium, and psychosis for paradoxical normalization. This group was defined by a prolonged psychotic state that was not related to the epileptic seizures. Typically, the psychotic states closely resemble schizophrenia, with 
paranoid ideas which might become systematized, ideas of influence, and auditory hallucinations often of a menacing quality. The points of difference are: common religious coloring of the paranoid ideas, tendency of the affect to remain warm and appropriate, and no typical deterioration to the hebephrenic state (Beard \& Slater, 1962). Patients had no history of previous psychiatric disorders (prior to seizure onset) or of substance dependence at any time. Global IQ was calculated after neuropsychological tests (complete WAIS-III or WAIS-R protocol).

\section{Tissue collection and immunohistochemical processing}

Specimens were segmented into $1 \mathrm{~cm}$ blocks transversely oriented to the hippocampal long axis. Blocks were placed in buffered paraformaldehyde (Sigma, St Louis, MO, USA). After 48-96 hours, specimens were paraffin embedded for immunohistochemistry.

Immunohistochemistry was performed with antibodies that identified immunoreactivity for reactive astrocytes (GFAP, 1:500 dilution; Dako, Glostrup, Denmark), activated microglia (HLA-DR, 1:100 dilution; Dako, Glostrup, Denmark), astroglial metallothionein I/II (MT-I/II, 1:500 dilution, Dako, Glostrup, Denmark) and perivascular aquaporin 4 (AQ4, 1:200 dilution; Santa Cruz Biotechnology, Santa Cruz, CA, USA). Antibodies specificity was verified and immunohistochemistry were performed as described in PeixotoSantos et al. (2012). Briefly, paraffin embedded MTLE and control hippocampi were processed together for each antibody, with overnight incubation at room temperature and developed simultaneously in $0.05 \%$ 3,3'diaminobenzidine tetrahydrochloride (Pierce, Rockford, USA) and 0.01\% hydrogen peroxide (Merck, Darmstadt, Germany). After sufficient colorization, reaction was halted by washing in several rinses of distilled water, dehydrated through graded ethanol to xylene (Merck, Darmstadt, Germany), and cover slipped with Krystalon (EM Science, Gibbstown, NJ, USA). Adjacent sections were hematoxilin-eosin stained (Laborclin, Pinhais, Brazil) and examined for tissue integrity. Control sections without the primary antisera did not reveal staining (data not shown).

\section{Semi-quantitative analysis of immunohistochemistry}


MTLE and control hippocampi were compared for immunoreactivity in several hippocampal formation subfields using Lorente de No's classification (Lorente de No, 1934), which included fascia dentata granular cells, hilar neurons, as well as pyramidal cells in CA4, CA3, CA2, CA1, prosubiculum, subiculum, parasubiculum, and entorhinal cortex layer III. Immunoreactivity were estimated in $8 \mu \mathrm{m}$ Neu-N stained slices at 200x magnification as previously described and well established in the literature for surgical hippocampal fragments (Mathern et al., 1995; Mathern et al., 1997; Mathern et al., 1999; Peixoto-Santos et al., 2012; Kandratavicius et al., 2013c).

Images of each hippocampal formation subfield from all specimens were collected and digitized with a high resolution CCD monochrome camera attached to an Olympus microscope. Uniform luminance was maintained and checked every 10 measurements using an optical density standard and a gray value scale ranging from 0 (white) to 255 (black). In brief, all digitized images were analyzed with Image J software, following the same criteria: (I) the software identifies the gray value distribution of a subfield's digital image; (II) the immunoreactive area is selected (i.e. positive stained pixels), limited to a threshold range; and (III) the threshold range is pre-settled based on control group sections, to exclude the low intensity gray value of background staining from the analysis. For GFAP, threshold selected allowed the quantification of positive staining present in the soma, branches and also of the fine and characteristic astroglial meshwork. For HLA-DR, threshold selected allowed the quantification of proteins present in the soma and branches of the immunostained cells, whereas MT-I/II threshold allowed the quantifications of proteins in the soma and proximal branches of astrocytes. As for AQP4, we selected a higher threshold, in order to quantify only AQP4 present in the endfeets of astrocytes (i.e., perivascular AQP4). A similar approach was used by our group elsewhere (Peixoto-Santos et al., 2012; Kandratavicius et al., 2013c). Analyses were conducted blind to hippocampal pathology and group classification.

\section{Data analysis}

Data were analyzed using the statistical program PAWS (version 18.0) and SigmaPlot (version 11.0). Groups were compared using analysis of variance (ANOVA one way, with Bonferroni post hoc test) or unpaired $t$ test for variables with normal distribution, and Kruskal-Wallis One Way Analysis of Variance on Ranks (with Dunn post hoc test) or Mann-Whitney Rank Sum Test for variables without normal distribution. 
Fisher Exact test was applied for comparison of relative frequencies of clinical variables between groups. Statistical significance was set at $p<0.05$ and values presented as mean \pm SD.

\section{Results}

Clinical profiles

The four patients groups did not show significant differences in gender, age or collected side (Table 1). Clinical variables such as presence of an initial precipitant injury, age of first seizure and seizure onset, seizure frequency, type and outcome, epilepsy duration, HS side, handedness, IQ, years at school and performance in neuropsychological tests were homogeneously distributed among MTLE groups.

All epileptic patients were on antiepileptic drugs (carbamazepine, oxcarbazepine, phenobarbital, and /or phenytoin). In addition, patients were also taking benzodiazepines (MTLE group: 11 of 17; MTLE+D: 10 of 15; MTLE+P group 8 of 11), fluoxetine (MTLE+D: 5 of 15) and haloperidol (MTLE+P group: 6 of 11). No differences in neuropsychological tests between patients taking or not taking benzodiazepines, fluoxetine or haloperidol were seen. No significant influence of fluoxetine or haloperidol was seen in GFAP, HLA-DR or AQ4 expression. Haloperidol influence on MT-I/II expression will be described below.

\section{Reactive astrocytes}

Immunohistochemistry for GFAP, a marker of reactive astrocytes, showed a higher number of immunopositive cells and astrocytic processes in MTLE patients (Figure $1 \mathrm{~A}-\mathrm{C}$ ), compared to staining in controls (Figure 1D). Evaluation of immunopositive area fraction (Figure 2A) revealed higher GFAP area in all MTLE groups in outer molecular layer, inner molecular layer, granule cell layer, hilus, CA4, CA3, CA1, prosubiculum, subiculum, and parasubiculum $(p \leq 0.024)$ when compared to controls. MTLE and MTLE+P had also increased immunopositive area in inner molecular layer, granule cell layer, and CA2 ( $\mathrm{p} \leq 0.049)$ compared to MTLE+D. In CA1, MTLE had higher immunopositive area than MTLE+D $(p<0.001)$. In the outer 
molecular layer, MTLE+P had higher GFAP immunopositive area than MTLE+D ( $p=0.013)$. In the entorhinal cortex, only the groups with psychiatric comorbidities (i.e., MTLE+D and MTLE+P) had increased GFAP immunopositive area, when compared to controls ( $p \leq 0.032)$.

\section{Activated microglia}

Activated microglia, evaluated with antibody against HLA-DR, was observed in MTLE patients as small, highly branched cells, well defined and spaced from each other (Figure 1E-G). In control specimens, activated microglia were rarely seen, and when present were in much smaller number than in MTLE cases (Figure $1 \mathrm{H}$ ). Quantitative evaluation of activated microglia (Figure $2 \mathrm{~B}$ ) revealed increased immunopositivity in the outer molecular layer, granule cell layer, hilus, CA3, CA2, CA1, and prosubiculum of MTLE+P when compared to control $(p \leq 0.047)$. Patients of MTLE+P group had also higher immunopositive area in the hilus $(p=0.04)$ and CA2 $(p<0.001)$, when compared to MTLE, and also in CA2, when compared to MTLE+D $(p=$ 0.002). MTLE patients had increased HLA-DR immunopositive area, compared to control, in granule cell layer, CA3 and CA2 ( $p \leq 0.038)$.

\section{Metallothioneins $I / I I$}

The immunopositive staining for MT-I/II was observed in cells with astroglial morphology (see Figure 1I-L). Although only patients from the MTLE group had significant increase in MT-I/II immunopositive cells, qualitatively all MTLE groups present a higher number of MT-I/II positivity (compare the micrography L with the micrographies I-K in Figure 1). Higher immunopositive staining (Figure 3A) was observed in the inner molecular layer, CA2, CA1, parasubiculum and entorhinal cortex of MTLE when compared to control ( $p \leq$ 0.015). Compared to MTLE+P, higher immunopositive area was observed in granule cell layer, $C A 1$ and the parasubiculum of MTLE cases $(p \leq 0.019)$. In the parasubiculum, the group MTLE had higher area fraction than MTLE+D $(p<0.001)$. 
MT-I/II expression was increased in the inner molecular layer of MTLE+P patients taking haloperidol when compared to those not taking it (with haloperidol, mean area fraction $=7.5 \pm 3.5$; without haloperidol, mean area fraction $=1.7 \pm 2.2 ; t(9)=2.885 ; \mathrm{p}=0.02$ ). Also, we found a trend to increased MT-I/II expression in CA2 of those patients who achieved complete seizure remission after surgery (remission, mean area fraction $=20.3 \pm 24.6 ;$ no-remission, mean area fraction $=9.1 \pm 6.2 ; t(38)=-1.946 ; p=0.06)$.

\section{Aquaporin 4}

AQ4 immunohistochemistry revealed a reduction in the perivascular staining intensity in MTLE specimens, when compared to controls (compare micrography P with micrographies M-O in Figure 1). Also, a significant decrease in the perivascular immunopositive area (Figure 3B) was observed in MTLE compared to control. In the hilus, all MTLE groups had decreased area fraction $(p \leq 0.015)$, whereas in CA4 only MTLE+P showed significant decrease $(p=0.026)$, and in the subiculum MTLE and MTLE+P had reduced immunopositive area $(p \leq 0.015)$ when compared to controls. A direct correlation was seen between IQ and AQP4 expression in CA1 $(R=0.530 ; p=0.006)$ and in prosubiculum $(R=0.529 ; p=0.008)$ of MTLE patients. Also, we found a trend to increased AQP4 expression in CA2 of those patients who achieved complete seizure remission after surgery (remission, mean area fraction $=9.9 \pm 9.0$; no-remission, mean area fraction $=5.3 \pm 2.9 ; t(38)=-1.930 ; p=0.07)$.

\section{Discussion}

Studies with humans and animal models of epilepsy have shown upregulation of several inflammatory molecules (Vezzani et al., 2008; Arisi, 2014). However, only a few studies have focused on inflammatory changes in correlates of major depression comorbid with epilepsy. For example, rats injected with pilocarpine exhibit behavioral equivalents of anhedonia and despair, and alterations in inflammatory molecules as found in human major depression (Pineda et al., 2010; Xie et al., 2014). No information 
regarding neuroinflammatory mechanisms in psychosis of epilepsy is available to date. In the present study we investigated the expression of glial proteins GFAP, HLA-DR, MT-I/II and perivascular AQP4 in the hippocampal formation of MTLE with and without psychiatric comorbidities and in nonepileptic controls. Comparing MTLE groups, we found increased immunoreactive area of GFAP and HLA-DR, and decreased MT-I/II and AQP4 in specimens from MTLE patients with psychosis, while in specimens from patients with MTLE and major depression GFAP and MT-I/II was decreased. Differences between MTLE and control, being astrogliosis, microgliosis, increased MT-I/II and decreased perivascular AQP4 in the epileptogenic hippocampus, were similar to what is currently described in the literature (Eid et al., 2005; Peixoto-Santos et al., 2012). Given that differences between epileptogenic and control hippocampi are already well established in the literature, our discussion will focus mainly on psychiatric subgroups and their differences when compared to MTLE without psychiatric comorbidities, unless otherwise specified.

Astrocytic GFAP expression in the hippocampus is increased in MTLE (Peixoto-Santos et al., 2012; Kandratavicius et al., 2013c) and decreased in major depression (Muller et al., 2001; Rajkowska \& Stockmeier, 2013). Likewise, we detected decreased GFAP immunoreactive area in specimens of MTLE patients with major depression, when compared to MTLE and MTLE+P. Despite GFAP expression in the prefrontal cortex of patients with schizophrenia is increased (Feresten et al., 2013), other cortical areas and the hippocampus have shown inconclusive results (Radewicz et al., 2000; Webster et al., 2001; Steffek et al., 2008). In MTLE patients with interictal psychosis we found increased GFAP expression, especially when compared to MTLE+D cases, in agreement with a recent hypothesis that astrocyte pathology may be associated with psychotic symptoms, although the exact nature of this change remains unclear (Feresten et al., 2013). In particular, increased GFAP in schizophrenia/ psychotic symptoms could be closely related to increased neuroinflammatory markers (Catts et al., 2014). A recent study comparing MTLE hippocampi from patients with and without de novo psychosis (post-operative interictal psychosis) analyzed GFAP expression and found no qualitative differences between groups. In our present series quantitative differences in GFAP between MTLE and MTLE+P were also subtle, and major differences were seen in respect to MTLE+D group. 
Increased cortical and hippocampal HLA-DR microglia has been described in schizophrenia

(Radewicz et al., 2000; Busse et al., 2012), in accordance to our findings in the hippocampus of MTLE patients with interictal psychosis. Of note, increased hippocampal HLA-DR was particularly associated with paranoid schizophrenia (Busse et al., 2012), a core symptom especially represented in interictal psychosis (Kandratavicius et al., 2014). HLA-DR levels in MTLE specimens from patients without psychiatric comorbidities and in those with major depression were similar and higher than in controls. Microglia is an important source of inflammatory molecules (Arisi, 2014) and higher expression of pro-inflammatory cytokines is observed in major depression (Rosenblat et al., 2014). Similar microglial activation in MTLE and MTLE+D could partially explain why patients with epilepsy frequently develop mood disorders, an association still incompletely understood (Kanner, 2012). However, the levels of microglial-related molecules remain to be evaluated in human epilepsy with and without major depression.

MT-I/II gene expression in the prefrontal cortex has been found increased in schizophrenia (Choi et al., 2008) and decreased in major depression (Shelton et al., 2011). No reports are available regarding the hippocampus on these psychiatric illnesses, but in our series we found decreased values in cases with psychosis and on those with major depression when compared to MTLE without psychiatric comorbidities in several hippocampal subfields. Interestingly, we have found in other series of patients decreased mossy fiber sprouting in MTLE+P and increased in MTLE+D (Kandratavicius et al., 2012a; Kandratavicius et al., 2013a). Since mossy fibers are zinc-enriched and MT-I/II chelates zinc, cadmium and copper, it would be expected that hippocampi from MTLE+D to have a deficient metal homeostasis and likely zinc excess in neurons, glias and in the neuropile. A possible mechanism would be through zinc overflow from serum to brain (Takeda, 2000) due to an inefficient blood-brain barrier in major depression (Najjar et al., 2013b). In fact, low zinc serum is a hallmark of major depressive disorders (Szewczyk et al., 2011). Our results of decreased hippocampal MT-I/II in MTLE associated to psychosis can be related to decreased hippocampal zinc levels in interictal psychosis (Kandratavicius et al., 2012a; Kandratavicius et al., 2013a), as well as in schizophrenia (Goldsmith \& Joyce, 1995; Kolomeets et al., 2007). We also found a trend to increased MT-I/II 
in CA2 of patients who achieved complete remission after surgery, in agreement to MT-I/II role in excitability control (Carrasco et al., 2000). As another indicative of excitability control by MT-I/II, in a different series of patients we have described that in MTLE patients who show per se increased hippocampal MT-I/II, those without secondarily generalized seizures exhibit higher MT-I/II levels (PeixotoSantos et al., 2012). Indeed, other recent evidences indicate that hippocampal expression of proteins used as markers of full blown epileptogenesis might be able to predict seizure outcome.

AQ4 is able to regulate the brain response to insults or injury, and also influence synaptic plasticity and behavior (Scharfman \& Binder, 2013). In the AQP4 knockout mouse memory is impaired (Skucas et al., 2011), and our results showed a direct correlation between perivascular AQP4 expression in the Sommer sector and IQ scores. AQ4 participation in synaptic plasticity and cognition occurs together with neurotrophin (NT) receptors (Skucas et al., 2011). Of note, NTs and NT receptors are differentially regulated in MTLE with psychiatric comorbidities, which could further change how AQP4 modulates plasticity. For instance, brain derived neurotrophic factor (BDNF) is increased in MTLE but decreased in MTLE+P (Kandratavicius et al., 2013a). In addition, TrkB (a BDNF receptor) is increased in MTLE+P but not in MTLE. Given that low levels of AQP4 associated with increased BDNF and TrkB or p75NTR may result in increased excitability, AQP4 levels near to control levels could be more efficient in the control of excessive excitatory activation trough a BDNF-TrkB or p75NTR loop (Skucas et al., 2011; Zhang et al., 2013). In fact, we found a trend to increased AQP4 in cases with complete seizure remission, thus reinforcing the role of AQP4 in controlling neuron activity. In addition, AQP4 has an important role in $\mathrm{K}^{+}$homeostasis (Amiry-Moghaddam et al., 2003; Binder et al., 2006), and the AQ4 knockout mice have higher seizure threshold but longer seizure duration (Binder et al., 2006).

In conclusion, we described hippocampal neuroinflammatory-related molecules that show in MTLE a distinct pattern of expression when patients present with a comorbid psychiatric diagnosis of interictal psychosis or major depression. Studies have reported successful treatment of patients with seizures, schizophrenia and major depression using drugs with anti-inflammatory effect as an add-on therapy (Muller 
et al., 2006; Chaudhry et al., 2012; Devinsky et al., 2013; Krogias et al., 2013). Given the differential expression of neuroinflammatory related molecules in MTLE with psychiatric comorbidities, these patients could also benefit from a more targeted treatment. Further research is needed to expand and validate these findings, and to better investigate possible causal mechanisms.

\section{Abbreviations}

AQ4: aquaporin 4

BDNF: brain derived neurotrophic factor

CA4: Cornus Ammonis region 4

CA3: Cornus Ammonis region 3

CA2: Cornus Ammonis region 2

CA1: Cornus Ammonis region 1

DSM IV: Diagnostic and Statistical Manual of Mental Disorders, 4th edition.

EEG: electroencephalogram

GFAP: glial fibrillary acidic protein

HLA-DR: human leukocyte antigen, MHC class II

HS: hippocampal sclerosis

ICD 10: The International Classification of Diseases, version 10

IQ: intelligence quotient

MTLE: mesial temporal lobe epilepsy

MTLE+D: MTLE+ major depression

MTLE+P: MTLE + interictal psychosis

MT-I/II: metallothionein I and II

NT: neurotrophin

p75ntr: p75 neurotrophin receptor

SD: standard deviation

TrkB: tyrosine kinase receptor, type 2

WAIS-III: Wechsler Adult Intelligence Scale, version III

\section{Acknowledgments}

This work was supported by Fundacao de Apoio a Pesquisa do Estado de Sao Paulo - Fapesp (CInAPCe

Project 05/56447-7, to JPL; PhD fellowship 2010/51515-2, to JEPS; PhD fellowship 2011/23691-3, to MRM), Conselho Nacional de Desenvolvimento Cientifico e Tecnologico - CNPq, and Coordenacao de Aperfeicoamento de Pessoal de Nivel Superior - CAPES (postdoc fellowship A034-2013, to LK). 


\section{Disclosures}

The authors declare that they have no conflict of interest. The funders had no role in study design, data collection and analysis, decision to publish, or preparation of the manuscript. Conception and design of research (LK); Performed research (LK, JEPS, MRM, RCS); Analyzed data (JEPS); Contributed with reagents/ analytic tools and/ or important intellectual input (JAA, CGC, JEH); Wrote the manuscript (LK, JEPS, JPL). All authors read and approved the final manuscript.

\section{References}

Amiry-Moghaddam M, Williamson A, Palomba M, Eid T, de Lanerolle NC, Nagelhus EA, Adams ME, Froehner SC, Agre P \& Ottersen OP. (2003). Delayed K+ clearance associated with aquaporin-4 mislocalization: phenotypic defects in brains of alpha-syntrophin-null mice. Proc Natl Acad Sci U S A 100, 13615-13620.

Arisi GM. (2014). Nervous and immune systems signals and connections: Cytokines in hippocampus physiology and pathology. Epilepsy Behav.

Babb TL, Kupfer WR, Pretorius JK, Crandall PH \& Levesque MF. (1991). Synaptic reorganization by mossy fibers in human epileptic fascia dentata. Neuroscience 42, 351-363.

Beard AW \& Slater E. (1962). The schizophrenic-like psychoses of epilepsy. Proc R Soc Med 55, 311-316.

Berg AT. (2009). Identification of pharmacoresistant epilepsy. Neurol Clin 27, 1003-1013.

Binder DK, Yao X, Zador Z, Sick TJ, Verkman AS \& Manley GT. (2006). Increased seizure duration and slowed potassium kinetics in mice lacking aquaporin-4 water channels. Glia 53, 631-636.

Busse S, Busse M, Schiltz K, Bielau H, Gos T, Brisch R, Mawrin C, Schmitt A, Jordan W, Muller UJ, Bernstein HG, Bogerts B \& Steiner J. (2012). Different distribution patterns of lymphocytes and microglia in the hippocampus of patients with residual versus paranoid schizophrenia: further evidence for disease course-related immune alterations? Brain Behav Immun 26, 1273-1279.

Carrasco J, Penkowa M, Hadberg H, Molinero A \& Hidalgo J. (2000). Enhanced seizures and hippocampal neurodegeneration following kainic acid-induced seizures in metallothionein-I + II-deficient mice. Eur J Neurosci 12, 2311-2322.

Catts VS, Wong J, Fillman SG, Fung SJ \& Weickert CS. (2014). Increased expression of astrocyte markers in schizophrenia: Association with neuroinflammation. Aust N Z J Psychiatry.

Chaudhry IB, Hallak J, Husain N, Minhas F, Stirling J, Richardson P, Dursun S, Dunn G \& Deakin B. (2012). Minocycline benefits negative symptoms in early schizophrenia: a randomised double-blind placebo-controlled clinical trial in patients on standard treatment. J Psychopharmacol 26, 1185-1193. 
Choi KH, Elashoff M, Higgs BW, Song J, Kim S, Sabunciyan S, Diglisic S, Yolken RH, Knable MB, Torrey EF \& Webster MJ. (2008). Putative psychosis genes in the prefrontal cortex: combined analysis of gene expression microarrays. BMC Psychiatry 8, 87.

Colvin RA, Fontaine CP, Laskowski M \& Thomas D. (2003). Zn2+ transporters and Zn2+ homeostasis in neurons. Eur J Pharmacol 479, 171-185.

Devinsky O, Vezzani A, Najjar S, De Lanerolle NC \& Rogawski MA. (2013). Glia and epilepsy: excitability and inflammation. Trends Neurosci 36, 174-184.

Ebadi M, Iversen PL, Hao R, Cerutis DR, Rojas P, Happe HK, Murrin LC \& Pfeiffer RF. (1995). Expression and regulation of brain metallothionein. Neurochem Int 27, 1-22.

Eid T, Lee TS, Thomas MJ, Amiry-Moghaddam M, Bjornsen LP, Spencer DD, Agre P, Ottersen OP \& de Lanerolle NC. (2005). Loss of perivascular aquaporin 4 may underlie deficient water and $\mathrm{K}+$ homeostasis in the human epileptogenic hippocampus. Proc Natl Acad Sci U S A 102, 1193-1198.

Engel J, Jr. (1996). Surgery for seizures. N Engl J Med 334, 647-652.

Feresten AH, Barakauskas V, Ypsilanti A, Barr AM \& Beasley CL. (2013). Increased expression of glial fibrillary acidic protein in prefrontal cortex in psychotic illness. Schizophr Res 150, 252-257.

Gittins R \& Harrison PJ. (2004). Neuronal density, size and shape in the human anterior cingulate cortex: a comparison of Nissl and NeuN staining. Brain Res Bull 63, 155-160.

Goldsmith SK \& Joyce JN. (1995). Alterations in hippocampal mossy fiber pathway in schizophrenia and Alzheimer's disease. Biol Psychiatry 37, 122-126.

Kandratavicius L, Hallak JE \& Leite JP. (2014). What are the similarities and differences between schizophrenia and schizophrenia-like psychosis of epilepsy? A neuropathological approach to the understanding of schizophrenia spectrum and epilepsy. Epilepsy Behav.

Kandratavicius L, Hallak JE, Young LT, Assirati JA, Carlotti CG, Jr. \& Leite JP. (2012a). Differential aberrant sprouting in temporal lobe epilepsy with psychiatric co-morbidities. Psychiatry Res 195, 144-150.

Kandratavicius L, Lopes-Aguiar C, Bueno-Junior LS, Romcy-Pereira RN, Hallak JE \& Leite JP. (2012b). Psychiatric comorbidities in temporal lobe epilepsy: possible relationships between psychotic disorders and involvement of limbic circuits. Rev Bras Psiquiatr 34, 454-466.

Kandratavicius L, Monteiro MR, Assirati JA, Jr., Carlotti CG, Jr., Hallak JE \& Leite JP. (2013a). Neurotrophins in mesial temporal lobe epilepsy with and without psychiatric comorbidities. J Neuropathol Exp Neurol 72, 1029-1042.

Kandratavicius L, Monteiro MR, Hallak JE, Carlotti CG, Jr., Assirati JA, Jr. \& Leite JP. (2013b). Microtubule-associated proteins in mesial temporal lobe epilepsy with and without psychiatric comorbidities and their relation with granular cell layer dispersion. Biomed Res Int 2013, 960126.

Kandratavicius L, Rosa-Neto P, Monteiro MR, Guiot MC, Assirati JA, Jr., Carlotti CG, Jr., Kobayashi E \& Leite JP. (2013c). Distinct increased metabotropic glutamate receptor type 5 (mGluR5) in temporal lobe epilepsy with and without hippocampal sclerosis. Hippocampus 23, 1212-1230.

Kandratavicius L, Ruggiero RN, Hallak JE, Garcia-Cairasco N \& Leite JP. (2012c). Pathophysiology of mood disorders in temporal lobe epilepsy. Rev Bras Psiquiatr 34 Suppl 2, S233-245.

Kanner AM. (2012). Can neurobiological pathogenic mechanisms of depression facilitate the development of seizure disorders? Lancet Neurol 11, 1093-1102. 
Kolomeets NS, Orlovskaya DD \& Uranova NA. (2007). Decreased numerical density of CA3 hippocampal mossy fiber synapses in schizophrenia. Synapse 61, 615-621.

Krogias C, Hoepner R, Muller A, Schneider-Gold C, Schroder A \& Gold R. (2013). Successful treatment of anti-Caspr2 syndrome by interleukin 6 receptor blockade through tocilizumab. JAMA Neurol 70, 1056-1059.

Lorente de No R. (1934). Studies on the Structure of the Cerebral Cortex II. Continuation of Study of the Ammonic System. J Psychol Neurol 46, 113-177.

Mathern GW, Babb TL, Pretorius JK \& Leite JP. (1995). Reactive synaptogenesis and neuron densities for neuropeptide $\mathrm{Y}$, somatostatin, and glutamate decarboxylase immunoreactivity in the epileptogenic human fascia dentata. $J$ Neurosci 15, 3990-4004.

Mathern GW, Mendoza D, Lozada A, Pretorius JK, Dehnes Y, Danbolt NC, Nelson N, Leite JP, Chimelli L, Born DE, Sakamoto AC, Assirati JA, Fried I, Peacock WJ, Ojemann GA \& Adelson PD. (1999). Hippocampal GABA and glutamate transporter immunoreactivity in patients with temporal lobe epilepsy. Neurology 52, 453-472.

Mathern GW, Pretorius JK, Kornblum HI, Mendoza D, Lozada A, Leite JP, Chimelli LM, Fried I, Sakamoto AC, Assirati JA, Levesque MF, Adelson PD \& Peacock WJ. (1997). Human hippocampal AMPA and NMDA mRNA levels in temporal lobe epilepsy patients. Brain 120 ( Pt 11), 1937-1959.

Muller MB, Lucassen PJ, Yassouridis A, Hoogendijk WJ, Holsboer F \& Swaab DF. (2001). Neither major depression nor glucocorticoid treatment affects the cellular integrity of the human hippocampus. Eur J Neurosci 14, 16031612.

Muller N, Schwarz MJ, Dehning S, Douhe A, Cerovecki A, Goldstein-Muller B, Spellmann I, Hetzel G, Maino K, Kleindienst N, Moller HJ, Arolt V \& Riedel M. (2006). The cyclooxygenase-2 inhibitor celecoxib has therapeutic effects in major depression: results of a double-blind, randomized, placebo controlled, add-on pilot study to reboxetine. Mol Psychiatry 11, 680-684.

Najjar S, Pearlman DM, Alper K, Najjar A \& Devinsky O. (2013a). Neuroinflammation and psychiatric illness. J Neuroinflammation 10, 43.

Najjar S, Pearlman DM, Devinsky O, Najjar A \& Zagzag D. (2013b). Neurovascular unit dysfunction with blood-brain barrier hyperpermeability contributes to major depressive disorder: a review of clinical and experimental evidence. J Neuroinflammation 10, 142.

Peixoto-Santos JE, Galvis-Alonso OY, Velasco TR, Kandratavicius L, Assirati JA, Carlotti CG, Scandiuzzi RC, Serafini LN \& Leite JP. (2012). Increased metallothionein I/II expression in patients with temporal lobe epilepsy. PLoS One 7, e44709.

Pineda E, Shin D, Sankar R \& Mazarati AM. (2010). Comorbidity between epilepsy and depression: experimental evidence for the involvement of serotonergic, glucocorticoid, and neuroinflammatory mechanisms. Epilepsia 51 Suppl 3, 110-114.

Radewicz K, Garey LJ, Gentleman SM \& Reynolds R. (2000). Increase in HLA-DR immunoreactive microglia in frontal and temporal cortex of chronic schizophrenics. J Neuropathol Exp Neurol 59, 137-150.

Rajkowska G \& Stockmeier CA. (2013). Astrocyte pathology in major depressive disorder: insights from human postmortem brain tissue. Curr Drug Targets 14, 1225-1236.

Rassendren FA, Lory P, Pin JP \& Nargeot J. (1990). Zinc has opposite effects on NMDA and non-NMDA receptors expressed in Xenopus oocytes. Neuron 4, 733-740. 
Rosenblat JD, Cha DS, Mansur RB \& Mclntyre RS. (2014). Inflamed moods: A review of the interactions between inflammation and mood disorders. Prog Neuropsychopharmacol Biol Psychiatry 53C, 23-34.

Sachdev P. (1998). Schizophrenia-like psychosis and epilepsy: the status of the association. Am J Psychiatry 155, 325336.

Scharfman HE \& Binder DK. (2013). Aquaporin-4 water channels and synaptic plasticity in the hippocampus. Neurochem Int 63, 702-711.

Shelton RC, Claiborne J, Sidoryk-Wegrzynowicz M, Reddy R, Aschner M, Lewis DA \& Mirnics K. (2011). Altered expression of genes involved in inflammation and apoptosis in frontal cortex in major depression. Mol Psychiatry 16, 751-762.

Skucas VA, Mathews IB, Yang J, Cheng Q, Treister A, Duffy AM, Verkman AS, Hempstead BL, Wood MA, Binder DK \& Scharfman HE. (2011). Impairment of select forms of spatial memory and neurotrophin-dependent synaptic plasticity by deletion of glial aquaporin-4. J Neurosci 31, 6392-6397.

Stan AD, Ghose S, Gao XM, Roberts RC, Lewis-Amezcua K, Hatanpaa KJ \& Tamminga CA. (2006). Human postmortem tissue: what quality markers matter? Brain Res 1123, 1-11.

Steffek AE, McCullumsmith RE, Haroutunian V \& Meador-Woodruff JH. (2008). Cortical expression of glial fibrillary acidic protein and glutamine synthetase is decreased in schizophrenia. Schizophr Res 103, 71-82.

Szewczyk B, Kubera M \& Nowak G. (2011). The role of zinc in neurodegenerative inflammatory pathways in depression. Prog Neuropsychopharmacol Biol Psychiatry 35, 693-701.

Takeda A. (2000). Movement of zinc and its functional significance in the brain. Brain Res Brain Res Rev 34, $137-148$.

Verkman AS, Binder DK, Bloch O, Auguste K \& Papadopoulos MC. (2006). Three distinct roles of aquaporin-4 in brain function revealed by knockout mice. Biochimica et biophysica acta 1758, 1085-1093.

Vezzani A, Ravizza T, Balosso S \& Aronica E. (2008). Glia as a source of cytokines: implications for neuronal excitability and survival. Epilepsia 49 Suppl 2, 24-32.

Webster MJ, Knable MB, Johnston-Wilson N, Nagata K, Inagaki M \& Yolken RH. (2001). Immunohistochemical localization of phosphorylated glial fibrillary acidic protein in the prefrontal cortex and hippocampus from patients with schizophrenia, bipolar disorder, and depression. Brain Behav Immun 15, 388-400.

Xie W, Cai L, Yu Y, Gao L, Xiao L, He Q, Ren Z \& Liu Y. (2014). Activation of brain indoleamine 2,3-dioxygenase contributes to epilepsy-associated depressive-like behavior in rats with chronic temporal lobe epilepsy. $J$ Neuroinflammation 11, 41.

Zhang Z, Fan J, Ren Y, Zhou W \& Yin G. (2013). The release of glutamate from cortical neurons regulated by BDNF via the TrkB/Src/PLC-gamma1 pathway. J Cell Biochem 114, 144-151. 
Table 1 Demographic and clinical data

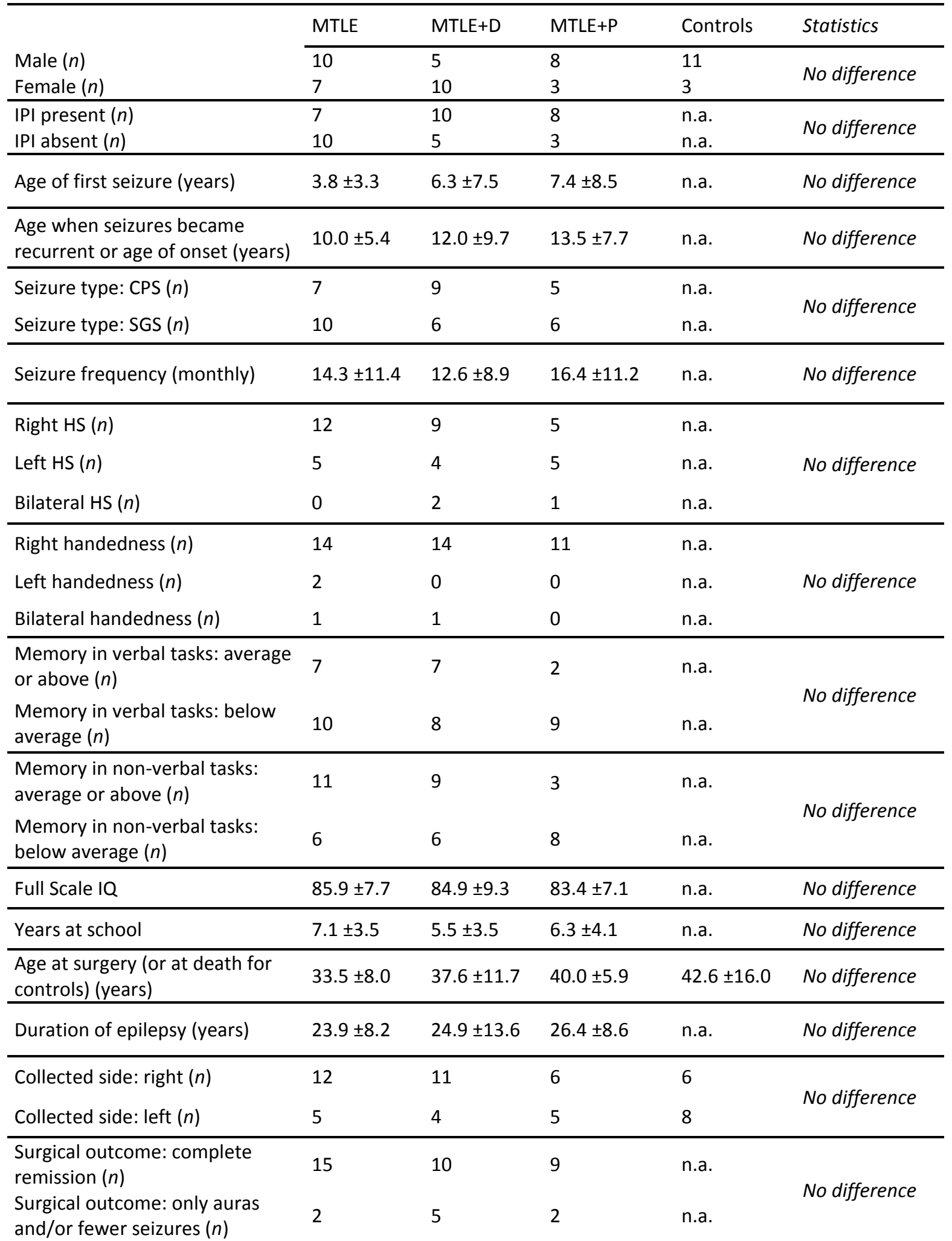

Values indicated as mean \pm std. deviation when applicable. IPI: initial precipitant injury; CPS: complex partial seizure; SGS: secondarily generalized seizures; HS: hippocampal sclerosis; n.a.: not applicable 

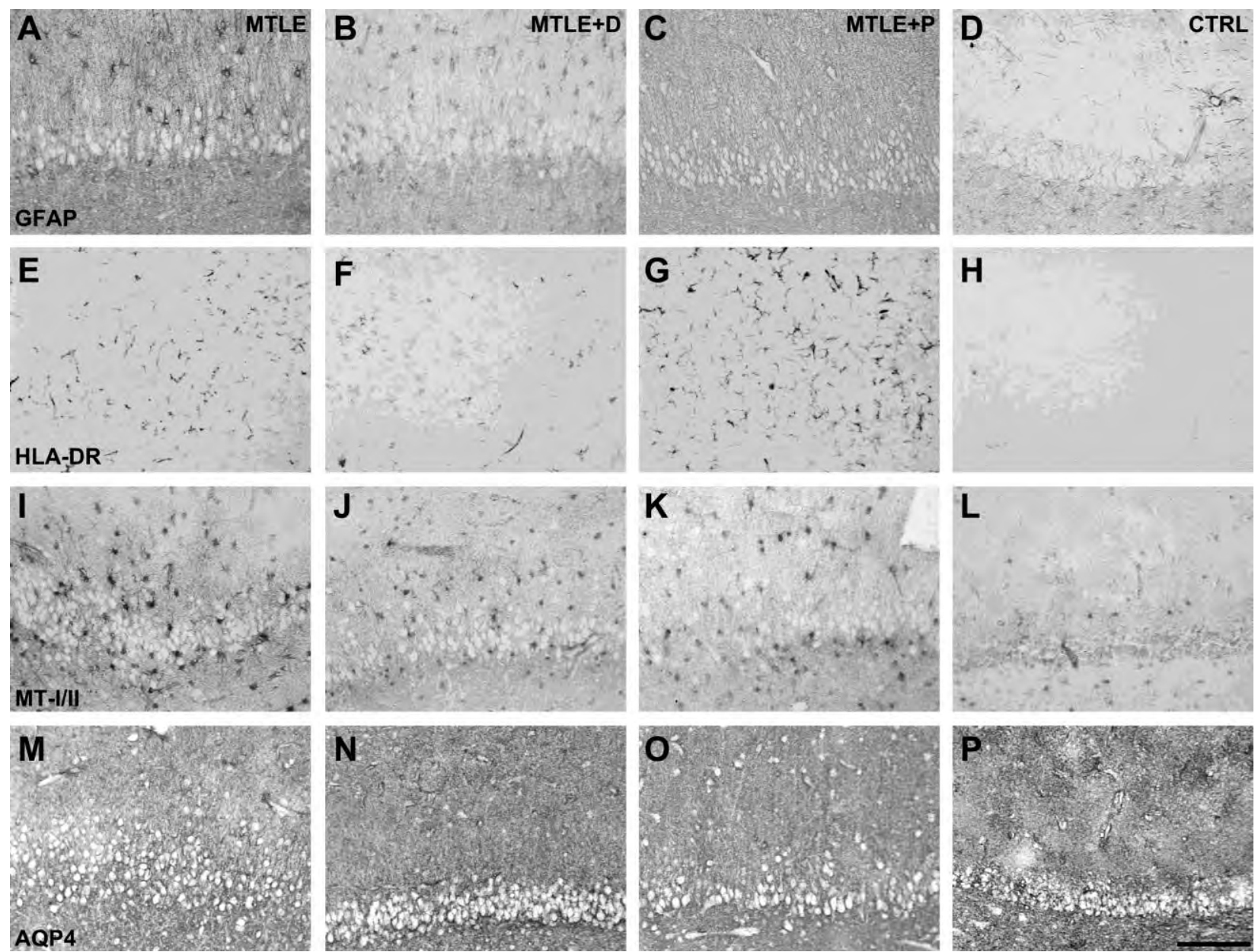

Figure 1. Representative images of Fascia dentata immunostained for GFAP (A-D), HLA-DR (E-H), MT-I/II (I$L)$, and AQP4 (M-P) from patients with MTLE (A, E, I and M), MTLE+D (B, F, J and N), MTLE+P (C, G, K and O) and autopsy controls $(D, H, L$ and $P)$. Observe the increased astroglial reaction $(A-C)$, microglial activation ( $E-$ $\mathrm{G}), \mathrm{MT}-\mathrm{I} / \mathrm{II}$ immunopositive astrocytes (I-K), and reduced perivascular aquaporin $4(\mathrm{M}-\mathrm{O})$ in MTLE groups (MTLE, MTLE+D and MTLE+P), when compared to the respective staining pattern of the CTRL group $(D, H, L$ and $P$ ). Overall, MTLE and MTLE+P groups had higher changes than MTLE+D, which is more similar to CTRL cases. Bar in P indicates 150 micrometers. 

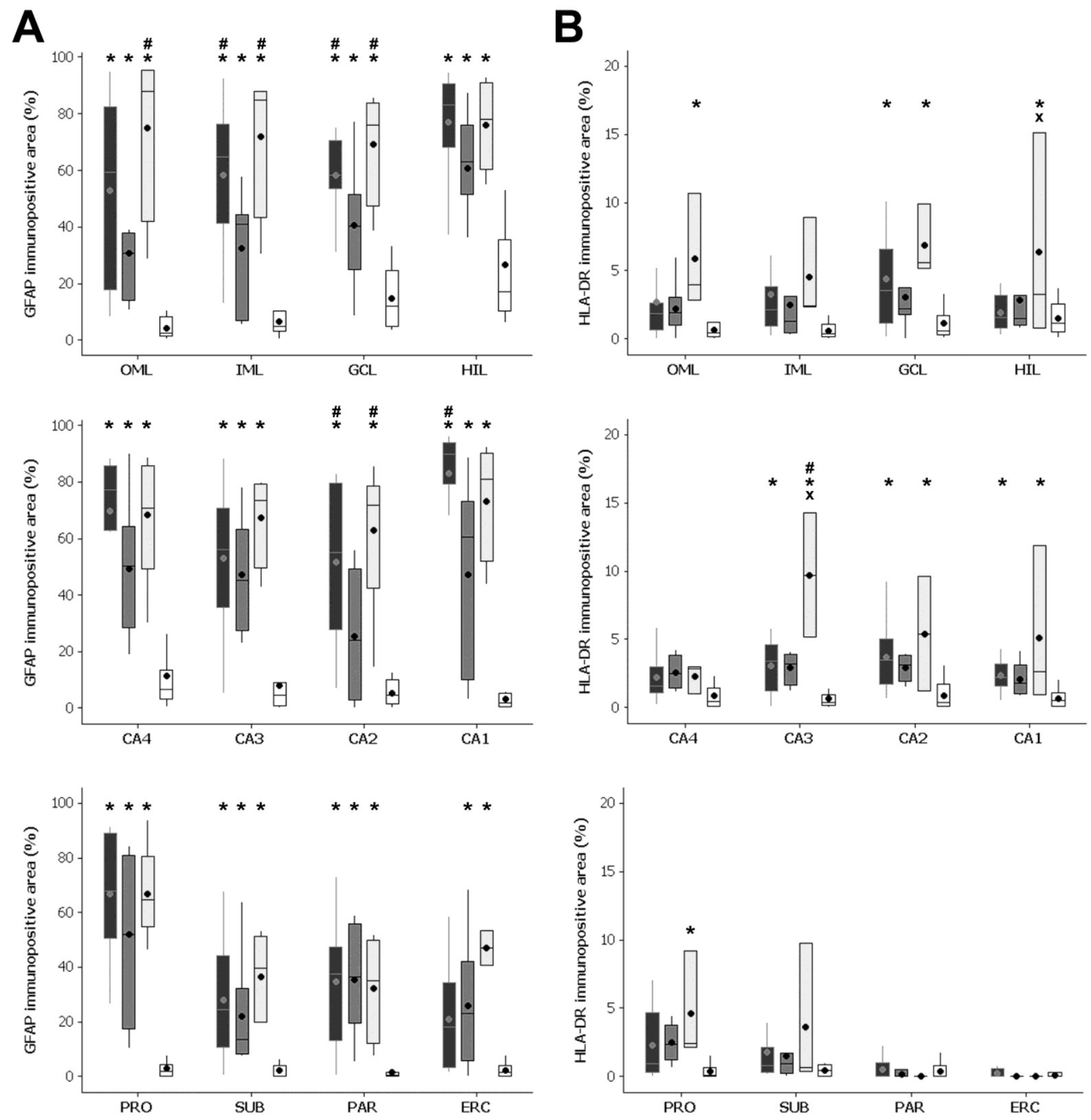

Figure 2. Immunopositive area fraction of GFAP (A) and HLA-DR (B) in the hippocampal subfields of MTLE (black boxplots), MTLE+D (dark gray boxplots), MTLE+P (light gray boxplots), and CTRL group (white boxplots). A: All TLE groups showed higher GFAP immunopositive area in OML, IML, GCL, HIL, CA4, CA3, CA1, PRO, SUB, and PAR (compared to CTRL). MTLE and MTLE+P had increased GFAP area in IML, GCL, and CA2 (compared to MTLE+D), and in the ERC (compared to CTRL). MTLE had increased GFAP area in CA1 and MTLE+P had higher GFAP area in the OML (compared to MTLE+D). B: MTLE+P had increased immunopositive HLA-DR area in CA2 (when compared to all other groups), in the HIL (compared to MTLE and CTRL), and OML, GCL, CA3, CA1, and PRO (compared to CTRL). MTLE patients had increased HLA-DR immunopositive area in $\mathrm{GCL}, \mathrm{CA} 3$, and $\mathrm{CA} 2$ (compared to $\mathrm{CTRL}$ ). OML = outer molecular layer; IML = inner molecular layer; $\mathrm{GCL}=$ granule cell layer; $\mathrm{HIL}=$ hilus; $\mathrm{PRO}=$ prosubiculum; $\mathrm{SUB}=$ subiculum; $\mathrm{PAR}=$ parasubiculum; ERC = entorhinal cortex. ${ }^{*}$ indicates difference from CTRL, ${ }^{\text {\# }}$ indicate difference from $M T L E+D$, and ${ }^{x}$ indicate difference from MTLE. 

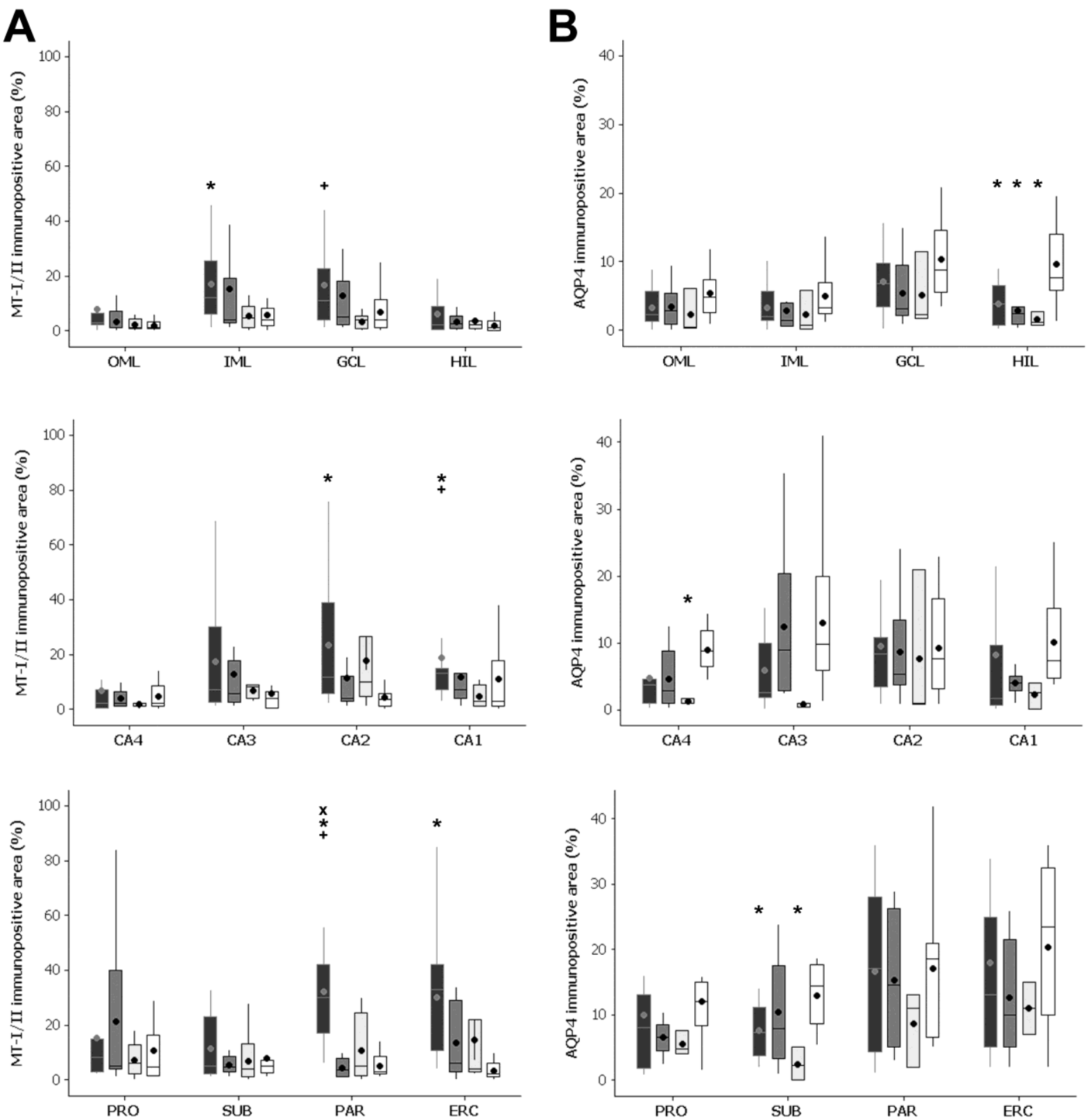

Figure 3. Immunopositive area fraction of MT-I/II (A) and AQP4 (B) in the hippocampal subfields of MTLE (black boxplots), MTLE+D (dark gray boxplots), MTLE+P (light gray boxplots), and control group (white boxplots). A: MTLE cases had higher MT-I/II immunopositive area in the PAR (compared to all other groups), CA1 (compared to CTRL and MTLE+P), IML, CA2, ERC (compared to CTRL), and in GCL (compared to MTLE+P). B: Decreased AQP4 area was observed in the hilus of all MTLE groups, in CA4 of MTLE+P, and in the SUB of MTLE and MTLE+P (compared to CTRL). OML = outer molecular layer; IML = inner molecular layer; $\mathrm{GCL}$ = granule cell layer; $\mathrm{HIL}=$ hilus; $\mathrm{PRO}=$ prosubiculum; $\mathrm{SUB}=$ subiculum; $\mathrm{PAR}$ = parasubiculum; $\mathrm{ERC}$ $=$ entorhinal cortex. ${ }^{*}$ indicates difference from CTRL, ${ }^{x}$ indicate difference from MTLE and ${ }^{+}$indicate difference from MTLE+P. 


\section{FICHA CATALOGRÁFICA}

Peixoto-Santos, José Eduardo.

Estudo das relações entre populações celulares, expressão de aquaporina-4 e sulfato de condroitina com o tempo de relaxamento e a taxa de transferência de magnetização no hipocampo de pacientes com epilepsia do lobo temporal farmacorresistente.

Ribeirão Preto, 2014.

175 p. : 50 il. ; $30 \mathrm{~cm}$

Tese de Doutorado, apresentada à Faculdade de Medicina de Ribeirão Preto/USP. Área de concentração: Neurociências.

Orientador: Leite, João Pereira.

1. Epilepsia do Lobo Temporal. 2. Ressonância Magnética. 3. Relaxamento T2. 4. Transferência de Magnetização. 5. Volumetria Hipocampal. 6. Gliose. 7. População Neuronal. 8. Matriz Extracelular. 9. Aquaporina 4 